\title{
Optimization of Radially
}

Heterogeneous 1000-MW(e) LMFBR fore Configurations

Volume 1: Design and Performance of Reference Cores

Keywords:

LMFBR Core

HCDA

Heterogeneous Core

No Void Coefficient

Bull's-Eye Core

\section{RECEIVED BY TIC APR $\quad 11980$}




\section{DISCLAIMER}

This report was prepared as an account of work sponsored by an agency of the United States Government. Neither the United States Government nor any agency Thereof, nor any of their employees, makes any warranty, express or implied, or assumes any legal liability or responsibility for the accuracy, completeness, or usefulness of any information, apparatus, product, or process disclosed, or represents that its use would not infringe privately owned rights. Reference herein to any specific commercial product, process, or service by trade name, trademark, manufacturer, or otherwise does not necessarily constitute or imply its endorsement, recommendation, or favoring by the United States Government or any agency thereof. The views and opinions of authors expressed herein do not necessarily state or reflect those of the United States Government or any agency thereof. 


\section{DISCLAIMER}

Portions of this document may be illegible in electronic image products. Images are produced from the best available original document. 


\title{
Optimization of Radially Heterogeneous 1000-MW(e) LMFBR Core Configurations Volume 1: Design and Performance of Reference Cores
}

\author{
NP-1000, Volume 1 \\ Research Project 620-25 \\ Interim Report, November 1979
}

\author{
Prepared by \\ ARGONNE NATIONAL LABORATORY \\ Applied Physics Division \\ EBR-II Division \\ 9700 South Cass Avenue \\ Argonne, lllinois 60439 \\ Principal Investigators \\ W. P. Barthold \\ Y. Orechwa \\ S. F. Su \\ E. Hutter \\ R. V. Batch \\ J. C. Beitel \\ R. B. Turski \\ P. S. K. Lam
}

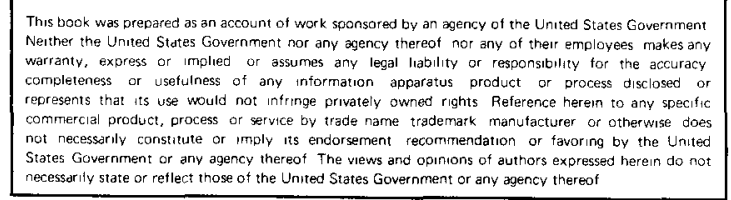

Prepared for

Electric Power Research Institute

3412 Hillview Avenue

Palo Alto, California 94304

EPRI Project Manager

Edward L. Fuller

Nuclear Power Division 


\section{ORDERING INFORMATION}

Requests for copies of this report should be directed to Research Reports Center (RRC) Box 50490, Palo Alto, CA 94303, (415) 961-9043 There is no charge for reports requested by EPRI member utilities and affiliates, contributing nonmembers, US utility associatıons, U S government agencies (federal, state, and local), media, and foreıgn organizations with which EPRI has an information exchange agreement On request. RRC will send a catalog of EPRI reports

EPRI authorizes the reproduction and distribution of all or any portion of this report and the preparation of any derivative work based on this report in each case on the condition that any such reproduction distribution and preparation shall acknowiedge this report and EPRI as the source

\section{NOTICE}

This report was prepared by the organizatıon(s) named below as an account of work sponsored by the Electric Power Research Institute Inc (EPRI) Neıther EPRI members of EPRI the organization(s) named below nor any person acting on their behalf (a) makes any warranty or representation express or implied with respect to the accuracy completeness or usefulness of the information contained in this report or that the use of any information apparatus method or process disclosed in this report may not infringe privately owned rights or (b) assumes any liabilities with respect to the use of or for damages resulting from the use of any information apparatus method or process disclosed in this report

Prepared by

Argonne National Laboratory

Argonne, lllinois 
EPRI PERSPECTIVE

PROJECT DESCRIPTION

A hypothetical core disruptive accident (HCDA) and the impact it might cause, particularly on the underside of the head of a liquid metal fast breeder reactor (LMFBR) is a controversial issue. The debate is how much capability for safe absorption of impact energy must be designed into the reactor vessel and head. Neutronics and thermo-hydraulics analysts and core designers are the ones to whom this report is directed. Reactor vendors of early large-size LMFBRs can use this work as a sound starting base for improvements. The immediate application of this work is to provide the core design for the prototype large breeder reactor design studies conducted under EPRI Research Project 620.

This work, "Optimization of Radially Heterogeneous 1000-MW(e) LMFBR Core Configurations," is presented in four volumes. These are as follows:

- Volume 1: Design and Performance of Reference Cores

- Volume 2: Appendix A--Design Assumptions and Constraints Appendix B--Radially Heterogeneous Core Configurations

- Volume 3: Appendix C--Optimization of Core Performance Parameters

- Volume 4: Appendix D--Optimization of Core Configurations Appendix E-Component Designs

PROJECT OBJECTIVES

The objective of the work reported here is to make the characteristics of large cores such that the impact energy of an HCDA would approach zero. Without special provisions, an LMFBR vessel and head will have greater impact resistance than would be needed by such a core, thus relieving the controversy and assuring a safe design feature.

This report presents the results of the second of three phases of effort to optimize a radial heterogeneous 1000-MW(e) LMFBR core design that will minimize energetics in 
an HCDA and yet have highly desirable breeding gain and core performance. The final results of the three phases are intended to establish a reference core design that will be safe, licensable, reliable, and efficient.

\section{PROJECT RESULTS}

Although not reflected in the work reported, doubling time is not the simple figure of merit that it originally appeared to be. A minimum compound system doubling time is quite desirable when the U.S. utility industry is plutonium limited, i.e., all of the available Pu (owned by the utilities) is being fully utilized in breeder plants. However, this is not the case and probably will not be true until well after the year 2010. Emphasis will be shifted to maximize total net plutonium produced rather than doubling time. In-core inventory will optimize at a somewhat higher quantity of Pu.

As stated in the text there are too many uncertainties in the fuel costs to make them a figure of merit between designs. However, on a consistent basis of estimating, the promising core designs show only small differences in costs. It is highly probable that costs can be significantly improved over those listed in the text.

Edward L. Fuller, Project Manager R. K. Winkleblack, Program Manager Nuclear Power Division 
A parameter study was conducted to determine the interrelated effects of: loosely or tightly coupled fuel regions separated by internal blanket assemblies, number of fuel regions, core height, number and arrangement of internal blanket subassemblies, number and size of fuel pins in a subassembly, etc. The effects of these parameters on sodium void reactivity, Doppler, "incoherence," breeding gain, and thermohydraulics were of prime interest. Trends were established and ground work laid for optimization of a large, radially-heterogeneous, LMFBR core that will have low energetics in an HCDA and will have good thermal and breeding performance. 
-

- 
Table of Contents

Page

1.0 INTRODUCTION . . . . . . . . . . . . . . . . . . 1-1

1.1 DESIGN OBJECTIVES . . . . . . . . . . . . . . . . 1-1

1.2 OUTLINE OF STUDY . . . . . . . . . . . . . . . . 1-2

2.0 CONCLUSIONS AND RECOMMENDATIONS . . . . . . . . . . . 2-1

2.1 ConClustons . . . . . . . . . . . . . . . . 2-1

2.2 RECOMMENDATIONS . . . . . . . . . . . . . . . . 2-3

3.0 DESIGN ENVIRONMENT . . . . . . . . . . . . . . . . 3-1

3.1 DESIGN GROUNDRULES . . . . . . . . . . . . . . . . 3-1

3.2 DESIGN APPROACH . . . . . . . . . . . . . . . . 3-1

3.2.1 Preliminary Analyses . . . . . . . . . . . . 3-1

3.2.2 Final Design Analysis .............. 3-3

3.3 OPTIMIZATION . . . . . . . . . . . . . . . . . . . 3-3

3.3.1 Configuration ................ . 3-3

3.3.2 Design Parameters . . . . . . . . . . . . 3-4

3.4 METHODOLOGY . . . . . . . . . . . . . . . . 3-5

3.4.1 Design Analysis Flow Sheet . . . . . . . . . . 3-5

3.4.2 Computational Methods .............. 3-6

3.4.3 Calculational Approach . . . . . . . . . . . 3-8

4.0 CORE DESIGN AND ANALYSIS . . . . . . . . . . . . . . . 4-1

4.1 NUCLEAR DESIGN ANALYSIS . . . . . . . . . . . . . 4-1

4.1.1 Core Layout .................... . 4-1

4.1.2 Fissile Inventory ................ 4-2

4.1.3 Burnup and Reactivity Swing . . . . . . . . . . . 4-2

4.1.4 Control Requirements ............... 4-3

4.1.5 Power and Flux Distribution . . . . . . . . . . . 4-4

4.1.6 Breeding Performance . . . . . . . . . . . . 4-6

4.1.7 Safety Parameters .. . . . . . . . . . . . . 4-7

4.1.9 Transient Response . . . . . . . . . . . . 4-7 
4.1.9.1 Introduction . . . . . . . . . . . . 4-7

4.1.9.2 Methodology .. . . . . . . . . . . 4-7

4.1.9.3 Reactivity Insertions . . . . . . . . . . 4-8

4.1.9.4 Transient Results . . . . . . . . . . . 4-8

4.1.9.4.1 Configuration A. . . . . . . . 4-8

4.1.9.4.2 Configuration B . . . . . . . . . 4-8

4.1.9.5 Conclusions . . . . . . . . . . . . 4-9

4.2 THERMAL-HYDRAULIC ANALYSES . . . . . . . . . . . . . 4-9

4.2.1 Inlet and Outlet Temperature of Configuration A . . . . 4-9

4.2.2 Orificing Scheme of Configuration A.......... . 4-9

4.2.3 Temperature Distributions of Configuration A . . . . . 4-10

4.2.4 Sensitivity of Cladding Temperature to Orificing

Criteria of Configuration A. . . . . . . . . . 4-11

4.2.5 Inlet and Outlet Temperature of Configuration B . . . . . 4-11

4.2.6 Orificing Scheme of Configuration B . . . . . . . . . 4-12

4.2.7 Temperature Distributions of Configuration B . . . . . . 4-12

4.2.8 Sensitivity of Cladding Temperature of Orificing

Criteria of Configuration B........... 4-13

4.3 MECHANICAL DESIGN ANALYSES . . . . . . . . . . . . 4-14

4.3.1 Fuel Pin Design .................... 4-14

4.3.2 Fuel Assembly Design .............. . 4-14

4.3.3 Blanket Fuel Pin ................. 4-15

4.3.4 B1anket Assembly ............... 4-15

4.3.5 Control Assembly ................ 4-15

4.3.6 Duct Life.................. 4-15

4.4 FUEL CYCLE COST . . . . . . . . . . . . . . . 4-16

5.0 DESIGN EVALUATION . . . . . . . . . . . . . . . . 5-1

5.1 CENTER CORE VS. CENTER BLANKET CONFIGURATION . . . . . . . . 5-1

5.2 LOOSELY VS. TIGHTLY COUPLED CORES . . . . . . . . . . . 5-2

5.3 CONTINUOUS RING VS. BROKEN RING CONFIGURATIONS . . . . . . . 5-3 


\section{List of Figures}

No.

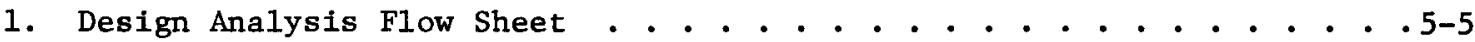

2. Preliminary Optimum Configurations . . . . . . . . . . . . 5-6

3. Configuration A, Peak Power Density at BOL, No Rods Inserted . . . . 5-7

4. Configuration A, Peak Power Density at BOL, Row 11 Rods 15\% Inserted . . . . . . . . . . . . . . . . . . . . 5-7

5. Configuration A, Peak Power Density at BOEC Conditions . . . . . . .5-8

6. Configuration A, Peak Power Density at MOEC Conditions . . . . . . . .5-8

7. Configuration A, Peak Power Density at EOEC Conditions . . . . . . . 5-9

8. Configuration B, Peak Power Density at BOL, No Rods Inserted . . . . .5-9

9. Configuration B, Peak Power Density at BOL, Row 11 Rods Inserted . . .5-10

10. Configuration B, Peak Power Density at BOEC . . . . . . . . . . . . 5-10

11. Configuration B, Peak Power Density at MOEC . . . . . . . . . . . . . .5-11

12. Configuration B, Peak Power Density at EOEC . . . . . . . . . . .5-11

13. Configuration A, Total Flux Distribution at BOL, No Control Inserted . . . . . . . . . . . . . . . . . .5-12

14. Configuration A, Total Flux Distribution BOL, Row 11 Control Rod Inserted . . . . . . . . . . . . . . . .5-13

15. Configuration A, Total Flux Distribution at BOL, Primary Contro1 Rods Inserted . . . . . . . . . . . . . . . . . .5-14

16. Configuration A, Total Flux Distribution at BOL, Secondary Control Rods Inserted . . . . . . . . . . . . . . . . .5-15

17. Configuration A, Total Flux Distribution at BOL, Row 11 and Secondary Control Rods Inserted . . . . . . . . . . . . . .5-16

18. Configuration A, Total Flux Distribution at BOL, All Rods Inserted . .5-17

19. Configuration A, Total Flux Distribution at BOEC . . . . . . . . .5-18

20. Configuration A, Total Flux Distribution at MOEC . . . . . . . . . .5-19

21. Configuration A, Total Flux Distribution at EOEC . . . . . . . . . .5-20

22. Configuration B, Total Flux Distribution BOL, No Control Rods Inserted ...................... . . 5-21

23. Configuration B, Total Flux Distribution at BOL, Row 11 Control Rods Inserted . . . . . . . . . . . . . . . . .5-22

24. Configuration B, Total Flux Distribution at BOL, Primary Control Rods Inserted . . . . . . . . . . . . . . . . . .5-23 
No.

25. Configuration B, Total Flux Distribution at BOL, Secondary Control Rods Inserted . . . . . . . . . . . . . . . . .5-24

26. Configuration B, Total F1ux Distribution at BOL, Row 11 and Secondary Control Rods Inserted . . . . . . . . . . . . .5-25

27. Configuration B, Total Flux Distribution at BOEC . . . . . . . . . 5-26

28. Configuration B, Total Flux Distribution at MOEC . . . . . . . . . 5-27

29. Configuration B, Total Flux Distribution at EOEC . . . . . . . . 5-28

30. 60 c Reactivity Step Insertion, Configuration A . . . . . . . . . 5-29

31. $60 \mathrm{c} / 500 \mathrm{~ms}$ Reactivity Ramp, Configuration A............ 5-29

32. $60 c$ Reactivity Step Insertion, Configuration B . . . . . . . . . 5-30

33. $60 \mathrm{c} / 500 \mathrm{~ms}$ Reactivity Ramp, Configuration B . . . . . . . . . . . 5-30

34. Orificing Scheme of Configuration A with Equal Peak Clad Temperature at BOL in Core and at EOL in the Internal Blankets . . . .5-31

35. Configuration A BOL Average Coolant Temperature at Core Mid-Plane (Orificed for Minimum Peak Temperature) . . . . . . . . . . . 5-32

36. Configuration A BOL Average Coolant Temperature at Top of Core (Orificed for Minimum Peak Temperature) . . . . . . . . . . .5-33

37. Configuration A BOL Average Coolant Temperature at Outlet (Orificed for Minimum Peak Temperature) . . . . . . . . . . . .5-34

38. Configuration A BOEC Average Coolant Temperature at Core Mid-Plane (Orificed for Minimum Peak Temperature) . . . . . . . . . 5-35

39. Configuration A EOEC Average Coolant Temperature at Top of Core (Orificed for Minimum Peak Temperature) . . . . . . . . . . . 5-36

40. Configuration A EOEC Average Coolant Temperature at Outlet (Orificed for Minimum Peak Temperature) . . . . . . . . . . . 5-37

41. Configuration A BOL Average Duct Wall Temperature at Core Mid-Plane (Orificed for Minimum Peak Temperature) . . . . . . . . . .5-38

42. Configuration A BOL Average Duct Wall Temperature at Top of Core (Orificed for Minimum Peak Temperature) . . . . . . . . . . . 5-39

43. Configuration A BOL Average Duct Wall Temperature at Outlet (Orificed for Minimum Peak Temperature) . . . . . . . . . . . 5-40

44. Configuration A EOEC Average Duct Wall Temperature at Core Mid-Plane (Orificed for Minimum Peak Temperature) . . . . . . . . . . . 5-41

45. Configuration A EOEC Average Duct Wall Temperature at Top of Core (Orificed for Minimum Peak Temperature) . . . . . . . . . . . . 5-42

46. Configuration A EOEC Average Duct Wall Temperature at Outlet (Orificed for Minimum Peak Temperature) . . . . . . . . . . .5-43

47. Coolant Temperatures at Mid-Plane . . . . . . . . . . . . . . 5-44

48. Coolant Temperatures at Top of Core . . . . . . . . . . . . . . 5-45

49. Coolant Temperatures at Outlet . . . . . . . . . . . . . 5-46

50. Nominal Clad Temperatures at Mid-Plane . . . . . . . . . . . 5-47

51. Nominal Clad Temperatures at Top of Core . . . . . . . . . . 5-48 
52. Nominal $\mathrm{Clad}$ Temperatures at Outlet . . . . . . . . . . . . . . 5-49

53. 2o Clad Mid-Wall Temperatures at Mid-Plane . . . . . . . . . 5-50

54. $2 \sigma \mathrm{Clad}$ Mid-Wall Temperatures at the Top of Core . . . . . . . . 5-51

55. $2 \sigma$ Clad Mid-Wall Temperatures at the Outlet . . . . . . . . . 5-52

56. Orificing Scheme of Configuration A with Equal Peak Clad Temperature at EOEC ................. . . . . . . . . . . . .

57. Orificing Scheme of Configuration B with Equal Peak Clad Temperatures at BOL in the Core and at EOL in the Internal Blankets . . . . . . . . . . . . . . . . . 5-54

58. Configuration B BOL Average Coolant Temperature at Core Mid-Plane (Orificed for Minimum Peak Temperature) . . . . . . . . . .5-55

59. Configuration B BOL Average Coolant Temperature at Top of Core (Orificed for Minimum Peak Temperature) . . . . . . . . . . .5-56

60. Configuration B BOL Average Coolant Temperature at Outlet (Orificed for Minimum Peak Temperature) . . . . . . . . . . . 5-57

61. Configuration B EOEC Average Coolant Temperature at Core Mid-Plane (Orificed for Minimum Peak Temperature). . . . . . . . . . .5-58

62. Configuration B EOEC Average Coolant Temperature at Top of Core (Orificed for Minimum Peak Temperature) . . . . . . . . . . . .5-59

63. Configuration B EOEC Average Coolant Temperature at Outlet (Orificed for Minimum Peak Temperature) . . . . . . . . . . . 5-60

64. Configuration B BOL Average Duct Wall Temperature at Core Mid-Plane (Orificed for Minimum Peak Temperature) . . . . . . . . . . . 5-61

65. Configuration B BOL Average Duct Wall Temperature at Top of Core (Orificed for Minimum Peak Temperature) . . . . . . . . . . . .5-62

66. Configuration B BOL Average Duct Wall Temperature at outlet (Orificed for Minimum Peak Temperature) . . . . . . . . . . . 5-63

67. Configuration B EOEC Average Duct Wall Temperature at Core Mfd-Plane (Orificed for Minimum Peak Temperature) . . . . . . . . . . . 5-64

68. Configuration B EOEC Average Duct Wall Temperature at Top of Core (Orificed for Minimum Peak Temperature) . . . . . . . . . . .5-65

69. Configuration B EOEC Average Duct Wall Temperature at Outlet (Orificed for Minimum Peak Temperature) . . . . . . . . . . .5-66

70. Coolant Temperature at Midplane . . . . . . . . . . . . . 5-67

71. Coolant Temperatures at Top of Core . . . . . . . . . . . . 5-68

72. Coolant Temperatures at Outlet . . . . . . . . . . . 5-69

73. Nominal Clad Temperatures at Mid-Plane . . . . . . . . . . . 5-70

74. Nominal Clad Temperatures at Top of Core . . . . . . . . . 5-71

75. Nominal Clad Temperatures at Outlet . . . . . . . . . . . 5-72

76. 20 Mid-Wall Clad Temperatures at Mid-Plane . . . . . . . . . . 5-73

77. $2 \sigma$ Mid-Wall Clad Temperatures at Mid-Plane ........... . . . . . . . . . 
78. 2o Mid-Wall Clad Temperatures at Outlets . . . . . . . . . . . 5-75

79. Orificing Scheme of Configuration B with Equal Peak Clad Temperature at EOEC . . . . . . . . . . . . . . 5-76

80. Total Power Per Assembly (MWth) at BOL, Configuration A . . . . . . 5-76

81. Total Power Per Assembly (MWth) at EOEC, Configuration A . . . . . . 5-77

82. Peak-to-Average Power Per Assembly at BOL, Configuration A . . . . . 5-77

83. Total Power Per Assembly (MWth) at BOL, Configuration B . . . . . . 5-78

84. Total Power Per Assembly (MWth) at EOEC, Configuration B . . . . . 5-78

85. Peak-to-Average Power Per Assembly at BOL, Configuration B . . . . 5-79 
List of Tables

No.

Title

$\underline{\text { Page }}$

I. Number of Assemblies Per Region . . . . . . . . . . . .5-80

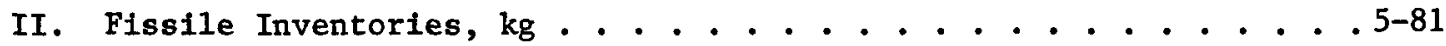

III. Average Fissile Enrichment, \% н.м. . . . . . . . . . . 5-82

IV. Discharge Burnups $(\mathrm{MWD} / \mathrm{T})$. . . . . . . . . . . . . 5-83

V. Primary and Secondary Control System Assignments . . . . . . 5-84

vI. Control Rod Worths . . . . . . . . . . . . . . . . . 5-84

VII. Control Rod Requirements . . . . . . . . . . . . . . 5-85

VIII. Power Distribution . . . . . . . . . . . . . . 5-86

IX. (Peak/Average) Power Densities . . . . . . . . . . . . 5-87

$\mathrm{X}$. Nominal Peak Nuclear Linear Heat Rating, kW/ft . . . . . . . 5-88

XI. Peak Fast Fluxes . . . . . . . . . . . . . . . . . . 5-88

XII. Breeding Ratios . . . . . . . . . . . . . . . . 5-89

XIII. Breeding Performance . . . . . . . . . . . . . . 5-89

XIV. Configuration A Sodium Vold Reactivities from Perturbation Calculations . . . . . . . . . . . . . . . 5-90

XV. Configuration B Sodium Void Reactivities from Perturbation Calculations . . . . . . . . . . . . . . . 5-90

XVI. Isothermal Doppler Coefficients of Configuration A . . . . . . 5-91

XVII. Isothermal Doppler Coefficients of Configuration B . . . . . . 5-91

XVIII. Normalized Peak Power Density $P(t) / P(0)$ for Configuration A in a 60 c Step Insertion into the Outer Core . . . . . . . . . . 5-92

XIX. Normalized Peak Power Density $P(t) / P(0)$ for Configuration A in a $60 \mathrm{c} / 500 \mathrm{~ms}$ Ramp into the Outer Core . . . . . . . . . . 5-92

XX. Normalized Peak Power Density $P(t) / P(0)$ for Configuration $B$ in a $60 c$ Step Insertion into the Outer Core . . . . . . . . . . 5-93

XXI. Normalized Peak Power Density $P(t) / P(0)$ for Configuration $B$ in a $60 \mathrm{c} / 500 \mathrm{~ms}$ Ramp into the Outer Core . . . . . . . . . . 5-93 
XXII. Inlet and Outlet Temperatures of Configuration A at EOEC . . . 5-94

XXIII. Inlet and Outlet Temperatures of Configuration A Orificed for Equal Clad Temperatures at EOEC . . . . . . . . . . . . . 5-94

XXIV. Orificing Scheme of Configuration A . . . . . . . . . . . . . 5-95

XXV. Orificing Scheme of Configuration A Orificed for Equal Clad Temperature at EOEC . . . . . . . . . . . . . . . . 5-95

XXVI. Nominal Cladding Temperature Axial Profiles for Design Limiting Fuel Pin, Configuration A . . . . . . . . . . . . 5-96

XXVII. $2 \sigma$ Cladding Temperature Axial Profiles for Design Limiting Fuel Pin, Configuration A . . . . . . . . . . . . . . 5-97

XXVIII. Peak Temperatures for the Assembly With the Hottest Fuel Pin, Configuration A . . . . . . . . . . . . . . . . 5-98

XXIX. Inlet and Outlet Temperatures of Configuration B . . . . . . . 5-99

XXX. Inlet and outlet Temperatures of Configuration B Orificed for Equal Clad Temperatures at EOEC . . . . . . . . . . . . 5-99

XXXI. Orificing Scheme of Configuration B . . . . . . . . . . . . 5-100

XXXII. Orificing Scheme of Configuration B Orificed for Equal Clad Temperatures at EOEC . . . . . . . . . . . . . . . . 5-100

XXXIII. $2 \sigma$ Cladding Temperature Axial Profiles for Design Limiting Fuel Pin, Configuration B . . . . . . . . . . . . . 5-101

XXXIV. Nominal cladding Temperature Axial Profiles for Design Limiting Fuel Pin, Configuration B . . . . . . . . . . . . . . 5-102

XXXV. Peak Temperatures in the Assembly With the Hottest Fuel Pin, Configuration A . . . . . . . . . . . . . . . . 5-103

XXXVI. Fuel Pin and Assembly Data . . . . . . . . . . . . . . . . . 5-104

XXXVII. Blanket Pin and Assembly Data . . . . . . . . . . . . . 5-105

XXXVIII. Control Assembly Composttions . . . . . . . . . . . . . . 5-106

XXXIX. Duct Wall Pressure Differential Profile for Design Limiting

Duct . . . . . . . . . . . . . . . . . . . 5-107

XL. Fabrication Cost Breakdown . . . . . . . . . . . . . . 5-108

XLI. Fuel Cycle Costs of Configuration A . . . . . . . . . . . . . . 5-109

XLII. Fuel Cycle Costs of Configuration B . . . . . . . . . . . . . 5-110 


\section{SUMMARY}

In unprotected loss-of-flow transients in large homogeneous LMFBRs, high ramp rates from sodium voiding can result in energy releases that may challenge the integrity of the containment. Thus there is a strong incentive for designing large LMFBRs that have a low sodium void reactivity. Heterogeneous designs that consist of successive radial core and blanket zones are most promising. Based on the results of previous safety analyses of heterogeneous cores, a sodium void reactivity of $\$ 2.50$ or less is considered sufficient to assure that the reactor will not become super-prompt critical. The sodium voided from the core is limited to that coming from the core fuel assembly and upper axial blanket regions. By properly arranging and sizing the core and blanket zones in such designs, a low value of sodium void reactivity can be obtained. The purpose of this research project was to determine what "properly arranged and sized core and blanket zones" meant in 1000 MWe LMFBRs and to develop optimum core configurations in regard to sodium void reactivity and compound system doubling time. During the course of this investigation the following questions had to be answered:

1. Should the different core regions be separated by blanket regions with a thickness of one or less row of blanket assemblies (tightly coupled) or more than one row (loosely coupled)?

2. Should the center of the reactor be a blanket or core fuel region? How thick should this region be?

3. Should the reactor have 2,3 , or more core regions?

4. Is the reduction in core height an effective means to lower the sodium void reactivity?

5. Is it more important to add blanket assemblies to the reactor core to lower sodium void reactivity or has a change in configuration a greater impact while maintaining the number of core fuel and blanket assemblies?

6. How important are the selection of the number of fuel pins per assembly and fuel pin diameter in regard to lowering sodium void reactivity? 
Very early results showed that it was easy to construct reactors which had the same number of fuel and internal blanket assemblies but which differed as much as a factor of two in sodium void reactivity. This placed even greater emphasis on the optimization of the core layout.

The optimization of the core layout proceeded in three steps. Each step required more detailed analysis but yielded also more information.

The first step was a screening of the various means to lower sodium void reactivity. At the end of the screening phase, six basic configurations were selected for further design and performance analysis and optimization. The major criterion for the selection of those six configurations was the achievable sodium void reactivity. However, both doubling time and power shape sensitivity were also considered. The second step was a sub-optimization of those six configurations with respect to fuel pin diameter and doubling time. The figures of merit in this optimization were (a) sodium void reactivity, (b) doubling time, (c) breeding ratio, (d) specific inventory, and (e) maximum change in linear heat rating in fuel assemblies over one cycle. At the completion of the sub-optimization, two core layouts and specific design parameters were selected. These configurations were optimized in the third step, the optimization phase. Upon completion of this phase, two optimized configurations were selected for detailed design and performance analysis. After this design and performance analysis was completed one core design was recommended for conceptual design.

The screening phase (first step) dealt with a comparative study of tightly and loosely coupled heterogeneous center core and center blanket configurations. Earlier assembly designs for fuel and blankets were used; the se had fuel, structure and coolant volume fractions of $0.3817 / 0.1689 / 0.3976$ and $0.5664 / 0.1267 / 0.2438$, respectively. The assembly size, however, was changed as the number of fuel pins per assembly changed.

Throughout this study the tightly and loosely coupled configurations were kept as separate as possible in order to identify more clearly the generic issues which must be taken into account when constructing a radially heterogeneous core. Although, as the final configurations of this study show, the optimum cores with respect to the design constraints are a hybrid of tightly and loosely coupled, the following conclusions were instrumental in arriving at these configurations.

1. With respect to achieving a low sodium void reactivity and a low doubling time neither center core nor center blanket configurations show a clear advantage. 
2. It is very difficult to construct a "reasonable" tightly or loosely coupled, center blanket or center core configuration with a $\$ 2.00$ sodium void reactivity at the EOEC. On the other hand cores with a $\$ 3.00$ limit on the sodium void reactivity can be readily constructed.

3. Center blanket configurations are less sensitive with regard to power peaking than center core configurations. In addition, 2-core zone configurations show a better burnup vs. power peaking peformance than 3 -core zone configurations. When a single enrichment is desirable a center core configuration leads to excessively high power peaking.

4. The sodium void reactivity contribution from the internal blanket assemblies on an assembly basis is significantly higher for tightly coupled cores than for loosely coupled cores.

5. Height reduction can be an effective means for reducing the sodium void reactivity for both tightly coupled and loosely coupled cores.

6. In general, primarily the configuration and not the number of internal blanket assemblies determines the sodium void reactivity.

7. In tightly coupled cores rearranging internal blankets to change the number of core zones does not significantly affect the sodium void reactivity.

8. Ranking configurations according to achievable sodium void reactivity favors loosely-coupled cores.

9. Ranking configurations according to breeding performance and power peaking sensitivity favors tightly-coupled cores.

10. Recommended for further analysis were the following basic configurations:

Coupling Configuration No. of Core Zones No. of Pins/Fuel Assembly

$\begin{array}{llll}\text { LC } & \text { CB } & 2 & 271 \\ \text { LC } & \text { CB } & 3 & 271 \\ \text { LC } & \text { CC } & 3 & 271 \\ \text { TC } & \text { CB } & 3 & 331 \\ \text { TC } & \text { CB } & 4 & 331 \\ \text { TC } & \text { CC } & 4 & 331\end{array}$

TC - tightly coupled, LC - loosely coupled, CB - center blanket

cC - center core 
During the sub-optimization phase (step 2) those six configurations were analyzed in more detail. Core height and fuel pin diameter were varied and for each configuration, detailed fuel assembly designs were developed which were all subject to the following basic design assumptions:

$\begin{array}{ll}\text { Reactor outlet temperature: } & 875^{\circ} \mathrm{F} \\ \text { Reactor coolant temperature rise: } & 280^{\circ} \mathrm{F} \\ \text { Fuel bundle pressure drop: } & \leq 75 \mathrm{psi} \\ \text { Fuel p/d ratio: } & \geq 1.18 \\ \text { C1adding thickness/fuel } 0 . \mathrm{D} .: & 0.05 \\ \text { Peak linear heat rating: } & 13.4 \mathrm{kw} / \mathrm{ft} \\ \text { Maximum allowable stress in } & \\ \quad \text { duct wall: } & 18,000 \mathrm{psi}\end{array}$

The performance analysis of a total of 36 cores which differed with respect to neutronic coupling, core height, and fuel pin diameter allowed the following conclusions:

1. To achieve sodium void reactivities of $\$ 2.50$ or less, tightly coupled cores require core heights of 36 inches or less. For the loosely coupled cores, heights of less than 48 inches are required.

2. As fuel pin size increases, the sodium void reactivity decreases.

3. The tightly coupled cores have generally lower doubling times than the loosely coupled cores.

4. Among the tightly and loosely coupled cores, the fuel pin sizes of 0.24 inches and 0.26 inches, respectively, show the lowest doubling times.

5. For the cores analyzed, no clear advantage in regard to specific inventory and sodium void reactivity can be identified for either tightly or loosely coupled systems.

6. Because of the high power swing over an equilibrium cycle observed for the center core configurations, they were eliminated from further analysis. Earlier analyis had shown that those configurations showed also a higher sensitivity in power peaking for small enrichment split changes. They always performed equal to or worse than the center blanket configuration.

7. Loosely coupled systems show a greater power swing than tightly coupled systems. 
8. A loosely coupled and a tightly coupled 3-core zone center blanket configuration with 271/331 fuel pins per assembly, core height of $40 / 36$ inches and $0.26 / 0.24 \mathrm{in}$. fuel pins, respectively, were chosen for further optimization.

During the optimization phase (step 3) the core layouts of these two candidate cores were modified to see if any improvement could be made with regard to breeding performance, power peaking, power shape sensitivity, power swing, etc. The pin diameters for the respective cores remained unchanged during the optimization of the configurations. The modification for the $40 \mathrm{in}$. core concentrated on tightening the coupling and at the same time reducing the core region sizes to keep the sodium void reactivity below $\$ 2.50$. The modifications for the 36 in. core emphasized the reduction of the center blanket size and the creation of a broken ring-arrangement of internal blanket assemblies to improve the power peaking performance and to simplify the reactivity control.

Upon completion of this task the following conclusions could be drawn:

1. The design constraints of

a. $\leq \$ 2.50$ sodium void reactivity

b. $\leq 15$ year doubling time

are very restrictive.

2. The selection of configuration is very important in regard to

a. sodium void reactivity

b. power shape sensitivity

c. power swing

d. burnup swing and control requirements

3. The following performance parameters are also affected by the configuration selection but to a lesser extent

a. specific inventory

b. breeding ratio

c. doubling time

4. For a given core height, tightly coupled configurations generally perform better than loosely coupled configurations with respect to the performance parameters listed in 2 except for the sodium void reactivity.

5. The region size split among the three core regions is important for sodium void reactivity reductions.

6. The highest power swing over a burnup cycle exists in the outermost core region. This region has always a negative power swing. 
7. The introduction of isolated internal blanket assemblies in the outermost core region

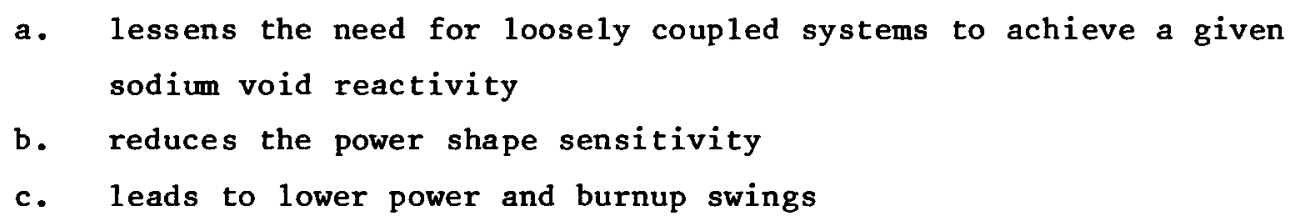

8. Broken ring arrangements are better than closed ring arrangements because
a. there is better coupling between regions
b. flux peaks are created which
- determine the location of control rods
- enhance control rod worth

9. Control rod positioning is very important

a. burnup can be controlled very efficiently by control rods located in the outermost core region because

- the outermost core region is the largest core region which makes a symmetrical arrangement less difficult

- the withdrawal of control rods counteracts the drop in assembly power observed in cores burned without control

b. control rods located next to an internal blanket region have a lower worth than control rods surrounded by fuel assemblies except for the outermost core region where for some configurations the worth of the control rod can be higher when placed next to an internal blanket assembly

10. While there is the potential for arranging the internal blanket assemblies such that only one core enrichment is needed, no extensive efforts were undertaken at this stage to develop such a core because of

a. calculational uncertainties

b. having different enrichment zones is a more conservative approach

11. The choice of calculational techniques is very important

a. $r-z$ models are good for

- inventory calculation

- breeding performance calculation

- sodium void reactivity estimates

b. hexagonal geometry models are needed for the calculation of

- a11 power shape information

- contro1 rod worth 
The two most promising core configurations chosen are both tightly coupled, although one evolved from a loosely coupled core. Both cores showed low power shape sensitivities to small enrichment split changes and low power and burnup swings and good power peaking characteristics.

A complete nuclear analysis of these two cores (derived from a loosely coupled configuration/derived from a tightly coupled configuration) determined the fissile inventories (4268.4/4213.4 kg at BOEC), burnup (83.90/100.7 MWd/t peak), reactivity swings $(0.49 / 1.8 \% \Delta k)$, control rod requirements (24/36 rods), total control rod worths $(7.29 / 8.76 \%$ total), power and flux distributions for different control insertion patterns, the breeding peformance (15.7/15.3 yrs. CSDT), the safety parameters, such as sodium void reactivity ( $\$ 2.38 / \$ 2.23$ at EOEC), isothermal Doppler coefficients for both sodium-in $\left(45.6 / 46.1 \mathrm{~T} \mathrm{dk} / \mathrm{dT} \times 10^{-4}\right.$ core at EOEC), and sodiumout conditions $\left(28.6 / 28.2 \mathrm{dk} / \mathrm{dT} \times 10^{-4}\right.$ core at EOEC), and the transient behavior which shows very little space-dependence during a $60 \$$ reactivity step on a ramp insertion.

The thermal-hydraulic analysis dealt with the calculation of coolant flow distribution, temperature distributions for coolant, cladding and duct, orificing schemes, fission gas plenum pressures, and assembly pressure drop. Emphasis was placed on keeping peak clad temperatures low and producing a uniform assembly coolant exit temperature. The orificing strategy employed equalized the maximum $2 \sigma$ cladding midwall temperature at the beginning-of-life for the core and the endof-life for the blankets in all orificing zones. The resulting peak $2 \sigma$ clad midwall temperatures consistent with an inlet temperature of $595^{\circ} \mathrm{F}$ and a mixed mean outlet temperature $875^{\circ} \mathrm{F}$ was $\left(1200.4^{\circ} \mathrm{F} / 1149.9^{\circ} \mathrm{F}\right)$.

Fuel assemblies for the two final cores were designed in detail taking into account duct rounding due to creep ( $0.140 / 0.133$ in.), dilation due to swelling $(0.0276 / 0.0707$ in.), and peak stresses in duct corners $(33,832 / 34,222$ psi). Finally, the design and analysis cores concluded with fuel cycle cost calculations yielding $(9.2 / 9.9 \mathrm{mils} / \mathrm{kWh})$.

Recommended for conceptual design is the $40 \mathrm{in}$. high core with 0.26 fuel pins. The main reason for this selection is the low number of control rods needed. 


\subsection{INTRODUCTION}

This report summarizes the work under EPRI contract No. RP620-25 on Task 1 of "Optimization of Safety and Breeding Characteristics of the PLBR Phase A Core Design" covering the period from May 1978 to December 1978.

\subsection{DESIGN OBJECTIVE}

The objective of the core design and analysis efforts is to develop practical design concepts of fuel assemblies, blanket assemblies, control assemblies and removable shield pieces as well as core, blanket, shield and restraint arrangements that are characterized by:
a. a doubling time of $\leq 15$ years
b. a sodium void reactivity of $\leq \$ 2.50$ for volding the flowing sodium from all fuel zones
c. incoherence in boiling that contributes to ultimate safety
d. a negative prompt power coefficient during approach to power as well as at high powers
e. design conservatism in regard to maximum clad temperature, peak linear power, low power peak to average ratio, small outlet temperature gradients
f. economical fabrication cost

The design which has been developed and will be refined is a way to accomplish the objectives. It is expected to establish feasibility and a "yardstick" against which other designs can be measured.

The first task of this design and optimization effort was to develop a core configuration and determine spectfic core design parameters (core height, fuel pin and assembly design, environment for operation, etc.) which meet the design objectives. This preconceptual design phase will be followed by a conceptual design effort. 


\subsection{OUTLINE OF STUDY}

The primary goal of the preconceptual design effort was to develop a core configuration and to determine core design parameters consistent with the overall design objectives. The study was very comprehensive, starting with an optimization procedure that led to selection of two designs for detailed analysis. This process led to many conclustons and recommendations, which are listed in Section 2. The methods used during the optimization and preconceptual design phases differred substantially, depending upon the goals for the various tasks. Section 3 describes the design approach, methodology, and optimization approach. The basis for the design was provided by design assumptions and constraints similar to those used in the Proliferation Resistant Core Design Study. Since there is a multitude of heterogeneous core arrangements, a procedure was designed In order to eliminate undesirable layouts, and identify the most promising layouts. A classification of different designs was made by dividing the possible arrangements into center core and center blanket configurations. The subdivison of these configurations into tightly and loosely coupled cores followed. This introduces an arbitrariness which is unavoidable since there is neither the tightly coupled core nor the loosely coupled core. There are differences in the degree of coupling and the assignment of "loosely" or "tightly" to measure coupling is by necessity arbitrary. In this study, cores with internal blankets of more than one row thickness are called loosely coupled. If the thickness of the internal blanket regions is one row or less, those cores are called tightly coupled.

At the beginning of the study an assessment was made of the vartous means of reducing sodium vold reactivities in radially heterogeneous cores. Both tightly and loosely coupled systems with center blanket or center core zones were investigated. Variables in this study were the number and size of core reglons, the number of internal blanket assemblies, core height, coupling, and the number of fuel pins per assembly. Upon completion of the study, six basic core configurations were selected, which were then optimized with respect to fuel pin diameter and core height. The two most promising tightly and loosely coupled cores were selected for further analysis.

The two most promising configurations were modified to see if it was possible to further improve the performance characteristics by changing the core layout slightly. The results of these analyses led to two cores which showed optimum performance. One core was derived from the loosely coupled systems and 
the other was derived from the tightly coupled systems. Both resultant cores are tightly coupled. The results of the performance analysis for those cores are shown in Section 4.0 of the main report.

The nuclear design effort covered the determination of core layout, fissile inventory, burnup and reactivity swing, control requirements, power and flux distribution, breeding performance, safety parameters, kinetics parameters and transient response. The details of this analysis are shown in Section 4.1 .

The thermal-hydraulic analyses dealt with the calculation of coolant flow distribution, temperature distribution for coolant, cladding and duct, orificing schemes, fission gas plenum pressures, and assembly pressure drop. Emphasis was placed on keeping peak clad temperatures low and producing a uniform assembly coolant exit temperatures. Details of this analysis are shown in Section 4.2 .

The results of the mechanfical design analyses are detailed in Section 4.3. They encompass fuel pin design, assembly design and duct life analysis. Results of both bundle-duct and cumulative damage fraction analyses are reported.

The core design and analysis activities are concluded by fuel cycle cost calculations which are reported in Section 4.4 .

An evaluation of center core vs, center blanket configuration, loosely vs. tightly coupled cores and tall vs. short cores is presented in Section 5.0.

The basis for this evaluation is presented in Appendices B, C, and D. A complete list of design assumptions and constraints is given in Appendix A. Details of the analysis leading to selection of the six basic core configurations are presented in Appendix $B$. Appendix $C$ presents the results of the core height and pin diameter optimization of the six basic core configurations and the selection process leading to the choice of the two most promising tightly and loosely coupled cores. Detalls of the final step of configuration optimization of these most promising cores are presented in Appendix D.

The results of generic hardware design activities including design options for assembly keys, lower grid design option, mixing promoters in assemblies etc. are shown in Appendix E. 


\subsection{CONCLUSIONS AND RECOMMENDATIONS}

\subsection{CONCLUSIONS}

Based on the analysis presented in this report, the following conclusions can be drawn:

1. Low sodium void reactivities can be achieved by

a. decoupling

b. core height reduction

c. adding blanket assemblies to increase the parasitic absorptions

2. The design constraints of

a. $\leq \$ 2.50$ sodium void reactivity

b. $\leq 15$ year doubling time

c. no significant power shape sensitivity

are very restrictive

3. The arrangement of internal blanket assemblies is very important with regard to
a. sodium void
b. burnup swing
c. doubling time

4. Tightly coupled cores perform better than loosely coupled cores regarding

a. doubling time

b. specific inventory

c. power shape sensitivity

5. Center blanket configuration perform better than center core configuration because

a. power peaking is less sensitive to

- enrichment

- burnup

b. center core regions have very high power swings

c. there is greater flexibility in core arrangement

d. fewer discriminator zones are needed.

6. Three core regions are sufficient to meet design constraints

a. four or more core regions increase complexity without improving performance 
b. two core regions cannot meet all design constraints

7. Broken ring arrangements are better than closed ring arrangements because

a. there is better coupling between regions

b. flux peaks are created which

- determine the location of control rods

- enhance control rod worth

8. Control rod positioning is very important

a. burnup can be controlled very efficiently by control rods

located in the outermost core region because

- the outermost core region is the largest core region, which makes a symmetrical arrangement less difficult

- the withdrawal of control rods counteracts the drop in assembly power observed in cores burned without control

b. control rods located next to an internal blanket region have a

lower worth than control rods surrounded by fuel assemblies, except for the outermost core region, where for some configurations

the worth of the control rod can be higher when placed next to an internal blanket assembly.

9. While there is the potential for arranging the internal blanket assemblies such that only one core enrichment is needed, no extensive efforts were undertaken at this stage to develop such a core because

a. of calculational uncertainties

b. having different enrichment zones is a more conservative approach

10. Meaningful figures of merit are

a. sodium void reactivity

b. doubling time

c. breeding ratio

d. specific inventory

e. peak burnup

f. damage fluence

g. maximum assembly power change during life and over one cycle

h. sensitivity of power shape

i. burnup swing and control rod requirements

Fuel cycle cost is not a meaningful figure of merit at present, although generic trends in fuel cycle cost should guide the design.

11. The choice of calculational techniques is very important

a. $r-z$ models are good for

- screening 
- inventory calculation

- breeding performance calculation

- sodium void reactivity estimates

b. hexagonal geometry models are needed for the calculation of

- enrichment split

- all power shape information

- contro1 rod worth

- accurate sodium void reactivities

12. Between the two configurations which were analyzed in detail there were only small difference with respect to the different figures of merit except for the control requirements

\subsection{RECOMMENDATIONS}

Upon completion of the pre-conceptual activities presented in this report, the following recommendations are made:

1. The following core configuration is recomended for further design analysis
a. tightly coupled
b. center blanket
c. 3-core region
d. 40 inch core height
e. 0.26 inch fuel o.d.
f. 271 pins per fuel assembly

2. Proceed with conceptual design and analysis

a. nuclear, thermal-hydraulic and mechanical design analyses

- assembly and fuel pin design

- core layouts

- breeding performance

- safety parameters

- power distribution and sensitivities

- temperature

- orificing

- cladding

- duct

- coolant

- pin and assembly life

- core restraint and seismic analyses

- fuel management

- fuel cycle cost assessment and optimization 
b. trade-off and sensitivity analyses

- number of enrichment zones versus power peaking versus fuel life

- number of enrichment zones versus number of orificing zones for a fixed number of discriminating zones

- axial and radial blanket thickness versus shield

- performance vs. design parameter changes

- performance vs. calculational methods

c. transient and safety analyses

- operational transients

- design-limiting transients

- accident analysis

d. startup analysis

- transition first core-equilibrium core

- temperature

e. power shape and reactivity control

f. instrumentation needs

g. component designs

- lower inlet plenum

- assembly keys

- assembly design (fuel, blanket, shield, contro1)

- fuel pin

- core restraint system

- upper internals

3. Assess calculational methods and data

a. nuclear analyses

b. thermal-hydraulic analyses

c. mechanical analyses

d. results of critical experiments 


\subsection{DESIGN ENVIRONMENT}

\subsection{DESIGN GROUNDRULES}

The reactor net electric power is in the 1000 MWe class. The reactor inlet temperature is $595^{\circ} \mathrm{F}$ and the reactor outlet temperature is $875^{\circ} \mathrm{F}$. The resulting thermal efficiency is 0.316 . The core layouts are those of heterogeneous reactors. Details of the design assumptions and constraints are listed In Appendix A. They cover:

1. Fuel assembly parameters

2. Blanket assembly parameters

3. Flow parameters

4. Limiting conditions

5. Material properties

6. Physics parameters

7. Fuel management

8. Economic parameters

9. Figures of merit

The hot channel factors used in this study are those developed for CRBRP. They are different for fuel and blanket assemblies. The structural material used in this study is an improved CW316SS similar to the N-lot stainless steel. In line with the design conservatism employed in this study the design was not pushed to every limit specified in the design assumptions and constraints. Examples for the conservatism in the selection of design parameters are bundle pressure drop ( 75 psi instead of $90 \mathrm{psi}$ ), linear heat rating of the reference design (less than $13.5 \mathrm{~kW} / \mathrm{ft}$ instead of $15 \mathrm{~kW} / \mathrm{ft}$ ).

\subsection{DESIGN APPROACH}

The design analysis efforts consisted of a preliminary set of analyses and then a final analysis of two designs.

\subsubsection{Preliminary Analyses}

The purpose of all preliminary analyses was to narrow down the multitude of design options to two designs which then would be analyzed in detail. This 
process of narrowing down design options was very complex and extended over several steps. First the means to reduce sodium void reactivity in radially heterogeneous cores were investigated. This effort covered loosely and tightly coupled center core and center blanket configurations. The design modifications were developed by changing:

- number of core regions

- degree of coupling

- size of center blanket regions

- size of center core regions

- core height

- number of fuel pins per assembly

- number of fuel assemblies per core region

Detalls of this analyses are reported in Appendix $B$.

Upon completion of these analyses, six basic heterogeneous configurations were Identified. They were three tightly coupled systems and three loosely coupled systems. Among both types of configurations were one center core configuration and two center blanket configurations. For the tightly coupled systems the center blanket configurations had either three or four core zones compared to two or three for the loosely coupled systems. The purpose of the analysis that followed was to determine optimum combination of fuel pin size, core height and core configuration. Since the power level was maintained at approximately $1000 \mathrm{MWe}$ any change in core height required a change in core layout. For tightly coupled cores, the core heights selected were 32 inches and 36 inches. The fuel pin diameters selected were $0.24 \mathrm{inch}, 0.26$ inch and 0.28 inch. For the loosely coupled cores, the chosen core heights were 40 inches and 48 inches with fuel pin diameters of 0.26 inch, 0.28 inch, and 0.30 inch.

After completion of these analyses the two most promising cores, one tightly and the other loosely coupled, were selected. While the previous step in the preliminary analysis aimed mostly at an optimization of fuel pin diameter, core height, and an elimination of less promising core concepts (see Appendix $C$ for details) the next step in the analysis attempted to optimize the core configuration. This was done by leaving the basic core configuration the same, i.e., a center blanket configuration with three core zones, but changing the detail of the assembly arrangements. After completion of the analysis, two core configurations with specific design parameters were selected for detailed performance analysis. 


\subsubsection{Final Design Analysis}

After completion of the preliminary analyses two promising configurations were identified with core heights of 36 inches and 40 inches and fuel pin sizes of 0.24 inch and $0.26 \mathrm{inch}$, respectively. There were more than those two configurations which showed good performance. Three of the tightly coupled cores showed approximately the same performance. The core selected was the one which had the lowest sodium void reactivity (\$2.23) and a low doubling time

(15.3 years). Among the cores derived from the loosely coupled systems were several arrangements which showed low sodium void reactivity and also low doubling time. The core finally selected was synthesized from cores which had been analyzed during the preliminary analyses.

The final analysis encompassed nuclear, thermal-hydraulic and mechanical design analysis. This analysis was subject to the design assumptions and constraints outlined in Appendix A. Upon completion of this analysis, a reference design was recommended for conceptual design analysis.

\subsection{OPTIMIZATION}

\subsubsection{Configuration}

The optimization of the core configuration was constrained by the $\$ 2.50$ sodium void reactivity limit. Only configurations which were able to meet this limit were analyzed in more detail. Among those configurations, the major criteria for the optimization were (1) the sensitivity of the power shape to slight changes in enrichment split and (2) the maximum power swing in a fuel assembly over a burnup cycle. Specific inventory, breeding ratio and doubling times were considered also in this optimization process but these figures of merit are less important than power shape sensitivity and power swing. The latter two performance characteristics relate to potential thermal hydraulic and subsequent safety problems. Since enrichment specifications have certain tolerances, these tolerances can be translated into a possible enrichment split uncertainty. If minor changes in enrichment split cause large changes in the peak power density, this leads to excessively high sodium and clad temperatures and possible pin failure. If this effect is taken into consideration in the design of the fuel assembly, it requires increased coolant flow through those assemblies which would be affected in case the enrichment split for the fuel as loaded was not at its nominal value. The possible undercooling on the other hand, raises peak clad temperature. 
Another aspect of the sensitivity of the power shape to enrichment split changes relates to the enrichment split change due to burnup. Very delicate control rod insertion patterns would be required to control not only the reactivity change but also a highly sensitive power shape. Therefore, even though a quantitative description of the limiting power shape sensitivity is not possible at the time, the less sensitivity a configuration shows the better.

The same qualitative description applies to the power swing over a burnup cycle. The larger the power swing is over a cycle the higher is the required overcooling and the higher are the clad temperatures. Therefore, the smaller the power swing the better the configuration.

\subsubsection{Design Parameters}

The optimization of design parameters was subject to two constraints. For one, the core configuration had to meet the $\$ 2.50$ sodium void reactivity criterion. Secondly, the configuration had to show low power shape sensitivity and a low power swing. The criteria for the optimization of design parameters were then in their order of importance:

$$
\begin{aligned}
& \text { - doubling time } \\
& \text { - specific inventory } \\
& \text { - control system simplicity }
\end{aligned}
$$

While the first two criteria are self-explanatory, the last criterion relates essentially to the control requirements. For example, a small pin design might yield a low specific inventory and also a low doubling time. However, the small fuel pin size might also lead to a very high burnup swing thus requiring a very large number of control assemblies. In this case, design trade-offs have to be considered. If doubling time and specific inventory are the same for several designs then the design with the least control requirements would be preferred if the reduced control requirements can also be translated into a reduction of the number of control assemblies. Because of the symetry requirements this reduction might not always be possible. In this case that design is preferred which perturbs the power shape the least during a cycle.

Fuel cycle cost was used as another figure of merit. The significance was not the actual mills/kWh data but the trend in fuel cycle cost resulting from a design change. The current uncertainties in fuel cycle cost data do not render fuel cycle cost to be a meaningful figure of merit in absolute terms. 


\subsection{METHODOLOGY}

Both detailed rigorous methods as well as approximate methods were employed in the design analyses presented in the report. Up to the selection of the reference design, approximate methods dominated the nuclear and thermalhydraulic design analysis. For the final design analyses, the more detafled rigorous methods were used for both nuclear and thermal design. The nuclear analysis was based upon NSMH properties with minor modifications. The irradiation induced swelling correlation is derived from the NSMH Rev. 7 correlation by increasing the incubation perfod $\tau$ from 6.3 to 9.0 . The steady-state swelling rate $R$ is reduced to $0.7 \mathrm{R}$. The irradiation induced creep calculation is based upon the nominal proposed NSMH Rev. 4 correlation using only $70 \%$ of the steady-state swelling rate and $\tau=9.0$. The stress rupture properties for steady-state analysis are the ones for nominal unirradiated $\mathrm{N}$-1ot steel.

\subsubsection{Design Analysis Flow Sheet}

The design analysis flow sheet is presented in Fig. 1. It shows schematically the various steps in the design evolution.

Performance Estimates: Estimates are required on clad and duct temperatures, fluence and power distribution.

Fuel Pin Design: Based on the design groundrules, the following fuel pin design parameters are fixed: cladding o.d., cladding thickness, fuel smear density, peak linear heat rating, plenum location and length. Active core length and axial blanket thicknesses are selected. CDF is estimated.

Fuel Assembly Design (NIFD Code): The following design parameters are calculated: duct diameter, duct wall thickness, creep and swelling dilation of the duct as a function of axial position, fuel pitch/diameter ratio, assembly pitch, pressure drop, spacer wire thickness. The code furthermore calculates bundle-duct-interaction (BDI), number of subassemblies required, flow requirements, as well as the following blanket assembly parameters: pin diameter, pitch-to-diameter ratio, wire thickness, assembly dimensions.

Preliminary Neutronics and T\&H Design (SYNBURN and REBUS Codes): For r-z core models, the SYNBURN and REBUS codes calculate the following parameters: spectfic fuel inventory, burnup swing, burnup, fluence, breeding performance, power distribution, mass balances. Based on these results, improved estimates are derived for blanket overcooling, clad and duct temperatures. 
Final Neutronics and T\&H Design (REBUS, DIF2D, PARC1D, PARC2D, CORE-3D, FLORF, ENERGY): Determined are: detailed core layout and control system layout, control rod worth, breeding performance, inventories at beginning of Iffe (BOL), beginning of equilibrium cycle (BOEC), end of equilibrium cycle (EOEC), power distribution, burnup swing, burnup, Doppler coefficient, sodium void coefficient. The T\&H analyses cover the following subjects: orificing, maximum coolant velocity, maximum pressure drop, flow distribution, core-wide clad, duct and coolant temperatures.

Remaining Performance Analyses (FX2, COST, ORIGEN, CAFAIL): The remaining analyses cover transient analyses, fuel cycle cost calculations, fission product decay heat calculations and CDF calculations.

\subsubsection{Computational Methods}

In the following, the calculational methods used for design analysis will be described briefly.

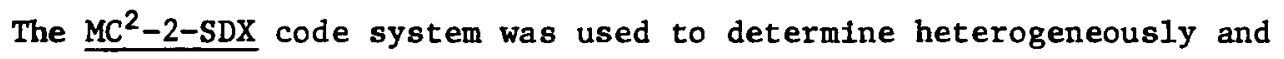
homogeneously self-shielded nuclear cross sectlons for core and blanket regions based on ENDF/B-IV cross section data.

For burnup analysis, 8-group cross sections and for sodium-void and Doppler calculations, 21 group cross sections were used. Separate cross section data sets were prepared for core and blanket regions as well as for four different temperatures and for cores with and without sodium.

The fuel assembly designs were carried out with the NIFD code. Input data for this code are coolant inlet and outlet temperature, bypass flow fraction, blanket temperature penalty, maximum coolant velocity, maximum linear heat rating, radial power peaking, core height and axial blanket thickness, fuel pin diameter, reactor power and power split, stress limits and fast fluence. Output data are fuel pitch-to-diameter ratio, duct wall thickness, duct stresses (corner, wall), duct inside flat-to-flat distance, required interassembly gap as a function of axial position (allowing for swelling, irradiation creep and handling), number of fuel assemblies needed, bundle pressure drop, and volume fractions. The code can handle both wire-wrapped as well as gridded assemblies. Based on the number of required fuel assemblies and the estimated number of control positions, the code also determines the actual number of fuel assemblies for a hexagonal core layout where the corners can be rounded off, if needed.

The approximate nuclear performance was obtained from the SYNBURN code. This code is a $2 \mathrm{D}$ synthesis burnup code which calculates beginning- and end-of- 
equilibrium cycle performance characteristics and mass balances. The buckling treatment which allows for some flexibility in this code was adjusted to bring good agreement with more rigorous methods. The SYNBURN code provided enrichment splits which were then used as first guesses in REBUS $r-z$ geometry calculations.

The approximate thermal analysis was based on adjustments to results obtained from rigorous methods by correcting for differences in linear heat rating, coolant flow rates and heat fluxes. In case no detailed analysis for a similar design was available, orificing was based on concentric orificing zones and the local peak-to-average power ratios.

The rigorous nuclear analysis of the first cycle and the equilibrium cycle was carried out with the REBUS code package. The REBUS code package performs burnup calculations in 1 and 2D. The code system handles discrete burnup, equilibrium cycle analysis, homogenized fuel management, discrete fuel management, fuel shuffling as well as a large variety of fuel recycle options. DIF2D is the 2-dimensional diffusion code used in REBUS. Burnup analysis was carried out using both $\mathrm{r}-\mathrm{z}$ and hexagonal geometry options. Control rod worth calculations were carried out in hexagonal geometry using bucklings obtained from $r-z$ geometry calculations.

$\underline{\text { PARC1D }}$ and PARC2D are one- and two-dimensional perturbation codes which were used for worth calculations in general and sodium void and Doppler reactivity distribution in particular.

After completion of the nuclear analysis, core layout, fuel management, and power distribution feed into the thermal analysis. The codes CORE-3D and ENERGY were used together with the FLORF code for a rigorous thermal analysis.

The CORE-3D code determines steady-state core-wide temperature distributions. It is based on the ENERGY code and takes interassembly heat transfer Into account without limiting the number of fuel assemblies of which the core consists. Fuel assemblies were orfficed individually. Coolant temperatures were calculated inside all fuel assemblies as well as duct temperatures and cladding hot-spot temperatures.

The ENERGY code determines the temperature distribution inside a fuel subassembly. The various mixing modes are lumped into an equivalent turbulent cross flow which is described by an effective eddy diffusivity. The code was used for a detailed thermal analysis of the design limiting assemblies. 
The FLORF code is used to assign orificing zone numbers to all assemblies in the core based solely on assembly power and regardless of the physical location of the assembly. Therefore, assemblies can be in the same orificing zone even though they are not positioned next to each other. The assignment of orificing zones is governed by maximum clad temperatures which should be equal in all zones. It is permissible to use different temperature limits in different regions of the reactor and/or to select power distributions at any time in life and any region which are considered the limiting distributions.

The steady state cumulative damage fraction (CDF) was calculated with the CAFAIL code which uses correlations for rupture life and cladding wastage as specified by the groundrules.

\subsubsection{Calculational Approach}

The methods employed in the various steps of the preliminary analysis and the final analysis differed greatly reflecting on the different purposes of each step.

During the preliminary analysis the first step was to investigate the means to reduce sodium void reactivity. Beginning-of-1ife (BOL) calculations were carried out in $\mathrm{r}-\mathrm{z}$ geometry. The enrichment split for the multi-core region arrangements was obtained from 1-D calculations. BOL sodium void reactivity calculations were carried out with a $2 \mathrm{D}$ perturbation code. The justification for using $\mathrm{BOL}$ conditions rather than end-of-equilibrium cycle (EOEC) conditions was the finding that for a two year residence time, the difference in sodium void reactivity for BOL and EOEC conditions was always $\$ 1.15 \pm 5 \mathrm{c}$. Therefore, a sodium vold reactivity target of $\$ 2.50$ at EOEC required a BOL value of $\$ 1.35$ or less. Using perturbation rather than direct eigenvalue calculations for the sodium vold reactivity provided insight into the spatial distribution of the sodium void reactivity and helped in the development of core configuration. During the first step of the preliminary analyses, r-z burnup calculations were carried out for selected cores. No detailed fuel pin or assembly designs were developed. But instead those designs were derived from the original Phase $A$ fuel pin and assembly design.

During the second step of the preliminary analyses, detailed burnup calculations were carried out in $\mathrm{r}-\mathrm{z}$ geometry. Specific fuel pin and assembly designs were developed subject to the design groundrules. Since the emphasis was placed on determining fuel pin sizes and core heights, no hexagonal geometry calculations were carried out at this stage. The performance parameters calculated at this step of the preliminary analysis were EOEC sodium 
void reactivities, breeding ratios, doubling times, fissile inventories, fluences and changes in assembly power output.

The step in the elimination process which followed was an optimization of the configuration. This required both $r-z$ and hexagonal geometry burnup analysis with explicit representation of control rods as well as their insertion and withdrawal.

The final analysis was carried out in $r-z$ and hexagonal geometry and included nuclear, thermal-hydraulic and mechanical design calculation. These calculations were complemented by transient and fuel cycle cost calculations. 


\subsection{CORE DESIGN AND ANALYSIS}

The analysis and optimization of the various types of tightly and loosely coupled configurations, as described in Appendices B, $C$, and $D$ has resulted in the two configurations shown in Fig. 2. These represent preliminary optimum configurations with respect to a compound system doubling time of about 15 years and EOEC sodium void reactivity less than $\$ 2.50$. We have two configurations because of the two distinct starting points in this study. Namely, the class of loosely coupled cores, which lead to configuration $A$, and the class of tightly coupled cores which lead to configuration $B$. The two configurations are similar in that they are both center blanket configurations and have three core zones. We note that neither of the final cores can be put into either the class of loosely or tightly coupled cores, and may be considered hybrids. A general feature of both configurations, with respect to the previous classification, is that the inner and middle core regions are more tightly coupled than the middle and outer core regions. Although the configurations have these common features, they also retain some features which reflect their evolutionary origin. For example, configuration $B$ which derives from the tightly coupled cores is shorter (36 in.) than configuration $A(40 \mathrm{in.}$ ) and the fuel assemblies have respectively 331 and 271 fuel pins. A more detalled description of the designs is given in section 4.3 of this report.

This section will present a detailed analysis of the nuclear, thermalhydraulic, and mechanical performance characteristics of configurations $A$ and B. Based on these data a final optimum core will then be chosen in a conceptual design study.

\subsection{NUCLEAR DESIGN ANALYSIS}

\subsubsection{Core Layout}

The core configurations for this analysis are given in Fig. 2. They are center-blanket cores with three core zones each. The number of assemblies per region are listed in Table $I$. The total number of core assemblies in configuration $A$ is 330 and in configuration $B$ it is 342 . Configuration $A$ has a 
total of 157 internal blanket assemblies divided into four region, while configuration $B$ has 145 separated into three reglons. The fourth internal blanket region in configuration A consist of clumps of three assemblies each and is not considered as a ring separating two core zones. It will be treated In the data tabulations as a part of internal blanket 3 . The number of radial blanket and radial shield assemblies is the same for both configurations. The total number of assemblies in configuration $A$ is 883 and in configuration $B$ it is 889 .

\subsubsection{Fissile Inventory}

The fissile inventories for the beginning of life (BOL), beginning of equilibrium cycle (BOEC), and the end of equilibrium cycle (EOEC), are listed for both configurations in Table II. The total reactor fissile inventory at BOL for configuration $A$ is $3861.9 \mathrm{~kg}$, at BOEC $4268.4 \mathrm{~kg}$, and at the EOEC $4575.0 \mathrm{~kg}$. For configuration $B$ the respective values are $3790.9 \mathrm{~kg}, 4213.4 \mathrm{~kg}$, and $4489.7 \mathrm{~kg}$. In the inner and middle core zones the fissile inventories of configuration B are higher, while for the outer core zone, the fissile Inventory of configuration $A$ is higher. Overall, configuration $A$ has a slightly higher fissile inventory. For BOEC conditions this difference of $1.3 \%$ is due mainly to the bigger pin size in configuration $A$.

The average fissile enrichment by region is given for the two configurations in Table III. The enrichment in the core zones varies from 17.7 to $19.4 \%$ H.M. at BOL, and reduces to from 16.3 to $17.5 \%$ H.M. at the EOEC as the power shifts from the core to the blankets.

\subsubsection{Burnup and Reactivity Swing}

The peak and average burnups for the two configurations under equilibrium cycle conditions are given in Table IV. Both peak and average core discharge burnups are higher for configuration $B$ than for configuration $A$. The highest value for configuration $B$ occurs in the outer core zone and is $100.7 \mathrm{MWD} / \mathrm{kg}$. This can be compared with the highest value of $83.90 \mathrm{MWD} / \mathrm{kg}$ for configuration $\mathrm{A}$, which also occurs in the outer core zone. The higher core burnup is due to the smaller pin size in configuration $B$. The peak discharge burnup in the internal blankets are comparable; the highest values occur in internal blanket 3 and are $22.10 \mathrm{MWD} / \mathrm{Kg}$ and $20.96 \mathrm{MWD} / \mathrm{Kg}$ for configuration $\mathrm{A}$ and $\mathrm{B}$, respectively.

The reactivity for both cores decreases over the equilibrium cycle. This reactivity swing is $0.49 \% \Delta \mathrm{k}$ for configuration $\mathrm{A}$ and $1.8 \% \Delta \mathrm{k}$ for configuration $\mathrm{B}$. 
This difference is due in part to the difference in the pin diameter between the two configurations, but mostly because of the enhanced internal breeding due to the addition of internal blanket four in configuration $A$. In addition, the larger reactivity swing in configuration $B$ implies a greater control requirement. This has been taken into account in the construction of the configurations by allowing 30 control positions in configuration $B$ as opposed to 24 in configuration A.

\subsubsection{Control Requirements}

The control assembly assignments for the two configurations are given in Table V. For configuration $A$ there are 12 control assemblies in the primary system and 12 in the secondary system, and for configuration $B$ there are 12 in the primary system and 18 in the secondary system, which were chosen arbitrarily. The primary system serves both a safety and an operational function. This system must have sufficient worth at any time in the reactor cycle to shut down the reactor from any operating conditions, and to maintain subcriticality over the full range of coolant temperatures expected during shutdown. In addition, the primary control system is designed to meet fuel burnup and load requirement for each cycle as well as to compensate for criticality and refueling uncertainties. The secondary control system must have sufficient worth at any time in the reactor cycle to shut down the reactor from any operating conditions to hot-standby conditions. Both primary and secondary control systems must be capable of performing the specified functions independently, even with the failure of any single active component (i.e., a stuck rod). Allowance must also be made for both control systems for the maximum reactivity fault associated with any anticipated occurence.

The control assembly compositions were assumed to be those of the CRBRP design with $92 \%$ enriched $\mathrm{B}_{4} \mathrm{C}$. The results of the control system worth calculations in hexagonal geometry are given in Table VI. The total worth of both the primary and the secondary system is somewhat greater for configuration $B$ than for configuration $A$.

The item-by-item reactivity requirements for the primary and secondary control systems are listed in Table VII. The requirement for controlling the excess reactivity (for the primary control system only), which usually is the most important component for a homogeneous reactor, is about a third smaller for configuration $A$ than for configuration $B$. This is because the burnup swing for the configuration $A$ core $(0.49 \% \Delta k)$ is also smaller when 
compared to that of configuration $B(1.8 \% \Delta \mathrm{k})$. This difference in burnup swings also leads to the difference in the control requirements for the maximum reactivity fault, for the amount of excess reactivity (plus uncertainties) dictates the maximum reactivity insertion that can occur due to any single rod run-out. The control requirement for cold criticality prediction uncertainty for CRBRP is $0.3 \% \Delta k$ and is adopted here for both configurations. The control requirement for fissile refueling tolerance $(0.3 \% \Delta \mathrm{k})$ is based on a $0.5 \%$ uncertainty in batch fisstle enrichment. The hot-to-cold component (requirement for both control systems) is assigned large uncertainties because the reactivity insertion due to the radial and axial core contractions is not readily available. The maximum reactivity control requirements, including uncertainties, for the primary and secondary control systems of configuration $A$ are 3.65 and $2.58 \% \Delta \mathrm{k}$ respectively, while for configuration $B$ they are 4.24 and $3.47 \% \Delta \mathrm{k}$, respectively.

In Table VII the control system worths including one stuck assembly are compared with the control requirements. For configuration $A$ the primary system worth is $3.65 \% \Delta \mathrm{k}$ and the secondary system worth $2.58 \% \Delta \mathrm{k}$. The values are substantially higher than the respective control requirements of $2.33 \% \Delta \mathrm{k}$ and $1.31 \% \Delta k$. On the other hand, for configuration $B$ almost no margin exists between the primary system worth of $4.24 \% \Delta \mathrm{k}$ and the requirement of $4.02 \% \Delta k$. For the secondary system the control worth is twice that of the requirement. It is therefore more appropriate to reassign some secondary control rods of configuration B as defined in Table VI to the primary system.

In making the above comparisons, it must be kept in mind that the reactivity worth of each control rod depends strongly on the positions of other control rods. This is especially true for a parfait core in which the flux distribution is very sensitive to the control rod insertion pattern. Thus, the above results must only be viewed with respect to the preliminary control system assignments in Table $\mathrm{V}$.

\subsubsection{Power and Flux Distribution}

The power fractions for the different regions of the two configurations at BOL, BOEC, and EOEC are given in Table VIII. For configuration $A$ the power fraction in the core region decreases from $89.9 \%$ at BOL to $75.7 \%$ at EOEC, and in the internal blankets the power fraction increases from $6.5 \%$ 
at BOL to $16.8 \%$ at EOEC. Similarly for configuration $B$, the change in core power is from $89.7 \%$ at BOL to $76.7 \%$ at the EOEC and in the internal blankets from $5.8 \%$ to $14.6 \%$ respectively.

The peak assembly powers at the mid-plane for BOL, BOEC, MOEC, and EOEC conditions for configuration $A$ are given in Figs. 3 through 7 . The peak power density of 809.1 watts/cc at BOL with no control rods inserted occurs in the outer core zone. Inserting the row 11 rods $15 \%$ to maintain reactor criticality decreases this peak to 643.4 watts/cc and shifts the peak power density to a value of $678.2 \mathrm{watts} / \mathrm{cc}$ in a subassembly in the middle core zone. In Fig. 5 the BOEC peak power densities are shown under the condition of the row 11 control rods inserted 15\%. As the burn cycle proceeds and the row 11 rods are withdrawn to compensate for the reactivity loss the peak power density shifts to the outer core zone and is 623.4 watts/cc at the EOEC (see Figs. 5 through 7).

Similar results are given in Figs. 8 through 12 for configuration B. The BOL peak power density with the row 11 rods completely inserted is 772.9 watts/cc and occurs in the middle core zone. At the EOEC with the rods withdrawn the peak power density is 694.1 watts/cc and is in the outer core zone.

The peak-to-average power densities at BOL, BOEC, and EOEC for the various reactor regions of the two configurations are given in Table IX. The total core peaking factor for configuration $A$ at BOL is 1.45 and increases to 1.54 at the EOEC. For configuration $B$ the respective change is from 1.53 to 1.60 . Overall, power peaking in configuration $A$ is somewhat lower than in configuration $B$. Some further descriptions of the power distributions are given in Figs. 80 through 85 .

The nominal peak nuclear linear heat ratings are listed for both BOL and EOL in Table $X$. Core configuration $A$ has a higher peak linear heat rating both at BOL and EOL, 13.4 and $12.0 \mathrm{~kW} / \mathrm{ft}$ as compared to 13.2 and $11.4 \mathrm{~kW} / \mathrm{ft}$ respectively for configuration $\mathrm{B}$. However, the EOL peak blanket linear heat ratings are higher for configuration $B$ than for configuration $A$. For the internal blanket and the radial blanket of configuration $A$ the values are $12.8 \mathrm{~kW} / \mathrm{ft}$ and $8.7 \mathrm{~kW} / \mathrm{ft}$ respectively, while $15.3 \mathrm{~kW} / \mathrm{ft}$ and $10.7 \mathrm{~kW} / \mathrm{ft}$ for configuration $\mathrm{B}$.

The peak fast fluxes in the core and blanket regions are given in Table XI. In the core the peak fast flux for configuration $A$ is $3.39 \times$ $10^{15} \mathrm{n} / \mathrm{cm}^{2}-\mathrm{sec}$ and $3.57 \times 10^{15} \mathrm{n} / \mathrm{cm}^{2}-\mathrm{sec}$ for configuration $B$. For a core 
residence time of 2 cycles at 255.5 days per cycle the peak fast fluence is $1.45 \times 10^{23} \mathrm{nvt}$ for configuration $\mathrm{A}$ and $1.50 \times 10^{23} \mathrm{nvt}$ for configuration $\mathrm{B}$. For the internal blankets, whose residence time is also 2 cycles, the respective peak fluences are $1.28 \times 10^{23} \mathrm{nvt}$ and $1.32 \times 10^{23} \mathrm{nvt}$.

In Figs. 13 through 21 contour flux maps are given for configuration A. The BOL reactor conditions are shown in Figs. 13 through 18 with different control rod insertions. The flux peaking at BOL about the row 11 primary rods is especially noteworthy, for this peak significantly enhances the worth of these control rods. The effect of inserting this rod can be seen in Figs. 13 and 14. The change in the flux distribution over the equilibrium cycle is shown in Figs. 19 through 21, where the reactivity swing is being controlled with the row 11 primary rods. As the burnup proceeds and these rods are withdrawn the buildup of the characteristic flux peak near this rod can be seen.

The analogous situations are shown in Figs. 22 through 29 for configuration B. We note (see Fig. 22 for example) that also in configuration $B$ a flux peak exists at the row 11 primary control positions, and therefore enhances the worth of these control rods.

\subsubsection{Breeding Performance}

The breeding ratios for the different regions of the two reactors are listed in Table XII for BOL, BOEC, and the EOEC. The core breeding ratio of configuration $\mathrm{A}$ is 0.550 at $\mathrm{BOL}$ and reduces to 0.497 at the EOEC as the power shifts to the blankets. For configuration $B$ the BOL core breeding ratio is 0.628 and reduces to the same value as that of configuration $A$, 0.497 , at the EOEC. The total reactor breeding ratios for configuration $A$ are 1.488 at BOL and 1.380 averaged over the equilibrium cycle. The respective values for configuration $B$ are 1.530 and 1.354 .

The compound system doubling times for the two configurations are listed in Table XIII. Under the assumptions of a two year residence time for core and internal blanket assemblies, a five year residence time for the radial blanket assemblies, a one year out-of-pile time, and $1 \%$ fuel cycle losses, the doubling time for configuration $A$ is 15.7 years and for configuration B 15.3 years. This could be reduced somewhat, as is shown for configuration $A$, by using a one year residence time for the internal blankets. In this case configuration $A$ has a 15.1 year compound system doubling time. 


\subsubsection{Safety Parameters}

The sodium void reactivities for the two configurations are given in Table XIV and XV. The results are calculated in first order perturbation theory and thus the break down with respect to voiding the individual zones is given. The values are for the removal of the flowing sodium only. Both configurations have sodium void reactivities, for voiding the flowing sodium from the core plus the upper axial blanket, which are below $\$ 2.50$ at the EOEC. The BOL value for configuration $B$ is almost half of the BOL sodium void reactivity of configuration $A$. However, due to the greater burnup of configuration $B$ its sodium void reactivity increases to within $15 c$ of the sodium void reactivity of configuration $A$ at the EOEC.

In Tables XVI and XVII the isothermal Doppler coefficients are given for both configurations with sodium-in and sodium-out conditions at BOL and at the EOEC. The total core Doppler coefficient at BOL for configuration $A$ is 0.0053 for sodium-in and 0.0031 for sodium-out and decreases to 0.0046 and 0.0029 respectively at the EOEC. The total internal blanket Doppler coefficient, on the other hand, is 0.0039 and 0.0031 at BOL for sodium-in and sodium-out, and increases to 0.0048 and 0.0036 respectively at the EOEC. For configuration $B$ the core Doppler coefficient is 0.0051 and 0.0031 at BOL for sodium-in and sodium-out, and at the EOEC 0.0046 and 0.0028 respectively. The internal blanket Doppler coefficients for configuration $B$ are somewhat lower than for configuration A. At BOL these are 0.0026 and 0.0022 for sodium-in and sodium-out and 0.0038 and 0.0029 respectively at the EOEC.

\subsubsection{Transient Response}

\subsubsection{Introduction}

Investigation of transient response of both configuration $A$ and. $B$ to reactivity insertions into the outer core region via control rod withdrawal was conducted. The aim here was primarily to assess the space dependent kinetics effect of these configurations. Comparison of results with the Phase $A$ design was made.

\subsubsection{Methodology}

The two-dimensional space-time kinetics code $\mathrm{FX}^{2}$ was used to study the configuration $A$ and $B$ designs in one-sixth hexagonal symmetry. The Doppler feedback effect came from the temperature-dependent cross sections. An adiabatic heat transfer model (i.e., a constant heat transfer rate from fuel to coolant throughout the transient) was used in the transient analysis. 


\subsubsection{Reactivity Insertions}

Two different reactivity insertion rates were studied: a $60 \mathrm{c}$ step and a $60 \mathrm{c} / 500 \mathrm{~ms}$ ramp, both coming from withdrawing the control rods from the outer core region.

\subsubsection{Transient Results}

\subsection{Configuration A}

When a 60 reactivity step was inserted into the outer core region, the peak power density normalized to its initial value for each of the three core zones (inner, middle and outer) rose rapidly in the first millisecond, and reached a peak value near 4 milliseconds. Furthermore, the outer core peak power density rise was only $2.3 \%$ and $3 \%$ higher than those of the middle core and inner core (2.507 vs. 2.511 and 2.501). These results were given in Table XVIII and Fig. 30.

For the $60 \mathrm{c} / 500 \mathrm{~ms}$, again the normalized peak power density in all three core zones rose in unison, with that of the outer core zone slightly greater $(2.3 \%$ and $2.7 \%$ ) than those of the middle and inner core zones (2.113 vs. 2.064 and 2.056). These results were shown in Table XIX and Fig. 31 .

\subsection{Configuration B}

The transient response of configuration $B$ was similar to that of configuration A to both the $60 \mathrm{c}$ step and $60 \mathrm{c} / 500 \mathrm{~ms}$ ramp. With the $60 \mathrm{c}$ step insertion, the normalized peak power density in the outer core reached the peak value of 2.553, while those of the middle and inner cores respectively reached 2.503 and 2.490 . The difference between the outer core normalized peak power density and those of the middle and inner cores were respectively $2.0 \%$ and $2.5 \%$.

For the $60 \mathrm{c} / 500 \mathrm{~ms}$ ramp, the normalized peak power density in the outer core reached its maximum value of 2.131 , relative to those of 2.083 and 2.071 for the middle and inner core. The difference here between the outer core normalized peak power density and those of the middle and inner cores were $2.3 \%$ and $2.9 \%$. These results were shown in Tables XX-XXI and Figs. 32-33. 


\subsubsection{Conclusions}

Based on the above analysis, the following conclusions can be made.

1. Both configuration $A$ and $B$ had very little space-dependence effects during a $60 c$ step or ramp insertion transient. The normalized peak power density in the outer core zone where reactivity was inserted was never more than $3 \%$ greater than that of the middle or inner core for both configurations $A$ and $B$ for either the $60 c$ step or ramp insertion.

2. In comparison, the Phase A design exhibited a maximum normalized peak power density of 3.3 in the inner core where reactivity was inserted, and about 2.5 in the middle and outer cores, when a 60 c step reactivity was inserted in the inner core.

\subsection{THERMAL-HYDRAULIC ANALYSES}

\subsubsection{Inlet and Outlet Temperature of Configuration A}

Inlet and outlet temperatures for core, core plus internal and radial blankets, and the reactor are given in Table XXII. The core inlet temperature is $595^{\circ} \mathrm{F}$, with a core $\Delta \mathrm{T}$ of $313^{\circ} \mathrm{F}$. The $\Delta \mathrm{T}$ across the core and blankets is $295^{\circ} \mathrm{F}$. The cold by-pass is $5 \%$ of the total reactor flow. Cold by-pass flow does not include flow through control channels. The $\gamma$ heating in those channels was taken into account in calculating the coolant temperature rise.

\subsubsection{Orificing Scheme of Configuration A}

The orificing zones are shown in Fig. 34. There are three orificing zones in the core, four in the internal and radial blankets, and one for the contro1 and radial reflector assemblies. BOL powers with control rods inserted were used for the core and EOL powers were used for the internal and radial blankets in determining the flow distribution. At these burnup stages, the peak cladding midwall temperatures ( $2 \sigma$ values) were made equal for the hottest fuel or blanket pin in each orificing zone.

The coolant flow rates, coolant velocities, and the number of assemblies in each of the orificing zones are given in Table XXIV. The flow splits are $74.8 \%, 24.9 \%$, and $0.5 \%$ for the core, internal and radial blankets, and control and shield assemblies. The maximum coolant velocity is $25.6 \mathrm{ft} / \mathrm{sec}$.

The sensitivity of peak cladding temperatures to using EOEC powers for the core and blankets will be discussed in section 4.2 .4 . 


\subsubsection{Temperature Distributions of Configuration A}

Temperature distributions for the duct and coolant on a core wide basis, orificed for minimum peak temperature, at various axial locations (core midplane, core and upper axial blanket interface, and the top of the upper axial blanket) are given in Figs. 35 to 46 . The duct temperature calculations took into account the interassembly heat transfer. The averaged duct temperatures given in Figs. 41 to 46 were averaged over the six-flats of each assembly. The highest average duct temperature is $894^{\circ} \mathrm{F}$, at the top of the upper axial blanket in an assembly in the twelfth row of the core at beginning of life.

The average coolant temperature is obtained from averaging the coolant subchannels interior to the assembly. The maximum coolant outlet temperature is $1013^{\circ} \mathrm{F}$, and occurs in the same assembly which has the highest average duct temperature.

While the highest average outlet temperatures are achieved in the assembly In the twelfth row, the limiting (or hottest) fuel pin is in an assembly in row eight. For the assembly with the hottest fuel pin, the coolant as well as nominal and 20 clad midwall temperatures are shown respectively in Figs. 47 to 55 for three axial locations. The peak coolant subchannel outlet temperature is $1003^{\circ} \mathrm{F}$. With a hot channel factor of 1.232 , the peak $2 \sigma$ coolant subchannel outlet temperature is $1098^{\circ} \mathrm{F}$. The peak nominal clad midwall temperature for the hottest pin in this assembly is $1026^{\circ} \mathrm{F}$ at the core and upper axial blanket interface. The peak $2 \sigma \mathrm{clad}$ midwall temperature for this pin is $1145^{\circ} \mathrm{F}$ at the same axial location. These temperatures occur at beginning-of-life conditions. How they vary from beginning-of-ife to end-ofIife conditions is shown in Tables XXVI and XXVII. At EOL, the peak nominal and $2 \sigma$ clad midwall temperatures are 973 and $1077^{\circ} \mathrm{F}$, which is a reduction of 53 and $68^{\circ} \mathrm{F}$, respectively. from their BOL values. Tables XXVI and XXVII also give the nominal and $2 \sigma$ temperature at the clad outer diameter. The temperature drop across half of the clad thickness is $23^{\circ} \mathrm{F}$ at the core and axial blanket interface where the clad midwall temperature reaches its maximum.

A summary of nominal and $2 \sigma$ peak temperatures for the cladding, coolant, and duct is given in Table XXVIII. The $2 \sigma$ peak cladding temperatures are 1122,1145 and $1178^{\circ} \mathrm{F}$ at the outer diameter, midwall and inner diameter, respectively. These temperatures occur for the hottest pin at BOL. As mentioned before, at EOL, a reduction of $68^{\circ} \mathrm{F}$ is observed. The $2 \sigma$ peak duct and coolant temperatures are 926 and $1024^{\circ} \mathrm{F}$, respectively. 


\subsubsection{Sensitivity of Cladding Temperature to Orificing Criteria of Configuration A}

The orificing strategy employed equalized the maximum $2 \sigma$ cladding temperature at beginning-of-life for the core and end-of-life for the blankets in all orificing zones. This means that the blanket pins and some of the driver fuel pins are overcooled for most of their life.

The flow split between core and blanket assemblies was changed to equalize the peak clad temperature at end-of-equilibrium cycle conditions. This led to the orificing scheme shown in Fig. 56. The coolant flow rates, velocities and number of assemblies in each zone are shown in Table XXV. While this orificing strategy lowered the peak clad temperatures at EOEC for the core from $1145^{\circ} \mathrm{F}$ to $1134^{\circ} \mathrm{F}$, some fuel assemblies had much higher temperatures at beginning-of-life conditions than obtained with the reference orificing. This is due to the fact that control rod insertion and the power shift to the blanket assemblies over an equilibrium cycle cause a large decrease in rating in driver fuel assemblies located far from the inserted rods. Consequently, determining the flow for these assemblies at EOEC conditions causes them to be undercooled at beginning-of-life. The fuel assemblies on the flats of rows thirteen and fourteen are very sensitive to control rod insertion. Orificing these assemblies for EOEC when control rods are withdrawn leads to clad midwall temperatures of more than $1200^{\circ} \mathrm{F}$ at BOL when the row twelve rods are inserted.

It needs to be assessed which orificing strategy improves performance. The latter strategy leads to higher clad temperatures at BOL when cladding hoop stresses are very small and lower temperatures at EOL when hoop stresses are high thus possibly improving fuel life.

\subsubsection{Inlet and Outlet Temperature of Configuration B}

Inlet and outlet temperatures for core, core plus internal and radial blankets, and the reactor are given in Table XXIX. The core inlet temperature is $595^{\circ} \mathrm{F}$, with a core $\Delta \mathrm{T}$ of $312^{\circ} \mathrm{F}$. The $\Delta \mathrm{T}$ across the core and blankets is $295^{\circ} \mathrm{F}$. The reactor $\Delta \mathrm{T}$ is $280^{\circ} \mathrm{F}$. The cold by-pass flow is $5 \%$ of the total reactor flow. Cold by-pass flow does not include control channels since $\gamma$ heating is taken into account in calculating the temperature rise through them. 


\subsubsection{Orificing Scheme of Configuration B}

The orificing zones are shown in Fig. 57. There are three orificing zones in the core, four in the internal and radial blankets and one zone for the control and radial reflector assemblies. BOL powers with control rods inserted were used for the core and EOL powers were used for the radial and internal blankets in determining the coolant flow distribution. At these burnup stages the $2 \sigma$ peak cladding midwall temperatures were made equal for the hottest fuel or blanket pin in each of the orificing zones.

The number of assemblies in each zone, the coolant flow rates and the coolant velocities are shown in Table Xxxr. The flow splits are $78.1 \%, 21.6 \%$ and $0.3 \%$ for the core, internal and radial blankets, and control and shield assemblies. The maximum coolant velocity is $25.6 \mathrm{ft} / \mathrm{sec}$.

The sensitivity of cladding temperatures to using EOEC powers for the core and blanket assemblies will be discussed in section 4.2.8.

\subsubsection{Temperature Distributions of Configuration B}

Temperature distributions for the duct and coolant on a core wide basis at three axial locations (core midplane, core and upper axial blanket interface, and top of the upper axial blanket) are shown in Figs. 58 to 69 . The calculations of duct temperatures took into account interassembly heat transfer. The average duct temperatures given in Figs. 64 to 69 were averaged over the six flats of each assembly. The highest average duct temperature is $817^{\circ} \mathrm{F}$, at the top of the upper axial blanket in an assembly in the thirteenth row of the core at beginning of life.

The average coolant temperature is obtained from averaging the coolant temperatures of the subchannels interior to the assembly. The maximum coolant outlet temperature is $1009^{\circ} \mathrm{P}$, and occurs in the same assembly which has the high average duct temperature.

While the highest average coolant temperatures are achieved in row 13, the limiting (or hottest) fuel pin is in an assembly in the ninth row. For the assembly with the limiting fuel pin, the coolant as well as nominal and 20 clad midwall temperatures are shown in Figs. 70 and 78 for three axial locations. The peak coolant subchannel outlet temperature is $1016^{\circ} \mathrm{F}$. Applying a hot channel factor of 1.232 for the coolant $\Delta T$ gives a $2 \sigma$ peak outlet temperature of $1114^{\circ} \mathrm{F}$. The peak nominal clad midwall temperature for this assembly is $1041^{\circ} \mathrm{F}$ at the core and upper axial blanket interface. The 
peak $2 \sigma$ clad midwall temperature for the hottest pin in this assembly is $1164^{\circ} \mathrm{F}$ at the same axial location. These temperatures occur at beginning of life conditions. Tables XXXIII and XXXIV show how the temperatures vary from beginning-of-1ife to end-of-11fe conditions. At EOL, the peak nominal and 20 clad temperatures are 990 and $1100^{\circ} \mathrm{F}$, which is a reduction of 51 and $64^{\circ} \mathrm{F}$, respectively, from $B O C$ values. Tables XXXIII and XXXIV also give the nominal and $2 \sigma$ temperature at the clad outer diameter. The temperature drop across half of the clad thickness is $24^{\circ} \mathrm{F}$ at the core and upper axial blanket interface where the clad temperature reaches its maximum.

A summary of nominal $2 \sigma$ peak temperatures for the cladding, coolant, and duct is given in Table XXXV. The $2 \sigma$ peak cladding temperatures are 1140 , 1164 , and $1188^{\circ} \mathrm{F}$ at the outer diameter, midwall and inner diameter, respectively. These temperatures occur for the hottest pin at BOL. As mentioned before, at EOL, a reduction of $64^{\circ} \mathrm{F}$ is observed. The $2 \sigma$ peak duct and coolant temperatures are 936 and $962^{\circ} \mathrm{F}$, respectively.

\subsubsection{Sensitivity of Cladding Temperature of Orificing Criteria of Configuration B}

The orificing strategy employed equalized the maximum $2 \sigma$ cladding temperature at beginning-of-life for the core and end-of-life for the blankets in all orificing zones. This means that the blanket pins are overcooled for most of their life and the driver fuel pins are overcooled after the initial core loading.

The flow split between core and blanket assemblies was changed to equalize the peak clad temperature at end-of-equilibrium cycle conditions. This resulted in the orificing scheme show in Fig. 79. The coolant flow rates, velocities and number of assemblies in each zone are shown in Table XXXII. This orificing strategy lowered the peak clad temperatures in the core at BOL from 1164 to $1125^{\circ} \mathrm{F}$. However, some fuel assemblies had much higher temperatures at beginning-of-life conditions than obtained with the reference orificing. This is due to the fact that control rod insertion and the power shift to the blanket assemblies over an equilibrium cycle cause a large decrease in rating in driver fuel assemblies located far from the inserted rod. Consequently, determining the flow for these assemblies at EOEC conditions causes them to be undercooled at beginning-oflife. Orificing for EOEC caused the fuel assemblies on the flats of rows five and six to be placed in flow zone three while the reference orificing 
placed them in zone two. The resulting decrease in flow raised the peak $2 \sigma$ clad midwall temperature from 1164 to $1204^{\circ} \mathrm{F}$ at BOL. This emphasizes the importance of using a detailed hexagonal power distribution including control rod insertion when orificing heterogeneous cores.

\subsection{MECHANICAL DESIGN ANALYSES}

The structural material used for claddings and ducts is $20 \%$ CW316SS. In the following, the designs of fuel pin, fuel assembly, blanket pin, blanket assembly, control assembly, as well as duct life will be discussed for both configurations $A$ and $B$.

\subsubsection{Fuel Pin Design}

The fuel pin design parameters are summarized in Table XXXVI. The optimization studies gave optimum fuel pin diameters of $0.26 \mathrm{in}$. and $0.24 \mathrm{in}$. The cladding thickness to diameter ratio $(t / d)$ selected is 0.050 which gives cladding thicknesses of $0.013 \mathrm{in}$. and $0.012 \mathrm{in}$. for configurations $A$ and $B$, respectively. At this stage of analysis, the fuel inside the cladding tube was characterized only by a fuel smear density of $88 \%$ T.D. The core fuel sections are $40 \mathrm{in}$. and $36 \mathrm{in.} \mathrm{Iong.} \mathrm{The} \mathrm{fuel} \mathrm{pins} \mathrm{are} \mathrm{wire-wrapped} \mathrm{with} \mathrm{a}$ helical pitch of $12 \mathrm{in}$. and wire thicknesses of $0.051 \mathrm{in}$. and $0.048 \mathrm{in}$.

The top fission gas plenum is 40 in. long for Core A and 36 in. long for Core $B$. The top and bottom axial blanket sections are 15 in. and 16 in. long and have a fuel smear density of $90 \%$ T.D.

It is expected that the plenum length for both cores can be reduced after detailed fuel lifetime analyses are carried out.

\subsubsection{Fuel Assemb1y Design}

The fuel assembly design parameters are summarized in Table XXXVI.

For Core A, the fuel assembly contains 271 fuel pins with a p/d ratio of 1.197. The fuel bundle pressure drop is 71.5 psi. For this design, the peak stress in the duct corner is 33,832 psi. This stress level is well below the maximum allowable stress for $20 \%$ CW316SS. The duct wall thickness was determined such that the combined primary membrane plus bending stress intensity is $18,000 \mathrm{psi}$. Further reduction in duct wall thickness are, therefore, possible.

For Core B, the fuel assembly contains 331 fuel pin with a $\mathrm{p} / \mathrm{d}$ ratio of 1.200. The fuel bundle pressure drop is $73.3 \mathrm{psi}$. The peak stress in the 
duct corner is 34,222 psi. As for Core A, the duct wall thickness for Core B can be further reduced.

\subsubsection{Blanket Fuel Pin}

The blanket fuel pin design parameters are summarized in Table XXXVII. The pin diameters are $0.425 \mathrm{in}$. and $0.484 \mathrm{in}$. and the cladding thicknesses are $0.013 \mathrm{in.}$ and $0.012 \mathrm{in}$. for Core $A$ and Core $B$, respectively. The fuel smear density is $90 \%$. The wire wrapped around the fuel pin is 0.030 in. thick and has a helical pitch of four in. At this stage of the analysis, no attempt was made to optimize the length of the fuel column to minimize fuel cycle cost. Blanket fuel pin analysis will also lead to a significant reduction in the plenum length.

\subsubsection{Blanket Assembly}

The assembly dimensions are identical to those of the fuel assemblies. The assembly contains 127 blanket pins with a p/d of 1.07 .

\subsubsection{Control Assembly}

No specific design for a control assembly was developed. For the control system design it was assumed that the control assembly for this reactor has the same volume fractions of steel, sodfum, and poison as for the CRBRP control assembly shown in Table XXXVIII.

\subsubsection{Duct Life}

Three sets of constraints govern the duct life analysis carried out for this study:

a. maximum duct wall stress

b. duct-duct interaction

c. bundle-duct interaction

The maximum wall stress defined for this study was 0.55 maximum allowable stress. With an ultimate tensile strength for $20 \%$ CW316SS of $78 \mathrm{ksi}$, the calculated nominsl maximum primary membrane plus bending stress intensities for driver ducts are 18,000 psi which are well below the allowable limit.

To avold duct-duct interaction, the distance between ducts was selected such that at end-of-life conditions none of the assemblies exceeds the pitch line. In calculating the duct dilation, both the swelling and creep effects were taken into consideration. The duct wall pressure differential profiles 
for the design limiting duct is shown in Table XXXIX. The maximum duct dilations for the hottest fuel assembly subject to the maximum fluence in the core occurs six in. above the core midplane. These dilations are $0.215 \mathrm{in.}$ and $0.200 \mathrm{in}$. for Core $A$ and Core $B$, respectively. They were chosen as the gap distances between assemblies.

A simplified seismic analysis showed that the thickness of a 4 in. wide load pad has to be approximately 0.200 in. to withstand the stresses in a seismic event. The load pad thickness was calculated according to the following formula:

$t=0.0013\left(\mathrm{~L}_{F}\right)^{\frac{1}{2}}\left(\sum w_{i}+B\right)^{\frac{1}{2}}$

with

$t=$ load pad thickness for a four-in. wide pad (in.)

$\mathrm{L}_{\mathrm{F}}=$ duct inside flat-to-flat distance (in.)

$\Sigma w_{1}=$ sum of the weights of heavy metal of a radial row of assemblies from the core center to the shield section

$B=$ correction term to account for bridging and even load distribution $=400$

The actual ACLP thicknesses for Core A and Core B are 0.328 in. and $0.317 \mathrm{In}$. which are well above the required thickness of $0.200 \mathrm{in}$. Using the correlations for bundle-duct interaction developed by GE and modified by CE for the Proliferation Resistant Large Core Design Study (PRLCDS) showed bundle-duct interferences of less than one spacer wire which is well below the allowable interference of 2-3 wires.

\subsection{FUEL CYCLE COST}

Fuel cycle cost were determined for Core $A$ and Core $B$. The economic assumptions for this analysis are shown in Appendix A. The fabrication cost were determined using the N-factor formula HEDL developed for the Proliferation Resistant Large Core Design Study. The results of the fabrication cost calculation are shown in Table XI. On an assembly basis, the fabrication cost are about the same for Core $A$ and Core $B$. The total fuel cycle cost shown in Tables XII and XIII show a $0.8 \mathrm{mill} / \mathrm{kWh}$ (or $9 \%$ ) advantage of Core A over Core B. Since neither of those cores is cost-optimized this difference is insignificant. By cutting down the length of the radial blanket pins the 
reprocessing charges can be reduced. This together with a slight increase

in fuel residence time can bring the fuel cycle cost well below 8 mill/kWh.

Nomenclature:

Zone 1-3 Core Zones

Zone 4-6 Axial Blanket Zones

Zone 7 Internal Blanket Zones

Zone 8 Radial Blanket Zones 


\subsection{DESIGN EVALUATION}

The basis for this evaluation is established in Appendices B, C, and D, which outline the steps of the elimination/optimization process. Thus, the following conclusions can be drawn regarding the choices between center core vs. center blanket configurations, loosely-coupled vs. tightly-coupled cores, and continuous ring vs. broken ring configurations.

\section{I CENTER CORE VS. CENTER BLANKET CONFIGURATION}

Both types of configurations can lead to feasible designs. For center core configurations, the relation between core region size and power plant output is of special significance. The center core region has to be small to permit a low overall sodium void reactivity. Typically it has not more than 4-5 rows of fuel, i.e. 37 to 61 fuel assemblies. The power output for this region is only approximately $300-450 \mathrm{MW}$ which represents $10-15 \%$ of the total reactor power output of a $3000 \mathrm{MW}$ plant. Therefore, for such a power level the reactor has to have at least three core regions. In case of a tightly coupled system, at least four core regions seem to be necessary to achieve a low sodium void reactivity core.

Center blanket configuration, on the other hand, can be constructed with as little as two core zones in a loosely coupled configuration and three in a tightly coupled configuration.

The different requirements on the number of core regions affects directly the number of different enrichments needed to flatten the power. Even though It might be possible to arrange the internal blanket assemblies such that they flatten the power sufficiently even for only one or perhaps two different core fuel enrichments, the uncertainties in the prediction of power shapes in heterogeneous cores are currently too great to rely solely on calculation for such arrangements. Therefore, center blanket configuration allows for core designs with fewer discriminator zones than center core configurations.

Because of the small size of the center core region required to yield low sodium void reactivities, a greater sensitivity especially in power peaking is observed in the center core configuration compared to center blanket configurations. Changing the enrichment in the inner-most core zone by $0.5 \%$ 
leads to substantially greater changes in peak power density in the inner-most core zone in center core than in center blanket configuration. Because any enrichment specification will have certain tolerances a center core configuration would require more corrective action by the control system to flatten the power than a center blanket configuration.

Center core configurations showed significantly higher assembly power swings over a burnup cycle than center blanket configurations. The result of these greater changes in assembly power is a higher peak clad temperature because the enhanced overcooling in one part of the core has to be compensated by higher coolant temperature rises in other parts of the core.

Center core configurations had in some instances slightly smaller specific inventories than center blanket configurations but whenever this occurred the differences were small. In regard to doubling time, sodium void reactivity and control requirements, no advantage could be identified for either configuration.

Therefore, center blanket configurations were chosen over center core configurations since the latter perform at best as well as the former but in addition have serious flaws in regard to power shape sensitivity.

\subsection{LOOSELY VS. TIGHTLY COUPLED CORES}

The neutronic coupling concept was introduced to distinguish between different core configurations. "Loosely" and "tightly coupled" cores were configurations which differed in the degree of neutronic coupling. Both terms are used to qualitatively describe different core configurations. The degree of neutronic coupling depends on the thicknesses of the internal blanket regions separating the core regions from each other. For a reactor with two core regions, Avery's coupling coefficients can be determined easily and related to power peaking. When going to more than two core zones and a broken ring rather than a continuous ring configuration is used, it is very difficult if not Imposstble to determine meaningful coupling coefficients and relate them to power peaking. Therefore, no efforts were made to determine coupling coefficients for the various cores which have been analyzed. The terms "loosely" and "tightly coupled" cores were applied to cores with more than one or less than one row of blanket assemblies separating core zones, respectively. 
Loosely coupled cores achieved low sodium void reactivities at core heights of $40 \mathrm{in.}$ or more. However, they showed high specific inventories, large doubling times and very strong sensitivities in power peaking.

Tightly coupled cores on the other hand required core heights of less than $40 \mathrm{in}$. to achieve sodium void reactivities of less than $\$ 2.50$. They generally showed lower specific inventories, lower doubling times and lower sensitivities in power peaking, than loosely coupled cores. For optimized cores, the reactor diameters for loosely and tightly coupled cores were quite similar since the lower core height required smaller fuel pins for optimum conditions thus offsetting the otherwise unavoldable increase in reactor size coming from the increase in the number of fuel pins necessary to maintain the reactor power leve1.

While the tightly coupled cores showed generally a better performance than the loosely coupled cores, neither the strictly tightly coupled cores nor the strictly loosely coupled cores were considered optimal. However, the optimum core configuration is closer to the tightly coupled system rather than a loosely coupled system. The disadvantages of the strictly tightly coupled cores were the low core height which either led to an increase in the number of fuel assemblies which had to be fabricated or an increase in the number of fuel pins per assembly which leads to increased fuel bundleduct interaction. The lower core height and the resulting smaller fuel pin size led to higher fuel burnups. The major disadvantage of the loosely coupled core is the strong sensitivities of the power shape to either uncertainties in enrichment or fuel burnup. Furthermore, the transient response of the core is very dependent on the specific location of the reactivity perturbation.

The core configuration finally selected is a "hybrid" in that it is more tightly coupled in the center of the reactor were the core regions are small in size and more loosely coupled in the outer core regions. With this arrangement, the advantages of both the loosely and tightly coupled cores were combined at only minor penalties in sodium vold reactivity and doubling time.

\subsection{CONTINUOUS RING VS. BROKEN RING CONFIGURATIONS}

The broken-ring arrangements showed definitive improvements over continuous ring configurations with regard to power peaking, power swing, and control rod worth. The broken ring arrangements create flux peaks where control rods can be located. These flux peaks enhance the worth of control rods. 
But by placing the control rods in the outermost core region additional benefits can be derived. For all core configurations, the outermost core region always has a substantial power reduction over an operating cycle if the burnup analysis is carried out with the control rods in their fully withdrawn position. By creating a flux peak in the outermost core region the insertion of a control rod would level out the fluxes at beginning-of-cycle condition. As burnup progresses the control rods are withdrawn thus counteracting the otherwise decreasing flux level.

In analyzing both configurations, it is important to realize the limitations of the calculational methods employed. $r-z$ models are not suitable for optimization of core configurations since the discrete control rod location have to be modelled as a control ring. This model will not give any valid information at all as to the required enrichment split, power peaking and control rod worth. To obtain these information, hexagonal geometry models have to be analyzed. 


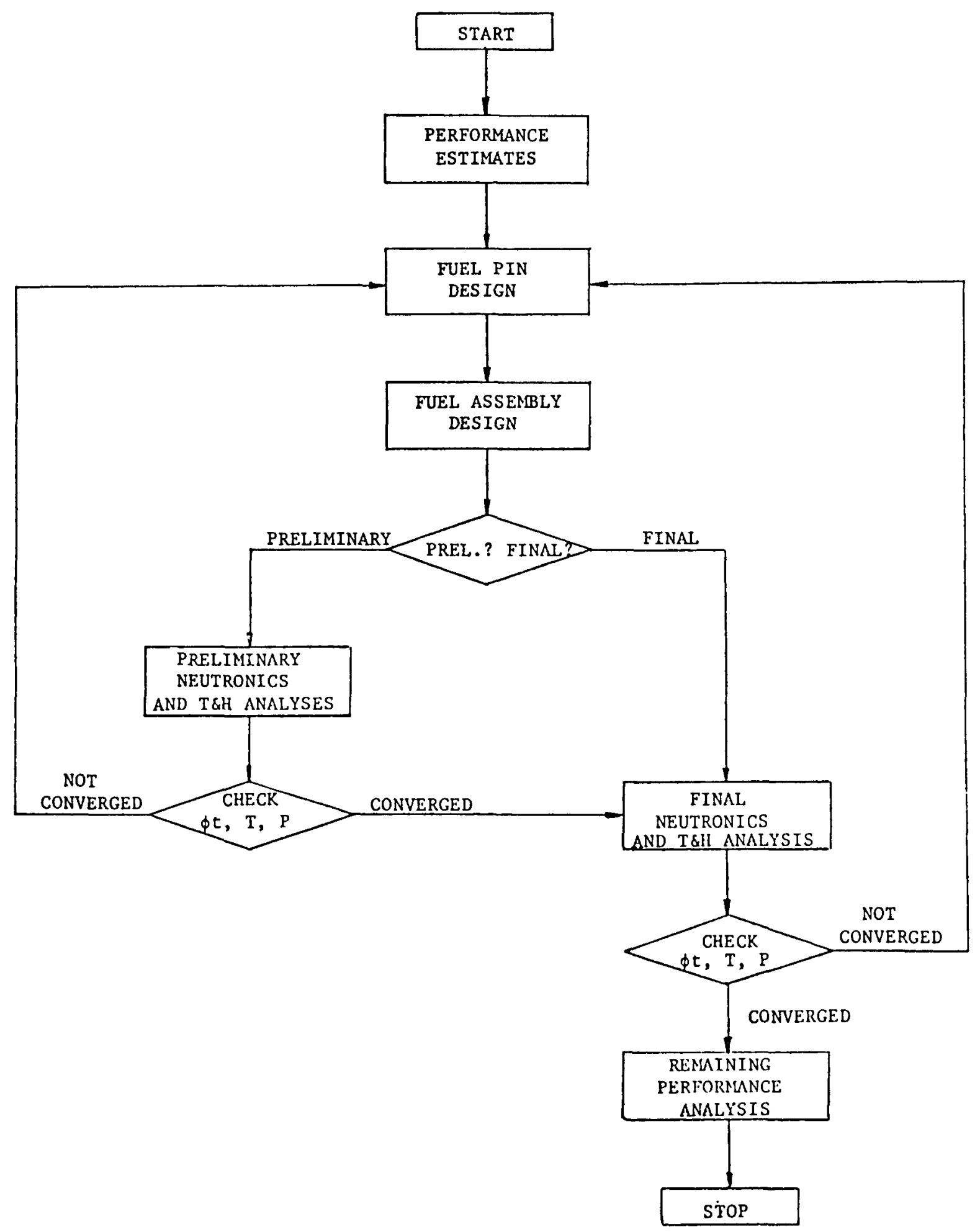

Fig. 1. Design Analysis Flow Sheet 

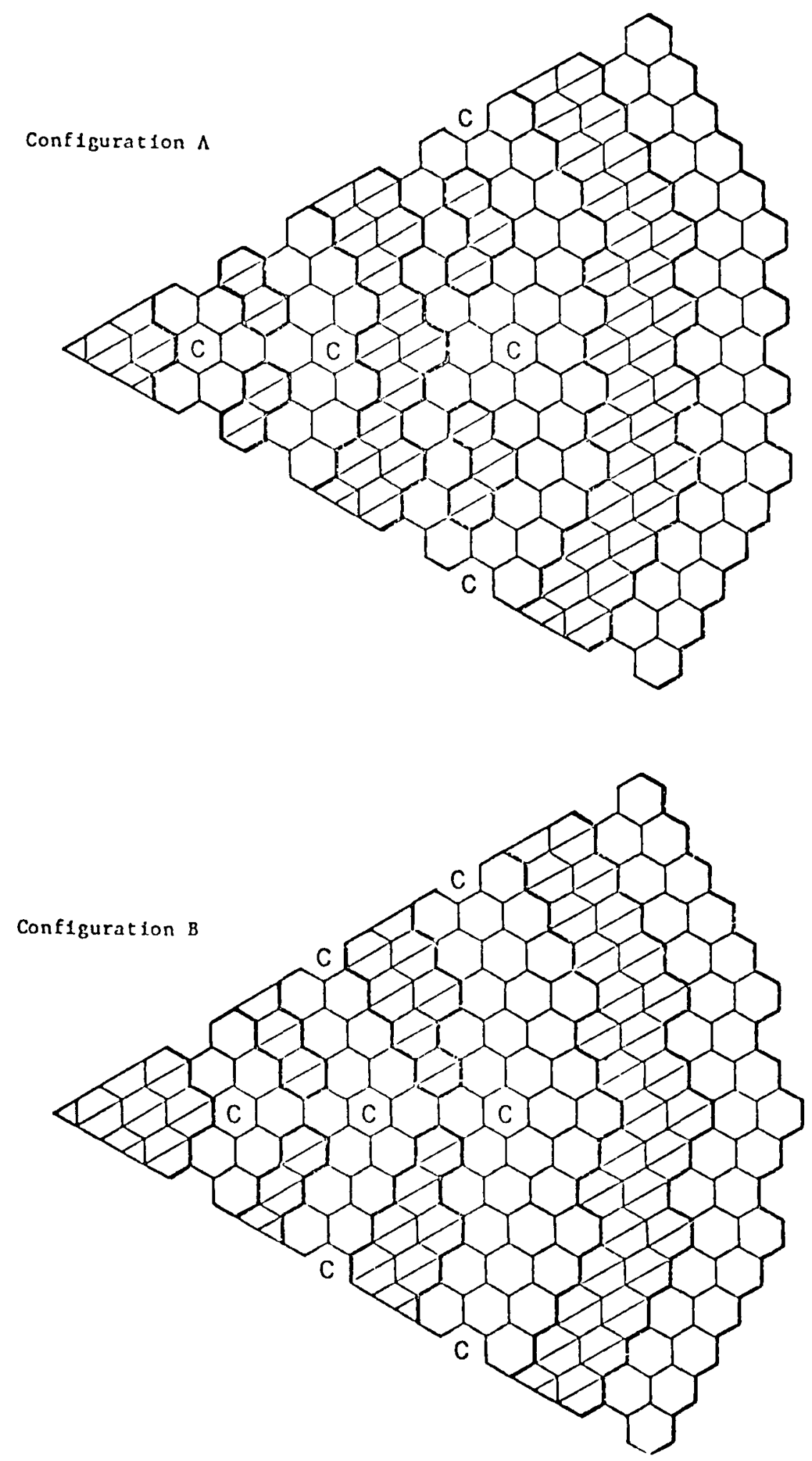

Fig. 2. Preliminary Optimum Configurations 


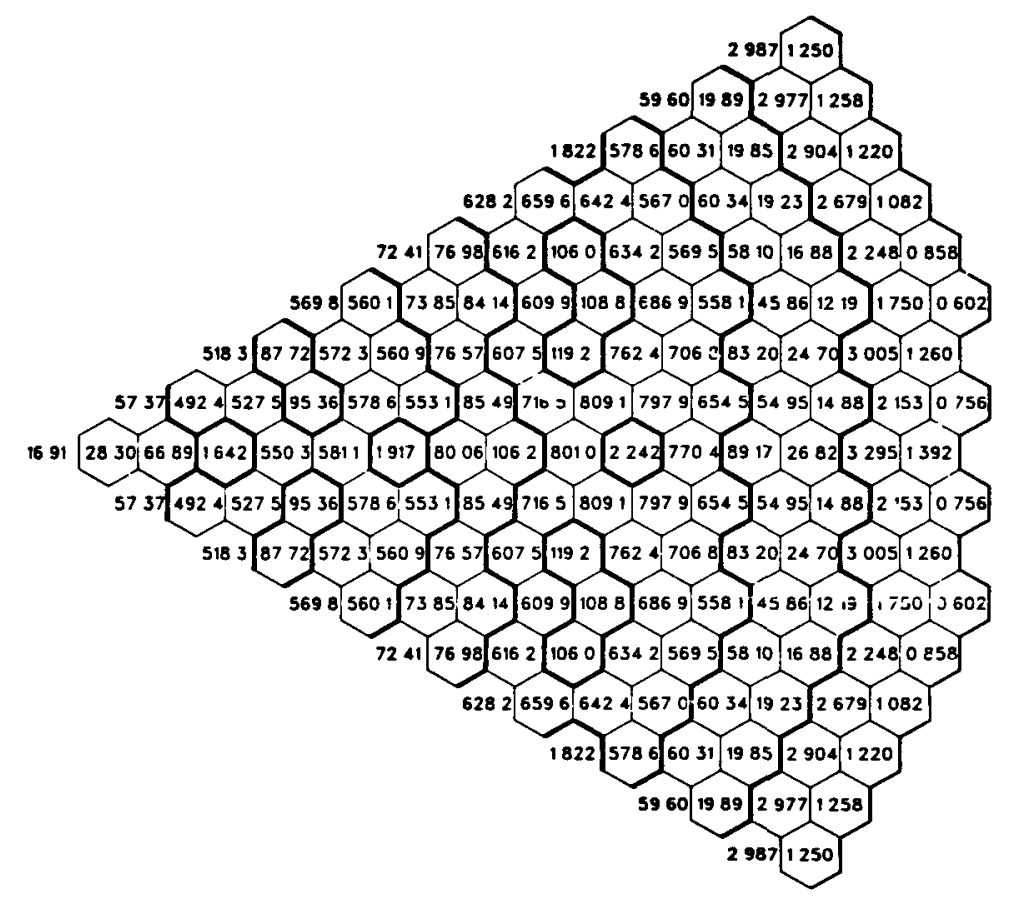

Fig. 3. Configuration A, Peak Power Density at BOL, No Rods Inserted

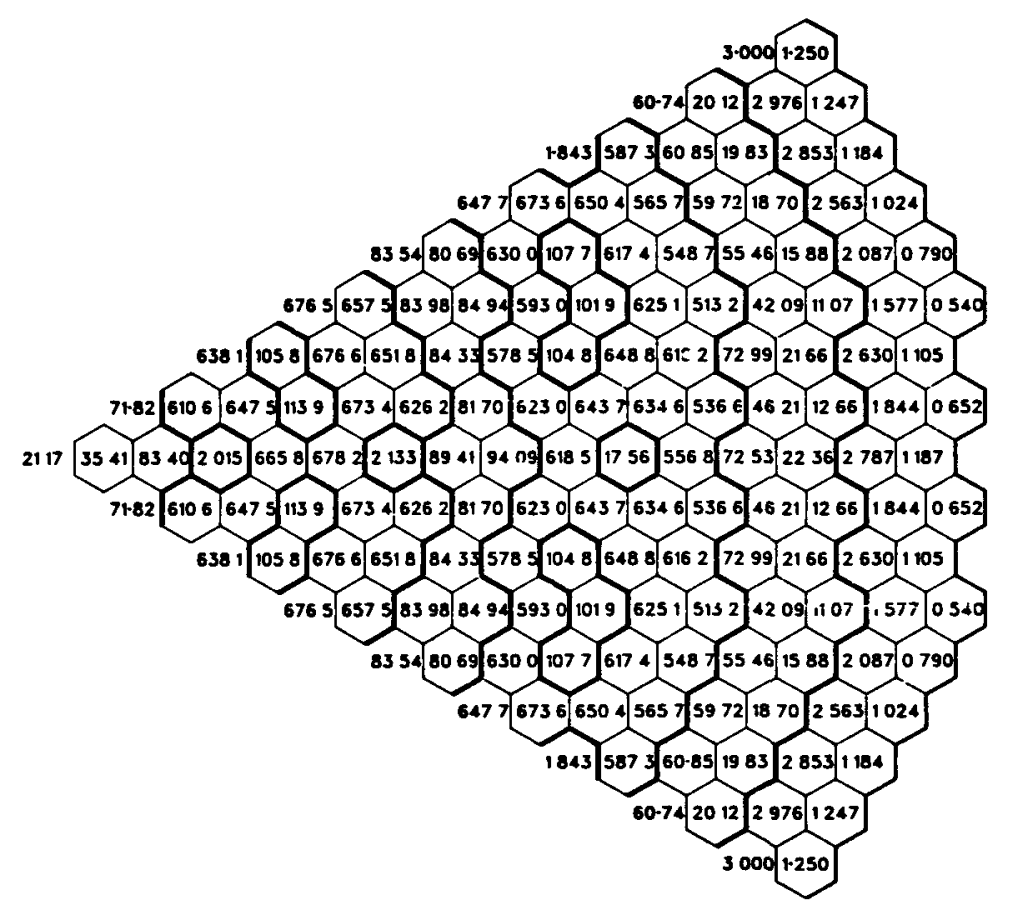

Fig. 4. Configuration A, Peak Power Density at BOL, Row 11 Rods 15\% Inserted 


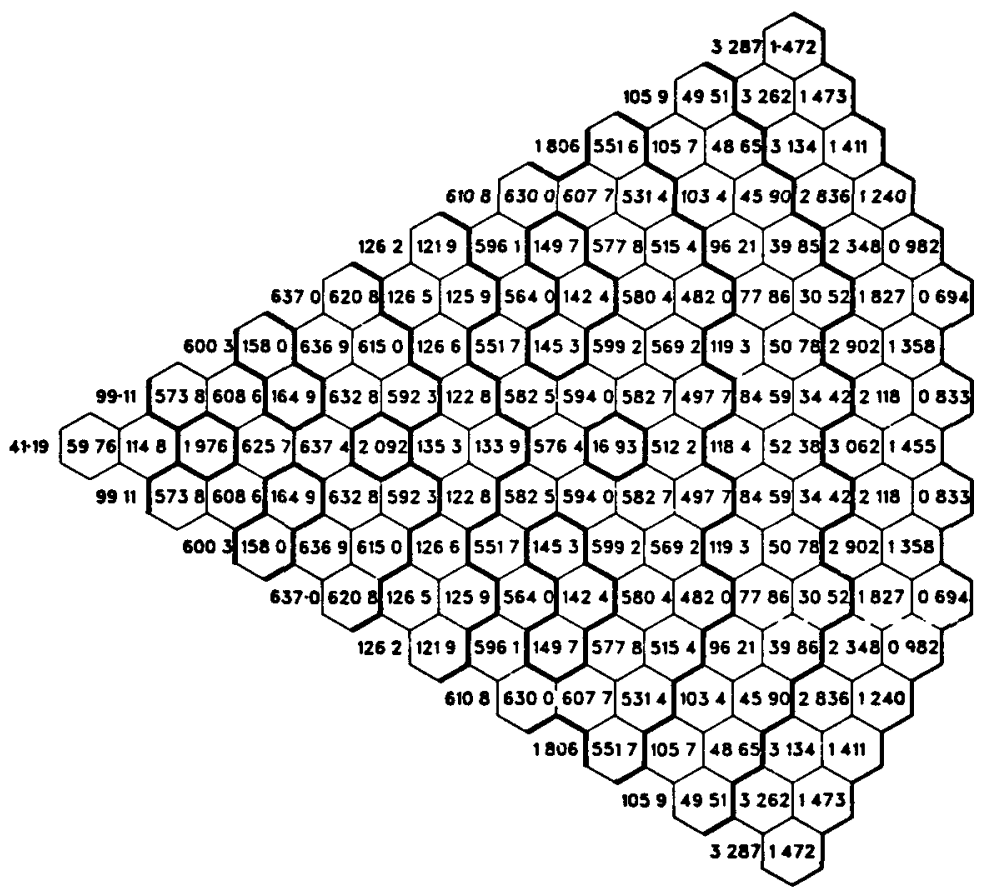

Fig. 5. Configuration A, Peak Power Density at BOEC Conditions

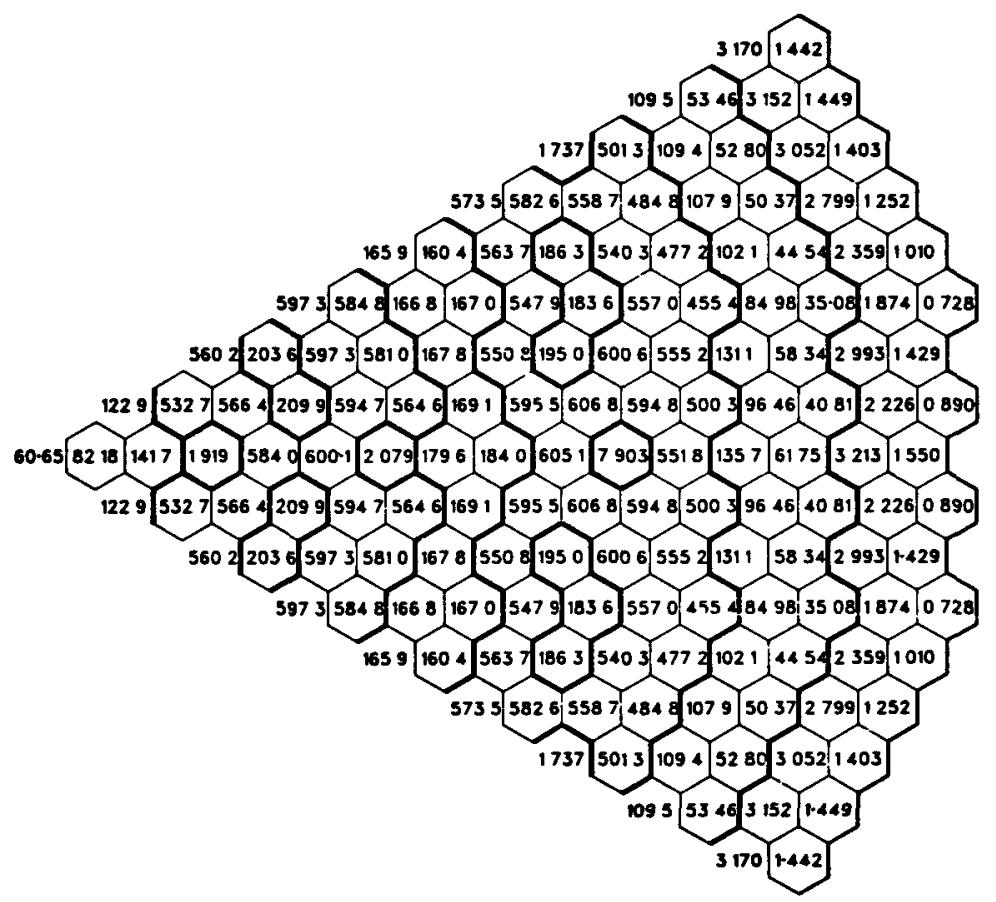

Fig. 6. Configuration A, Peak Power Density at MOEC Conditions 


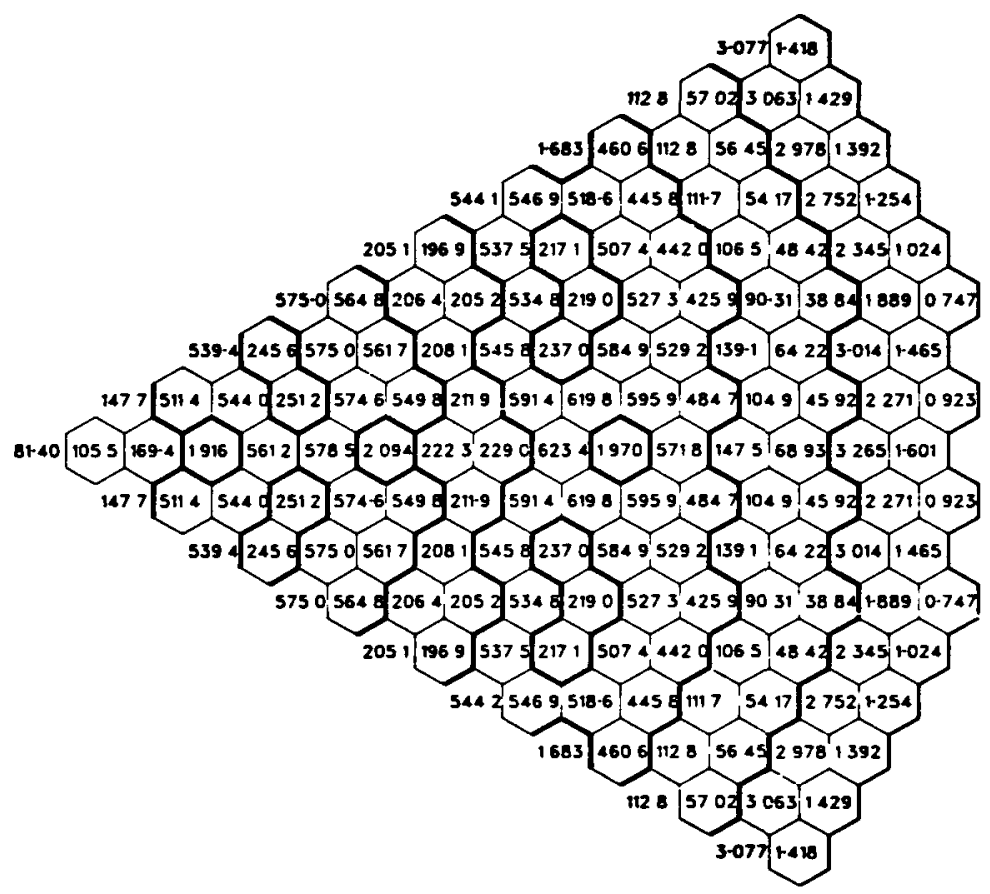

Fig. 7. Configuration A, Peak Power Density at EOEC Conditions

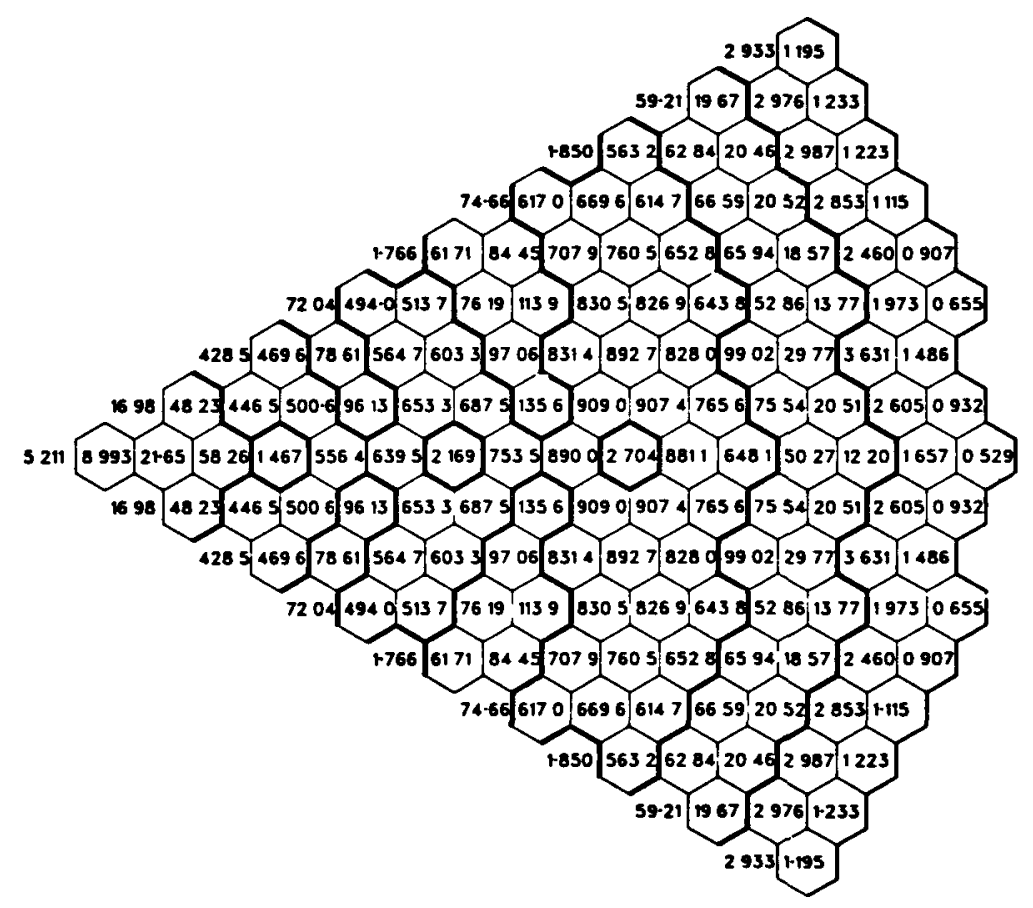

Fig. 8. Configuration B, Peak Power Density at BOL, No Rods Inserted 


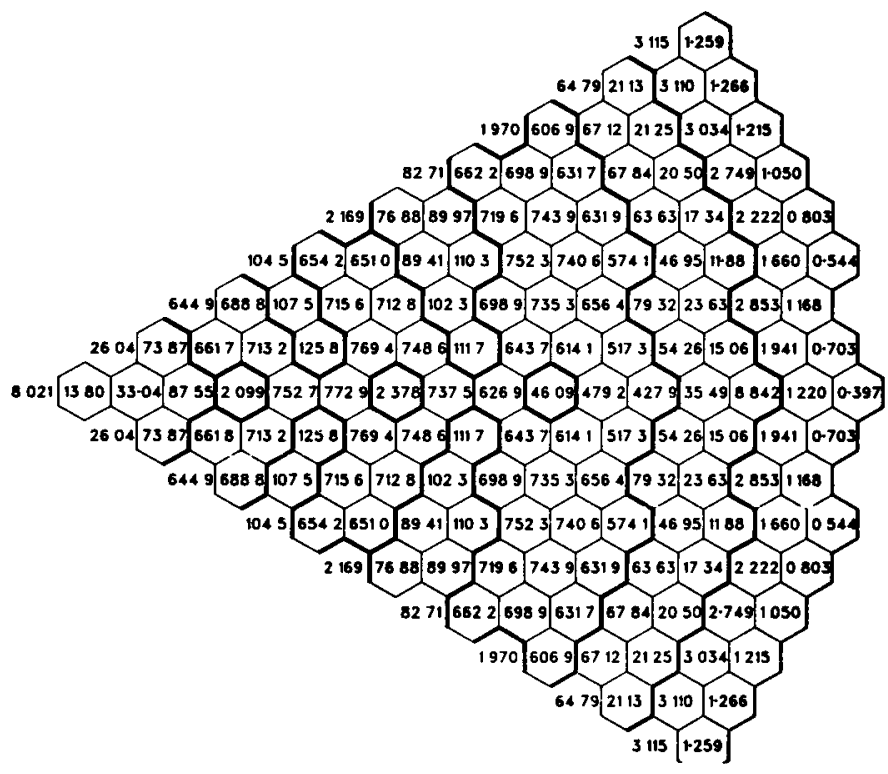

Fig. 9. Configuration B, Peak Power Density at BOL, Row 11 Rods Inserted

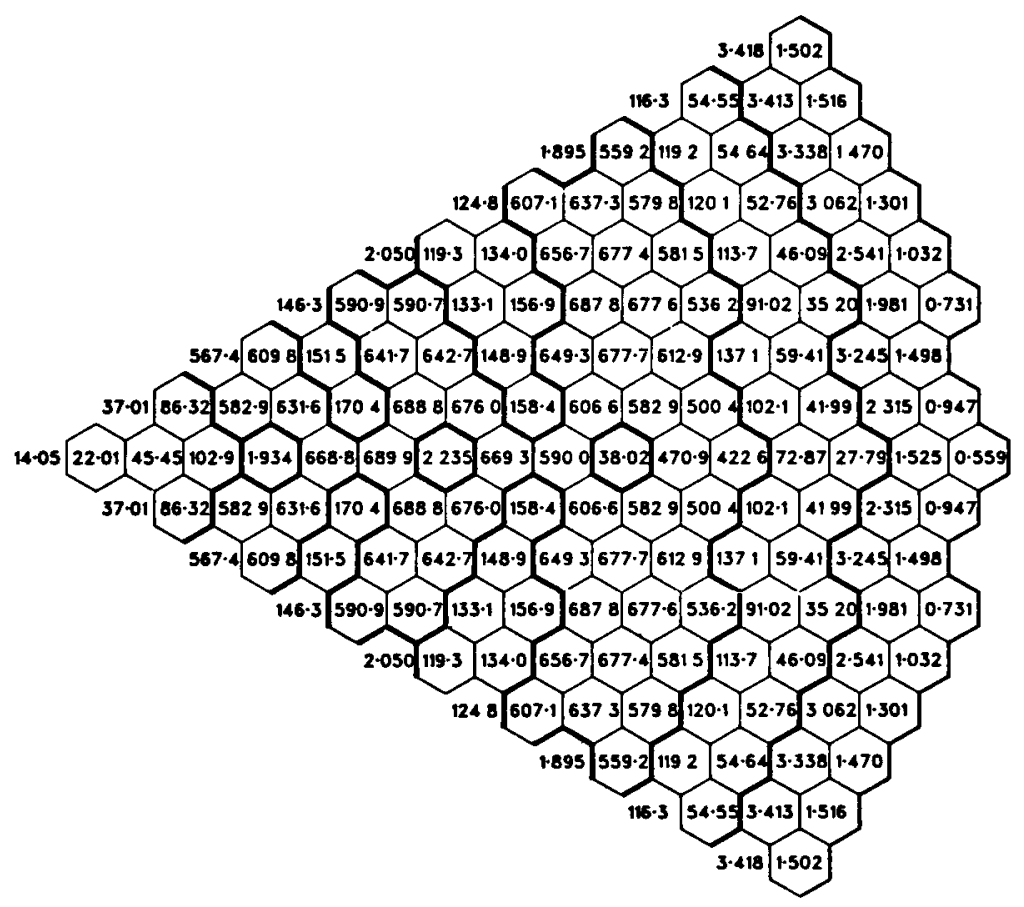

Fig. 10. Configuration B, Peak Power Density at BOEC 


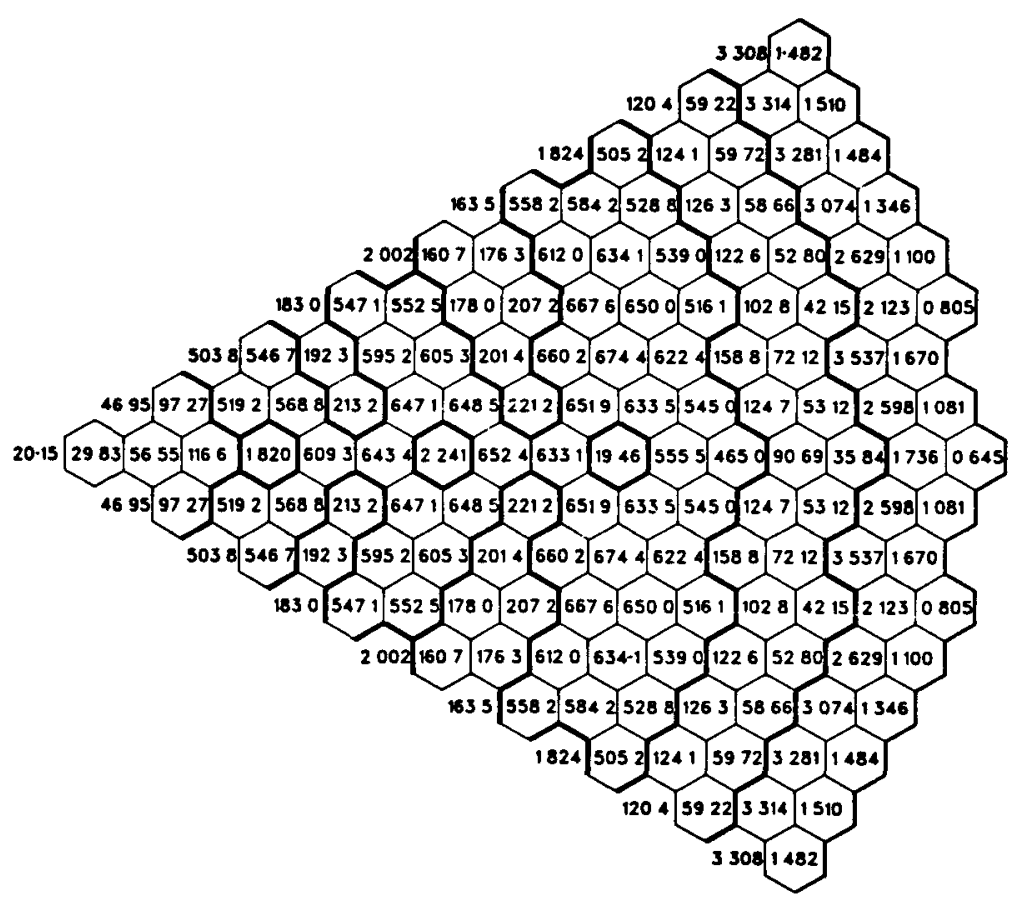

Fig. 11. Configuration B, Peak Power Density at MOEC

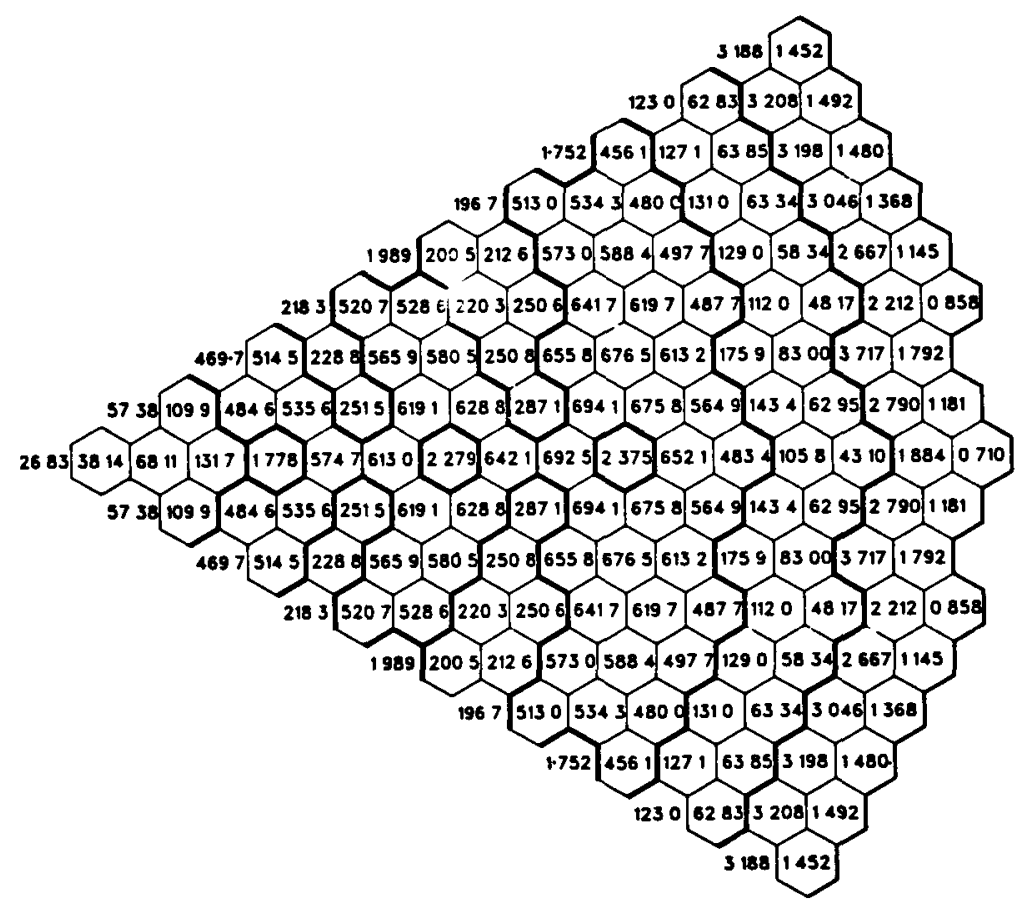

Fig. 12. Configuration B, Peak Power Density at EOEC 


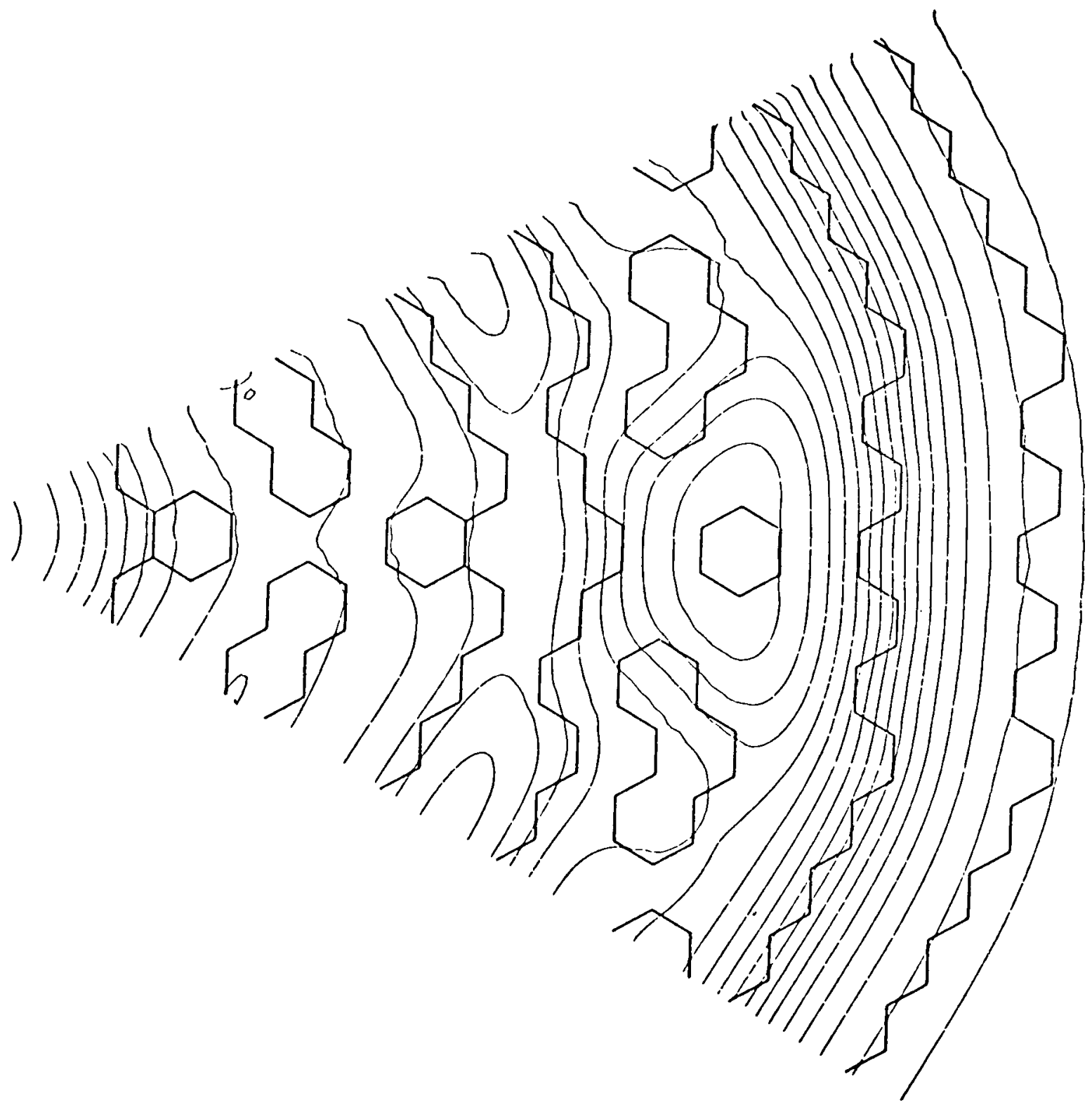

Fig. 13. Configuration A, Total Flux Distribution at BOL, No Control Inserted 


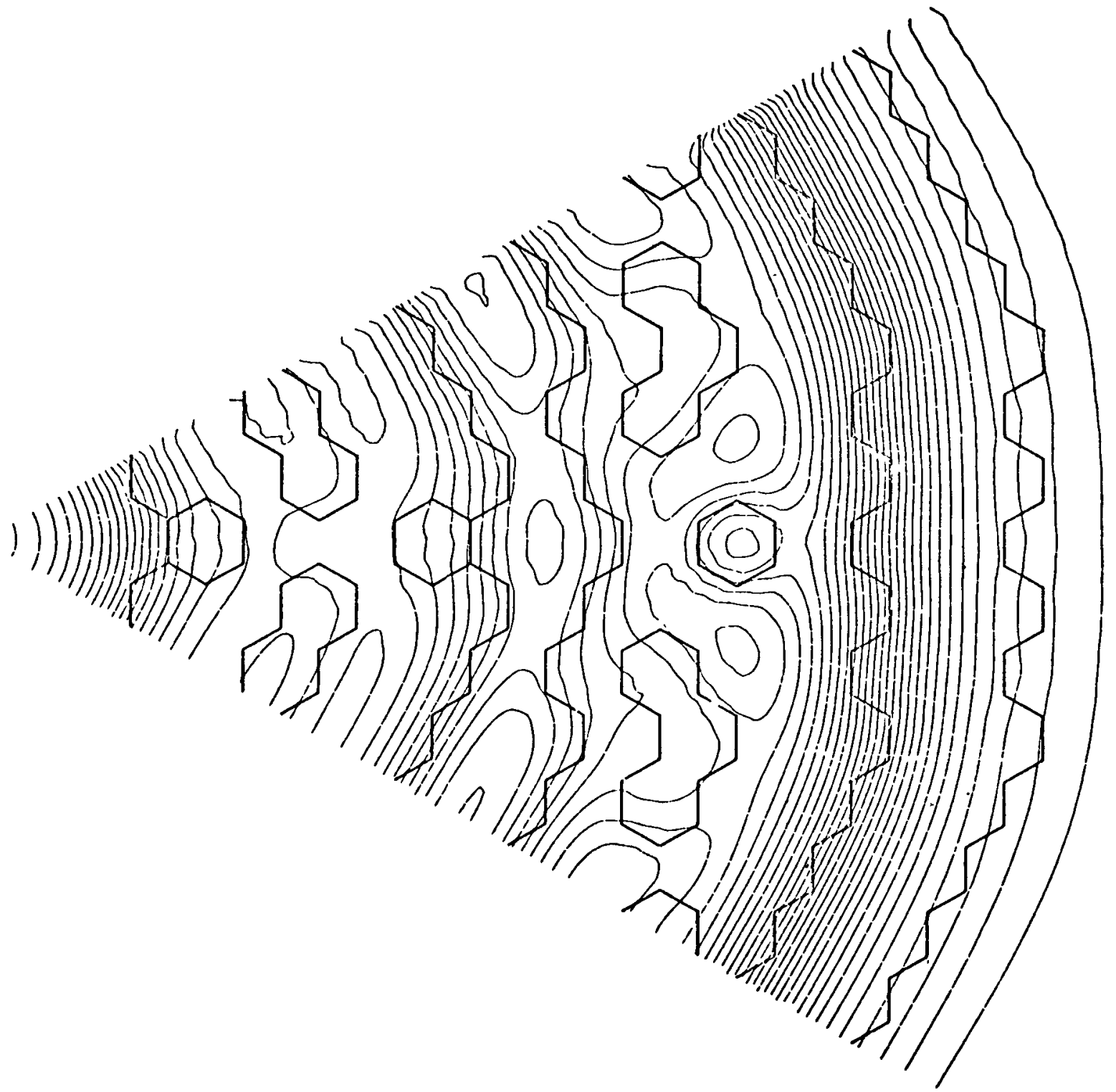
Fig. 14. Configuration A, Total Flux Distribution BOL,
Row 11 Control Rod Inserted 


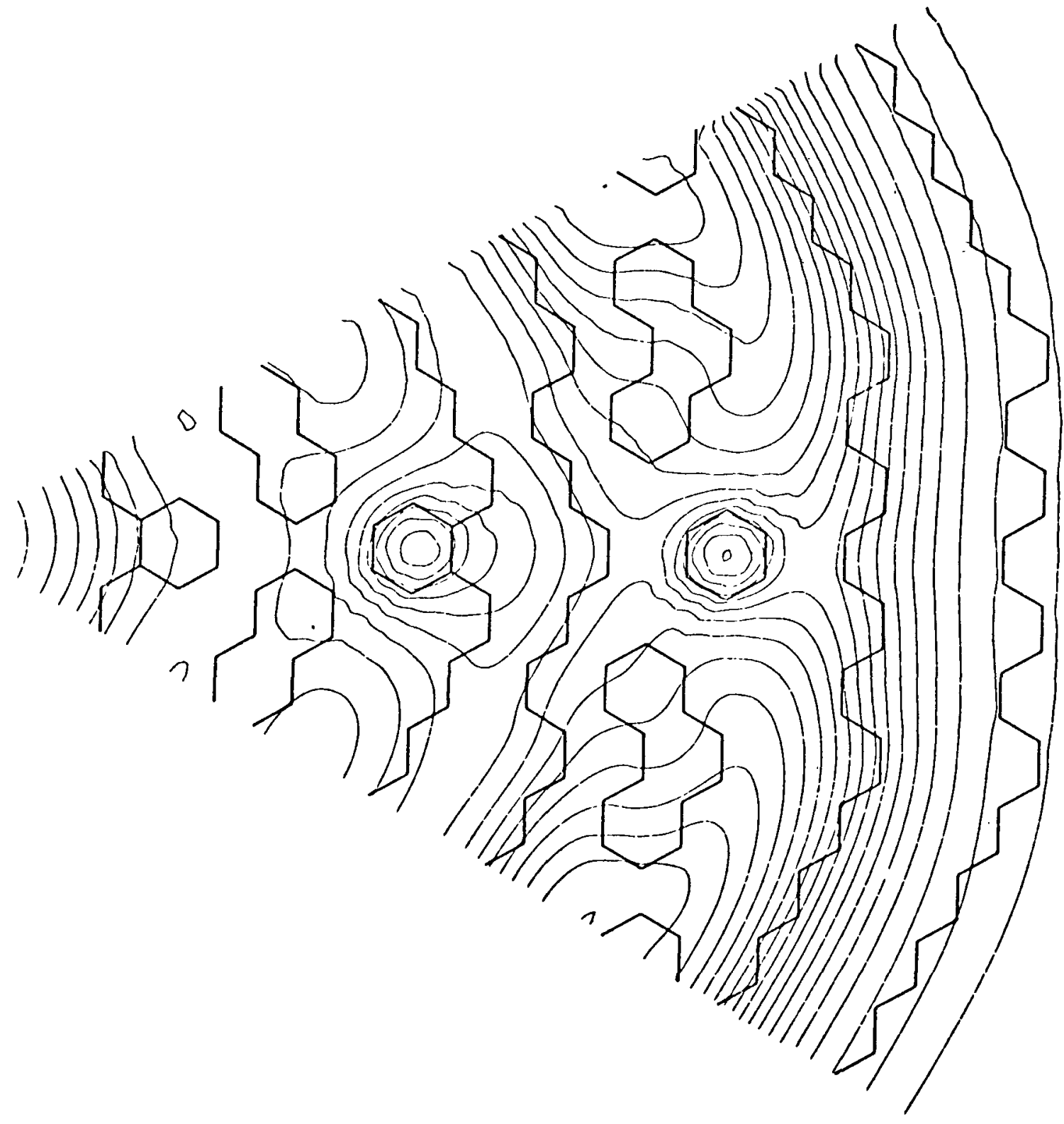

Fig. 15. Configuration A, Total Flux Distribution at BOL, Primary Control Rods Inserted 


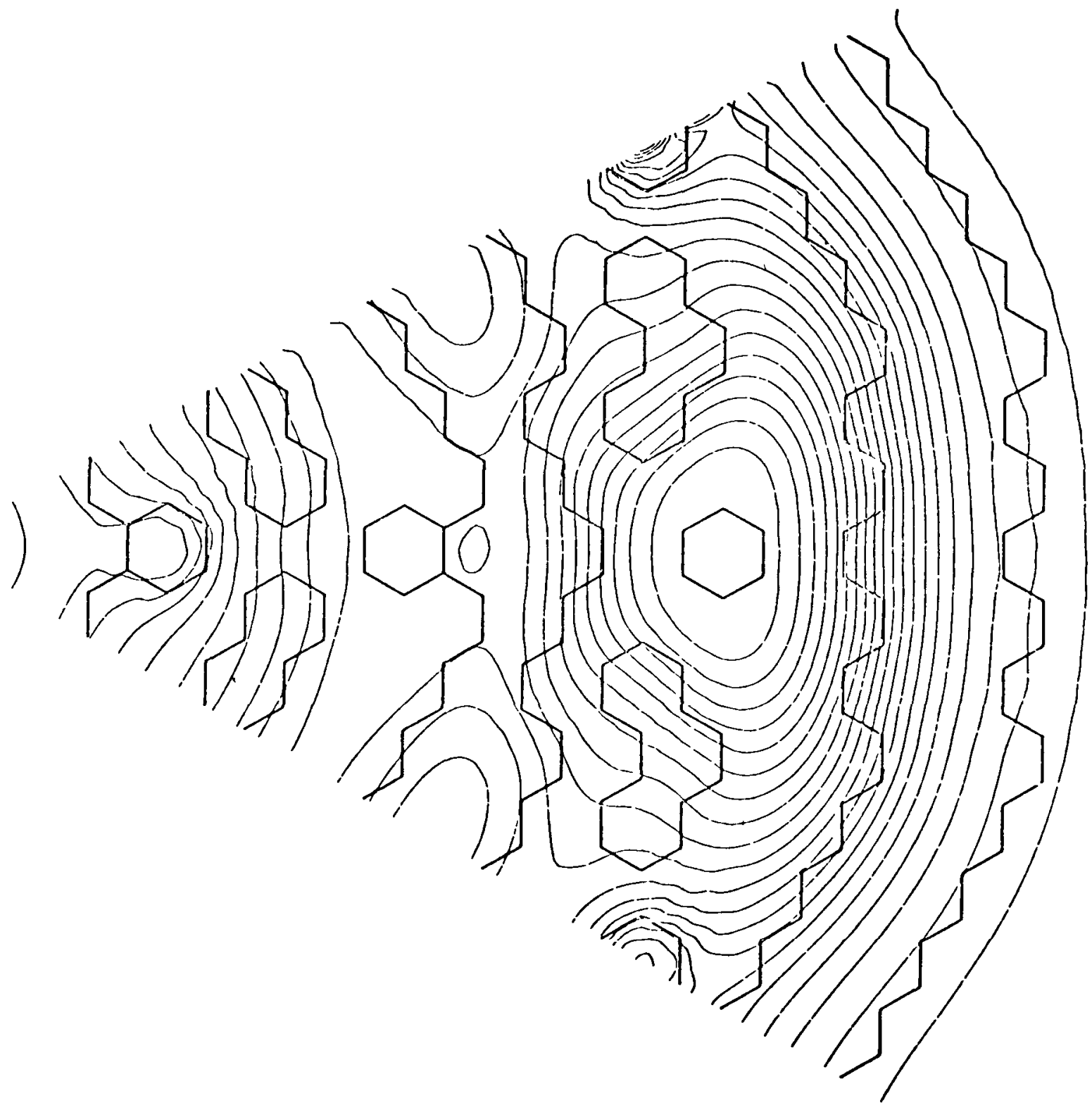

Fig. 16. Configuration A, Total Flux Distribution at BOL, Secondary Control Rods Inserted 


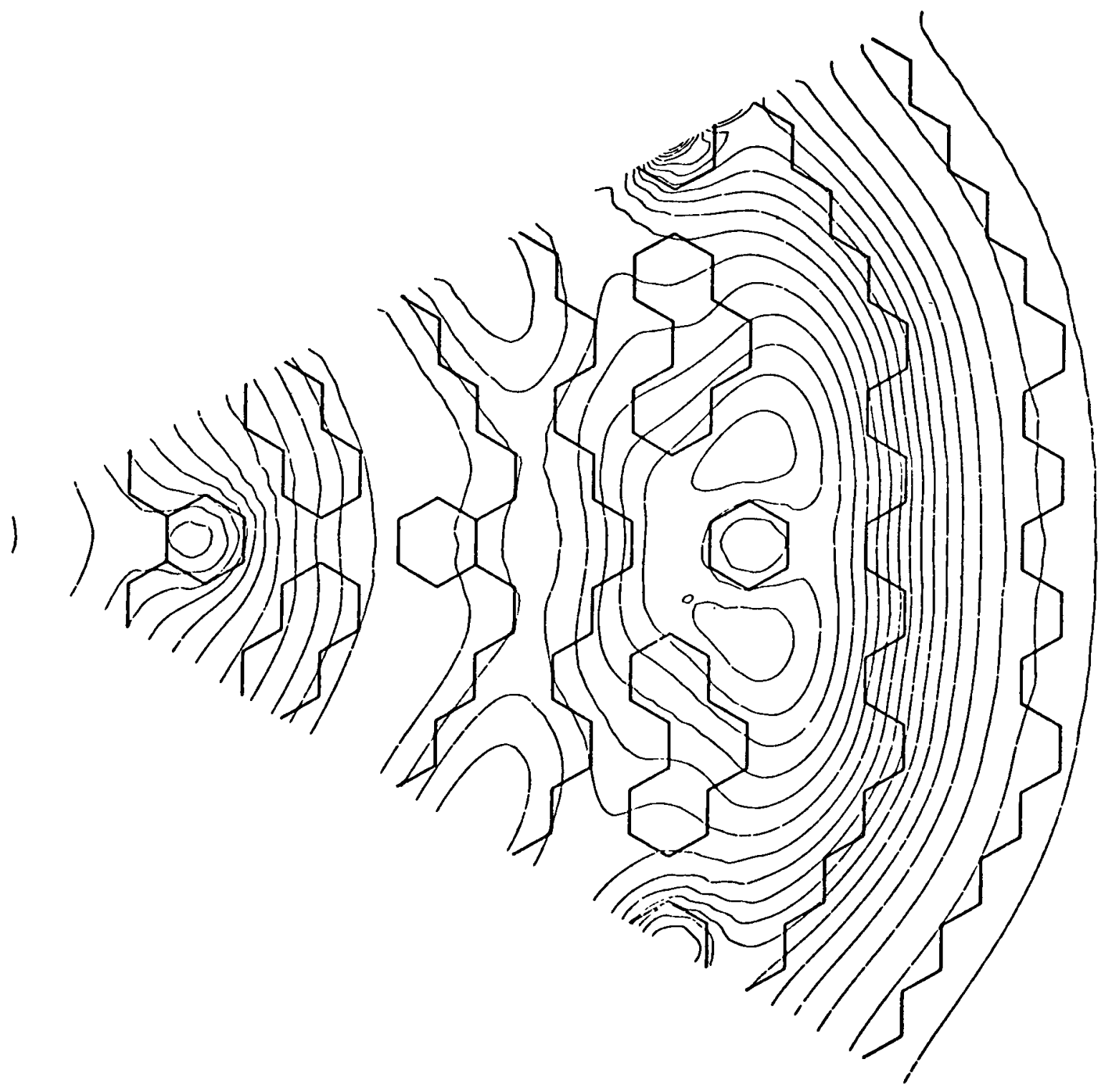

Fig. 17. Configuration A, Total Flux Distribution at BOL, Row 11 and Secondary Control Rods Inserted 


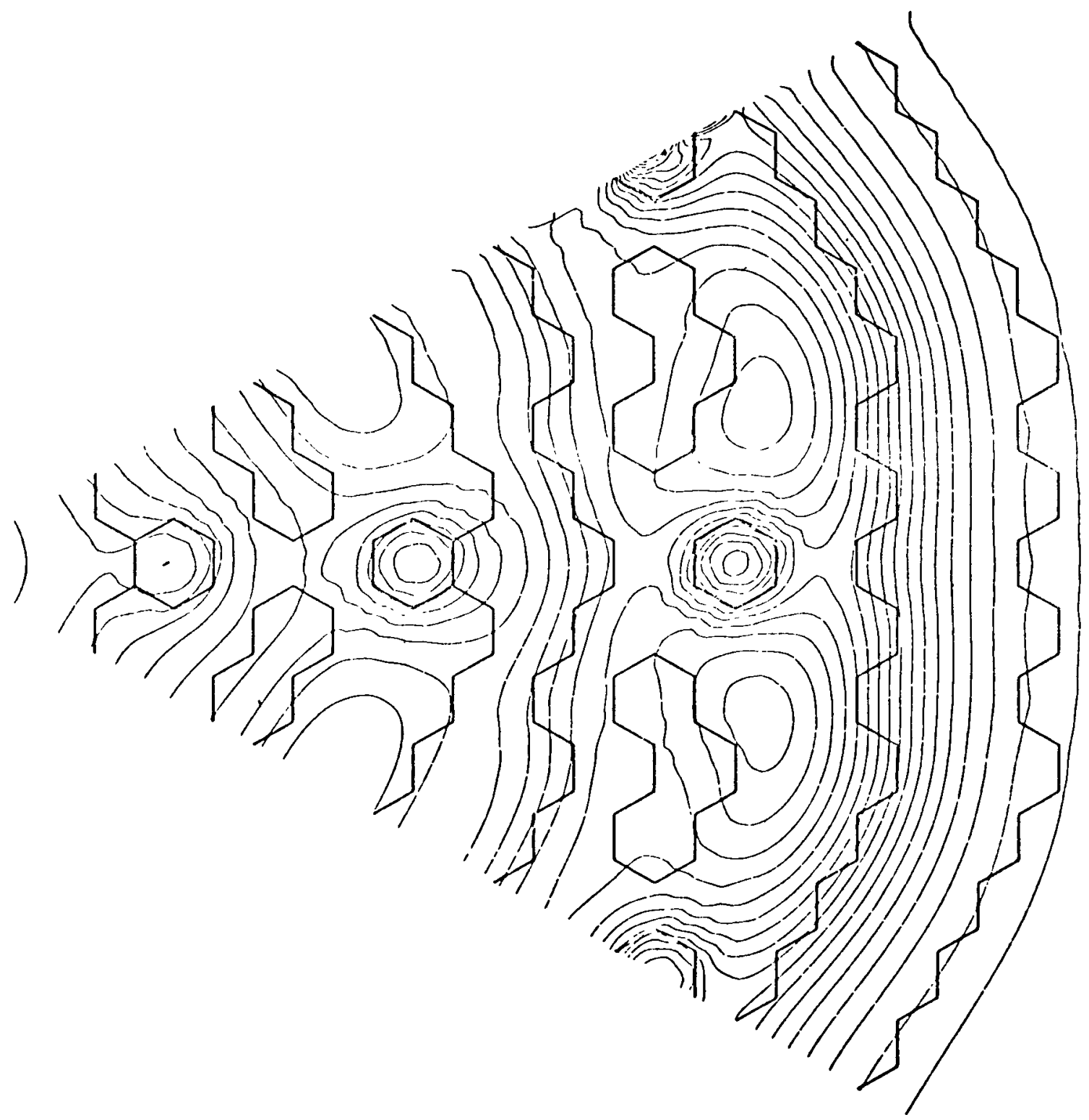

Fig. 18. Configuration A, Total Flux Distribution at BOL, All Rods Inserted 


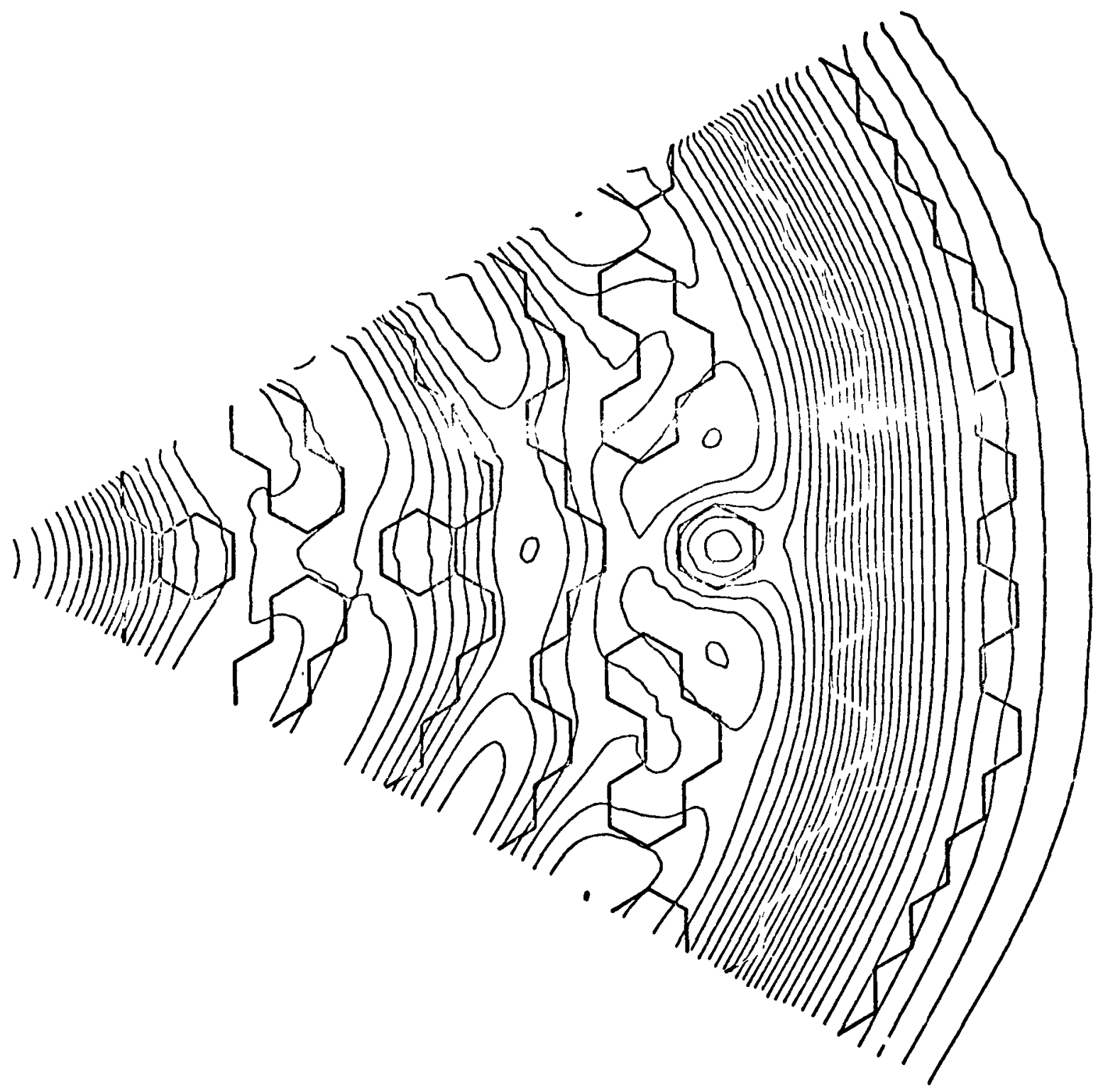

Fig. 19. Configuration A, Total Flux Distribution at BOEC 


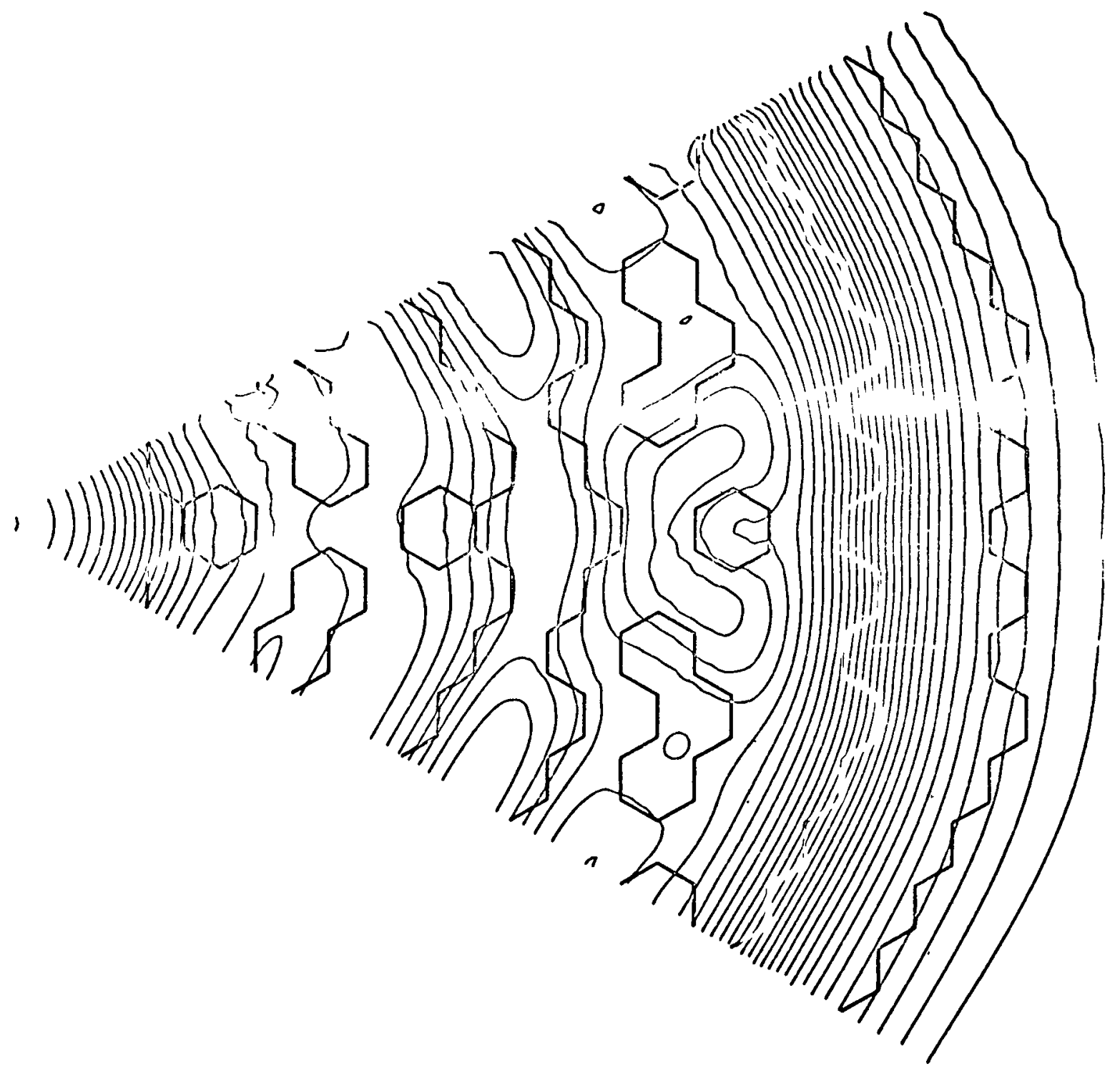

Fig. 20. Configuration A, Total Flux Distribution at MOEC 


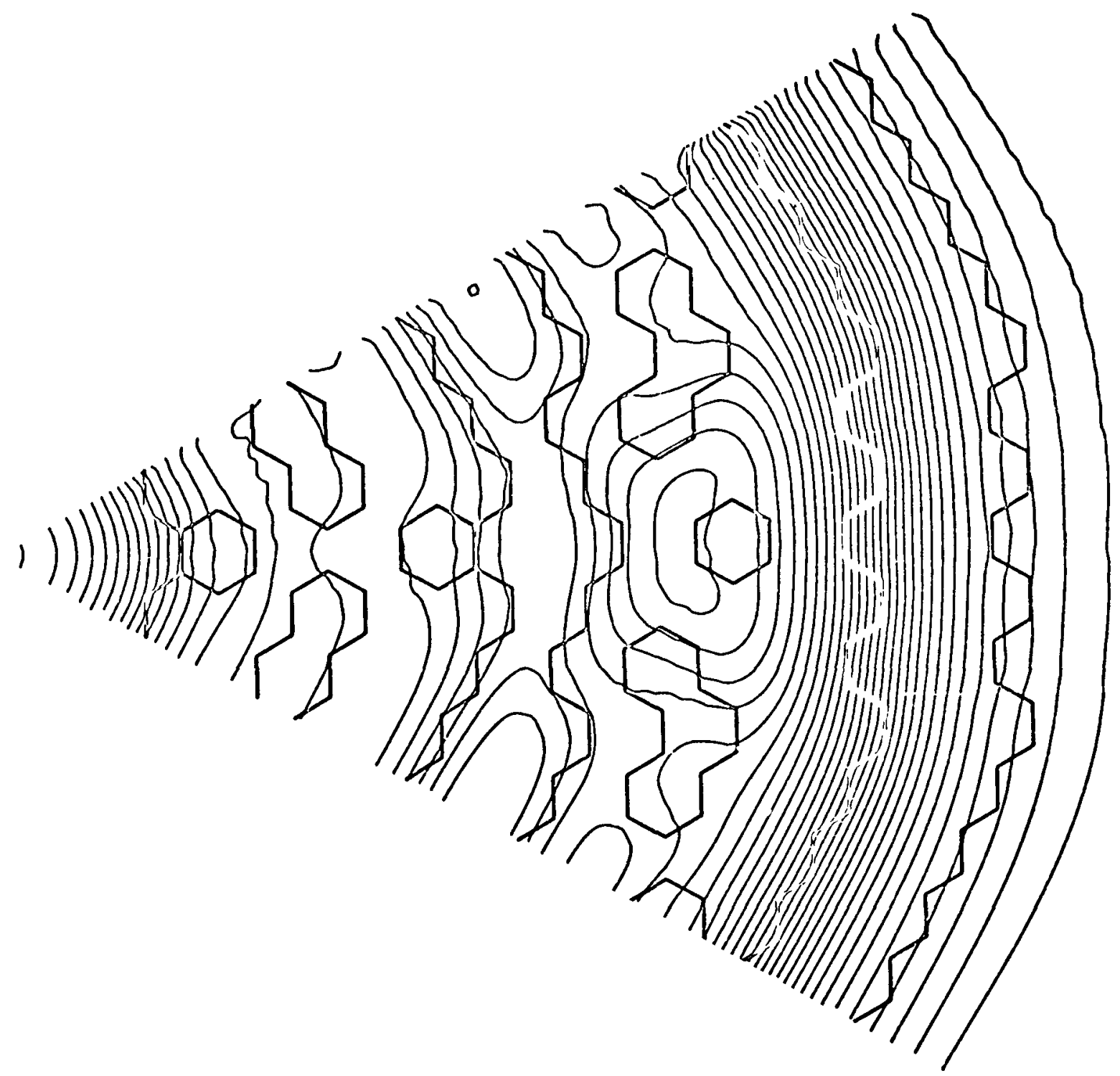

Fig. 21. Configuration A, Total Flux Distribution at EOEC 


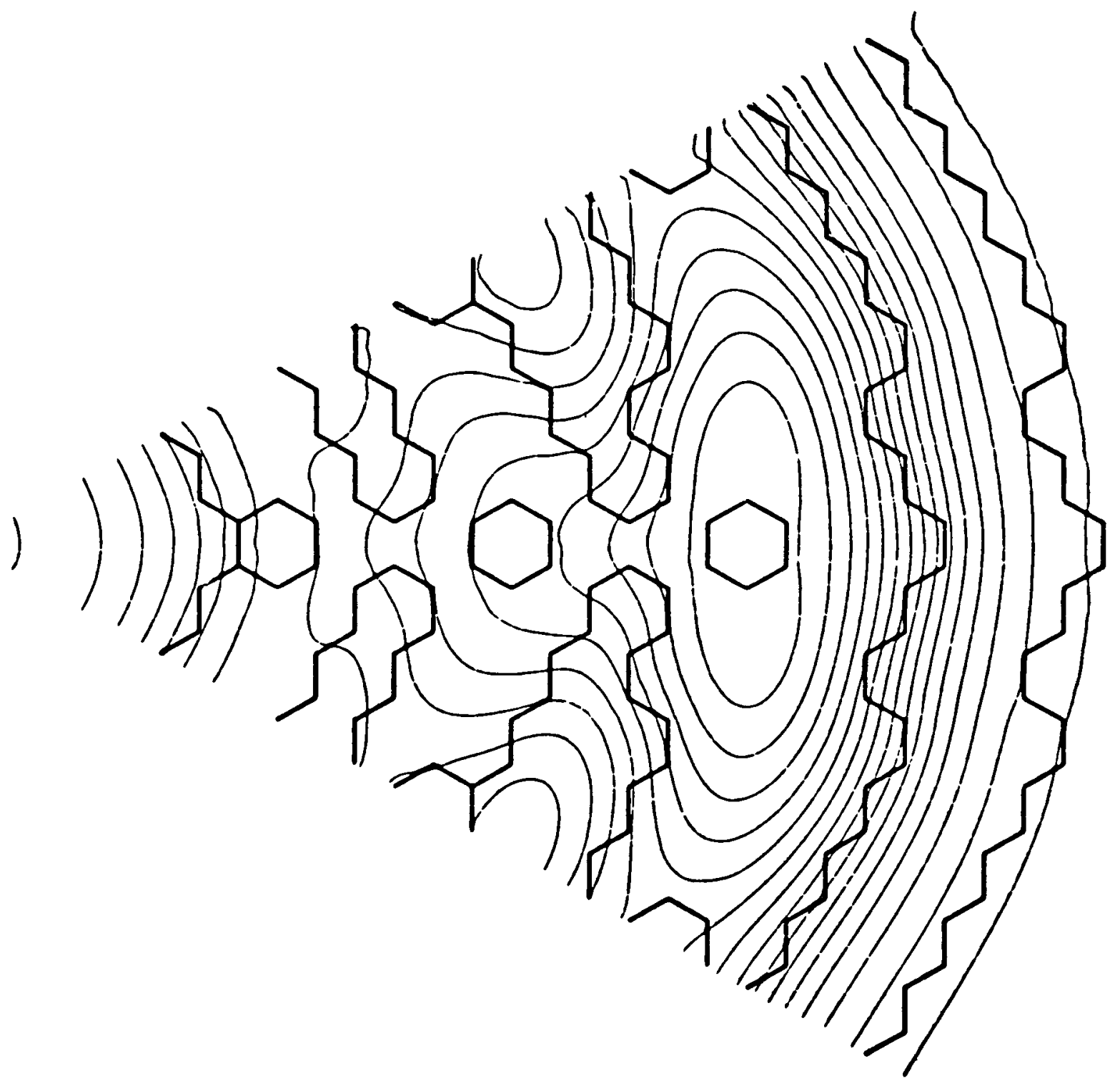

Fig. 22. Configuration B, Total Flux Distribution BOL, No Control Rods Inserted 


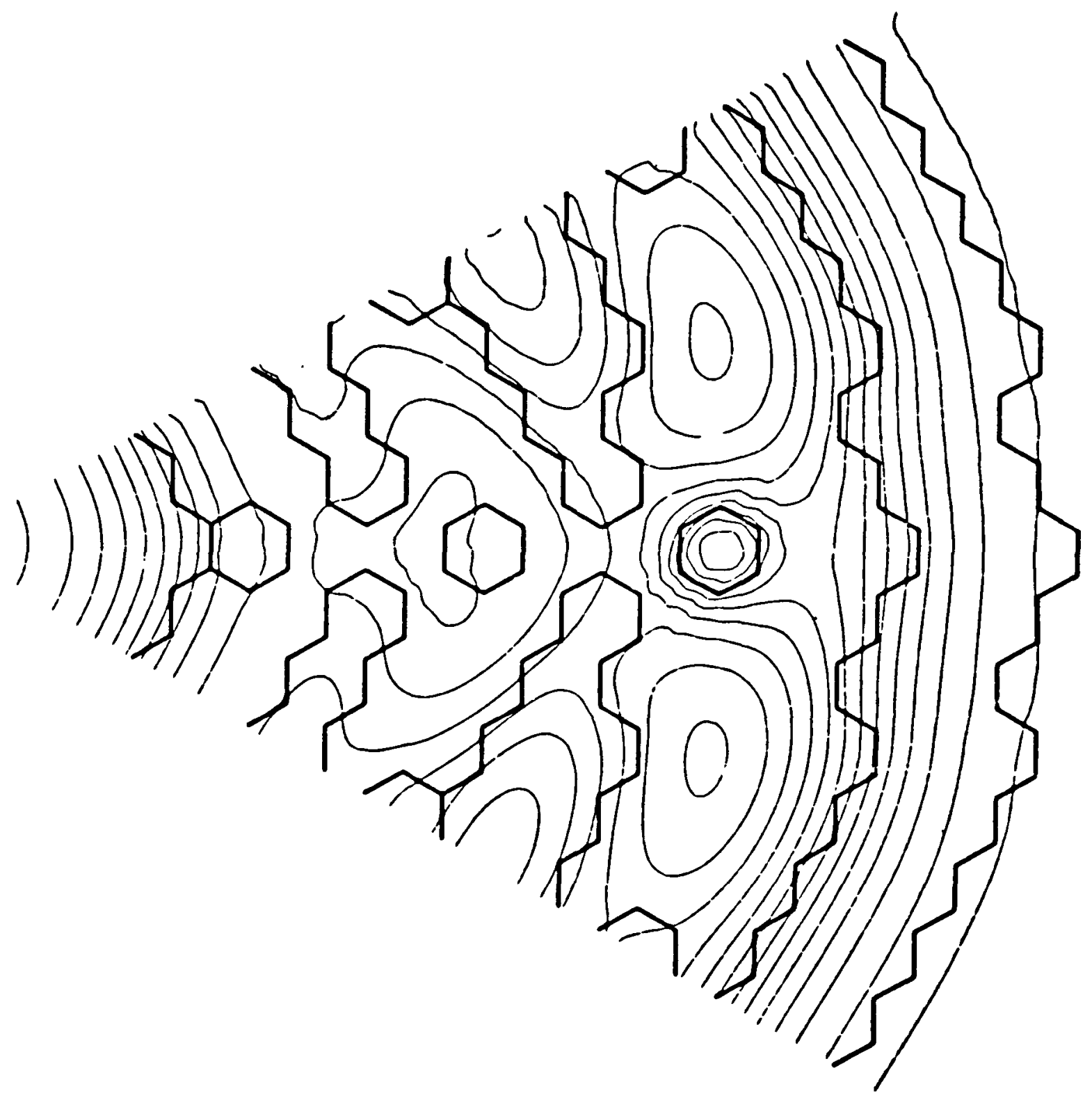

Fig. 23. Configuration B, Total Flux Distribution at BOL, Row 11 Control Rods Inserted 


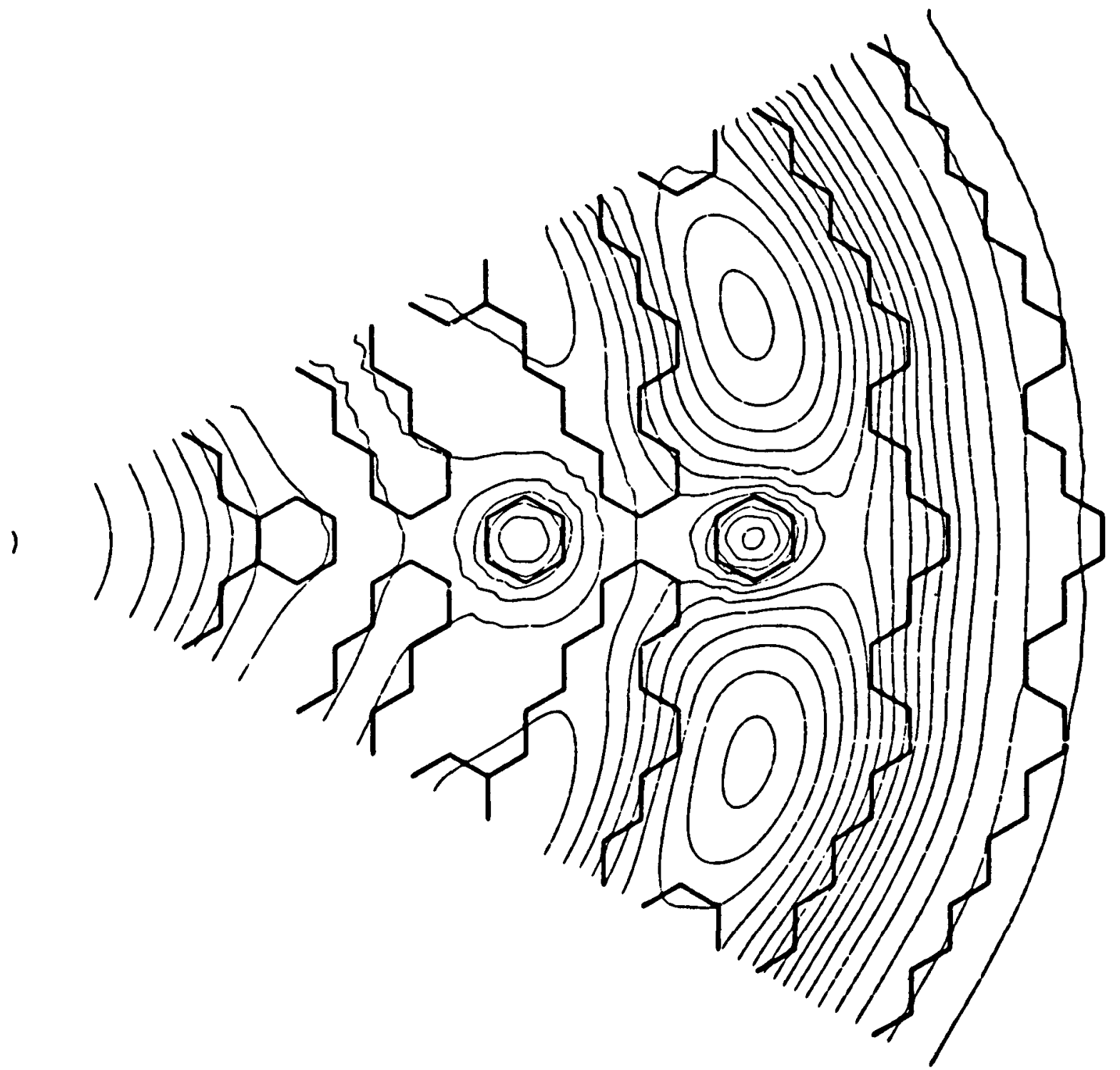

Fig. 24. Configuration B, Total Flux Distribution at BOL, Primary Control Rods Inserted 


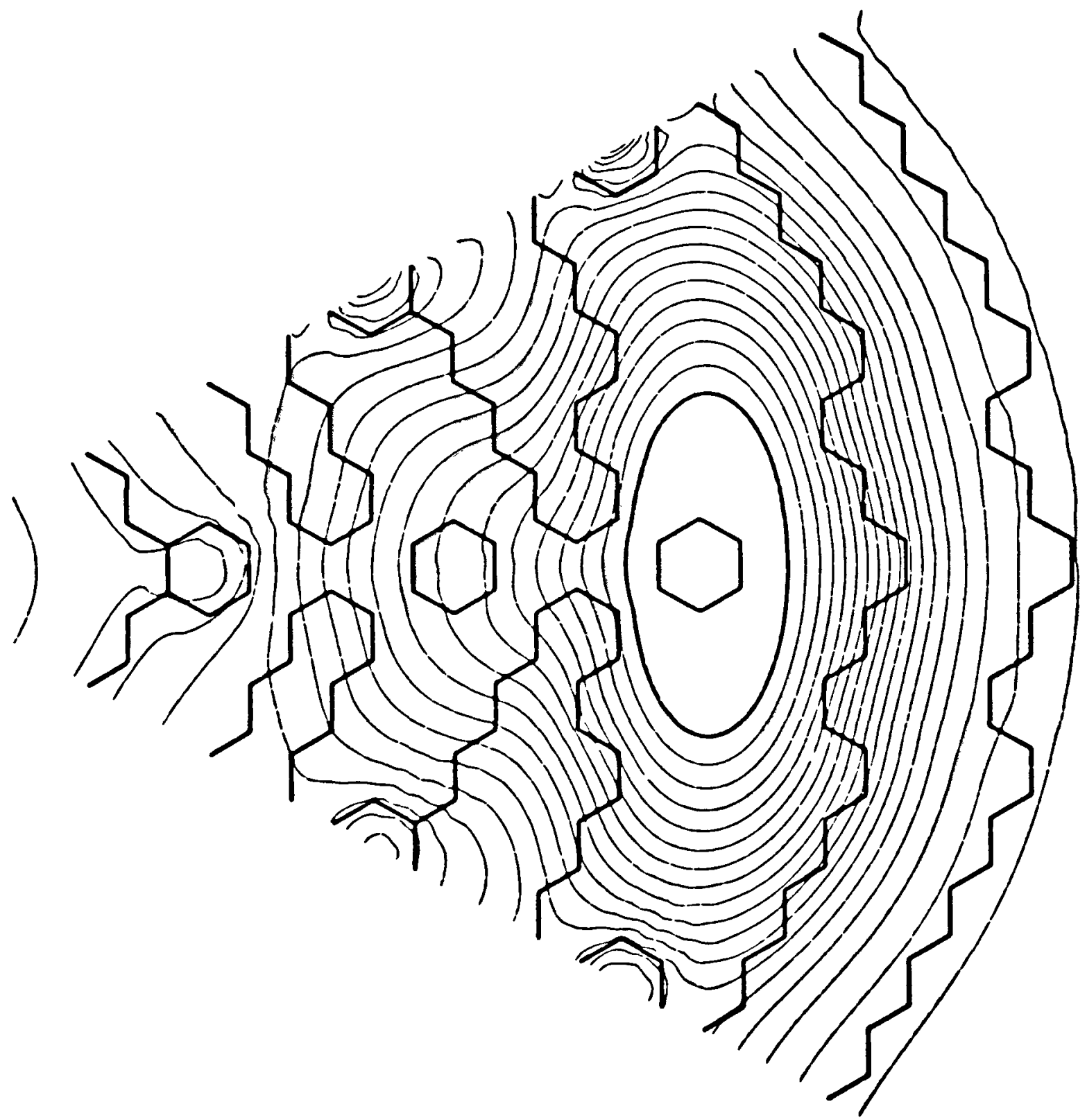

Fig. 25. Configuration B, Total Flux Distribution at BOL, Secondary Contro1 Rods Inserted 


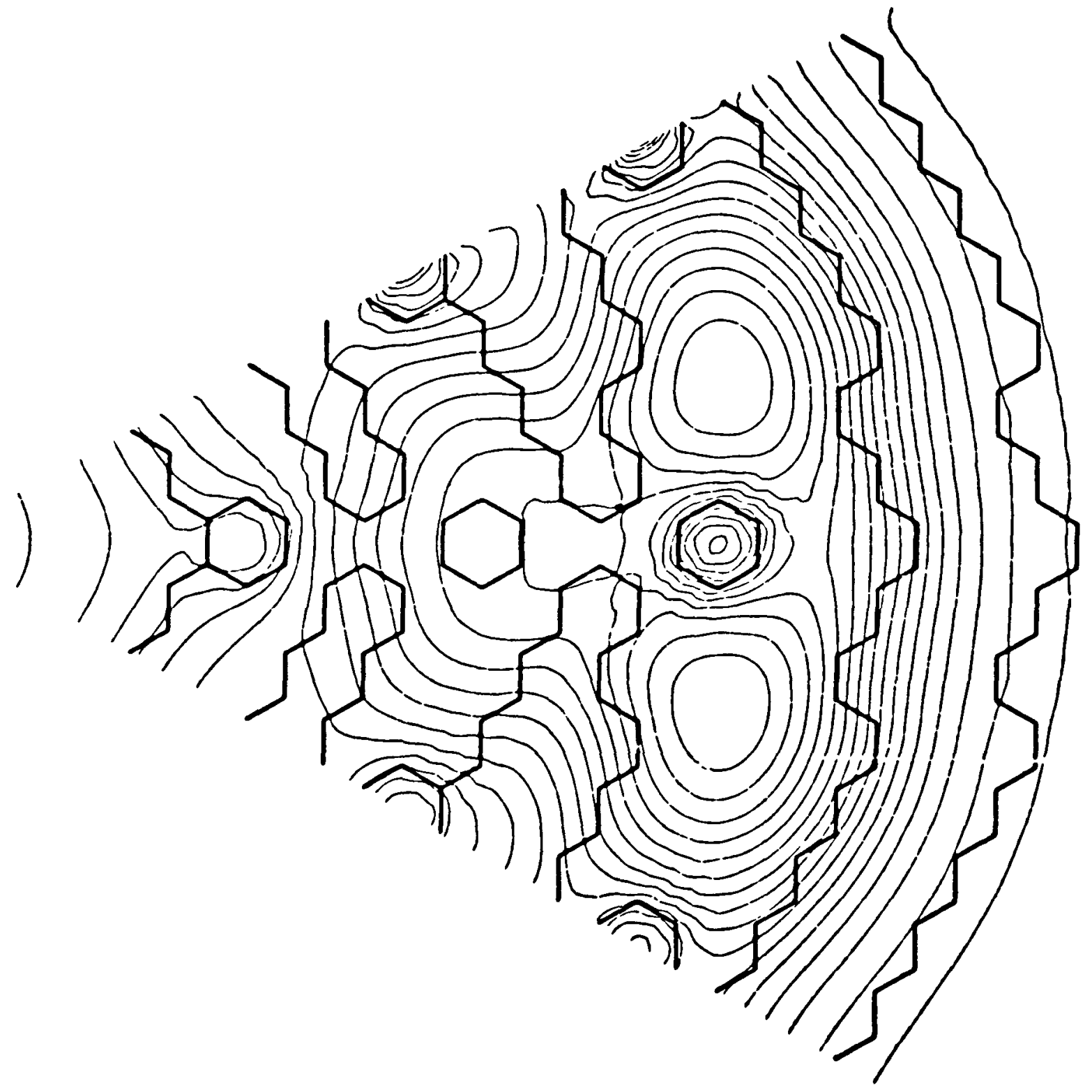

Fig. 26. Configuration B, Total Flux Distribution at BOL, Row 11 and Secondary Control Rods Inserted 


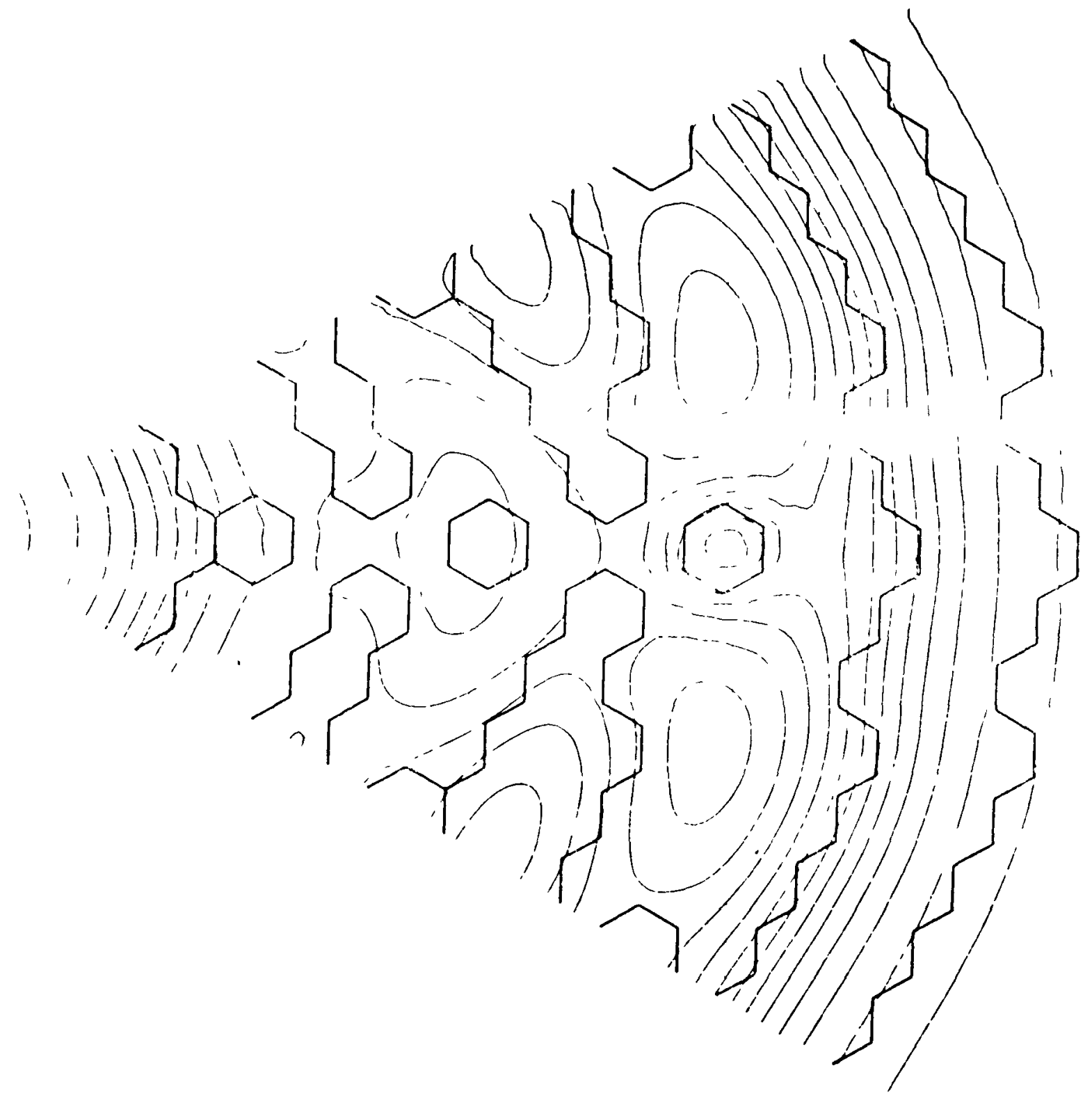

Fig. 27. Configuration B, Total Flux Distribution at BOEC 


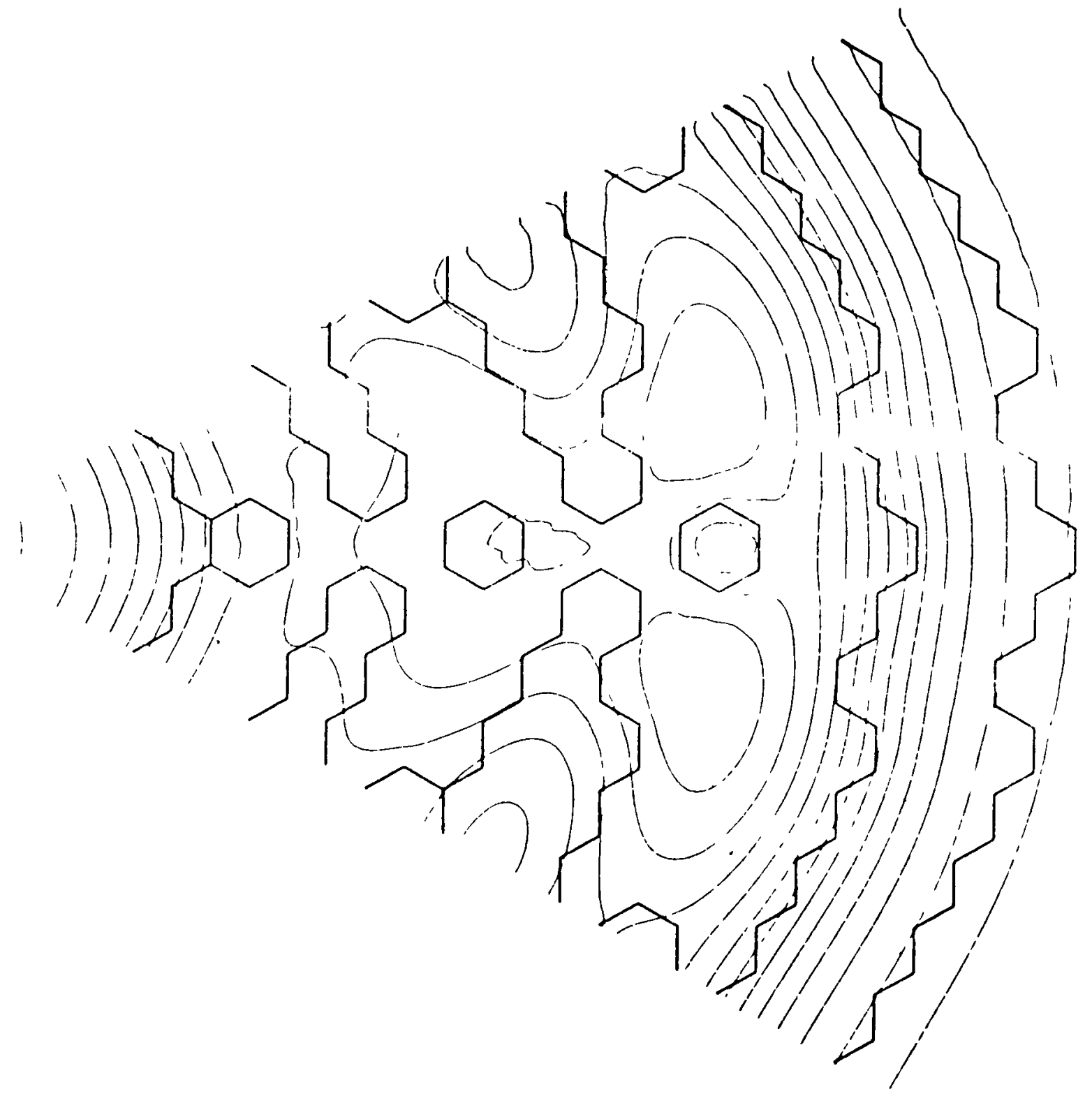

Fig. 28. Configuration B, Total Flux Distribution at MOEC 


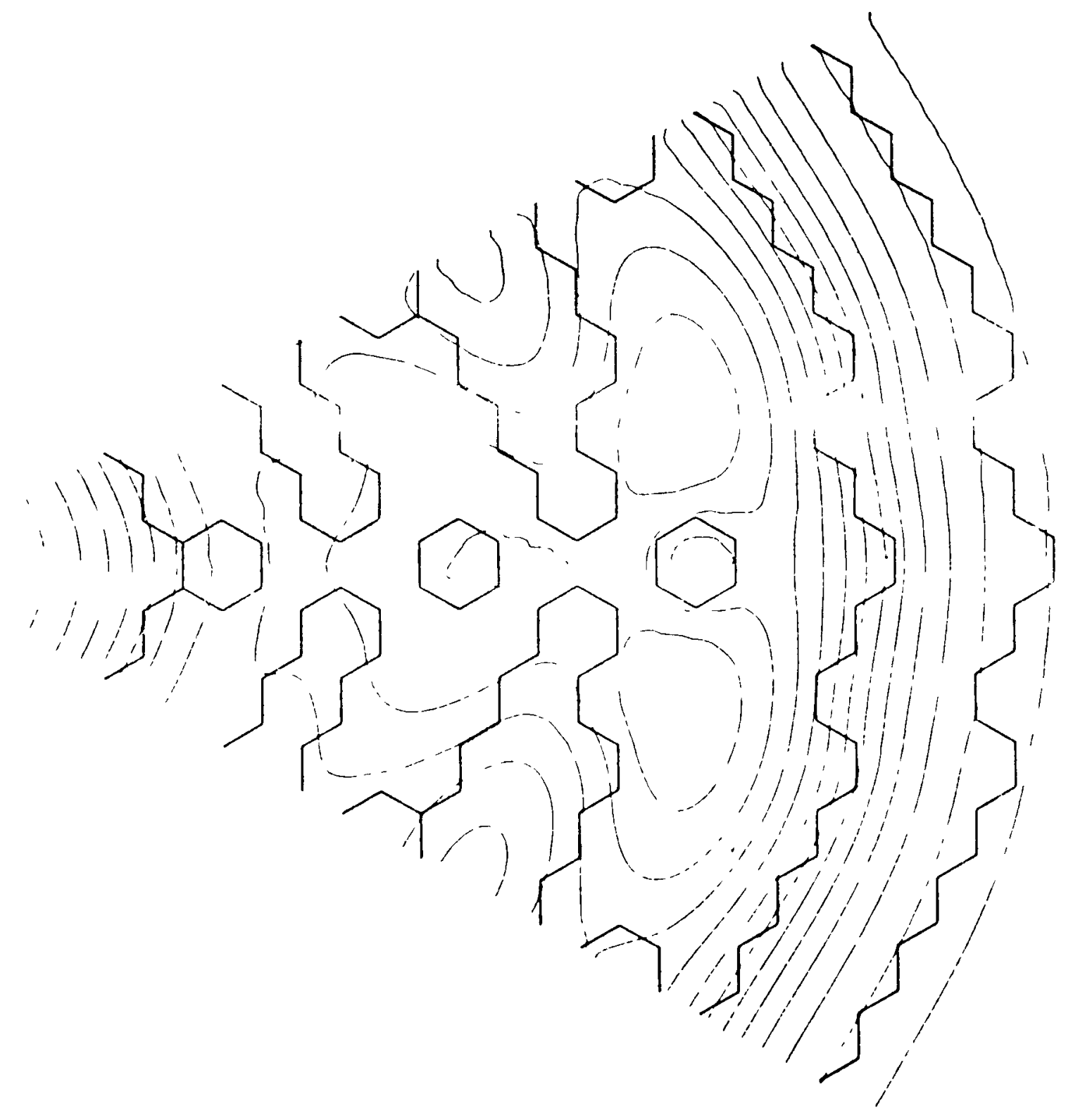

Fig. 29. Configuration B, Total Flux Distribution at EOEC 


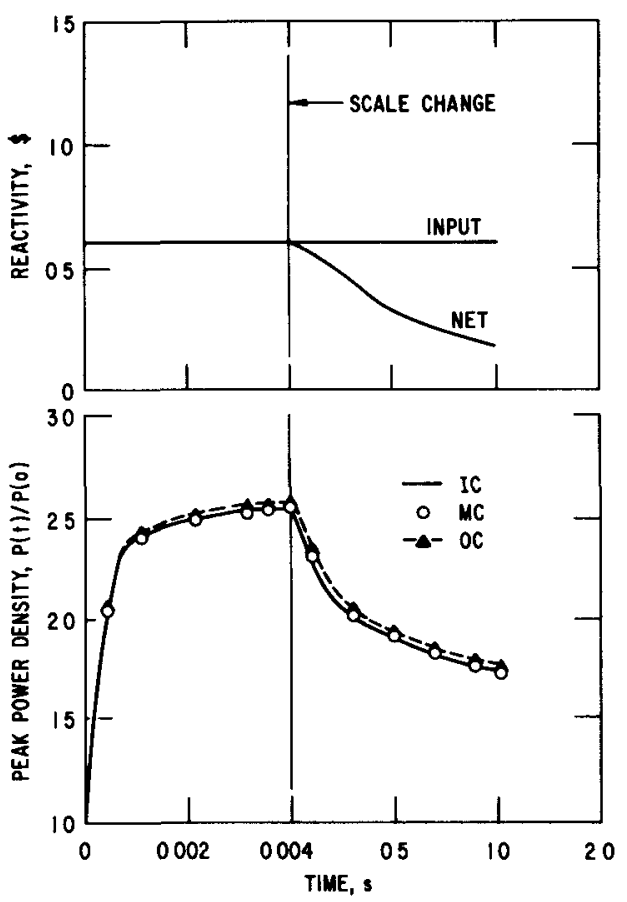

Fig. 30. 60 c Reactivity Step Insertion, Configuration A

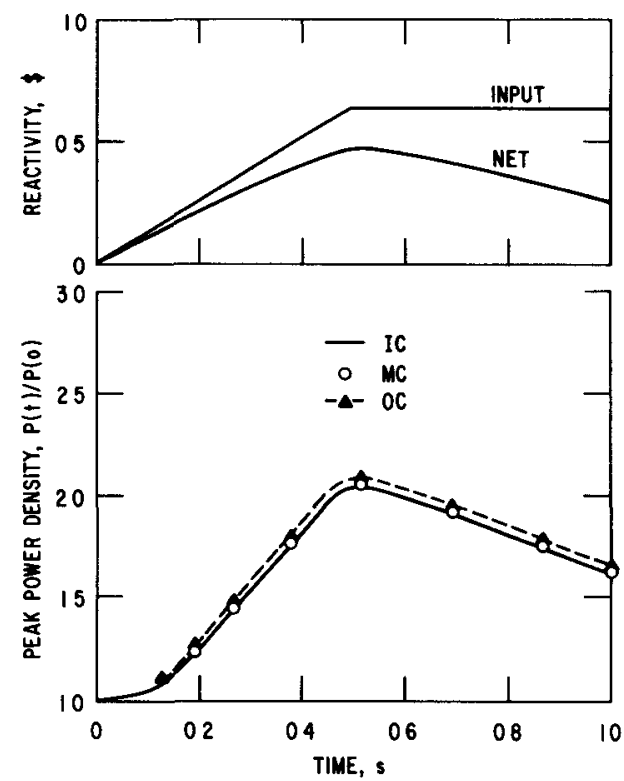

Fig. 31. $60 \mathrm{c} / 500$ ms Reactivity Ramp, Configuration A 


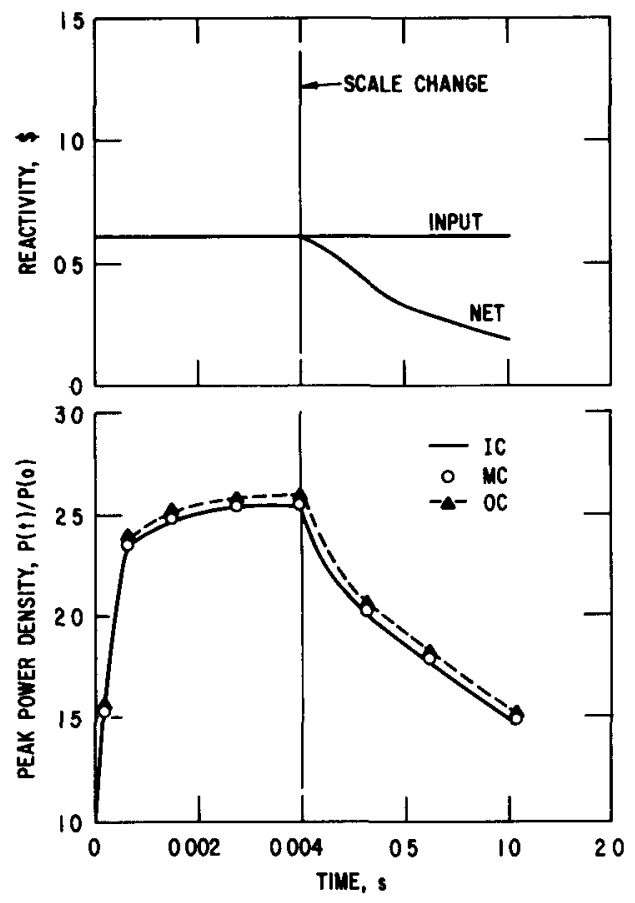

Fig. 32. $60 €$ Reactivity Step Insertion, Configuration $\mathrm{B}$
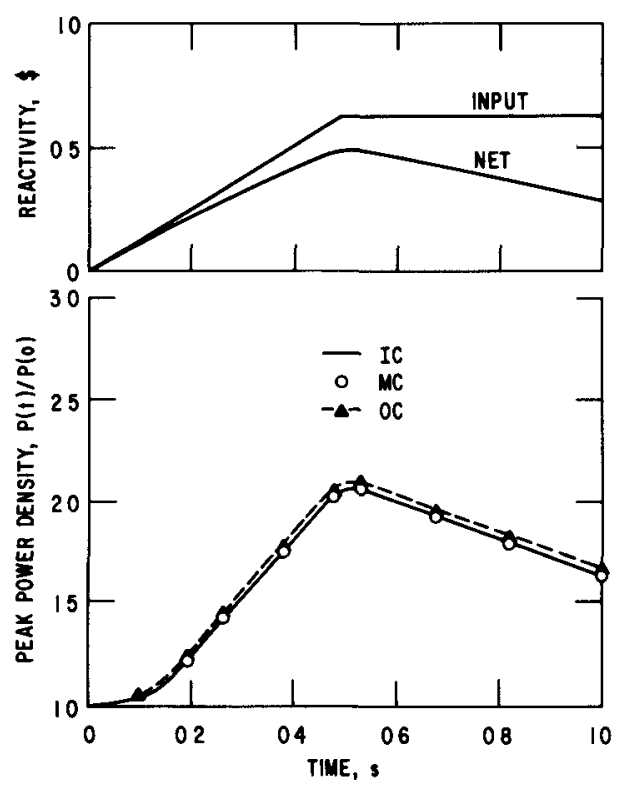

Fig. 33. $60 c / 500 \mathrm{~ms}$ Reactivity Ramp, Configuration $B$ 


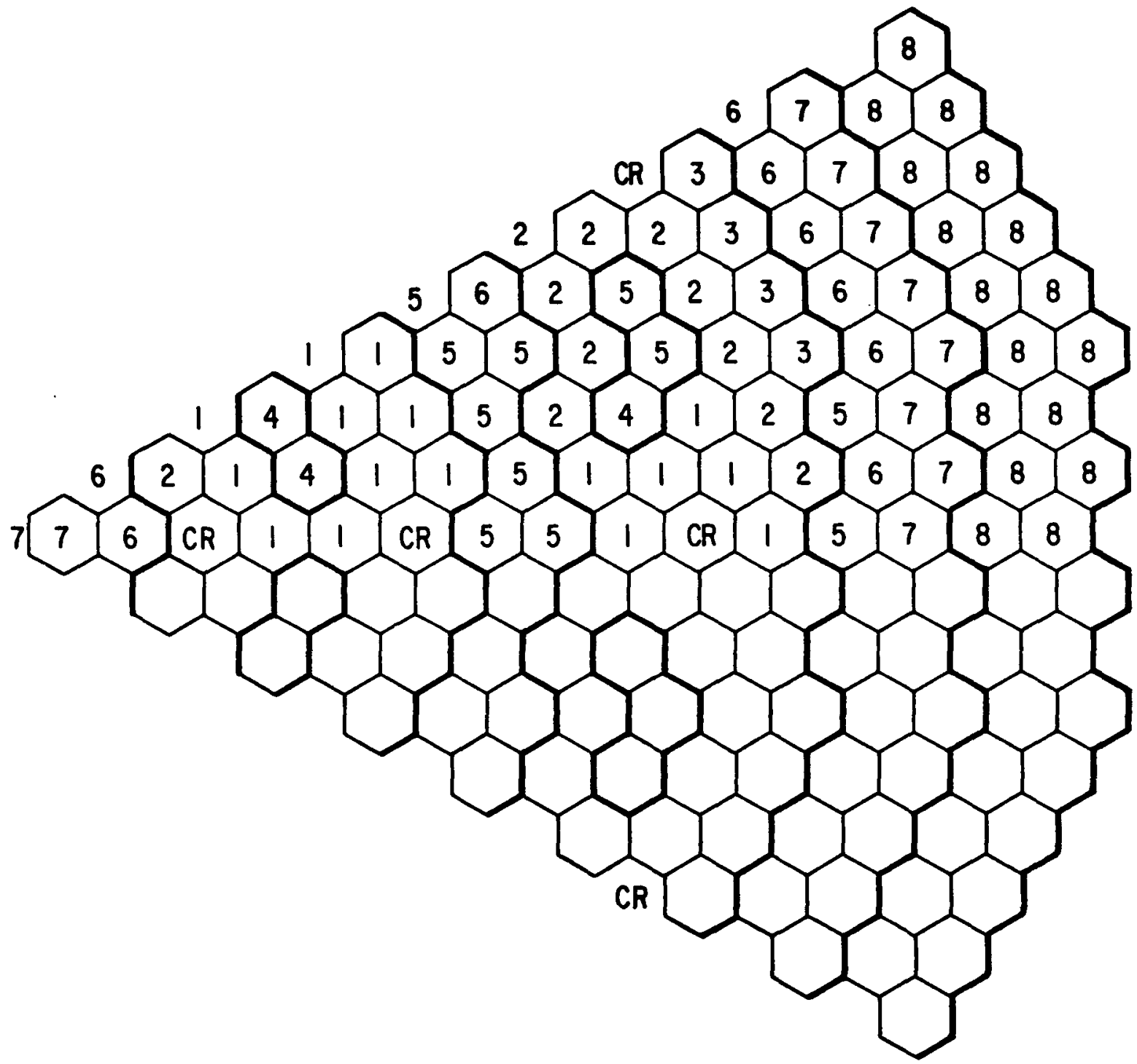

Fig. 34. Orificing Scheme of Configuration A with Equal

Peak Clad Temperature at BOL in Core and at

EOL in the Internal Blankets 


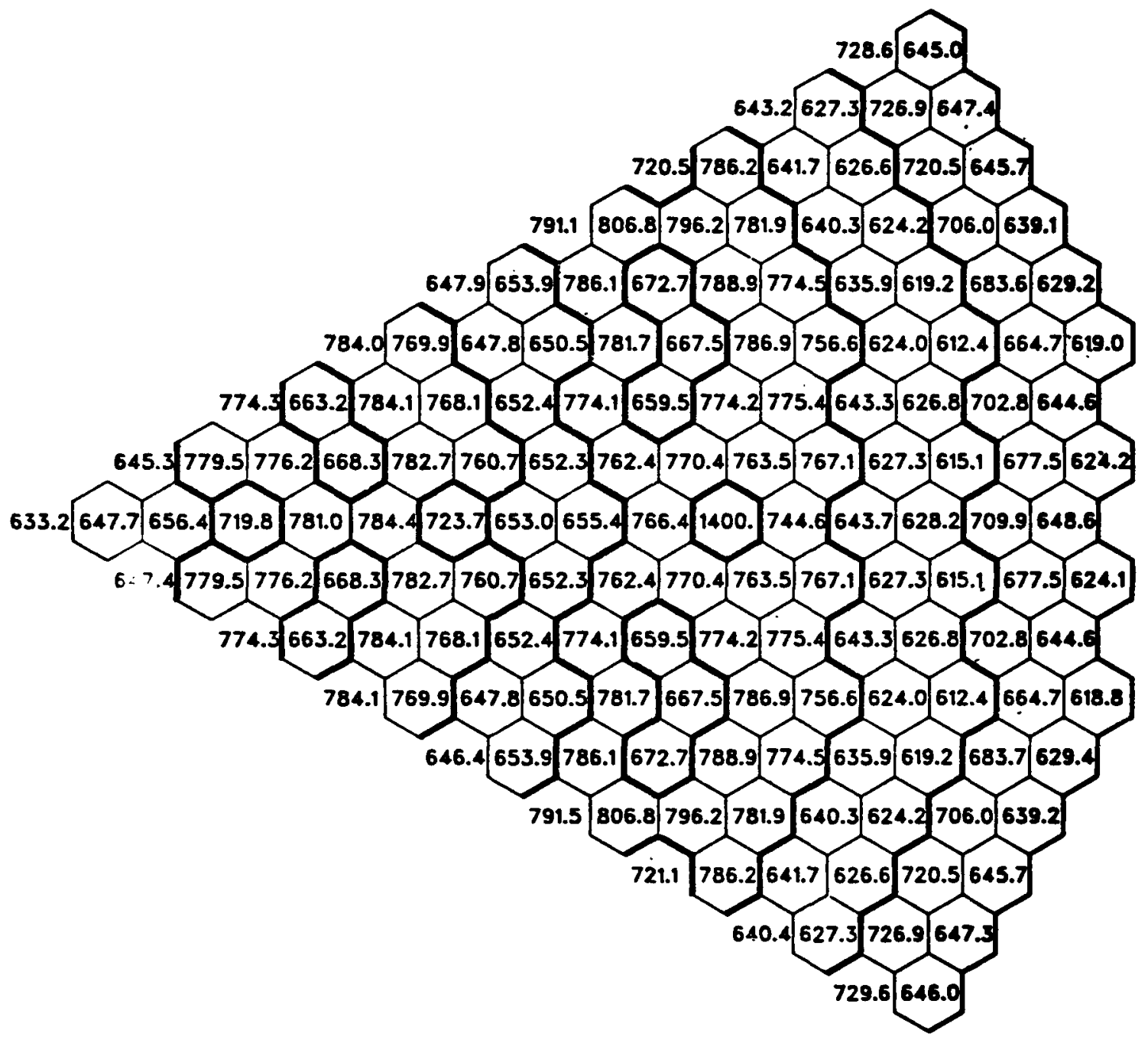

Fig. 35. Configuration A BOL Average Coolant Temperature at Core Mid-Plane (Orificed for Minimum Peak Temperature) 


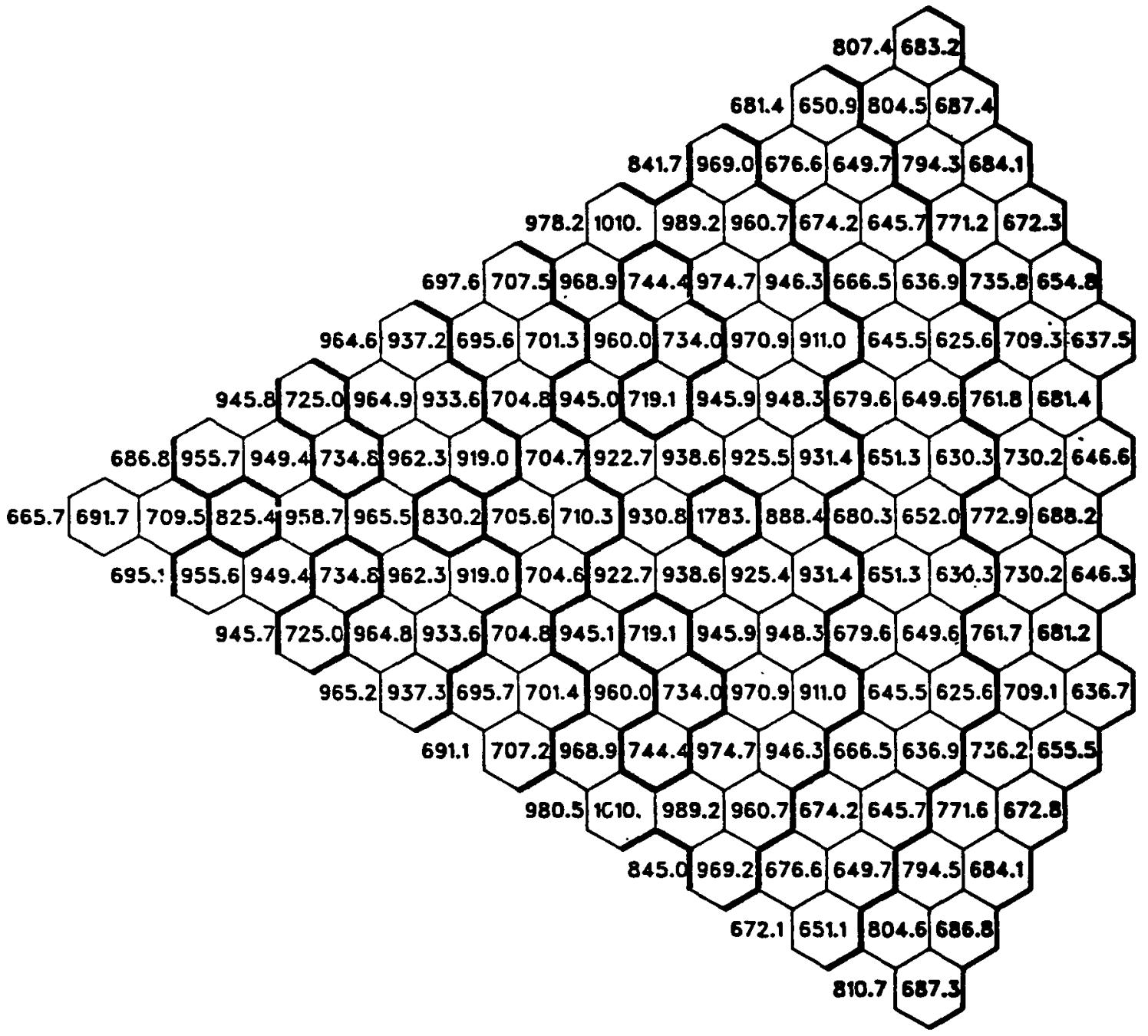

Fig. 36. Configuration A BOL Average Coolant Temperature at Top of Core (Orificed for Minimum Peak Temperature) 


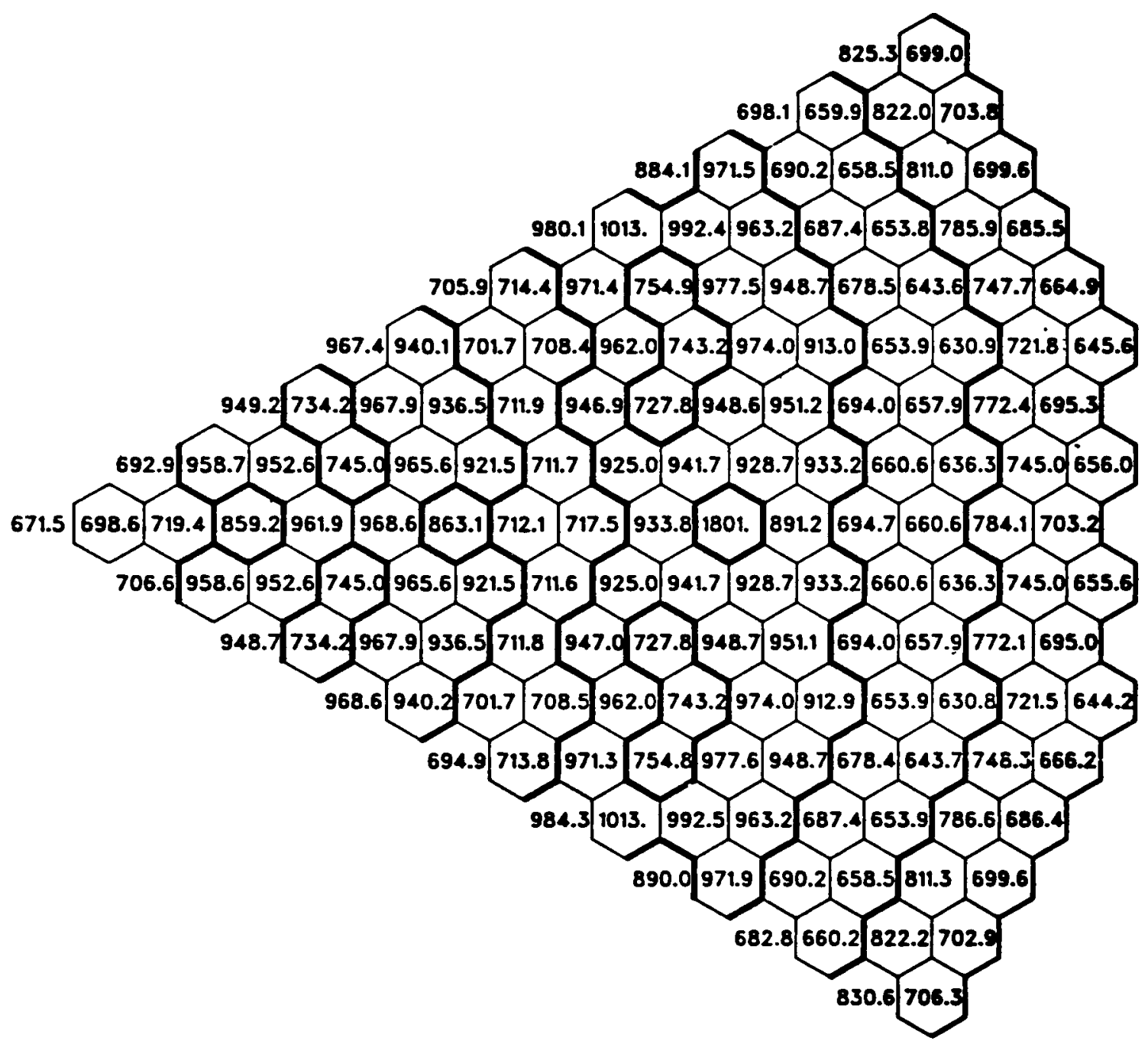

Fig. 37. Configuration A BOL Average Coolant Temperature at Outlet (Orificed for Minimum Peak Temperature) 


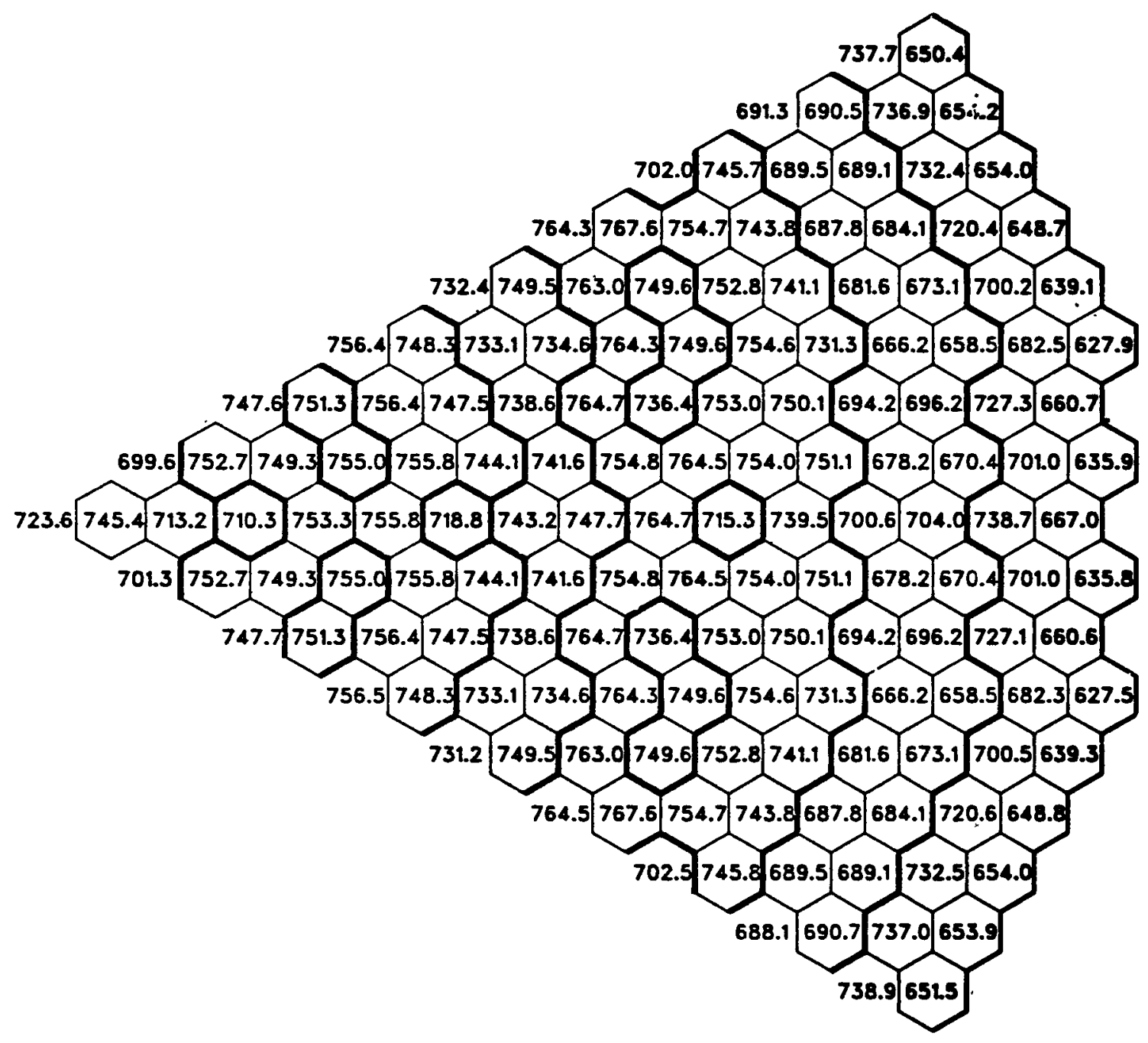

Fig. 38. Configuration A EOEC Average Coolant Temperature at Core Mid-P1ane (Orificed for Minimum Peak Temperature) 


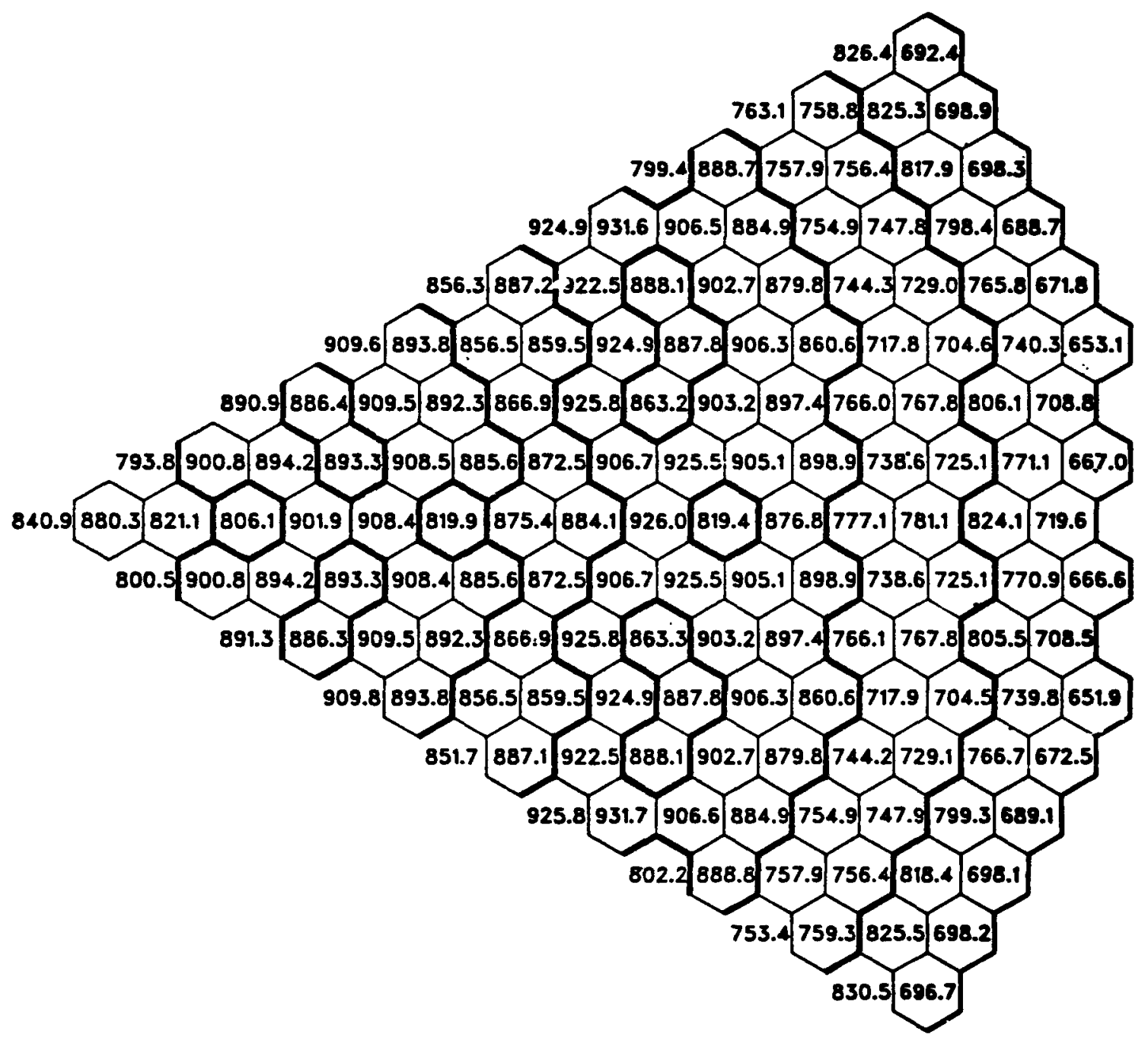

Fig. 39. Configuration A EOEC Average Coolant

Temperature at Top of Core (Orificed for Minimum Peak Temperature) 


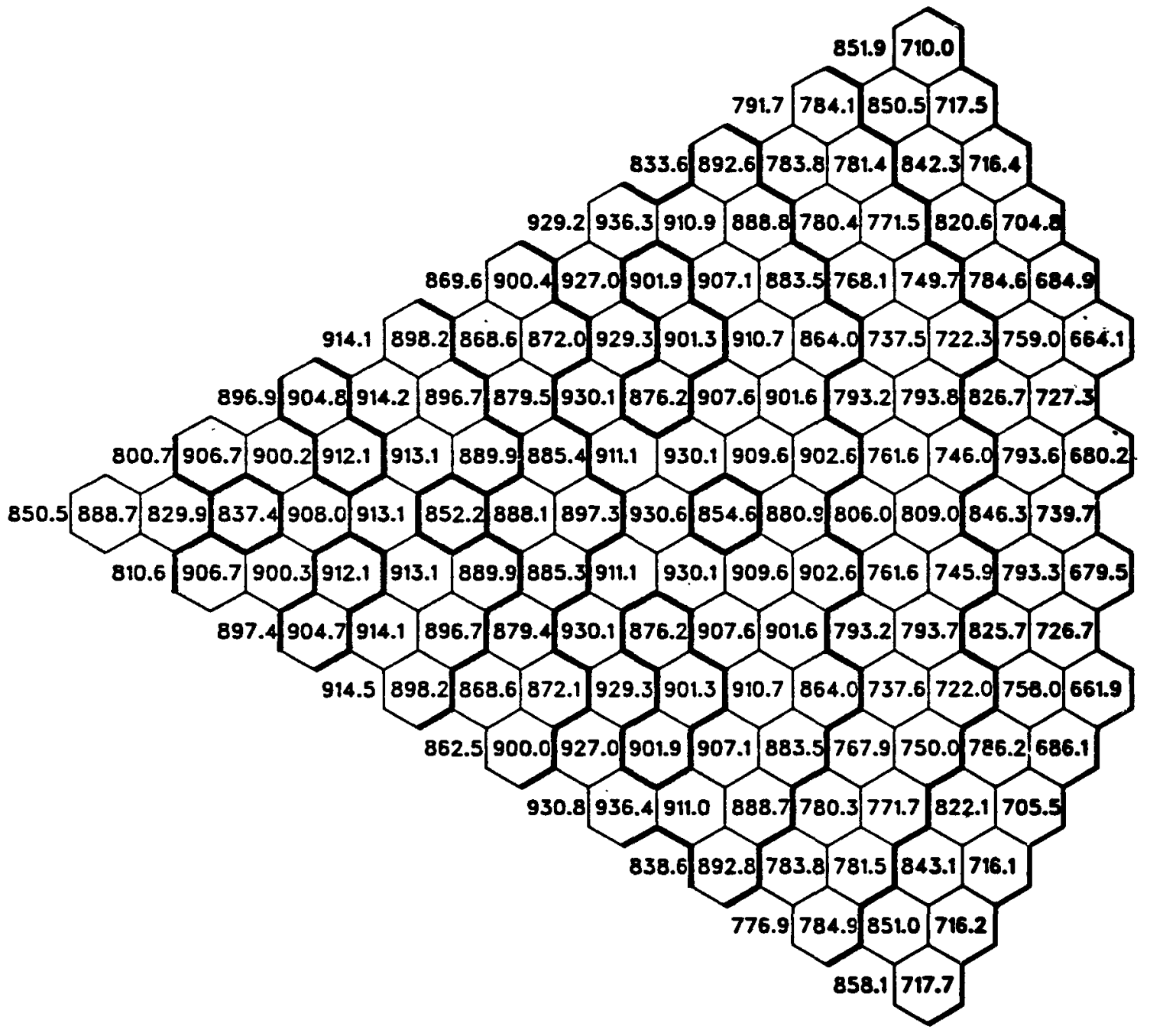

Fig. 40. Configuration A EOEC Average Coolant Temperature at Outlet (Orificed for Minimum Peak Temperature) 


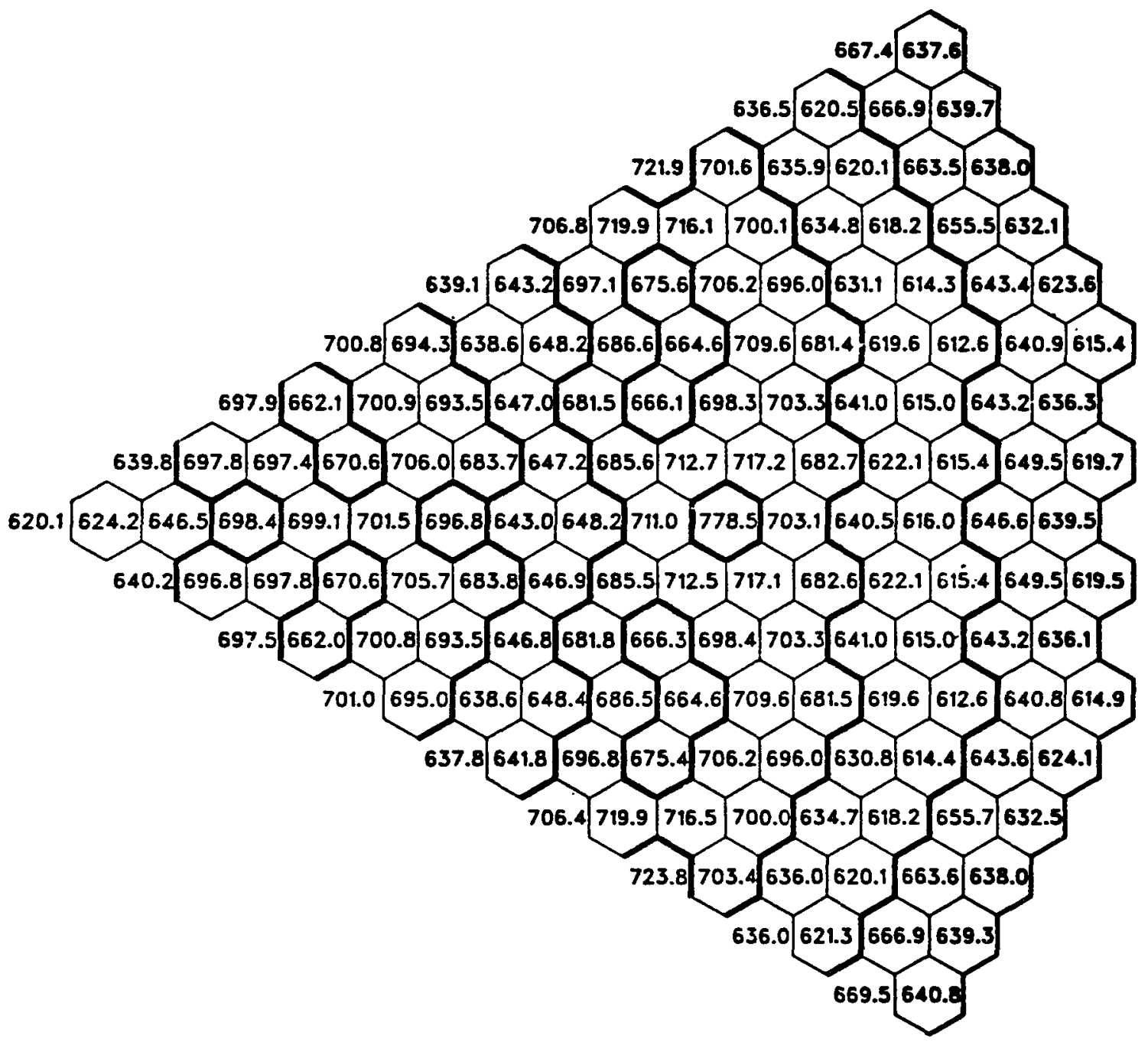

Fig. 41. Configuration A BOL Average Duct Wall

Temperature at Core Mid-Plane (Orificed for Minimum Peak Temperature) 


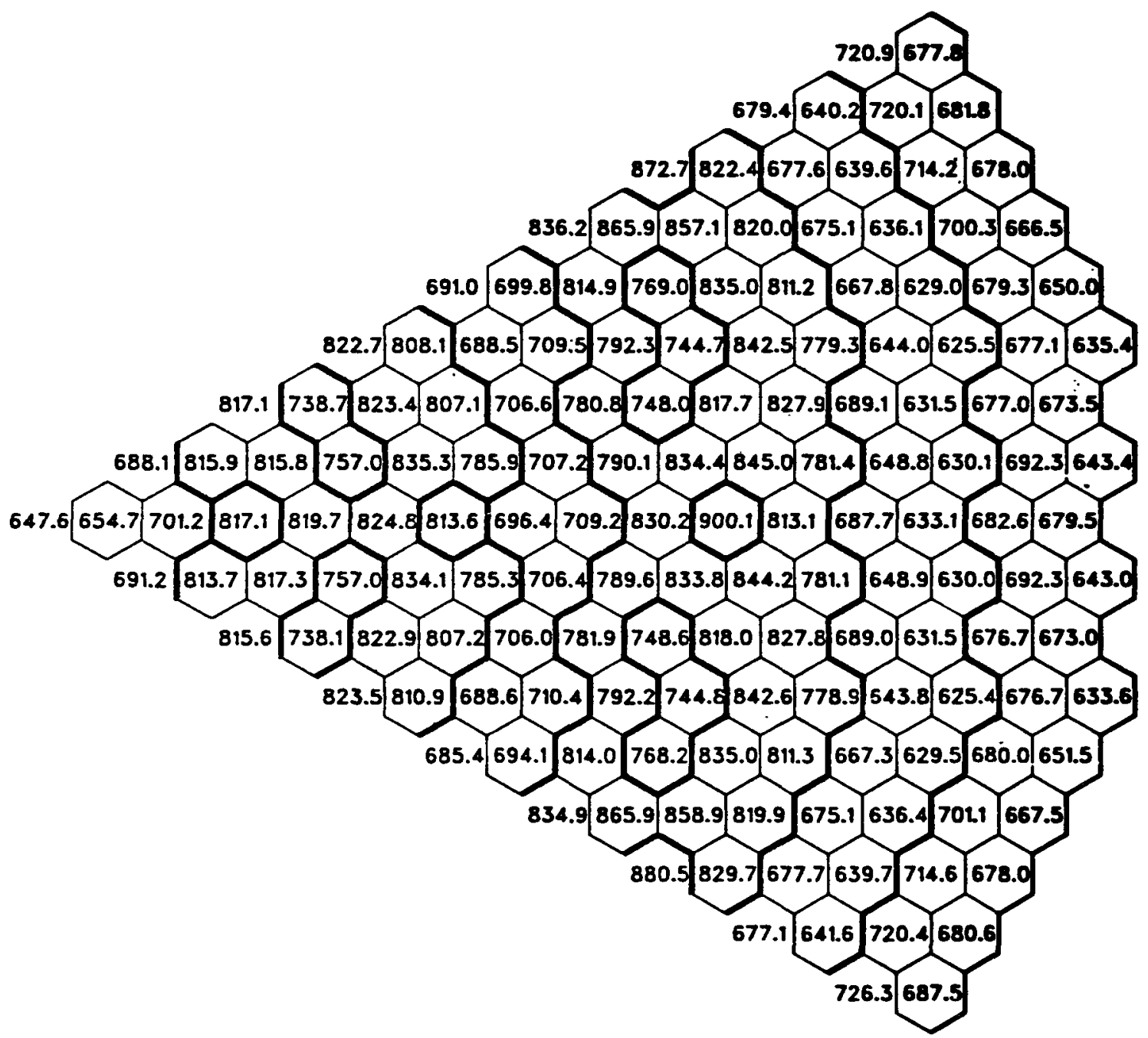

Fig. 42. Configuration A BOL Average Duct Wa11 Temperature at Top of Core (Orificed for Minimum Peak Temperature) 


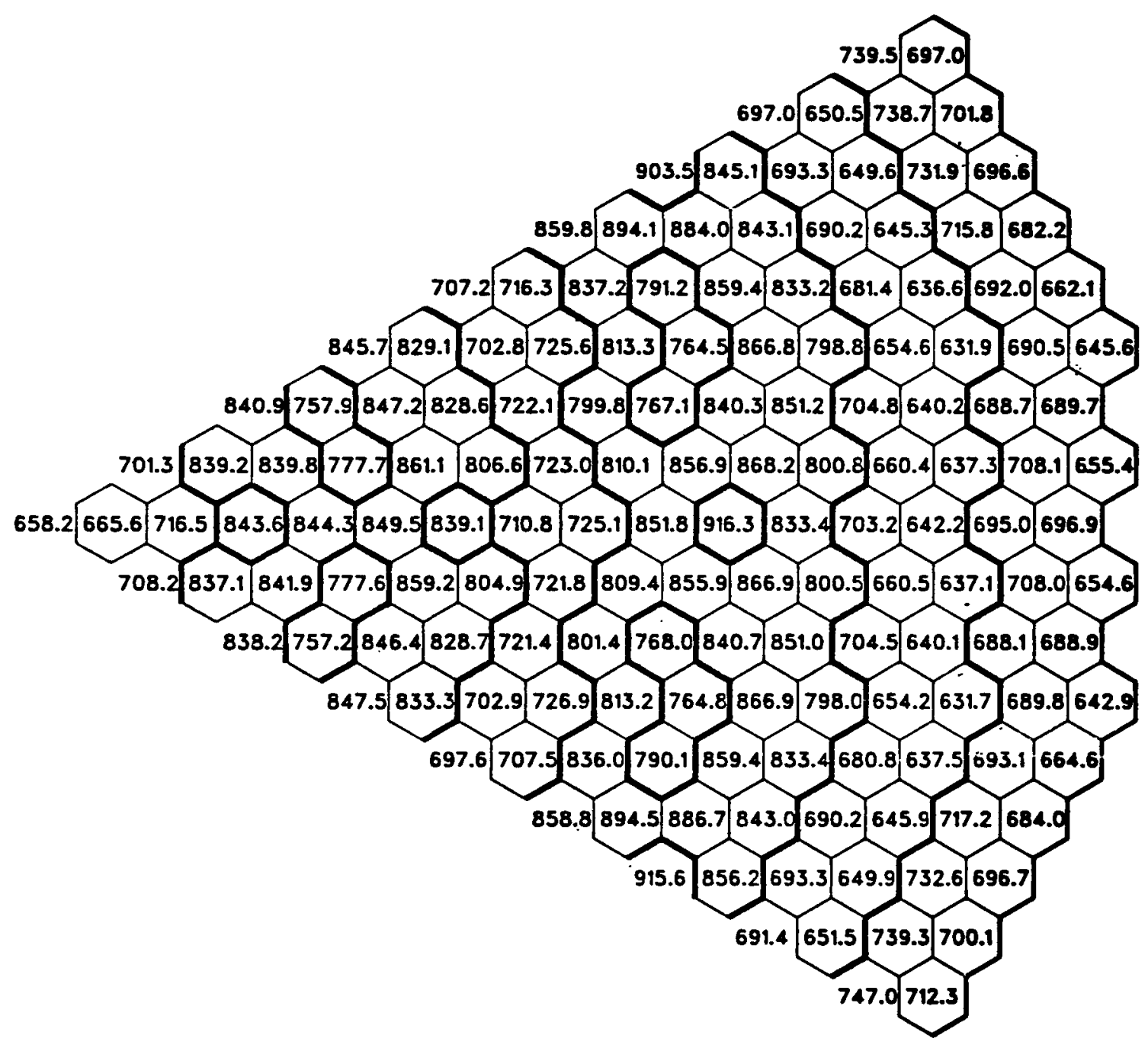

Fig. 43. Configuration A BOL Average Duct Wa11 Temperature at Outlet (Orificed for Minimum Peak Temperature) 


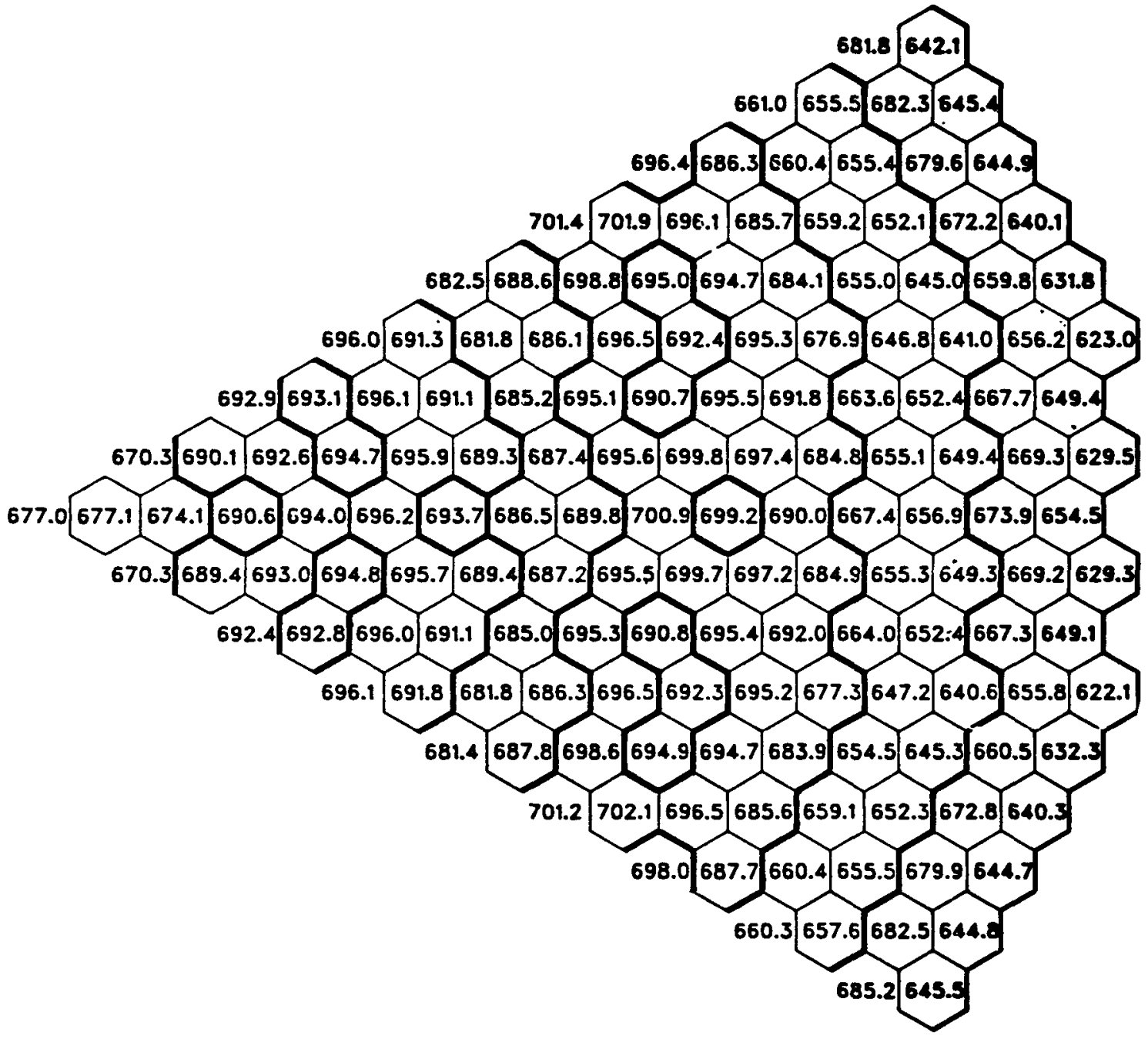

Fig. 44. Configuration A EOEC Average Duct Wall Temperature at Core Mid-Plane (Orificed for Mintmum Peak Temperature) 


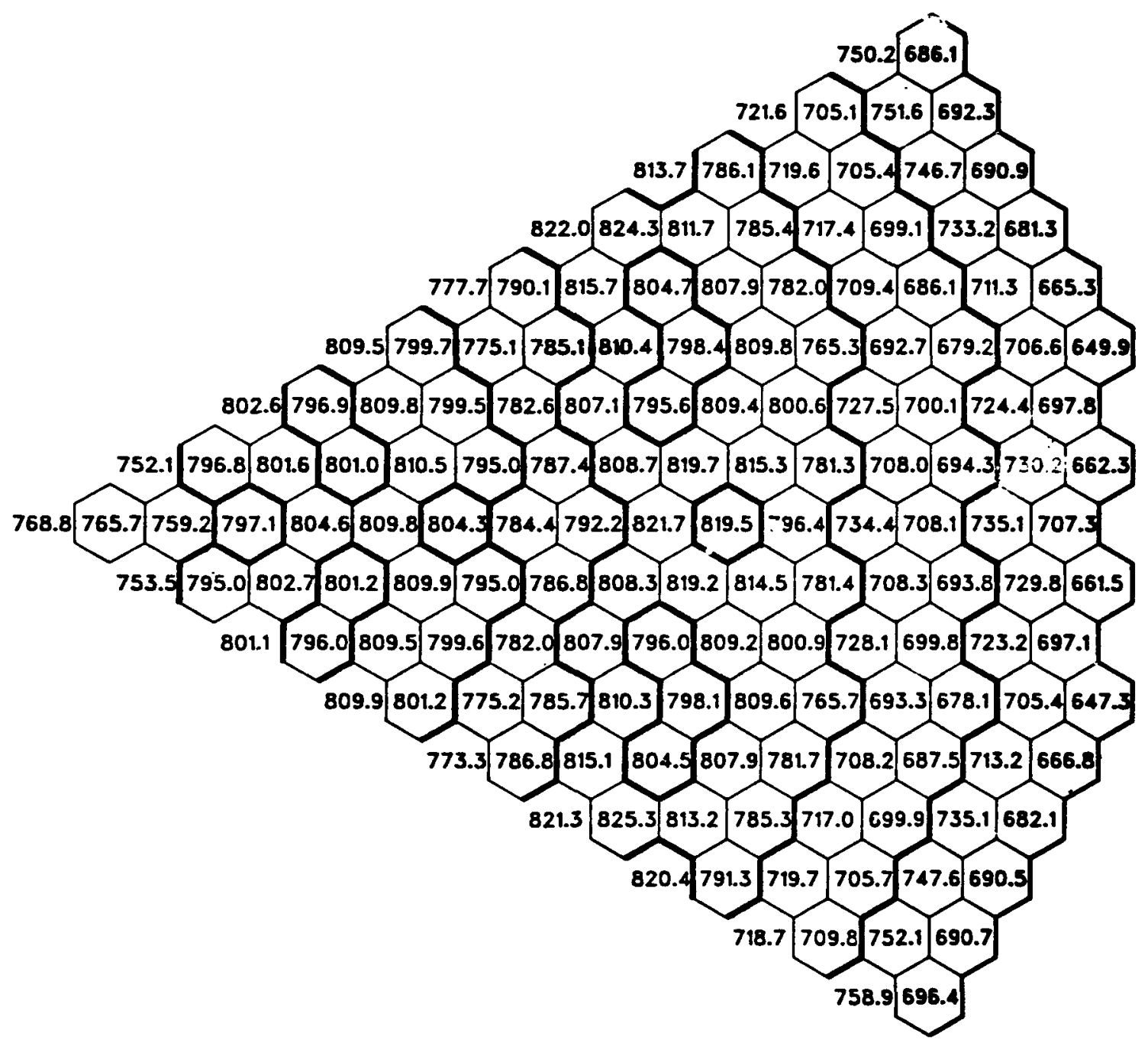

Fig. 45. Configuration A EOEC Average Duct Wall Temperature at Top of Core (Orificed for Minimum Peak Temperature) 


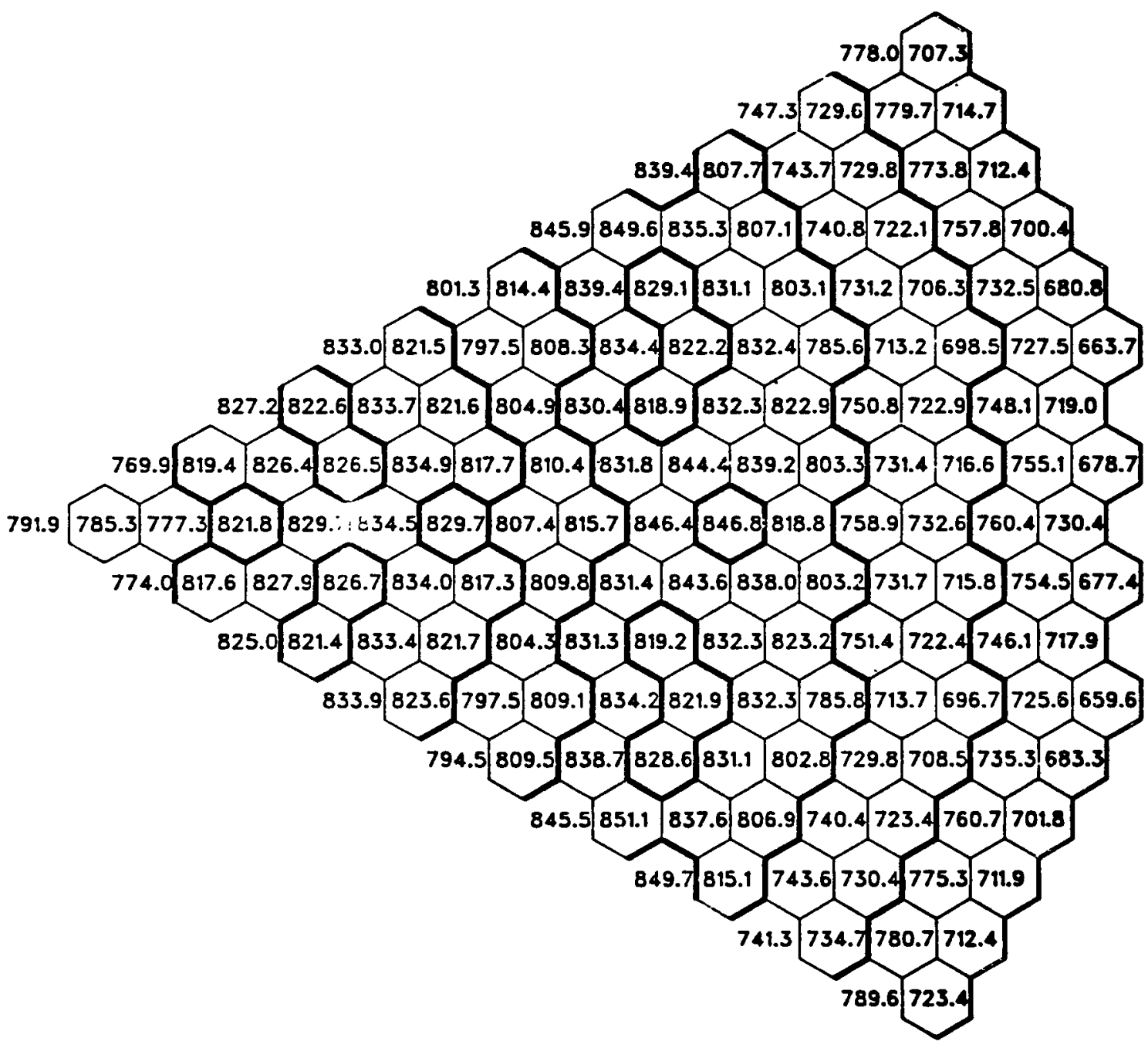

Fig. 46. Configuration A EOEC Average Duct Wall Temperature at Outlet (Orificed for Minimum Peak Temperature) 


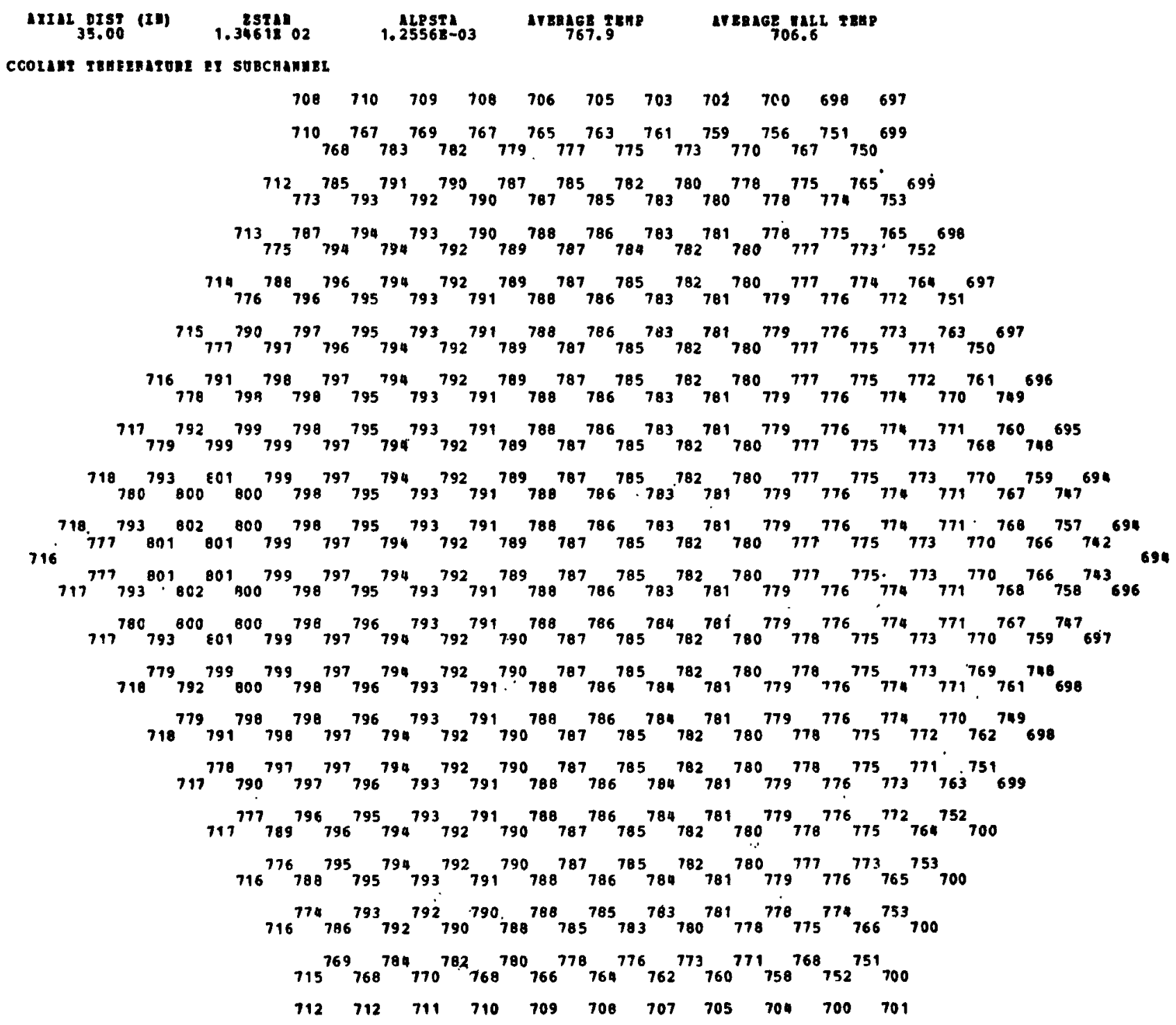

Fig, 47. Coolant Temperatures at Mid-Plane 


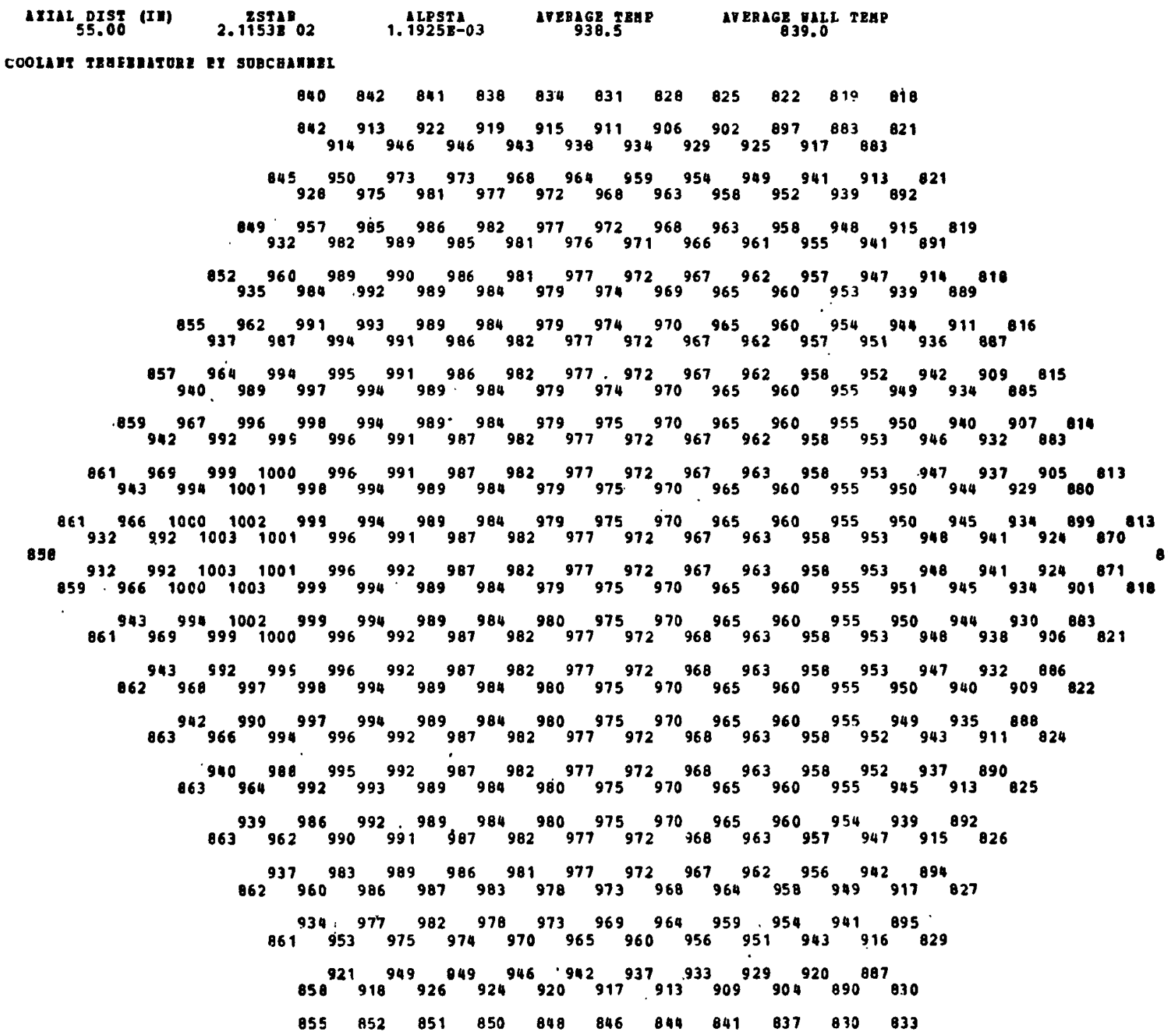

Fig. 48. Coolant Temperatures at Top of Core 


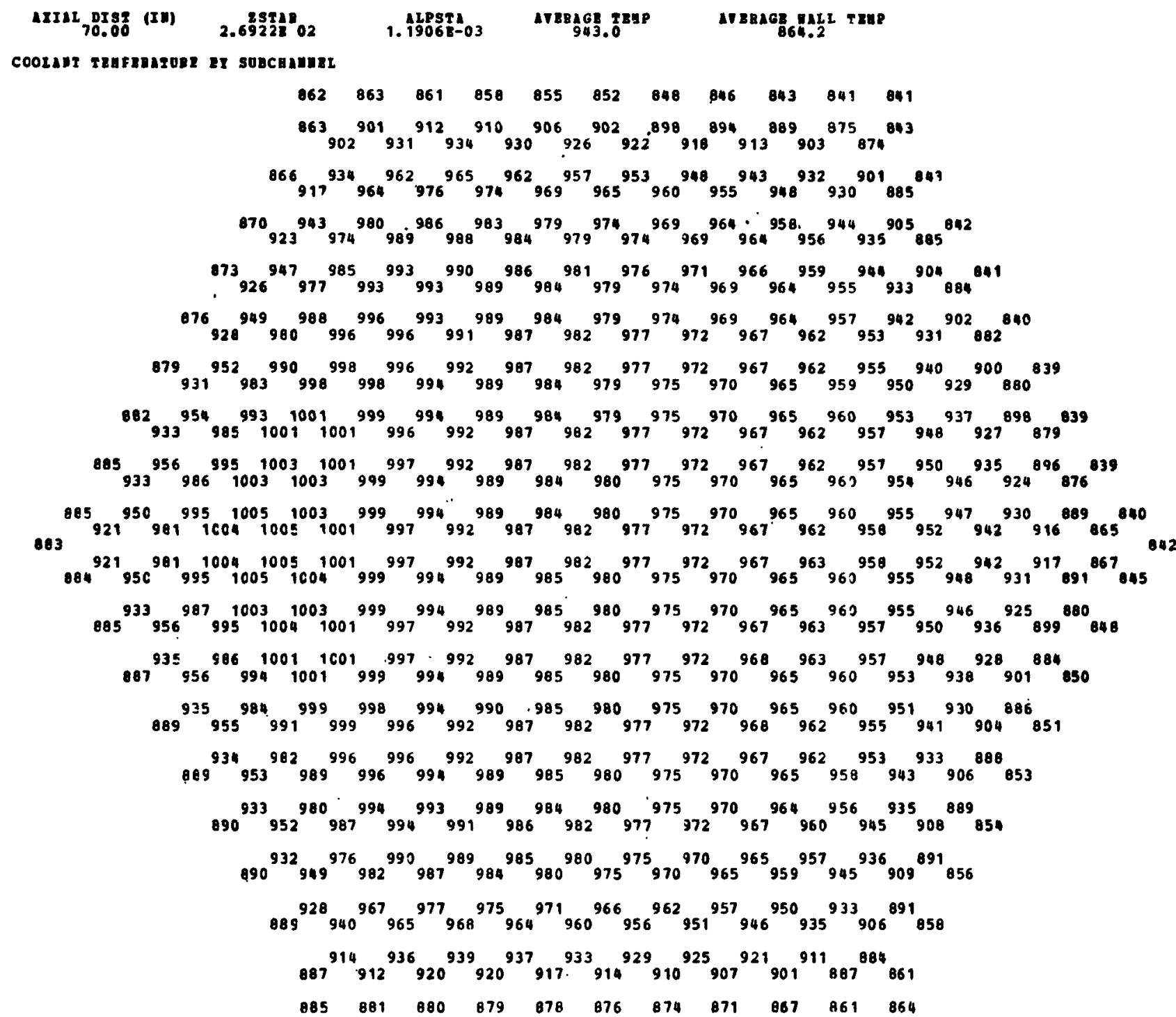

Fig. 49. Coolant Temperatures at Outlet 


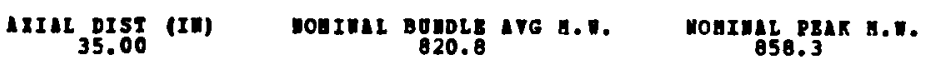

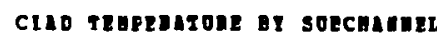

$$
\begin{aligned}
& \begin{array}{lllllllllll}
762 & 770 & 768 & 766 & 764 & 762 & 759 & 757 & 755 & 752 & 746
\end{array}
\end{aligned}
$$

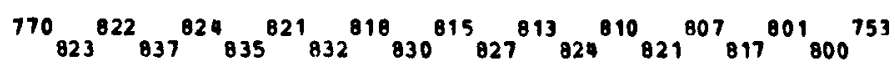

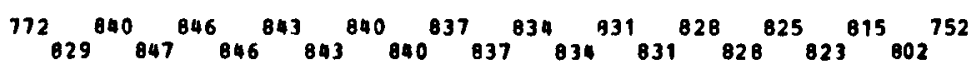

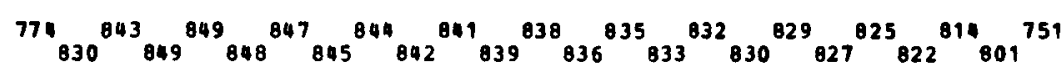

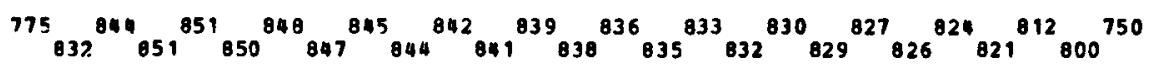

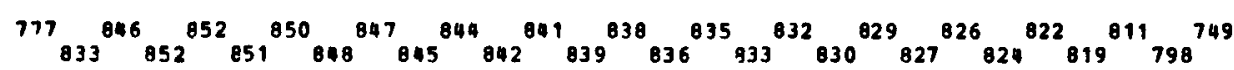

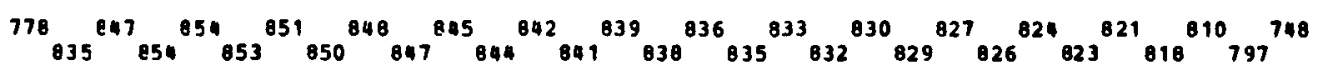

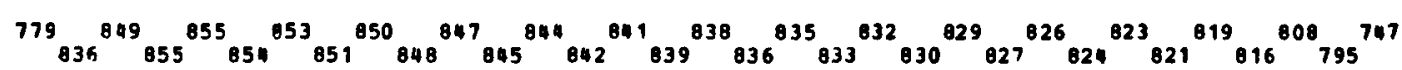

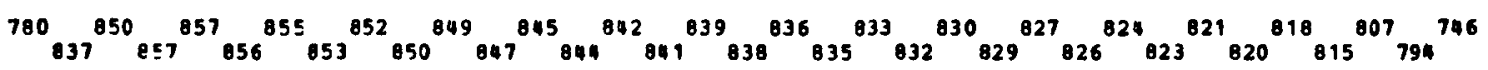

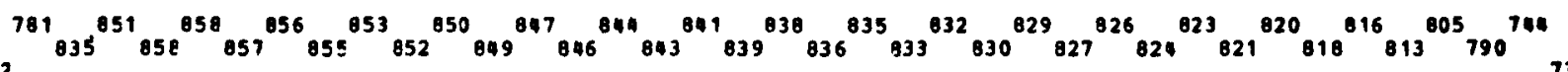

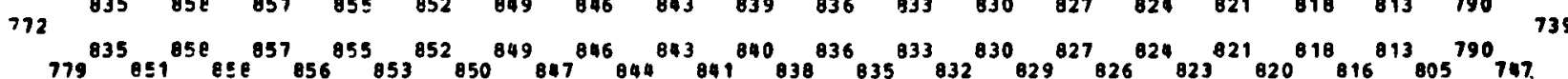

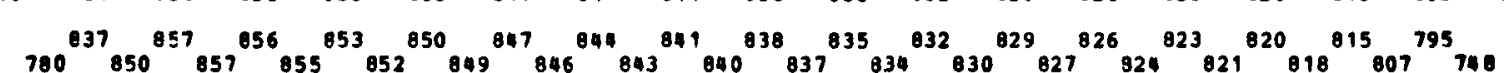

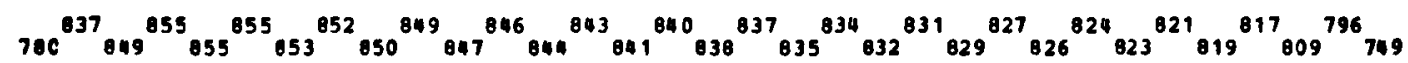

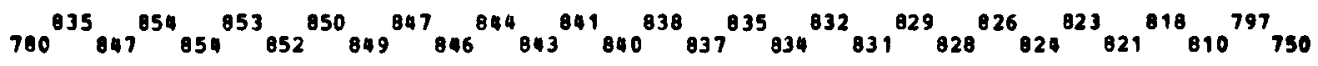

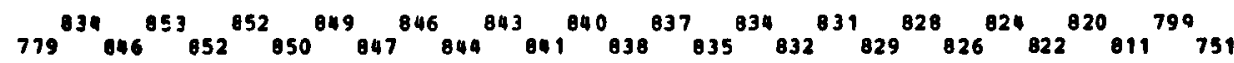

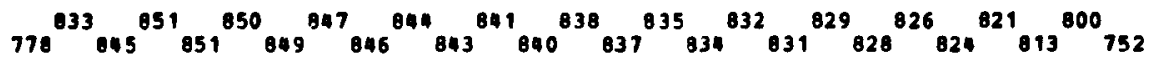

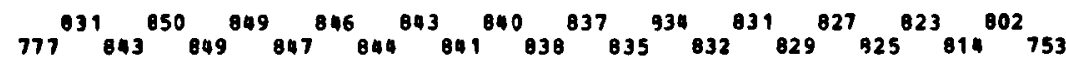

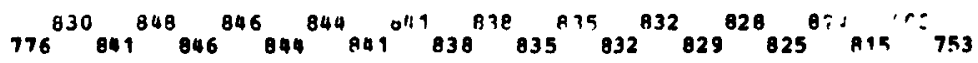

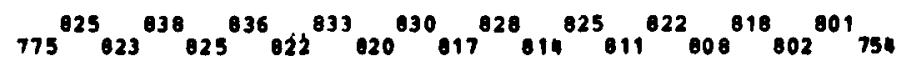

$$
\begin{aligned}
& \begin{array}{lllllllllll}
766 & 711 & 769 & 768 & 766 & 764 & 762 & 760 & 750 & 754 & 719
\end{array}
\end{aligned}
$$

Fig. 50. Nominal Clad Temperatures at Mid-Plane 


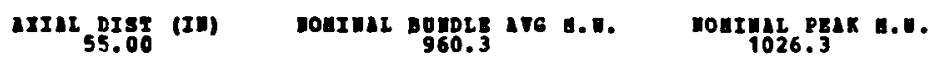

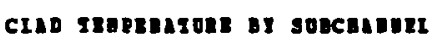

$$
\begin{aligned}
& \begin{array}{lllllllllll}
862 & 867 & 865 & 862 & 050 & 055 & 851 & 048 & 845 & 842 & 038
\end{array}
\end{aligned}
$$

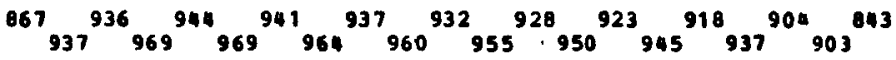

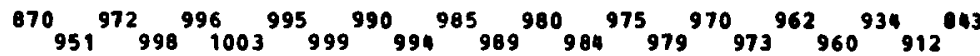

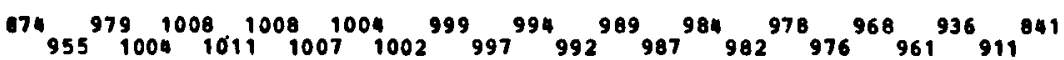

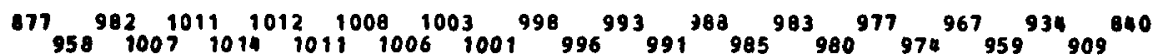

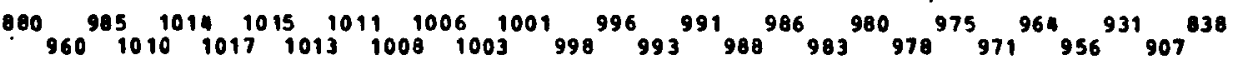

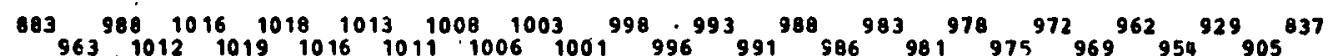

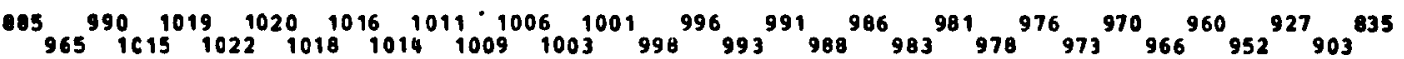

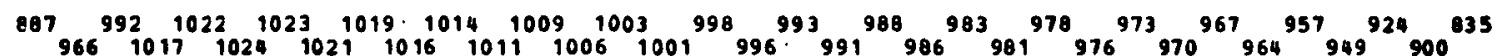

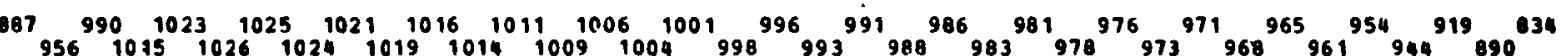

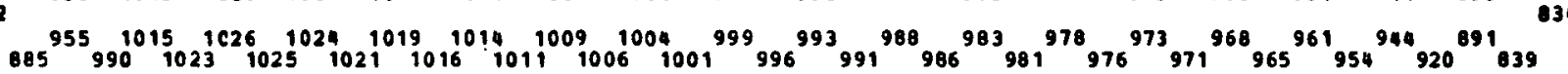

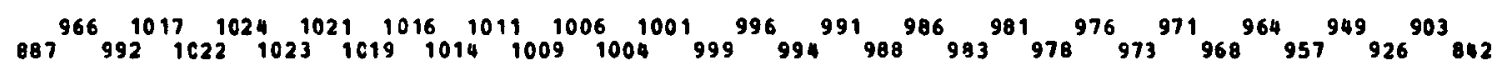

$888^{966} 991^{1015} 1019^{1022} 1021^{1019} 1016^{1014} 1011^{1009} 1006^{1004} 1001^{999} 996^{994} 991^{989} 986{ }^{983} 981^{978} 976^{973} 970^{967} 960^{952} 929^{906}{ }_{844}$ $688^{965} 989^{1013} 1011^{1020} 1018^{1016} 1014^{1011} 1_{009^{1006}} 9^{1004^{1001}} 999^{996} 994^{991} 989^{986} 984^{981} 978^{976} 973^{969} 963^{955} 931^{908} 845$

$888^{964}{ }_{987^{1011}} 1015^{1017^{1}} 1016^{1014} 101^{1009} 1001^{1004} 1001^{999} 996^{994} 991^{989} 986^{984} 981^{978} 975^{972} 965^{957} 933^{910} 847$

$680^{962} 985^{1008} 1012^{1015} 1013^{1011} 1009^{1006} 1004^{1001} 999^{996} 994^{991} 989^{986} 983^{981} 978^{974} 969^{960} 935^{912} 848$

$687^{960} 982^{1005}{ }_{1009}^{1012} 1009^{1008} 1005^{1003} 1000^{998} 9955_{990^{98}}^{984}{ }^{983} 979^{976} 969^{962} 937^{914} 849$ $886^{957} 976^{999} 997^{1004} 996^{1000} 991^{995} 987^{990} 982^{985} 977^{980} 972^{974} 964^{961} 936^{915} 851$

$883^{943} 941^{971} 948^{971} 946^{968} 942^{963} 938^{959} 934^{954} 930^{949} 925^{941} 911^{908} 852$

$\begin{array}{lllllllllll}877 & 877 & 875 & 874 & 972 & 869 & 867 & 864 & 859 & 852 & 853\end{array}$

Fig. 51. Nominal Clad Temperatures at Top of Core 


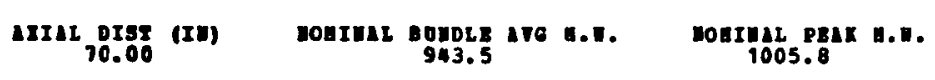

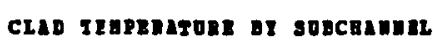

$$
\begin{aligned}
& \begin{array}{lllllllllll}
062 & 863 & 862 & 859 & 855 & 852 & 849 & 846 & 844 & 842 & 842
\end{array} \\
& { }_{903}^{064}{ }_{902}^{9021}{ }_{912}^{934}{ }^{911}{ }_{931}^{907}{ }_{927}^{903}{ }_{922^{899}}{ }_{918^{895}}{ }_{913^{809}}{ }_{903}{ }^{875}{ }_{975}{ }^{843}
\end{aligned}
$$

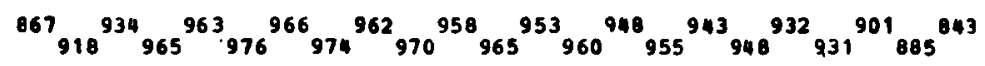

$$
\begin{aligned}
& { }_{923}^{943}{ }_{974}^{980}{ }_{989}^{987}{ }_{989}^{984} 989^{979}{ }_{979}^{975} 975{ }_{970}^{970}{ }_{965}^{964}{ }_{958}^{956}{ }_{944}^{935}{ }_{906}^{986}{ }_{842}^{842}
\end{aligned}
$$

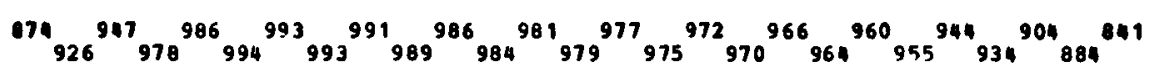

$$
\begin{aligned}
& 877{ }_{929}^{950}{ }_{981}^{988}{ }_{996}^{996}{ }_{996}^{994}{ }_{992}^{989}{ }_{987}^{985}{ }_{982}^{980}{ }_{971}^{975}{ }_{972}^{970}{ }_{968}^{965}{ }_{962}^{958}{ }_{953}^{942}{ }_{932}^{903}{ }_{982}^{840}
\end{aligned}
$$

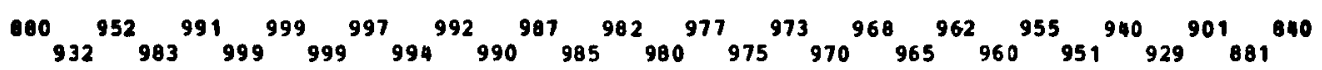

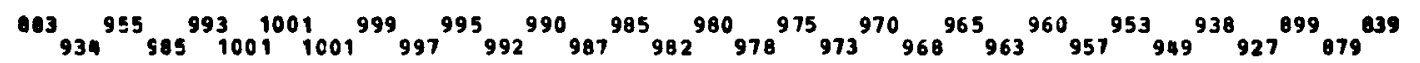

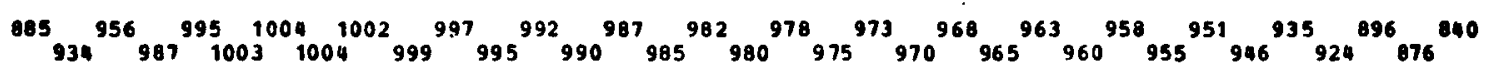

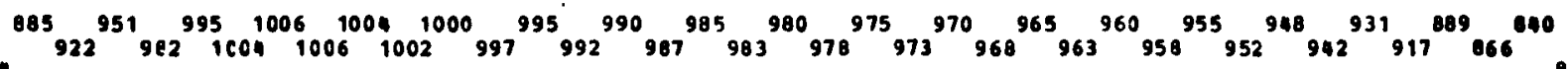

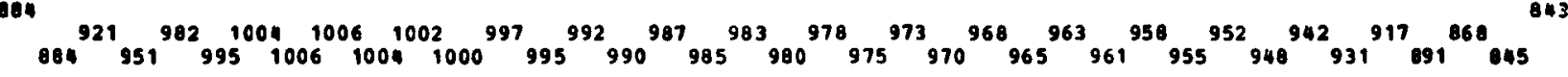

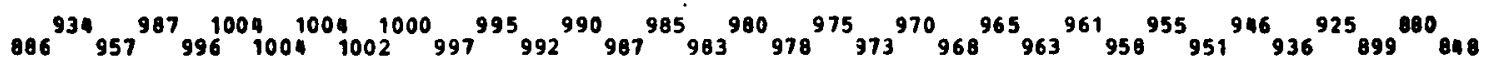

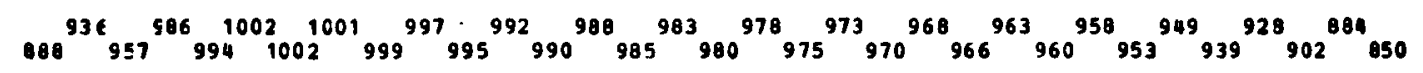

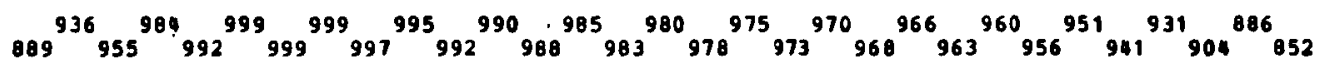

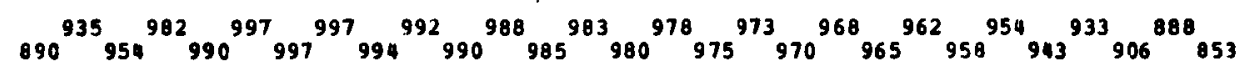

$$
\begin{aligned}
& 991^{934} 9522_{987}^{980}{ }_{994}^{994} 99499{ }^{990}{ }_{987}^{985} 982{ }^{980} 977^{975} 972{ }^{970} 9677_{960}^{956}{ }_{945}^{935}{ }_{908}^{890} 855
\end{aligned}
$$

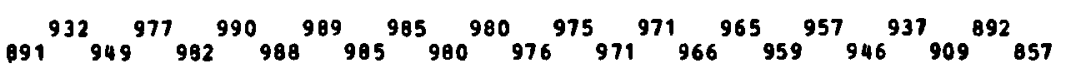

$$
\begin{aligned}
& { }_{890}^{928}{ }_{941}^{968}{ }_{966}^{978}{ }_{968}{ }^{976}{ }_{965}{ }^{971}{ }_{961}{ }^{967}{ }_{956}{ }^{962}{ }_{952}{ }^{957}{ }_{946}{ }^{950}{ }_{936}{ }^{933}{ }_{906}{ }^{892}{ }_{859} \\
& 880^{914} \cdot 9122_{921}^{937}{ }_{920}^{937}{ }_{917}^{934} 914^{930} 911{ }^{926}{ }_{907}^{921}{ }_{902}^{911^{987}}{ }_{804}^{861} \\
& \begin{array}{lllllllllll}
885 & 882 & 881 & 880 & 878 & 876 & 874 & 872 & 867 & 861 & 865
\end{array}
\end{aligned}
$$

Fig. 52. Nominal C1ad Temperatures at Outlet 


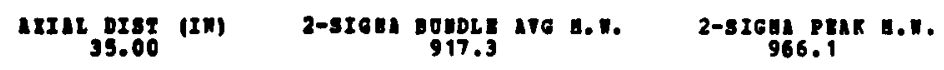

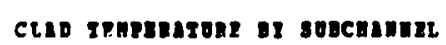

$$
\begin{aligned}
& \begin{array}{lllllllllll}
846 & 860 & 857 & 850 & 851 & 848 & 845 & 841 & 838 & 834 & 821
\end{array}
\end{aligned}
$$

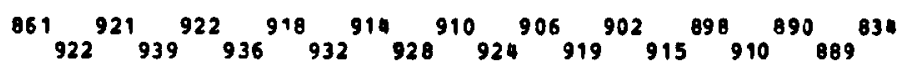

$$
\begin{aligned}
& 864{ }_{929}^{943} 951^{949} 949^{945} 945^{941} 949^{937} 936^{933}{ }_{932}^{929} 928^{924} 924^{920} 918^{907} 991^{833} \\
& { }_{966}^{86}{ }_{931}^{946}{ }_{954}^{953}{ }_{952}^{950}{ }_{948}^{946}{ }_{944^{941}}{ }_{939}^{937}{ }_{935}^{933}{ }_{931}^{929}{ }_{927}^{925}{ }_{922}^{920}{ }_{916}{ }^{905}{ }_{889}{ }^{832}
\end{aligned}
$$

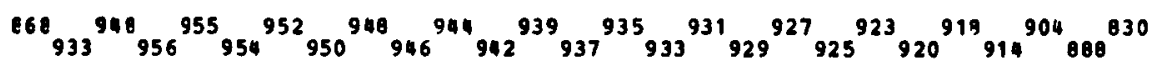

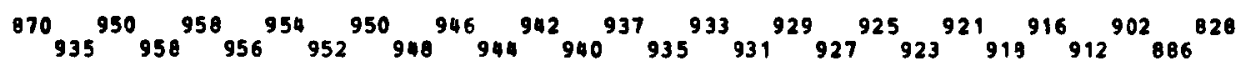

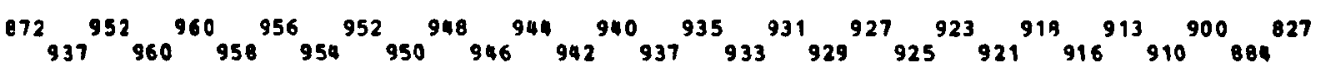

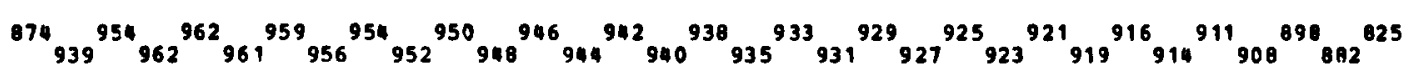

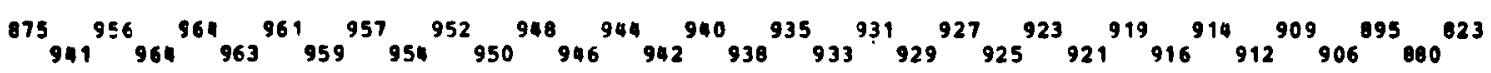

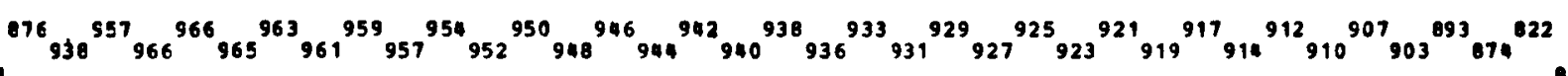

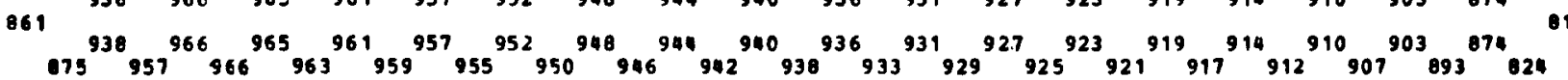

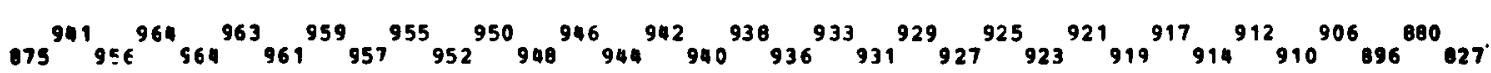

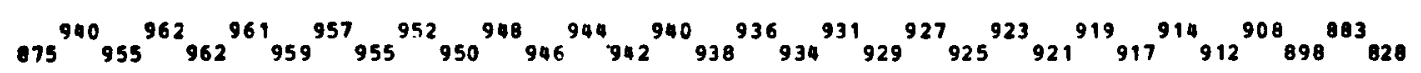

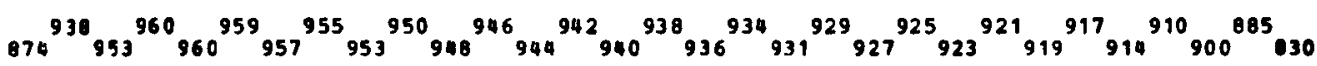

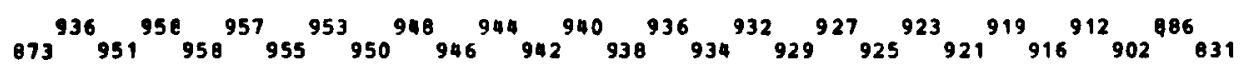

$$
\begin{aligned}
& 072^{934} 945^{956}{ }_{956}^{955}{ }_{953^{950}}^{9488^{946}} 944^{942} 9400_{936}^{938}{ }_{932}^{929} 927^{925} 923^{921} 919^{915}{ }_{904}{ }^{888}{ }_{933}
\end{aligned}
$$

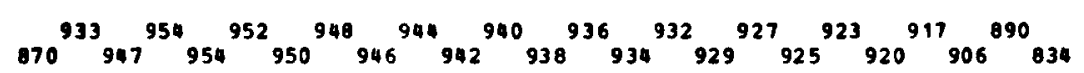

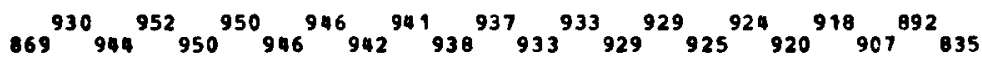

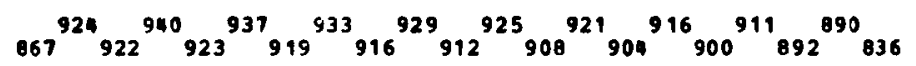

$$
\begin{aligned}
& \begin{array}{lllllllllll}
850 & 861 & 859 & 856 & 854 & 851 & 848 & 844 & 841 & 836 & 826
\end{array}
\end{aligned}
$$

Fig. 53. $2 \sigma \mathrm{Clad}$ Mid-Wall Temperatures at Mid-Plane 


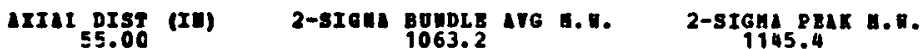

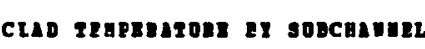

$$
\begin{aligned}
& \begin{array}{lllllllllll}
943 & 951 & 948 & 944 & 940 & 935 & 930 & 926 & 922 & 918 & 911
\end{array}
\end{aligned}
$$

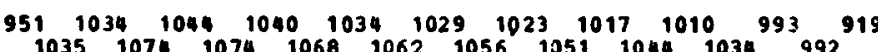

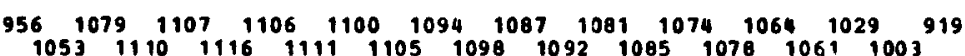

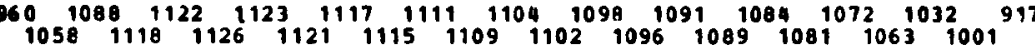$$
{ }^{964} 1061^{1091} 1121^{1127} 1130^{128} 1125^{1122} 1119^{1116} 1113^{1109} 1106^{1103} 100^{1997} 1093^{1090} 1087^{1083} 1079^{1070} 1060^{1029} 999^{915}
$$

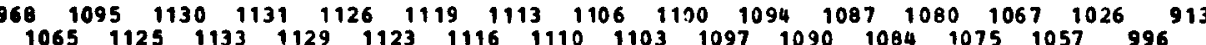

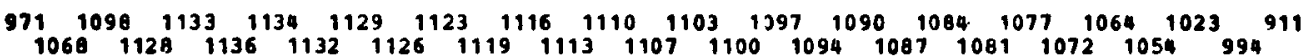

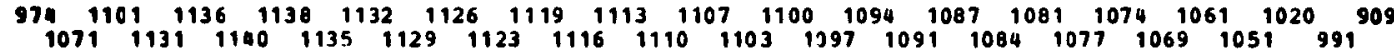

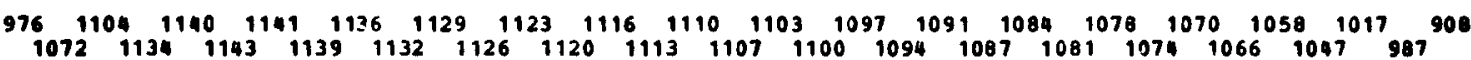

Fig. 54. 2 $\sigma \mathrm{Clad}$ Mid-Wall Temperatures at the Top of Core 


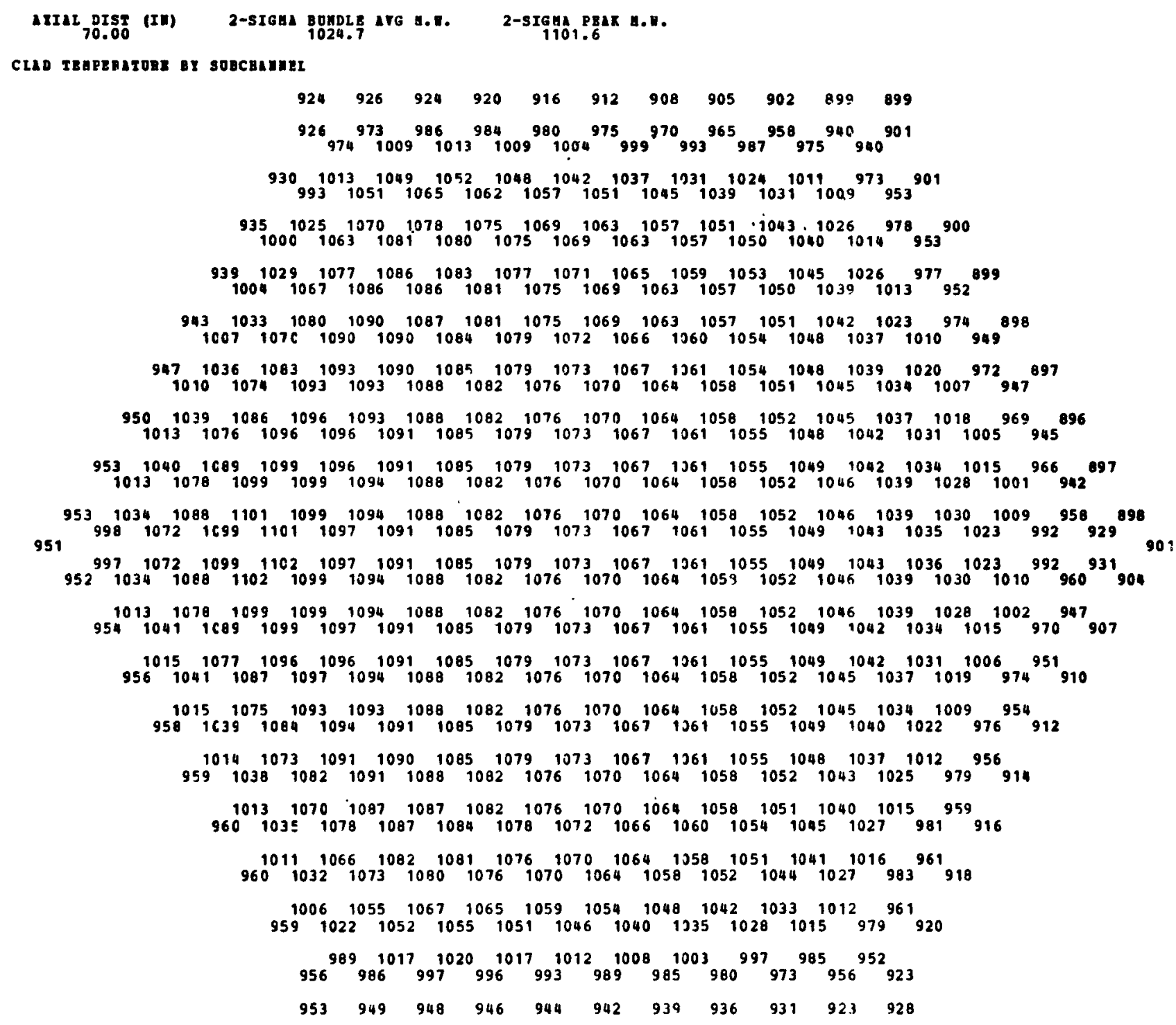

Fig. 55. 2o Clad Mid-Wall Temperatures at the Outlet 


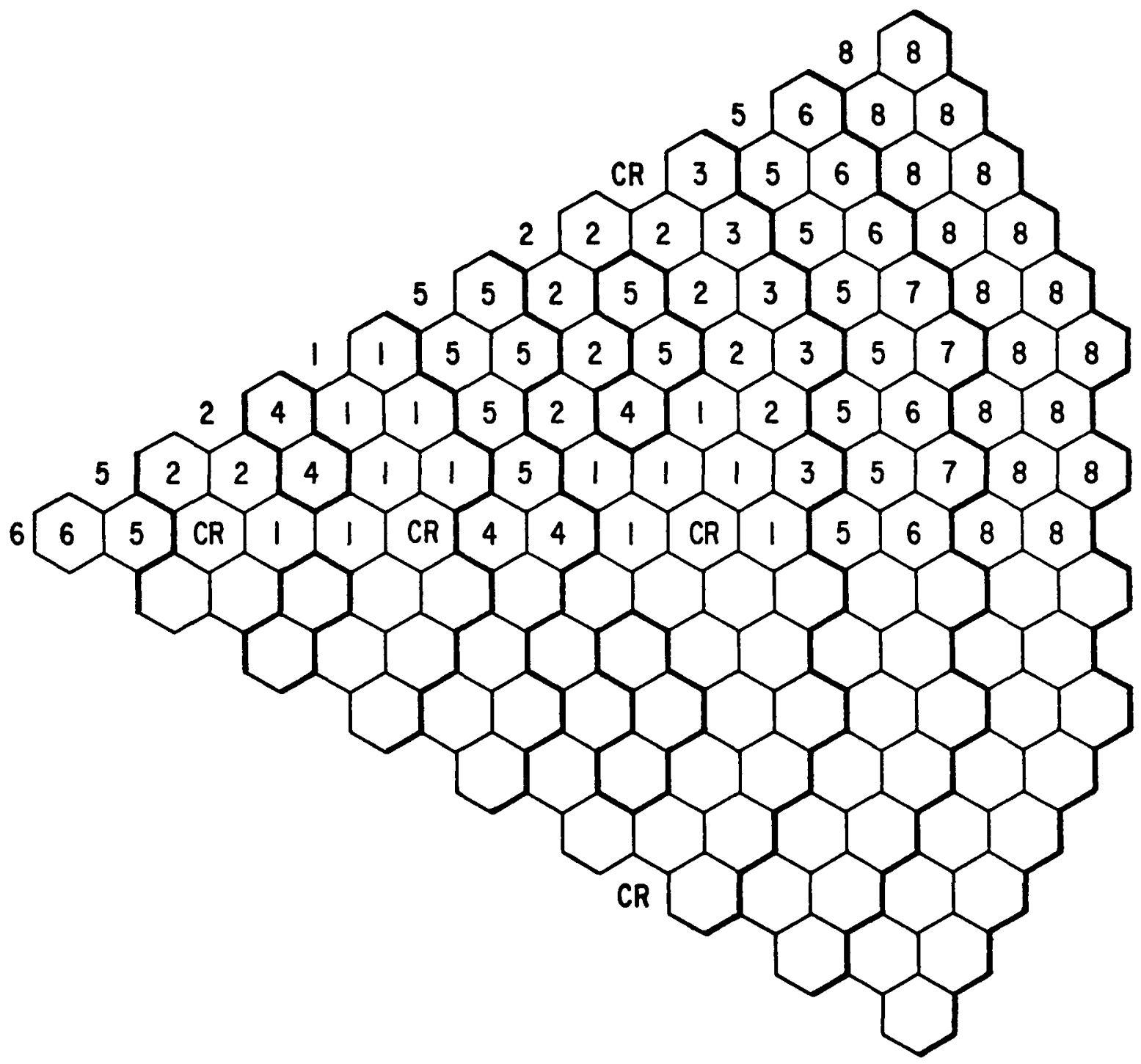

Fig. 56. Orificing Scheme of Configuration A with Equal Peak Clad Temperature at EOEC 


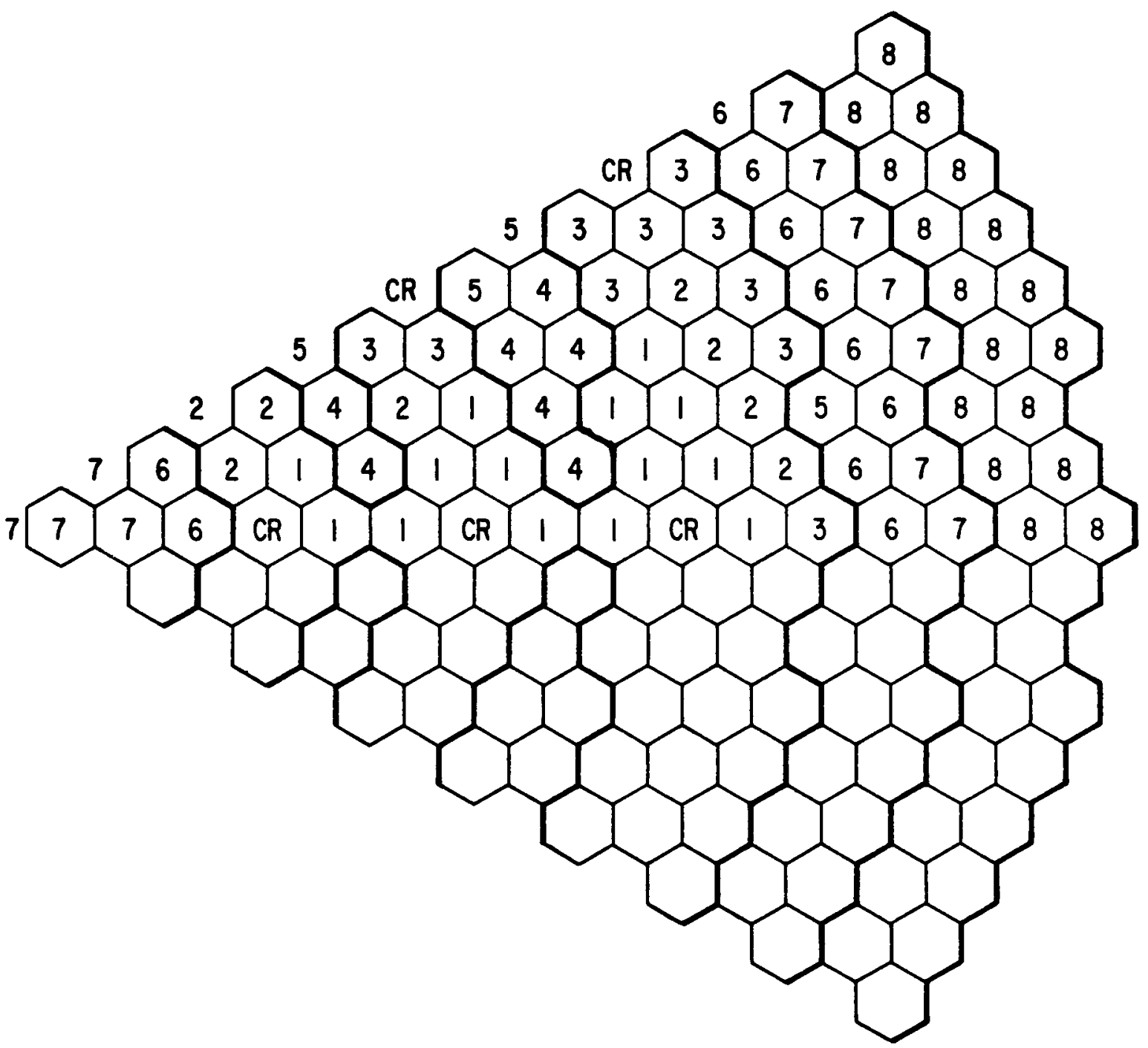

Fig. 57. Orificing Scheme of Configuration B with Equal

Peak Clad Temperatures at BOL in the Core and at $\mathrm{EOL}$ in the Internal Blankets 


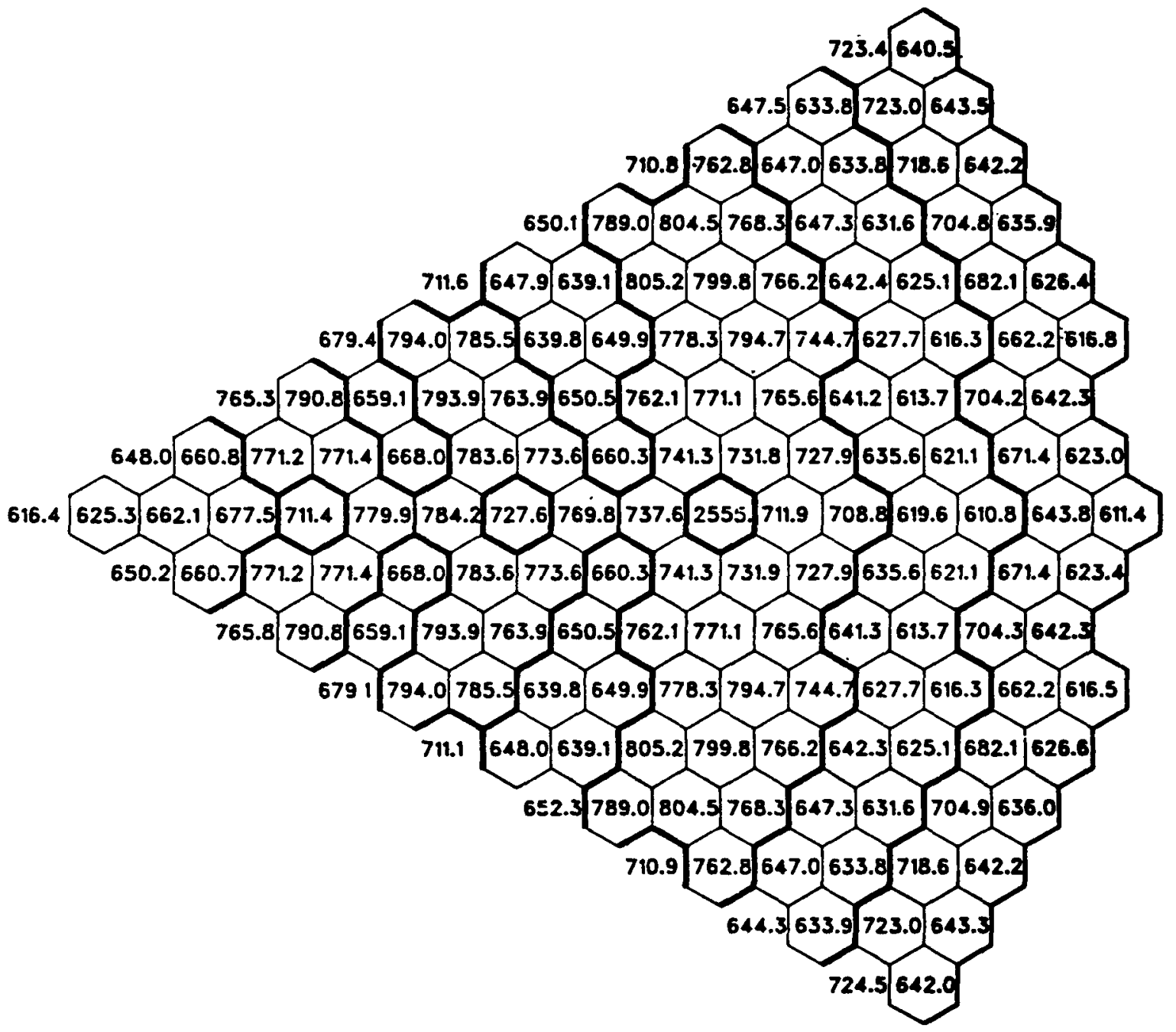

PIg. 58. Configuration B BOL Average Coolant

Temperature at Core Mid-Plane (Orificed

for Minimum Peak Temperature) 


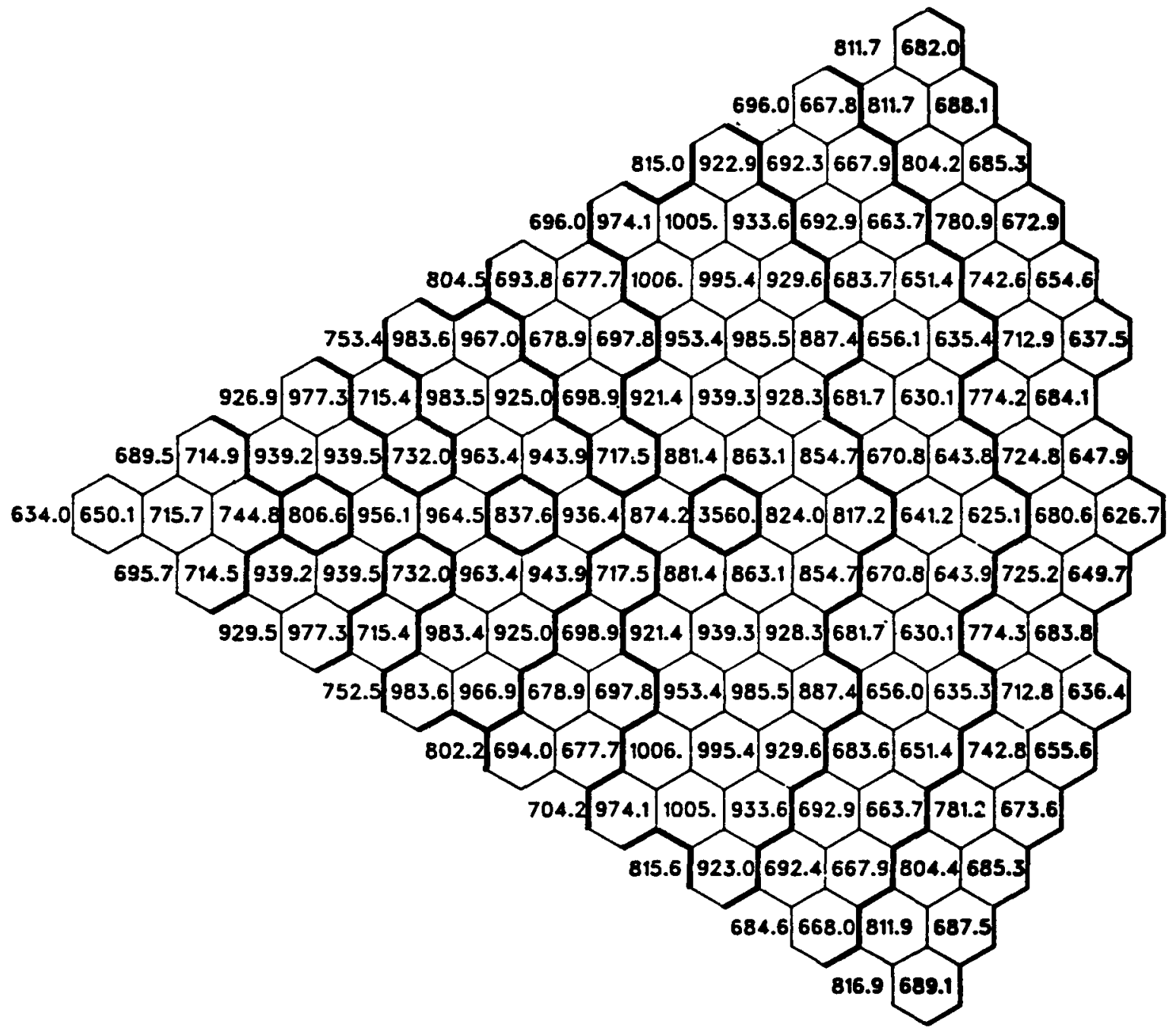

Fig. 59. Configuration B BOL Average Coolant Temperature at Top of Core (Orificed for Minimum Peak Temperature) 


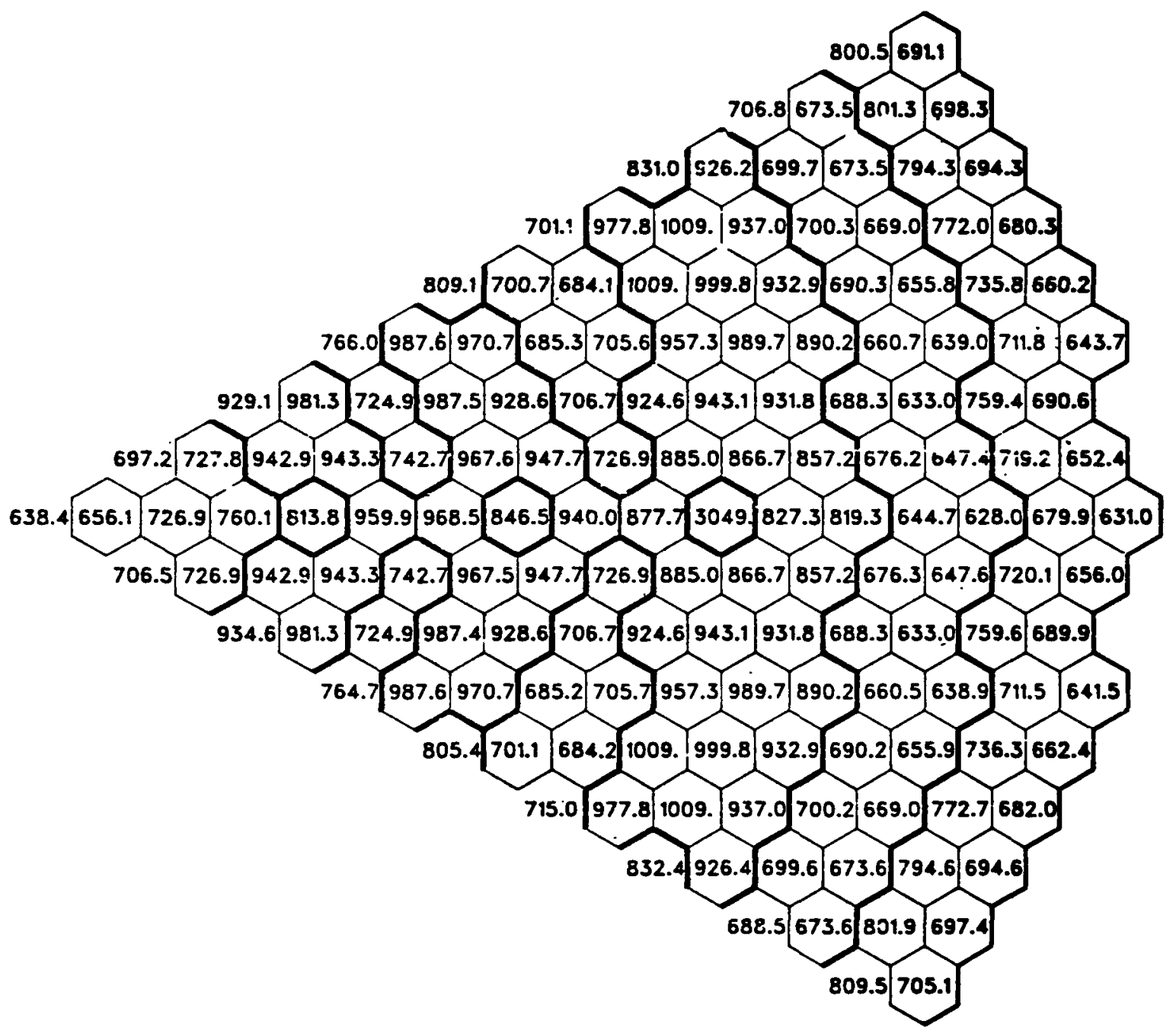

F1g. 60. Conflguration B BOL Average Coolant Temperature at outlet (Orificed for Minimum Peak Temperature) 


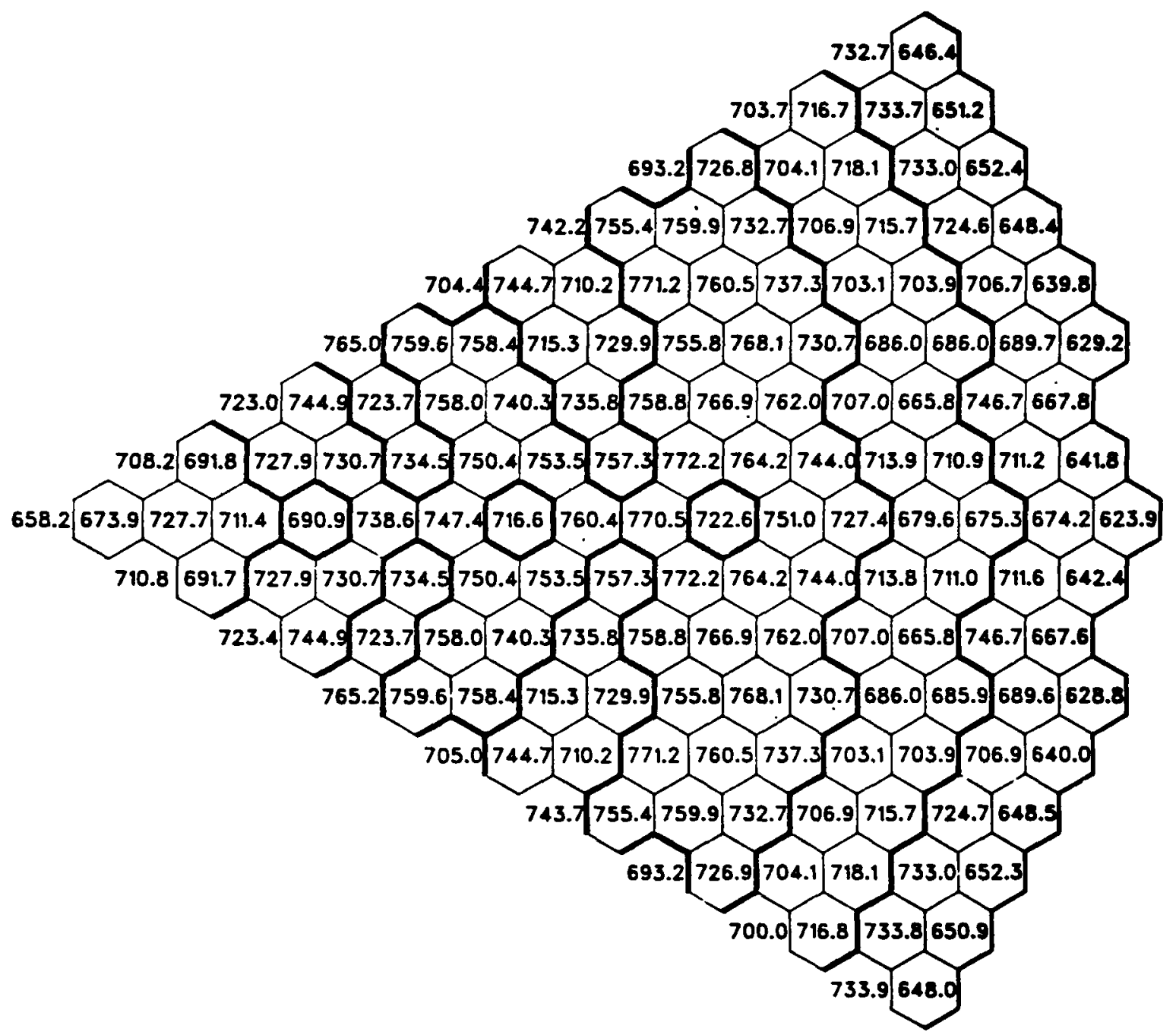

Fig. 61. Configuration B EOEC Average Coolant

Temperature at Core Mid-Plane (Orificed for Minimum Peak Temperature) 


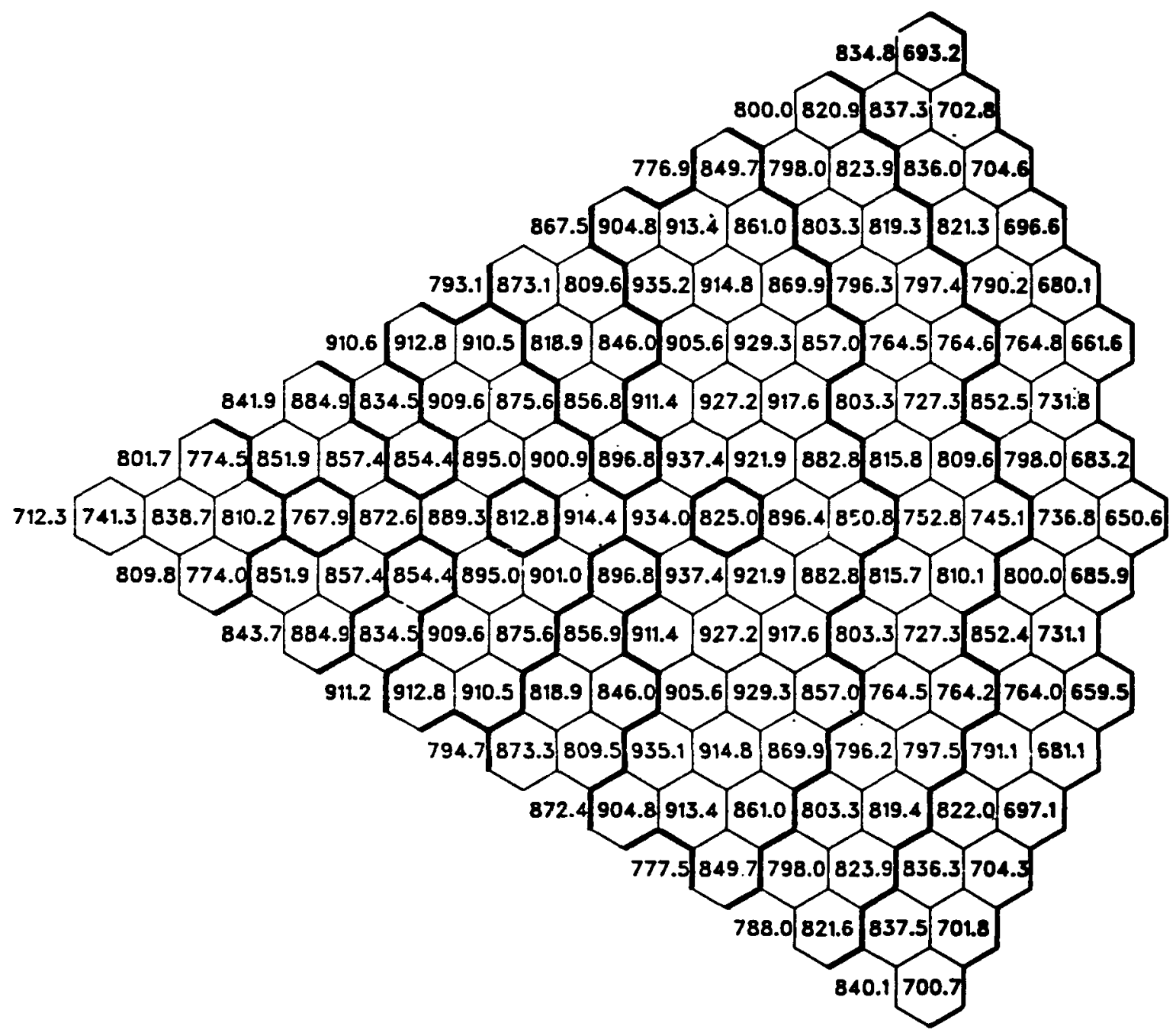

Fig. 62. Configuration B EOEC Average Coolant Temperature at Top of Core (Orificed for Minimum Peak Temperature) 


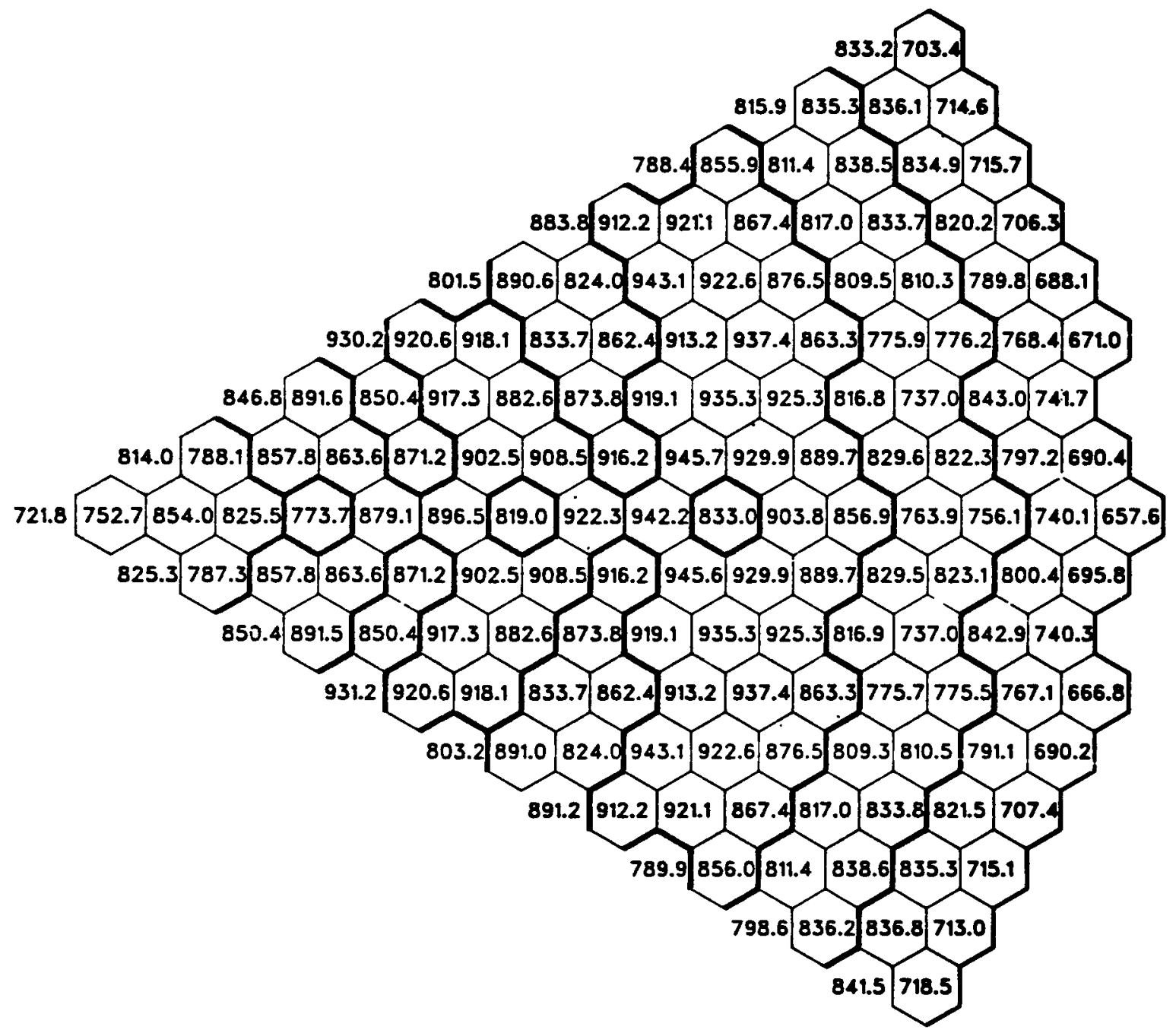

Fig. 63. Configuration B EOEC Average Coolant Temperature at Outlet (Orificed for Minimum Peak Temperature) 


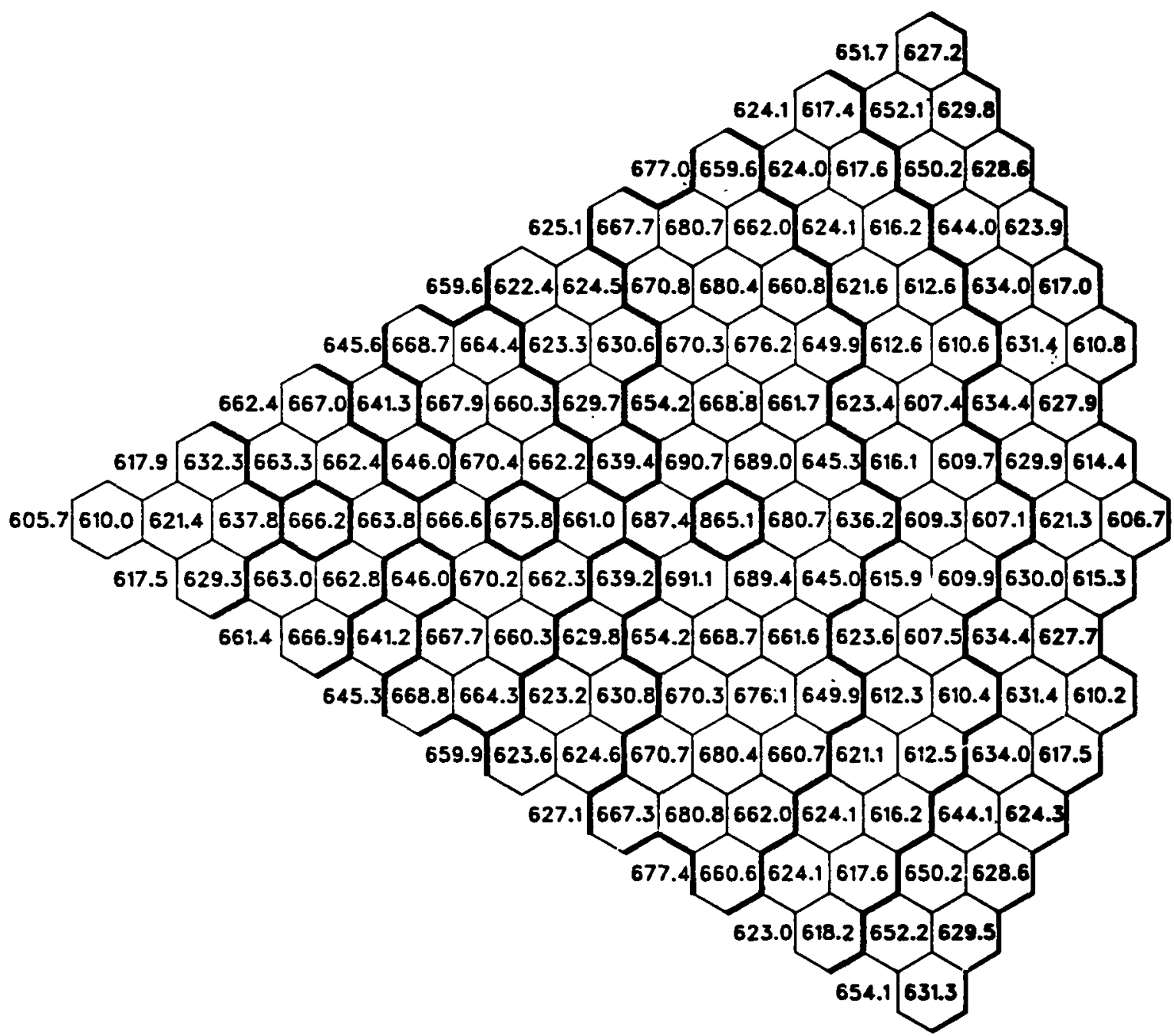

Fig. 64. Configuration B BOL Average Duct Wall

Temperature at Core Mid-Plane (Orificed

for Minimum Peak Temperature) 


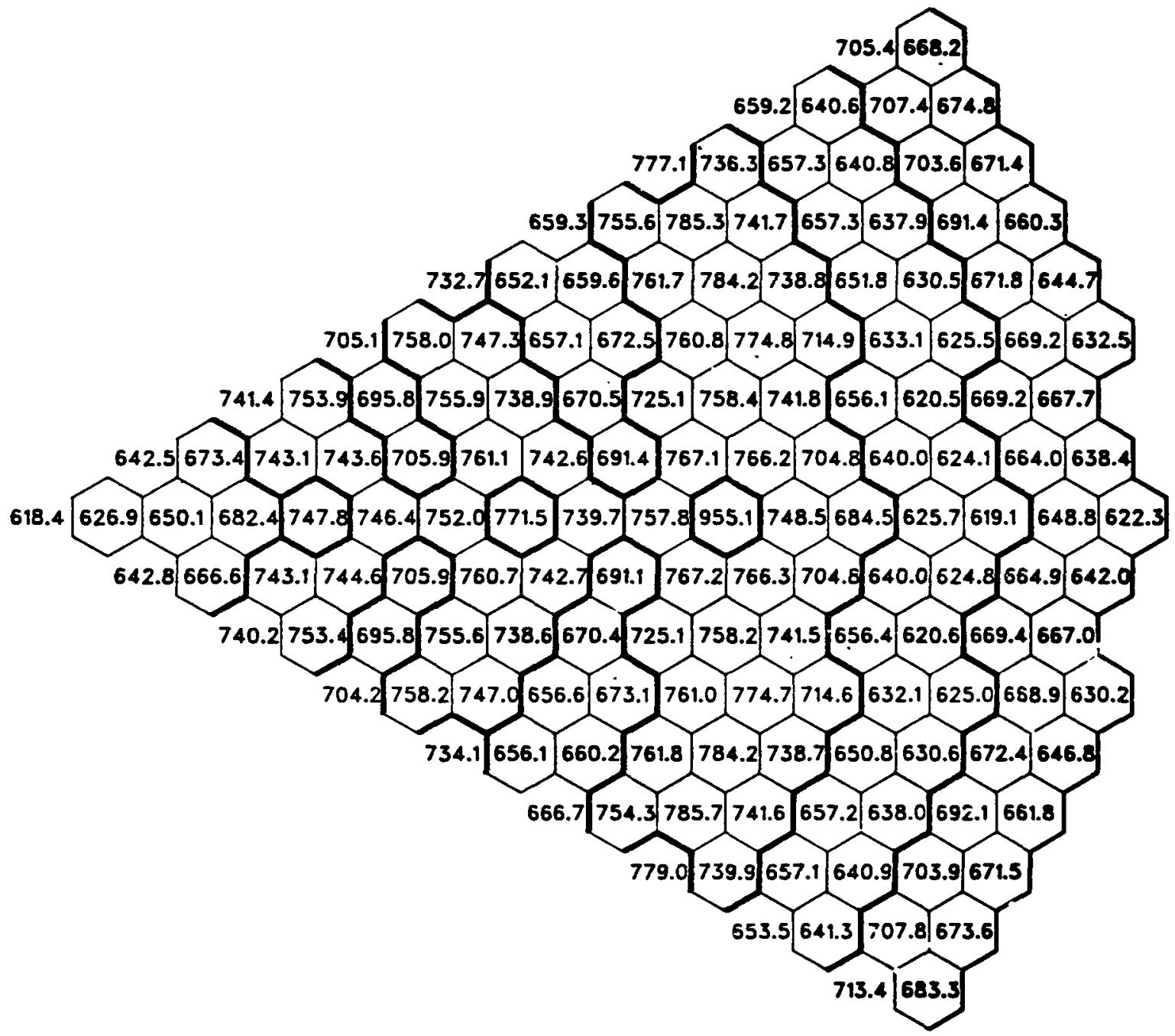

Fig. 65. Configuration B BOL Average Duct Wall Temperature at Top of Core (Orificed for Minimum Peak Temperature) 


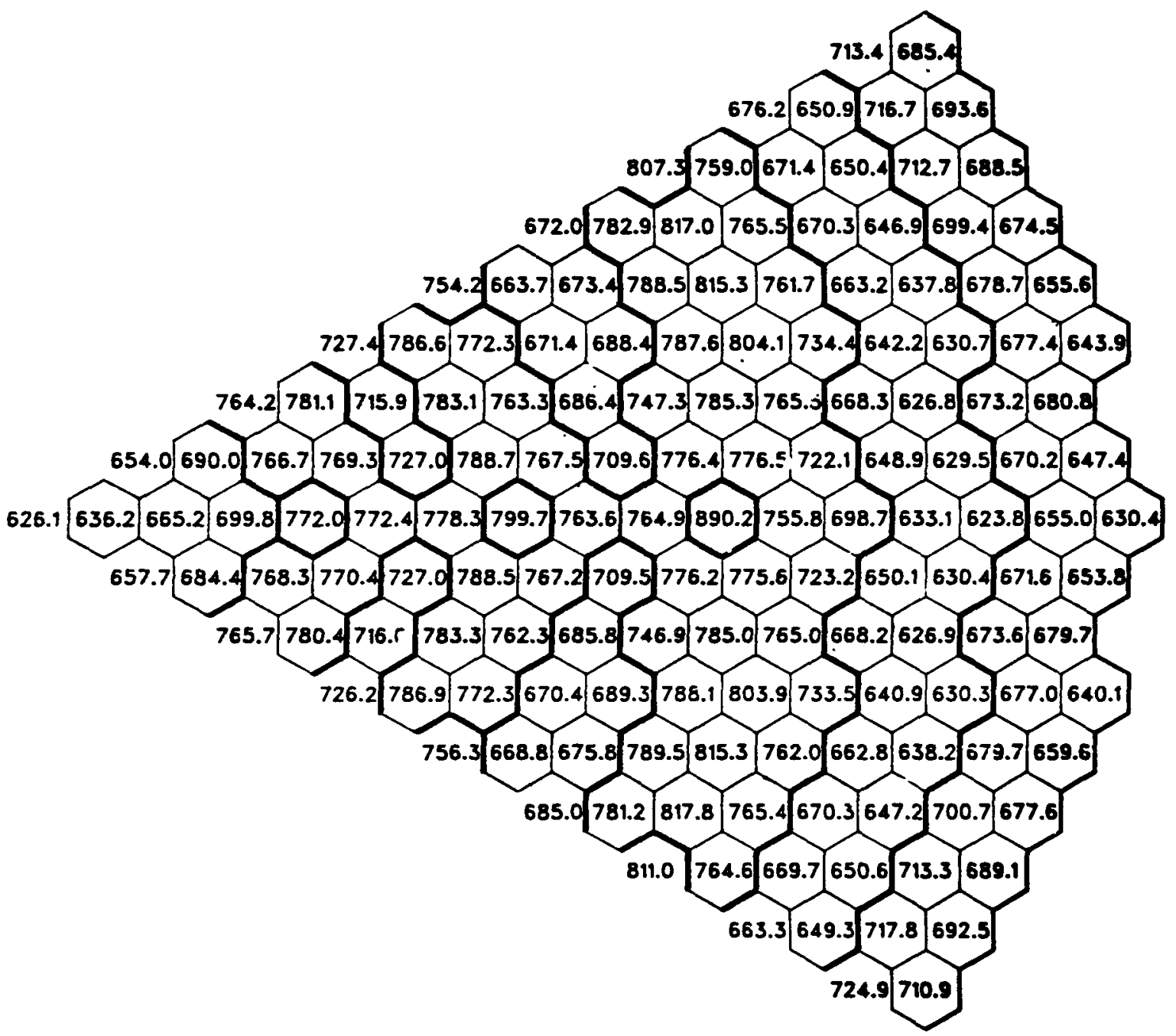

F \pm . 66. Configuration B BOL Average Duct Wall Temperature at Outlet (OrIficed for Minimum Peak Temperature) 


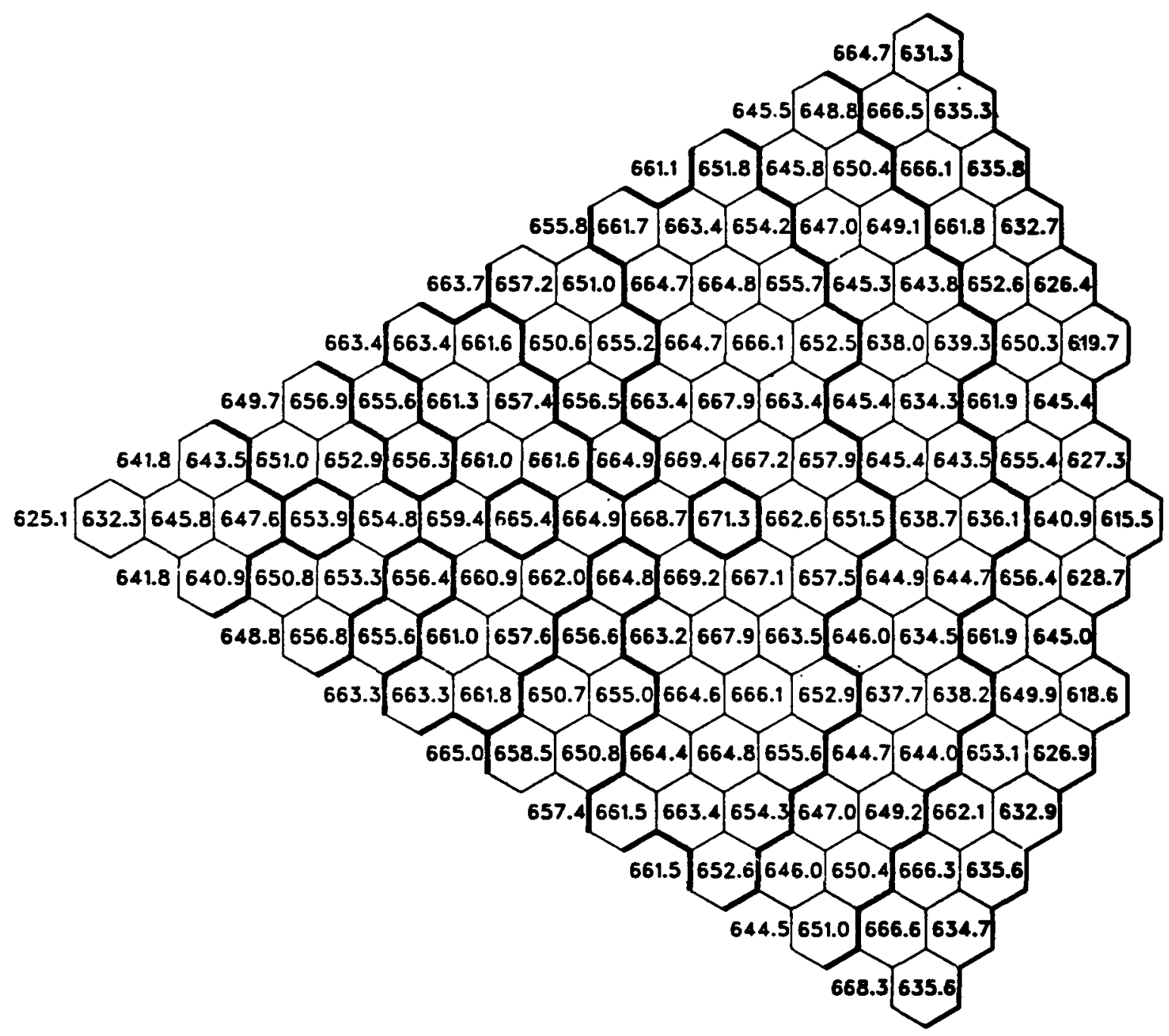

FIg. 67. Configuration B EOEC Average Duct Wall Temperature at Core Mid-Plane (Orificed for Minimum Peak Temperature) 


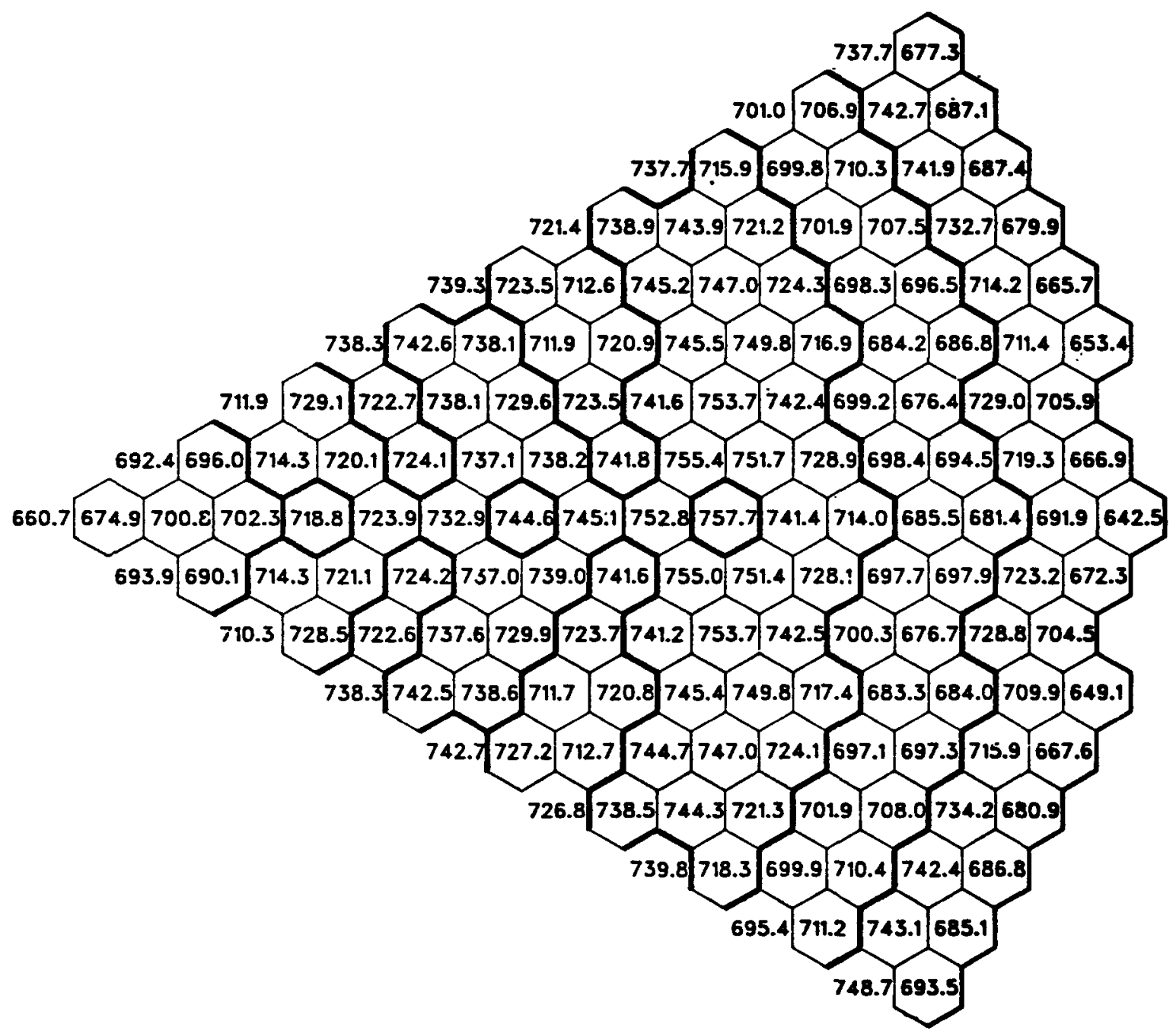

Fig. 68. Configuration B EOEC Average Duct Wall Temperature at Top of Core (Orificed for Minimum Peak Temperature) 


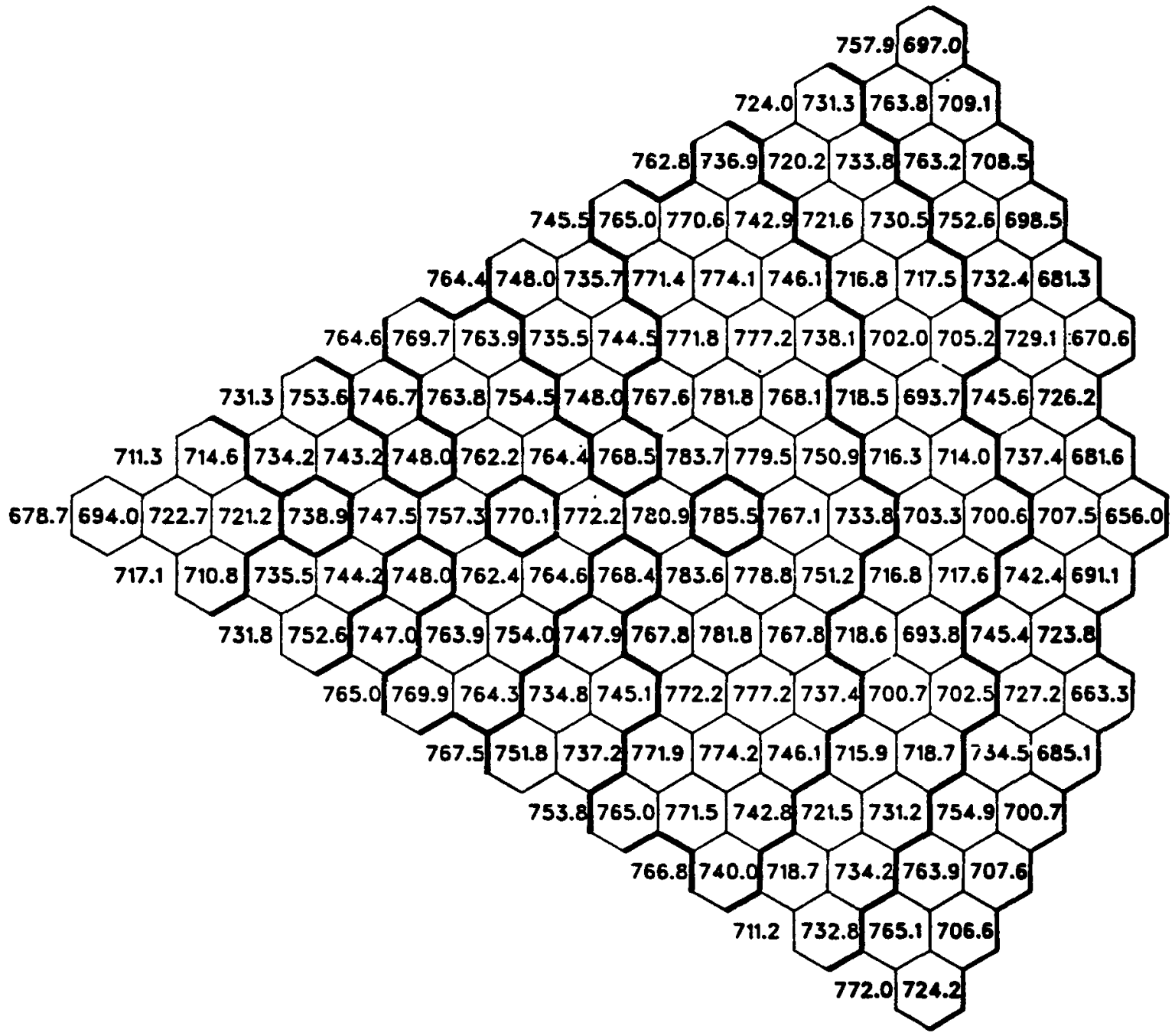

Fig. 69. Configuration B EOEC Average Duct Wall Temperature at Outlet (Orificed for Minimum Peak Temperature) 


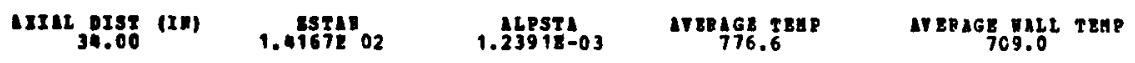

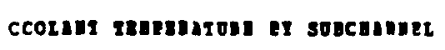

$$
\begin{aligned}
& \begin{array}{llllllllllll}
712 & 714 & 713 & 712 & 111 & 710 & 709 & 708 & 707 & 705 & 704 & 702
\end{array} \\
& { }^{713}{ }_{778}{ }^{778}{ }_{794}{ }^{780}{ }_{793}{ }^{718}{ }_{799}{ }^{777}{ }_{789} 9^{775}{ }_{789}{ }^{774}{ }_{786}{ }^{172}{ }_{784}{ }^{770}{ }_{783}{ }^{769}{ }_{780} 0^{764}{ }_{763}{ }^{704} \\
& { }^{715}{ }_{783}{ }^{795}{ }_{802}{ }^{804}{ }_{802}{ }_{800}{ }_{800}^{798}{ }_{798}{ }^{796}{ }_{796}{ }^{794}{ }_{795}{ }^{793}{ }_{793}{ }^{791}{ }_{791}{ }^{789}{ }_{789}{ }^{787}{ }_{786}{ }^{779}{ }_{766}{ }^{704}
\end{aligned}
$$$$
{ }_{786}^{716}{ }_{787}{ }_{803}{ }^{803}{ }_{803}^{802}{ }_{801}^{800}{ }_{799}{ }^{798}{ }_{797}{ }^{797}{ }_{796}{ }^{795}{ }_{794}{ }^{793}{ }_{792}{ }^{791}{ }_{790}{ }^{789}{ }_{788}{ }^{787}{ }_{785}{ }^{778}{ }_{765}{ }^{703}
$$

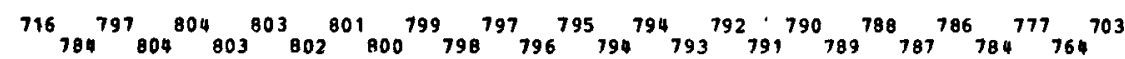$$
{ }^{717}{ }_{785}{ }^{798}{ }_{800}^{805}{ }_{804}{ }^{803}{ }_{802}{ }^{801}{ }_{800}^{800}{ }_{799}{ }^{798}{ }_{797}{ }^{796}{ }_{795}{ }^{794}{ }_{993}{ }^{793}{ }_{792}{ }^{791}{ }_{790}{ }^{789}{ }_{788}{ }^{787}{ }_{786}{ }^{785}{ }_{783}{ }^{776}{ }_{763}{ }^{702}
$$$$
{ }^{717}{ }_{785}{ }^{799}{ }_{805}{ }^{805}{ }_{805}^{804}{ }_{803}^{802}{ }_{801}^{800}{ }_{799}{ }^{798}{ }_{798}^{797}{ }_{796}{ }^{795}{ }_{194}{ }^{793}{ }_{792}{ }^{791}{ }_{790}{ }^{790}{ }_{789}{ }^{788}{ }_{787}{ }^{786}{ }_{785}{ }^{784}{ }_{782}{ }^{775}{ }_{762}{ }^{701}
$$$$
{ }^{719}{ }_{786}{ }^{799}{ }_{806}{ }^{806}{ }_{805}{ }^{805}{ }_{804}^{803}{ }_{802}{ }^{801}{ }_{800}{ }^{799}{ }_{798}{ }^{797}{ }_{796}{ }^{796}{ }_{795}{ }^{794}{ }_{793}{ }^{792}{ }_{791}{ }^{790}{ }_{789}{ }^{798}{ }_{787}{ }^{787}{ }_{786}{ }^{785}{ }_{784}{ }^{783}{ }_{781}{ }^{774}{ }_{761}{ }^{701}
$$

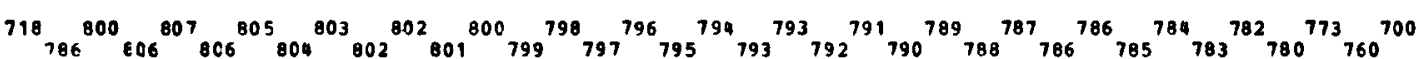

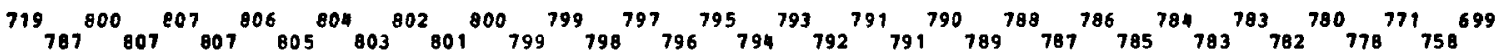

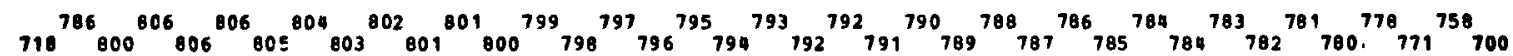

$710^{789}{ }_{199}^{805}{ }_{805}^{805}{ }_{804}^{803}{ }_{802}^{801}{ }_{800}{ }^{799}{ }_{798}{ }^{798}{ }_{797}{ }^{796}{ }_{795}{ }^{794}{ }_{793}{ }^{792}{ }_{791}{ }^{790}{ }_{789}{ }^{789}{ }_{789}{ }^{787}{ }_{786}{ }^{785}{ }_{784}{ }^{783}{ }_{782}{ }^{782}{ }_{780}{ }^{778}{ }_{711}{ }^{759}{ }_{701}$

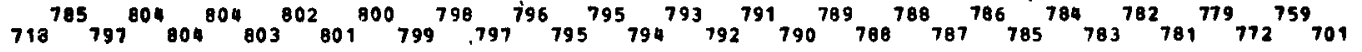
$711^{784}{ }_{796}^{803}{ }_{803}{ }^{802}{ }_{801}{ }^{801}{ }_{800}{ }^{799}{ }_{798}{ }^{797}{ }_{796}{ }^{795}{ }_{794}{ }^{794}{ }_{793}{ }^{792}{ }_{799}{ }^{790}{ }_{789}{ }^{788}{ }_{787}{ }^{786}{ }_{785}{ }^{785}{ }_{784}{ }^{783}{ }_{781}{ }^{780}{ }_{713}{ }^{760}{ }_{702}$ $717^{703}{ }_{795^{802}}{ }_{802}^{801}{ }_{800}{ }^{800}{ }_{199}{ }^{798}{ }_{797}{ }^{796}{ }_{795}{ }^{794}{ }_{793}{ }^{792}{ }_{791}{ }^{791}{ }_{790}{ }^{789}{ }_{788}{ }^{787}{ }_{786}{ }^{785}{ }_{784}{ }^{783}{ }_{782}{ }^{780}{ }_{713}{ }^{760}{ }_{702}$

Fig. 70. Coolant Temperature at Midplane 


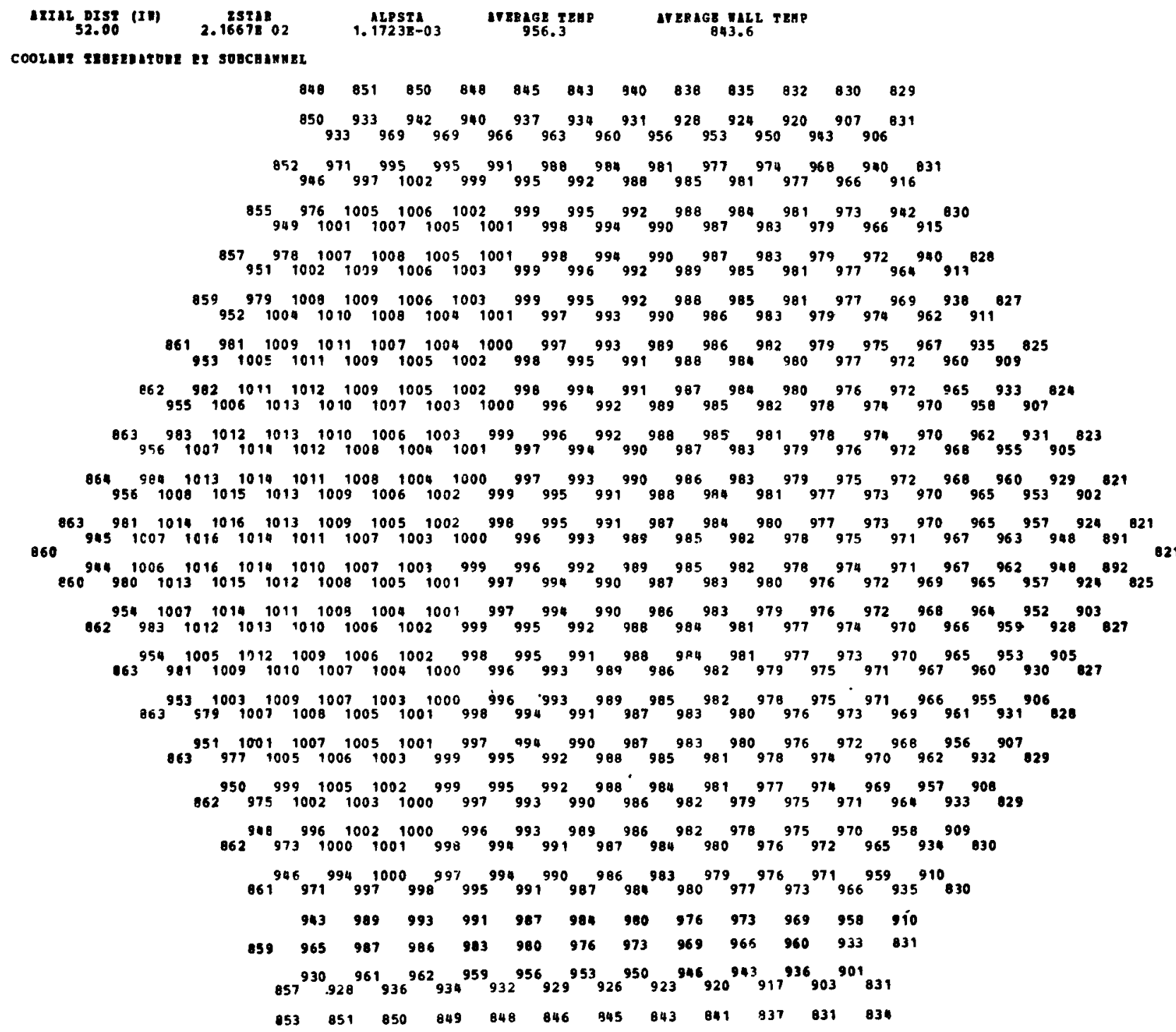

Fig. 71. Coolant Temperatures at Top of Core 


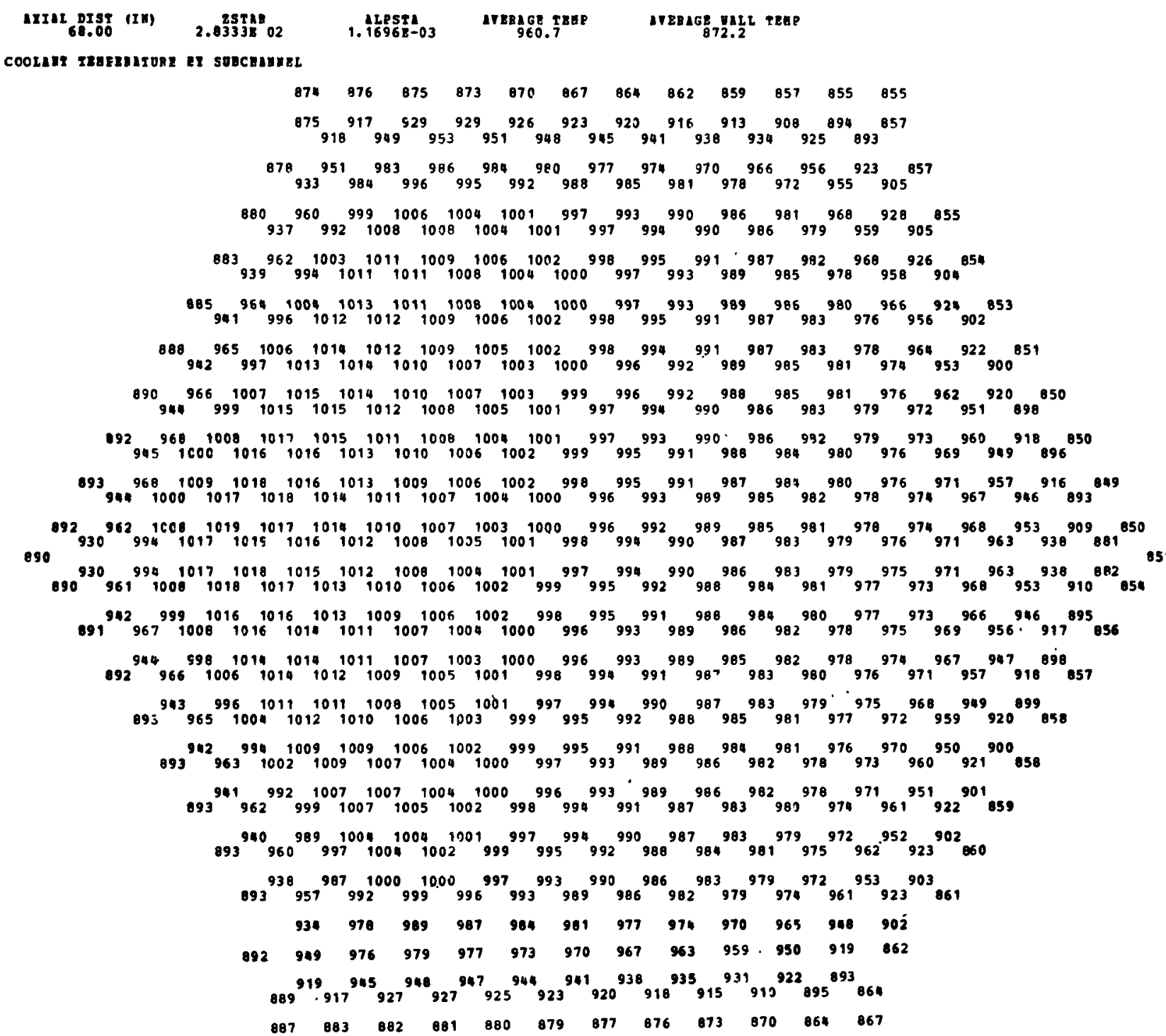

Fig. 72. Coolant Temperatures at Outlet 


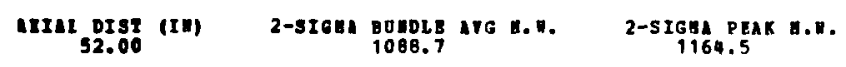

Cho tenplatope ay sobchun

$\begin{array}{llllllllllll}957 & 966 & 965 & 961 & 958 & 954 & 951 & 947 & 943 & 940 & 936 & 929\end{array}$

$965 \quad 1062 \quad 1073 \quad 1070 \quad 1066 \quad 1062 \quad 1057 \quad 1053 \quad 1049 \quad 1043 \quad 1026 \quad 938$

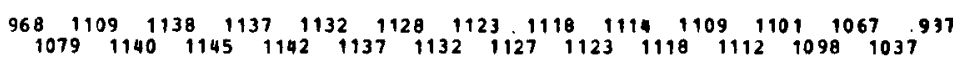

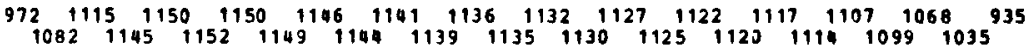

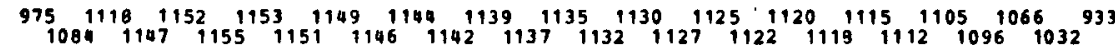

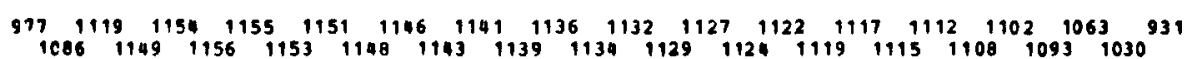

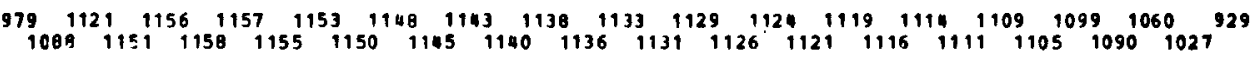

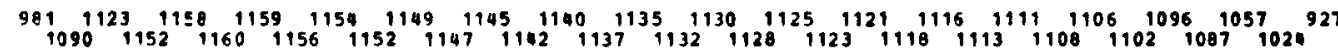

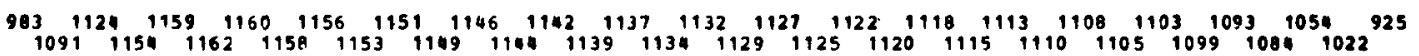

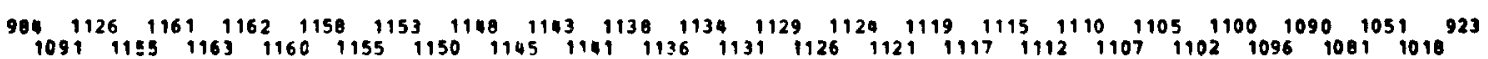

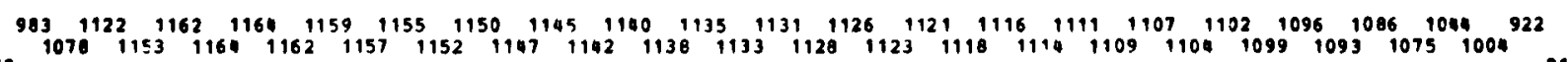

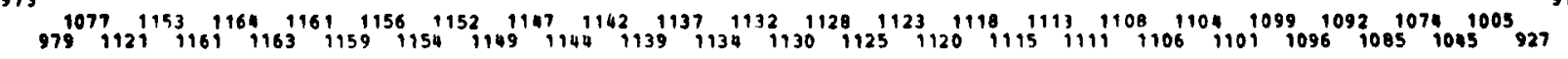

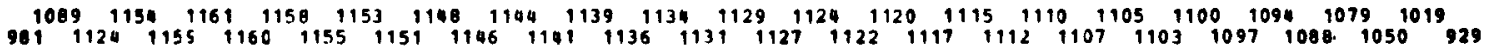

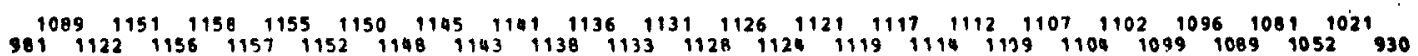

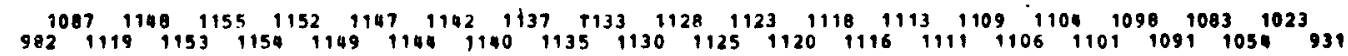

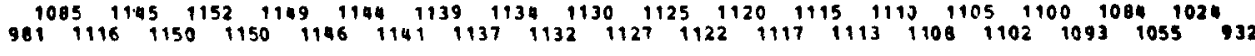

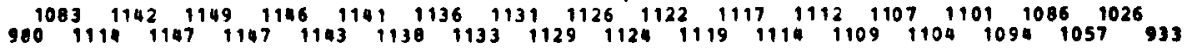

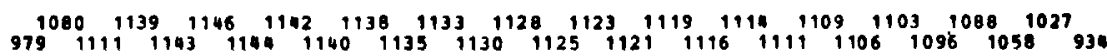

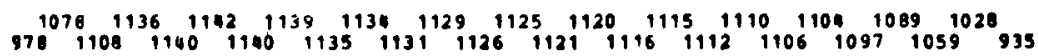

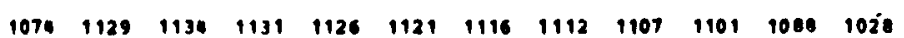

$\begin{array}{lllllllllllllll}976 & 1100 & 1127 & 1126 & 1121 & 1117 & 1112 & 1107 & 1103 & 1099 & 1090 & 1057 & 935\end{array}$

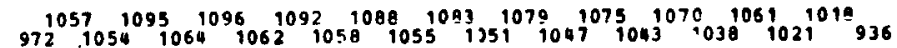

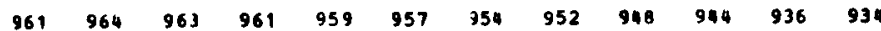

Fig. 73. Nominal Clad Temperatures at Mid-Plane 


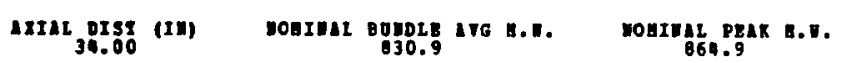

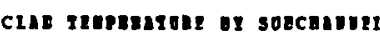

$$
\begin{aligned}
& \begin{array}{llllllllllll}
767 & 775 & 774 & 772 & 771 & 769 & 768 & 766 & 764 & 763 & 761 & 753
\end{array}
\end{aligned}
$$

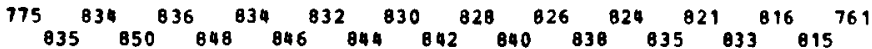

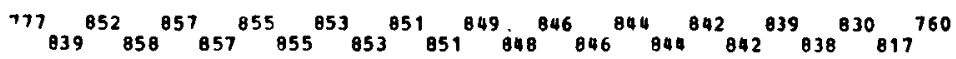

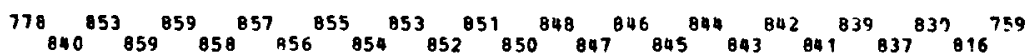

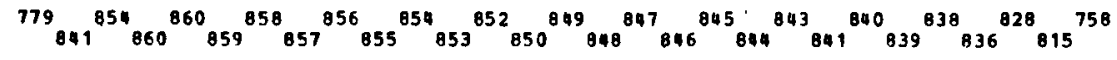

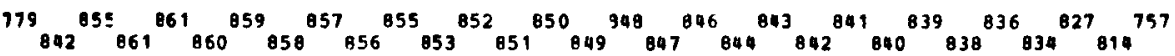

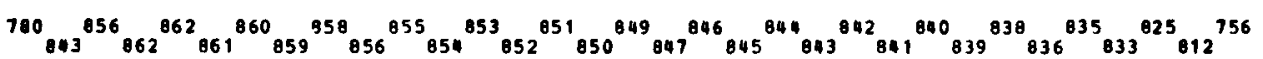

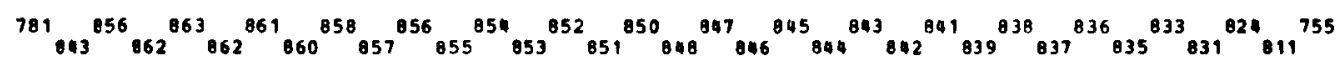

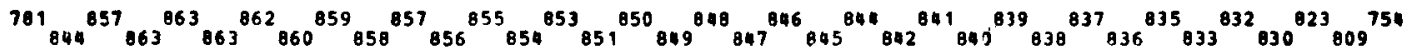

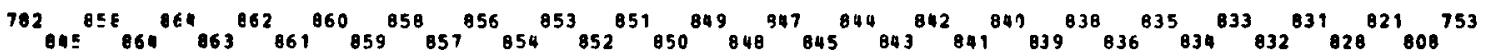

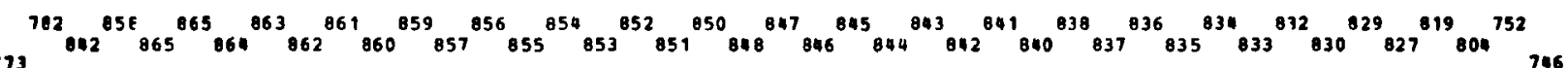

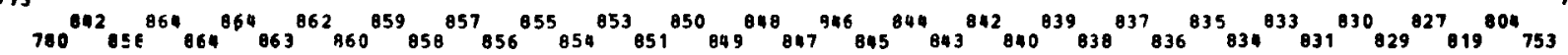

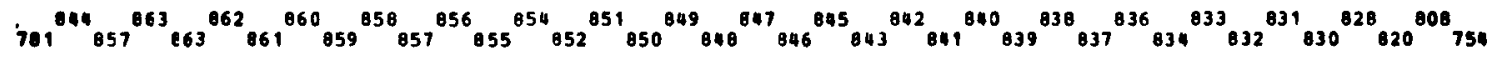

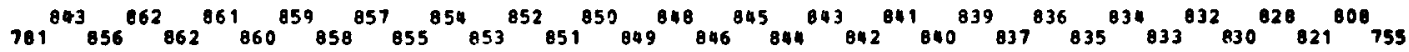

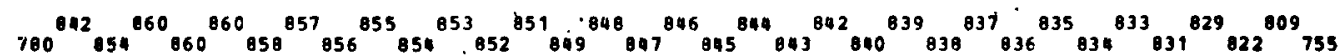

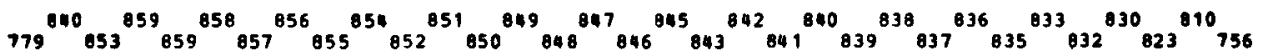

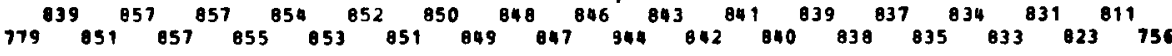

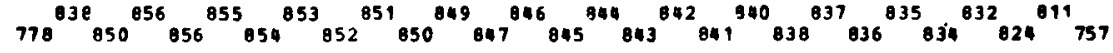

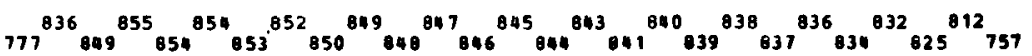

$$
\begin{aligned}
& \begin{array}{llllllllllll}
035 & 053 & 052 & 850 & 047 & 045 & 043 & 041 & 039 & 036 & 033 & 813
\end{array} \\
& \begin{array}{lllllllllllll}
176 & 047 & 052 & 050 & 047 & 045 & 043 & 841 & 039 & 036 & 034 & 825 & 757
\end{array} \\
& 774^{030}{ }_{029^{844}}^{831^{843}} 829^{801} 827^{839}{ }_{825^{836}}^{823^{834}} 821^{832} 819^{830}{ }_{817^{827}}^{811^{810}} 757 \\
& \begin{array}{llllllllllll}
766 & 711 & 770 & 769 & 768 & 766 & 765 & 763 & 762 & 760 & 757 & 752
\end{array}
\end{aligned}
$$

Fig. 74. Nominal Clad Temperatures at Top of Core 


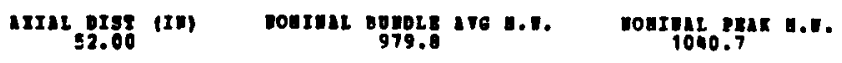

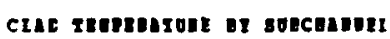

$$
\begin{array}{llllllllllll}
872 & 878 & 877 & 874 & 872 & 869 & 866 & 863 & 860 & 857 & 855 & 851 \\
877 & 958 & 956 & 964 & 961 & 956 & 954 & 951 & 946 & 943 & 930 & 956 \\
958 & 993 & 994 & 990^{961} & 987 & 983 & 980 & 976 & 972 & 966 & 929 & 90
\end{array}
$$

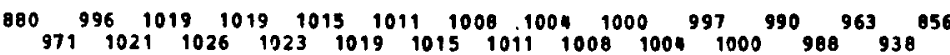

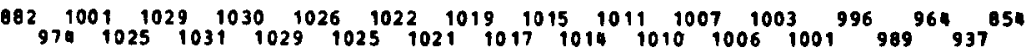

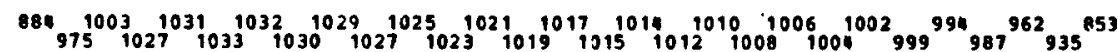

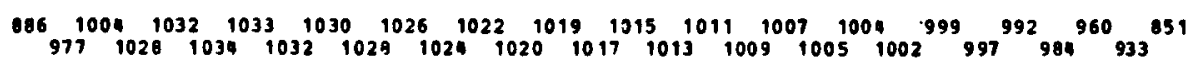

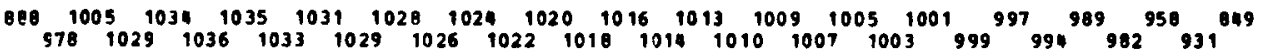

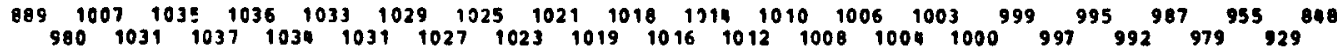

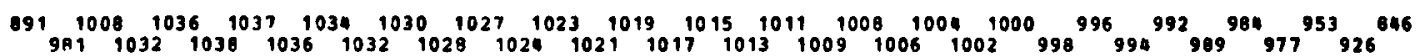

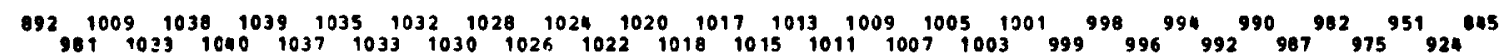

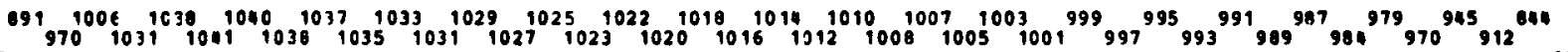

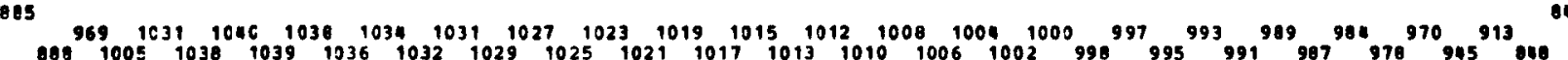

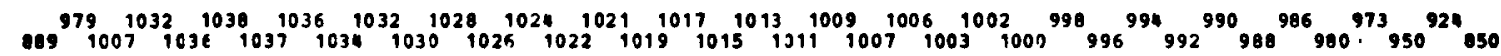

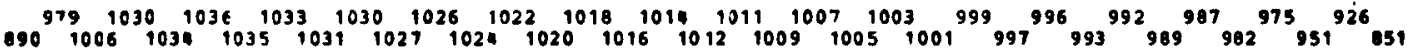

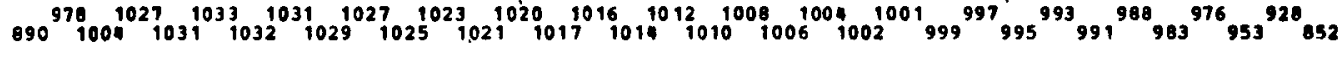

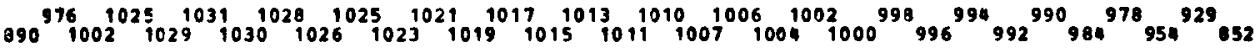

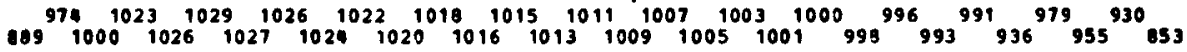

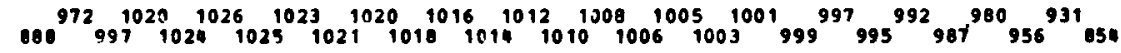

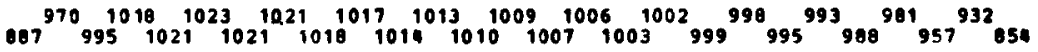

$\begin{array}{llllllllllll}967 & 1013 & 1017 & 1014 & 1090 & 1007 & 1303 & 999 & 993 & 991 & 940 & 932\end{array}$

$\begin{array}{llllllllllllll}006 & 989 & 1011 & 1010 & 1006 & 1003 & 999 & 995 & 992 & 989 & 902 & 955 & 055\end{array}$

$883^{954} .952^{905} 9600_{958}^{985} 955^{979} 9522_{949^{972}}^{9446}{ }_{943}^{962} 96599_{959}^{959}{ }_{926}^{923} 856$

$\begin{array}{llllllllllll}976 & 877 & 076 & 875 & 873 & 872 & 870 & 868 & 865 & 862 & 856 & 855\end{array}$

Fig. 75. Nominal Clad Temperatures at outlet 


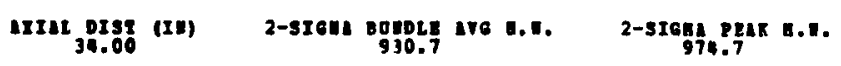

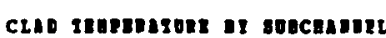

$$
\begin{aligned}
& \begin{array}{llllllllllll}
053 & 868 & 866 & 864 & 862 & 860 & 857 & 855 & 852 & 849 & 847 & 832
\end{array}
\end{aligned}
$$

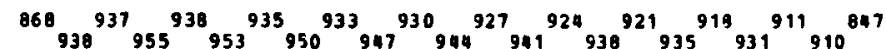

$$
\begin{aligned}
& { }_{943}^{870}{ }_{958}^{965}{ }_{964}^{964}{ }^{96}{ }_{961}{ }^{958}{ }_{958}{ }^{955}{ }_{955}{ }^{952}{ }_{952}{ }^{949}{ }_{949} 9_{946}^{945}{ }_{943}^{943}{ }_{949}^{939}{ }_{939}^{928}{ }_{912}^{846}
\end{aligned}
$$

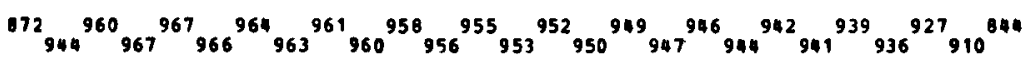

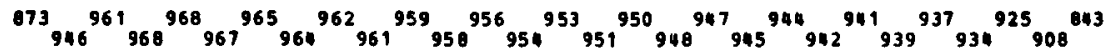

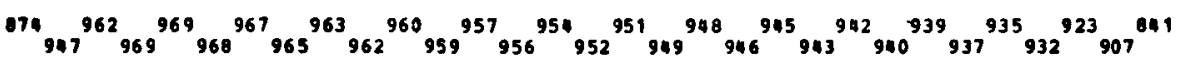

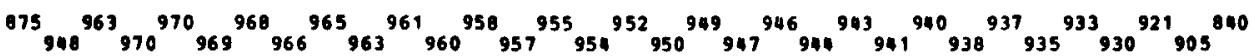

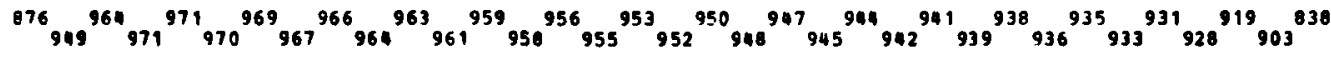

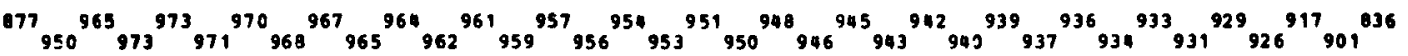

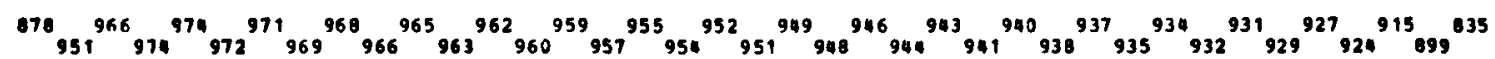

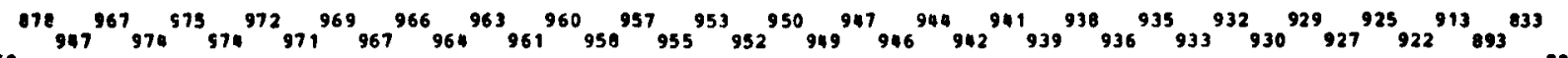

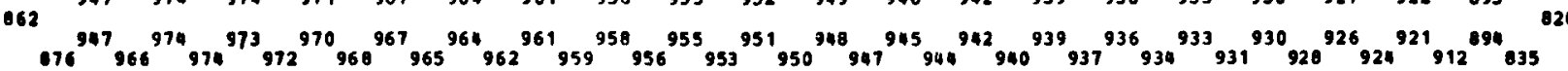

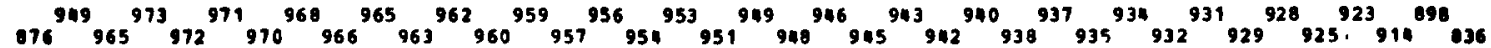

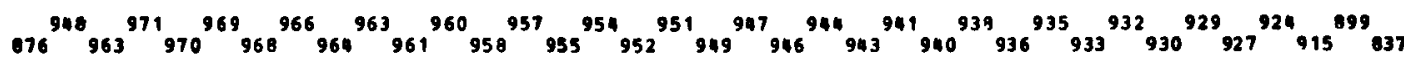

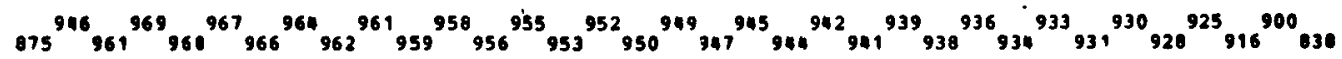

$$
\begin{aligned}
& 874^{944}{ }_{959}^{966}{ }_{966}^{965}{ }_{964}^{962}{ }_{960}^{959}{ }_{957}^{956}{ }_{954}^{953}{ }_{951}^{930}{ }_{948}^{9477}{ }_{945}^{943}{ }_{942}^{940}{ }_{939}^{937}{ }_{936}^{934}{ }_{932}^{931}{ }_{929}^{926}{ }_{917}^{90}{ }_{930}
\end{aligned}
$$

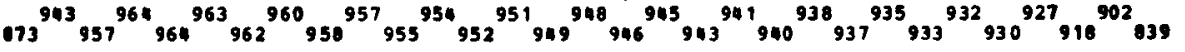

$$
\begin{aligned}
& 871^{911}{ }_{955}^{962}{ }_{962}^{961}{ }_{960}^{958}{ }_{956}^{955}{ }_{953}^{952}{ }_{950}^{949}{ }_{947}^{946}{ }_{944}^{993}{ }_{941}^{939}{ }_{938}^{936}{ }_{935}^{933}{ }_{931}^{929}{ }_{919}^{903}{ }_{910}
\end{aligned}
$$

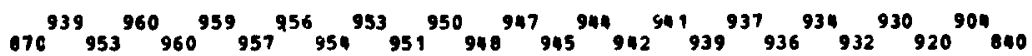

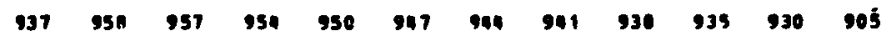

$$
\begin{aligned}
& \begin{array}{lllllllllllll}
061 & 951 & 956 & 954 & 951 & 940 & 964 & 941 & 938 & 935 & 932 & 921 & 011
\end{array} \\
& 866^{931}{ }_{929}^{947}{ }_{931}^{945}{ }_{928}^{942} 925^{939}{ }_{922}^{936}{ }_{919}^{933} 919^{930}{ }_{914^{927}}^{911}{ }_{923}^{904}{ }_{903}^{901} \\
& \begin{array}{llllllllllll}
050 & 862 & 860 & 858 & 856 & 854 & 852 & 850 & 847 & 845 & 841 & 829
\end{array}
\end{aligned}
$$

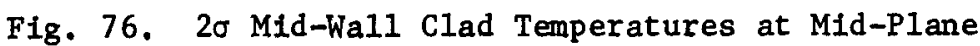




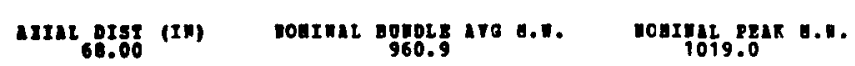

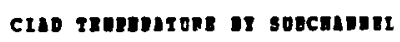

$$
\begin{aligned}
& \begin{array}{llllllllllll}
875 & 876 & 875 & 873 & 870 & 867 & 865 & 862 & 860 & 857 & 855 & 855
\end{array} \\
& { }_{918}^{916}{ }_{950}^{930} 954^{929} 951^{926}{ }_{948}^{923} 945^{920}{ }_{942}^{917} 938^{913} 934^{908} 925^{894}{ }_{894}^{857} \\
& { }_{978}^{873}{ }^{951}{ }_{984}^{983} 997^{987}{ }_{995}{ }^{984} 992^{981} 989^{977} 985^{974} 981^{970}{ }_{978}^{966} 972^{957} 955{ }^{923} 905^{857} \\
& 881{ }_{937^{960}}^{992}{ }^{999} 1008^{1006} 1008^{1004} 1005^{1001} 1001^{997} 997^{994} 994^{990} 990^{986} 9866^{981} 980^{969} 959^{928} 905^{856}
\end{aligned}
$$

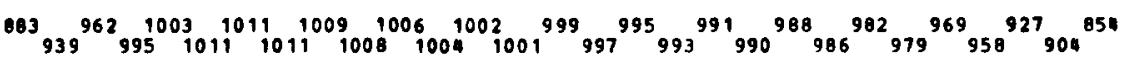

$$
\begin{aligned}
& 186{ }_{941}^{964} 996^{1005} 1012^{1013} 1013^{1011} 1009^{1000} 1006^{1004} 1002^{1000} 999^{997} 995^{993} 991^{990} 988^{986} 983^{980} 976^{967} 9566_{902}^{953}
\end{aligned}
$$

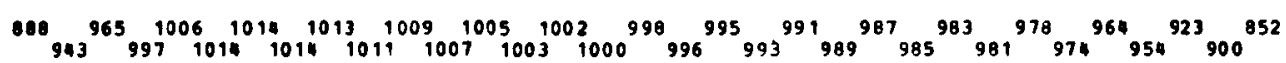

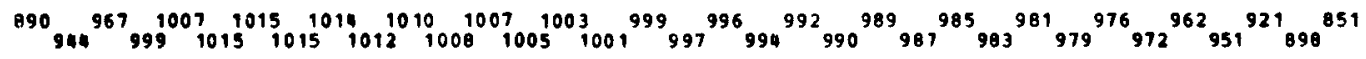

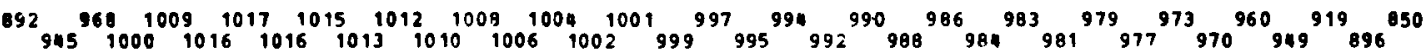

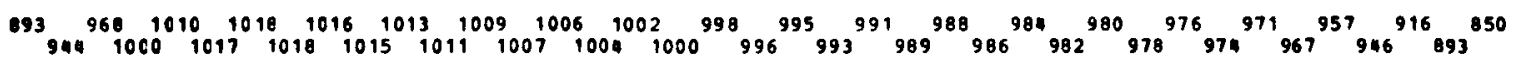

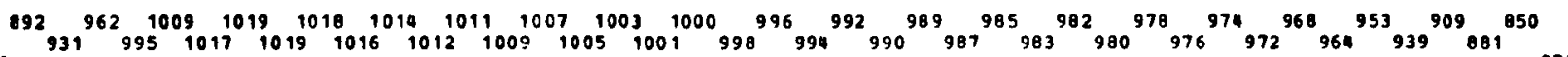

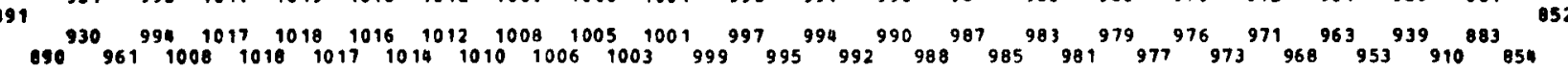

$$
\begin{aligned}
& 091^{943} 967^{999} 1008^{1016} 1016^{1016} 1015^{1013} 1011^{1010} 1008^{1006} 1001^{1002} 1000^{999} 997^{995} 993^{991} 989^{988} 9866_{982}^{984} 98199^{977} 975^{973} 969^{966} 9566_{917}^{946}{ }_{956}^{896}
\end{aligned}
$$

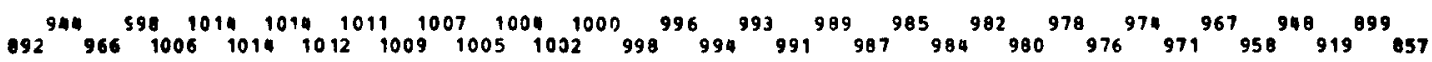

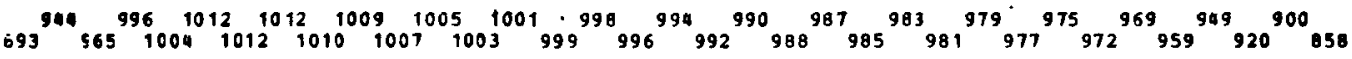

$$
\begin{aligned}
& 994^{943} 964^{994} 1002^{1009} 1009^{1009} 1008^{1008} 1004^{1003} 1001^{999} 997^{995} 993^{992} 990^{988} \cdot 986^{984} 9822^{981} 979^{977} 973^{970} 960^{950} 921^{901} 959 \\
& 094^{941} 962^{992} 999^{1007} 1007^{1007} 1005^{1004}{ }_{1002}^{1000} 998^{997} 995^{993^{\circ}} 991^{989} 987^{986} 984^{982} 9800^{978} 975^{971} 961^{951} 922{ }^{902} 959 \\
& 894^{940}{ }_{960}^{990}{ }_{997}^{1004} 1000^{1004} 1002^{1001} 999^{998} 995^{994} 992^{990} 988^{987} 985^{983} 981^{979} 976^{972} 9622^{952} 923^{902} 860 \\
& 093^{938}{ }_{957^{987}}^{993^{1001}} 999^{1000}{ }_{997^{997}}^{993^{994}} 990^{990}{ }_{986}^{986} 982^{983}{ }_{979^{979}}{ }_{974}^{972} 962^{953}{ }_{923}^{903} 961 \\
& \begin{array}{llllllllllll}
935 & 970 & 989 & 988 & 984 & 981 & 977 & 974 & 970 & 965 & 948 & 903
\end{array} \\
& \begin{array}{lllllllllllll}
092 & 949 & 976 & 979 & 977 & 974 & 970 & 967 & 964 & 950 & 950 & 919 & 863
\end{array} \\
& 089^{920} 2.17^{945}{ }_{927}^{949} 927^{947} 925^{944} 923^{941} 920^{93 \theta_{918} 935} 915^{932} 910^{923}{ }_{896}^{893} 864 \\
& \begin{array}{llllllllllll}
887 & 884 & 883 & 881 & 880 & 879 & 978 & 876 & 074 & 870 & 864 & 868
\end{array}
\end{aligned}
$$

Fig. 77. 2б Mid-Wall Clad Temperatures at Mid-Plane 


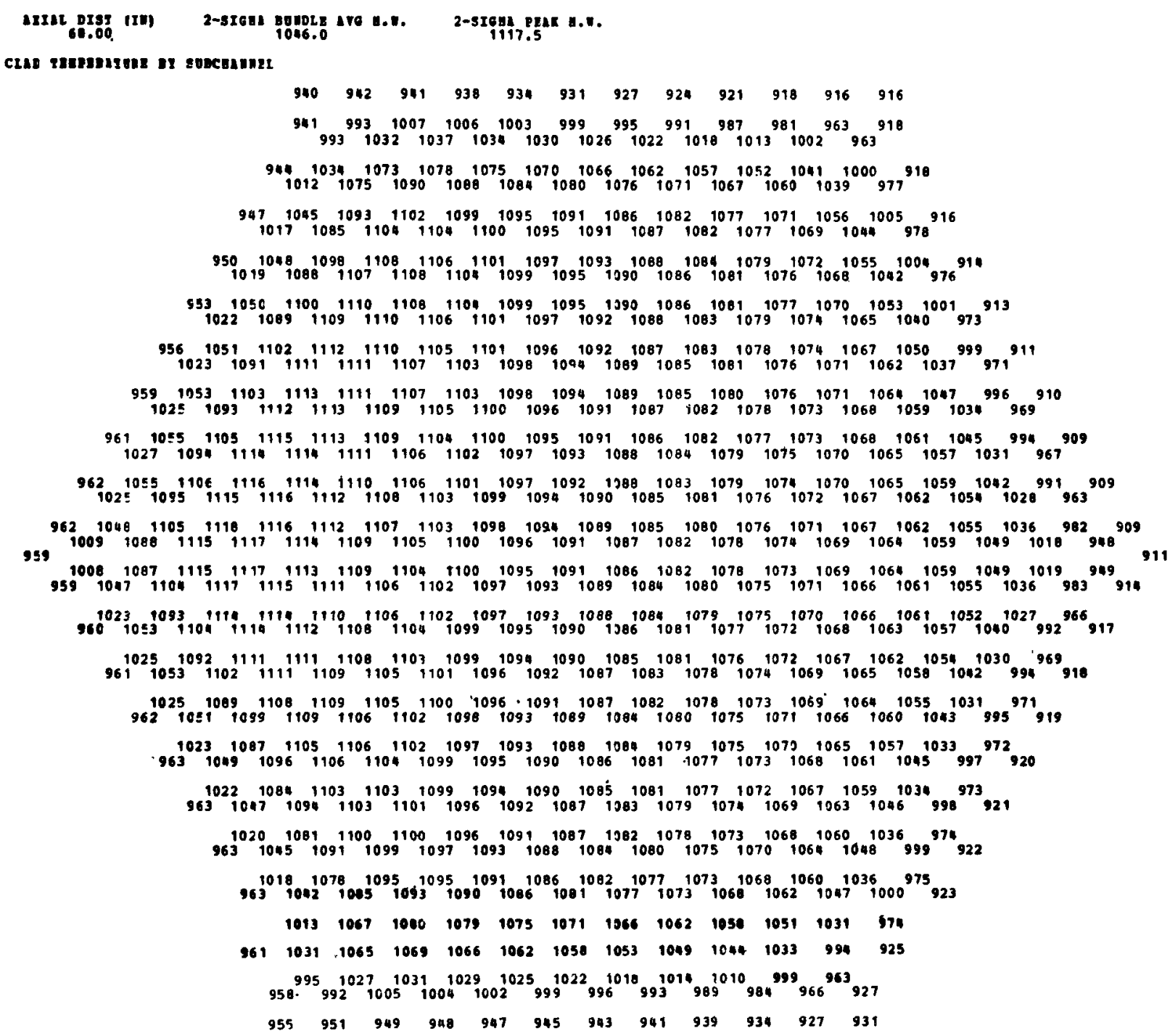

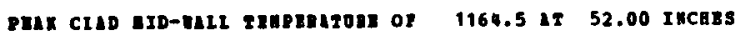

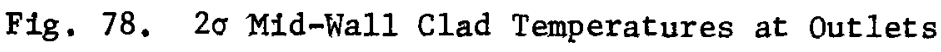




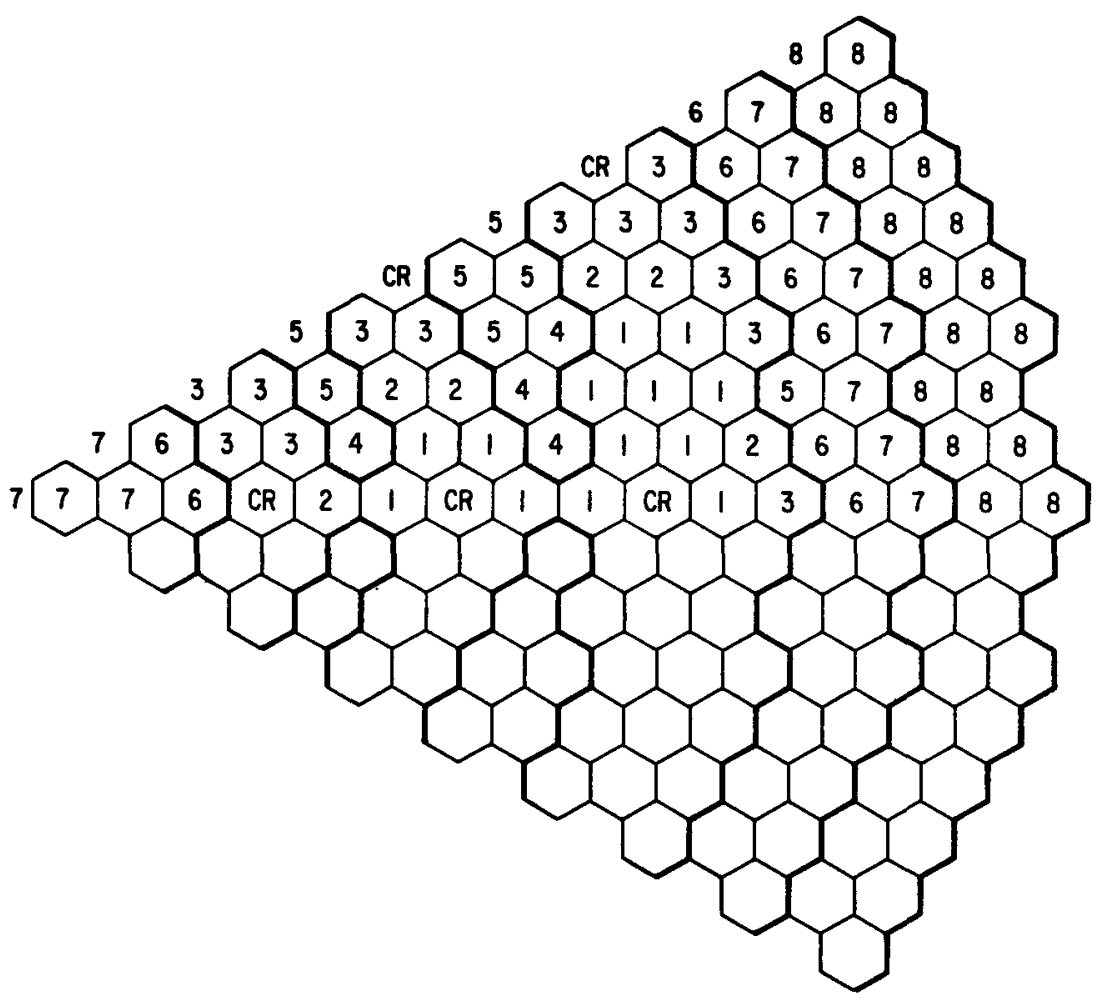

Fig. 7.9. Orificing Scheme of Configuration B with Peak Clad Temperature at EOEC

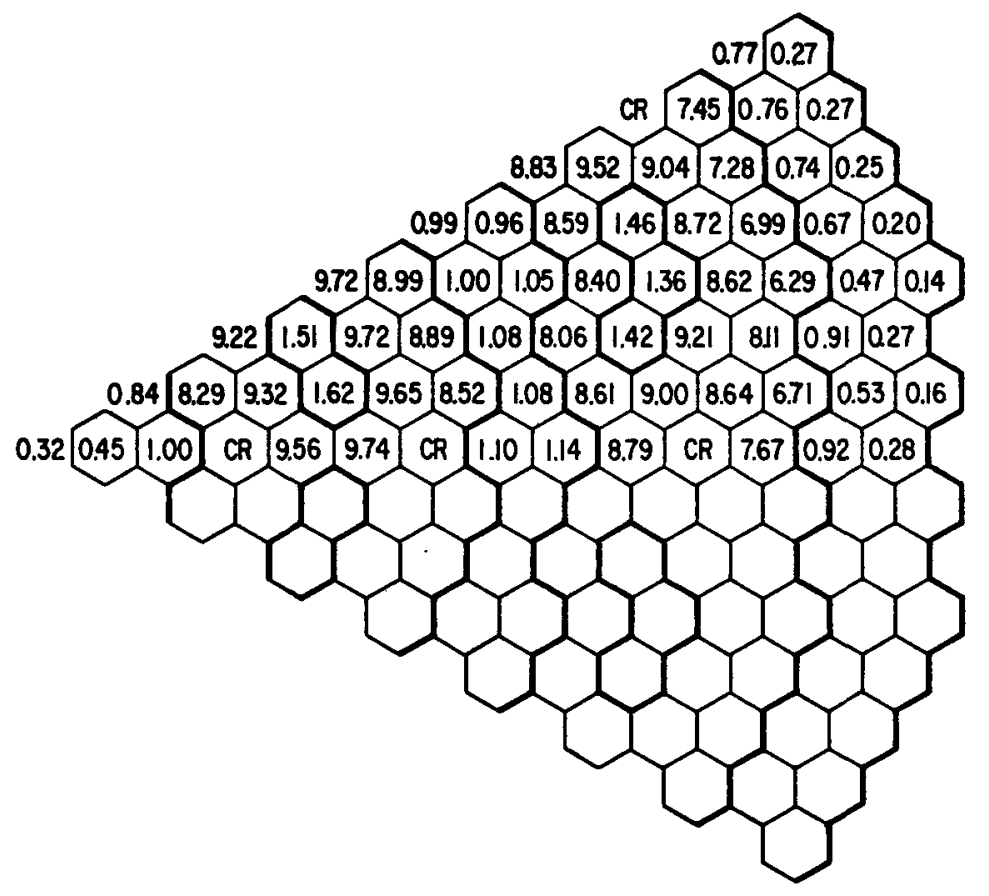

Fig. 80. Total Power Per Assembly (MWth) at BOL, Configuration A 


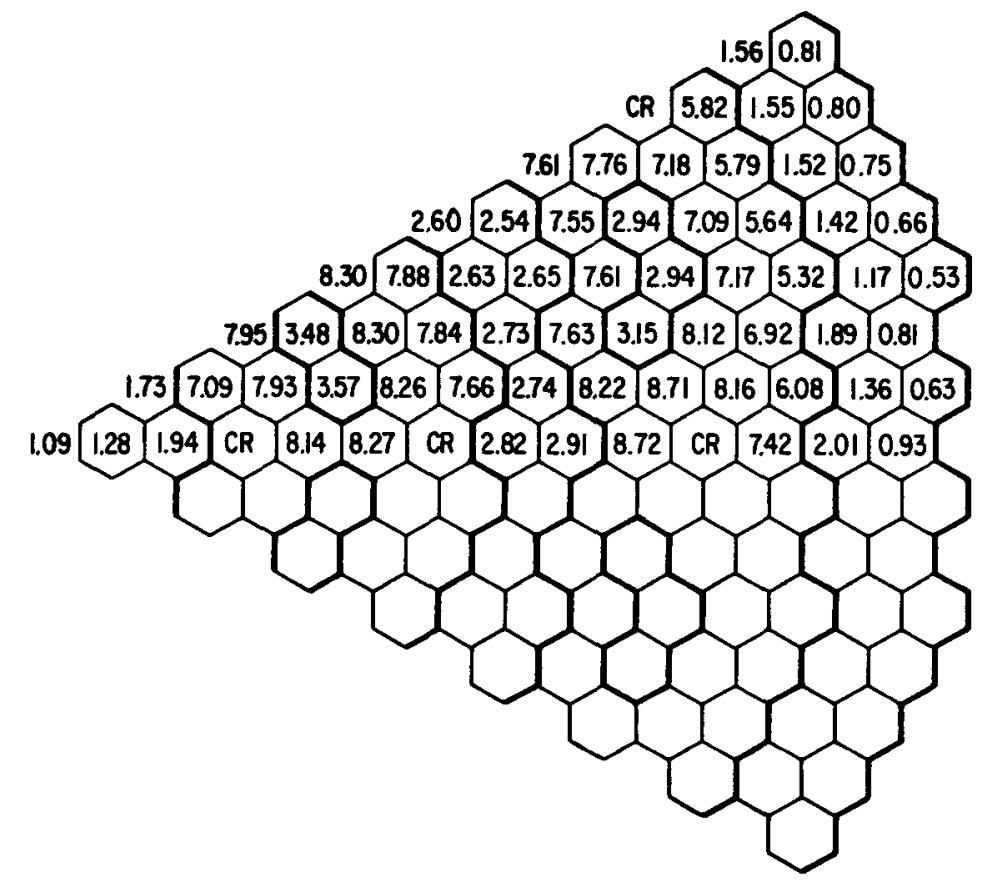

Fig. 81. Total Power Per Assembly (MWth) at EOEC, Configuration A

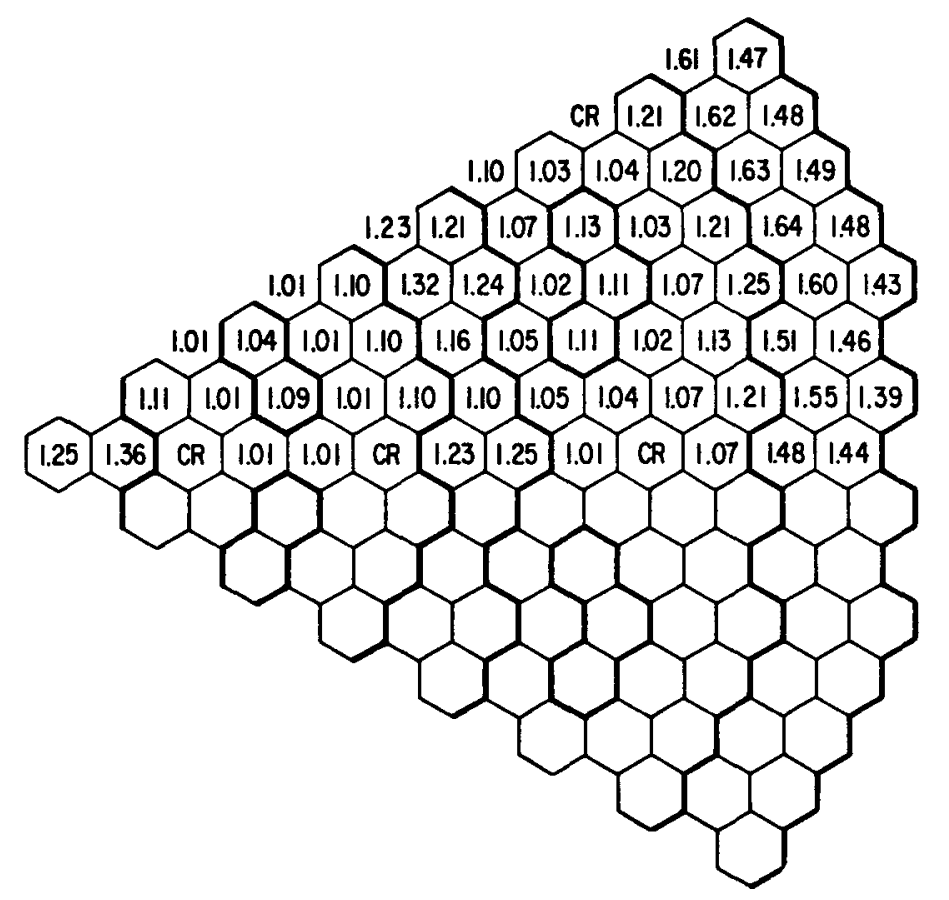

Fig. 82. Peak-to-Average Power Per Assembly at BOL, Configuration $A$ 
8.82 9.56 7.91 0.69 [.22

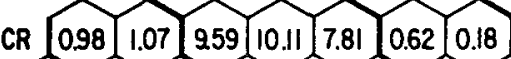

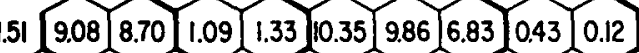

$\begin{array}{lllllllllllllllllllllllllll}8.42 & 9.67 & 1.55 & 9.83 & 9.53 & 1.35 & 9.43 & 9.93 & 8.42 & 0.82 & 0.24\end{array}$

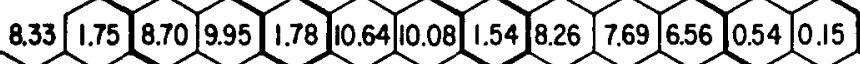

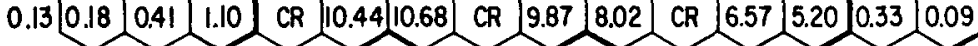

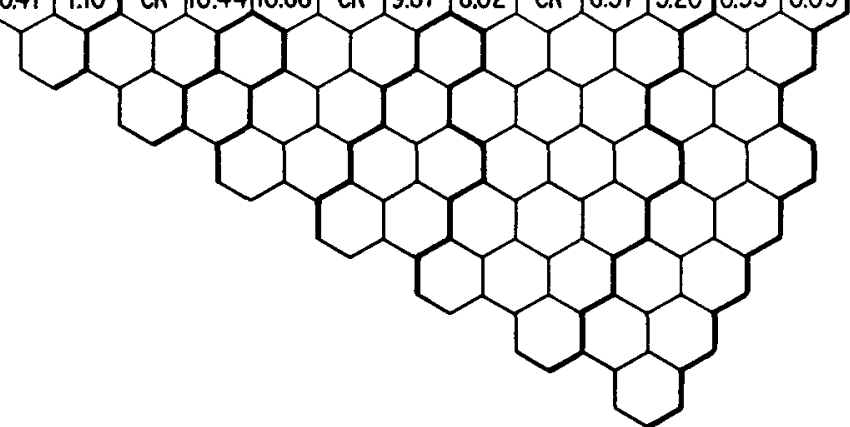

Fig. 83. Total Power Per Assembly (MWth) at BOL, Configuration B

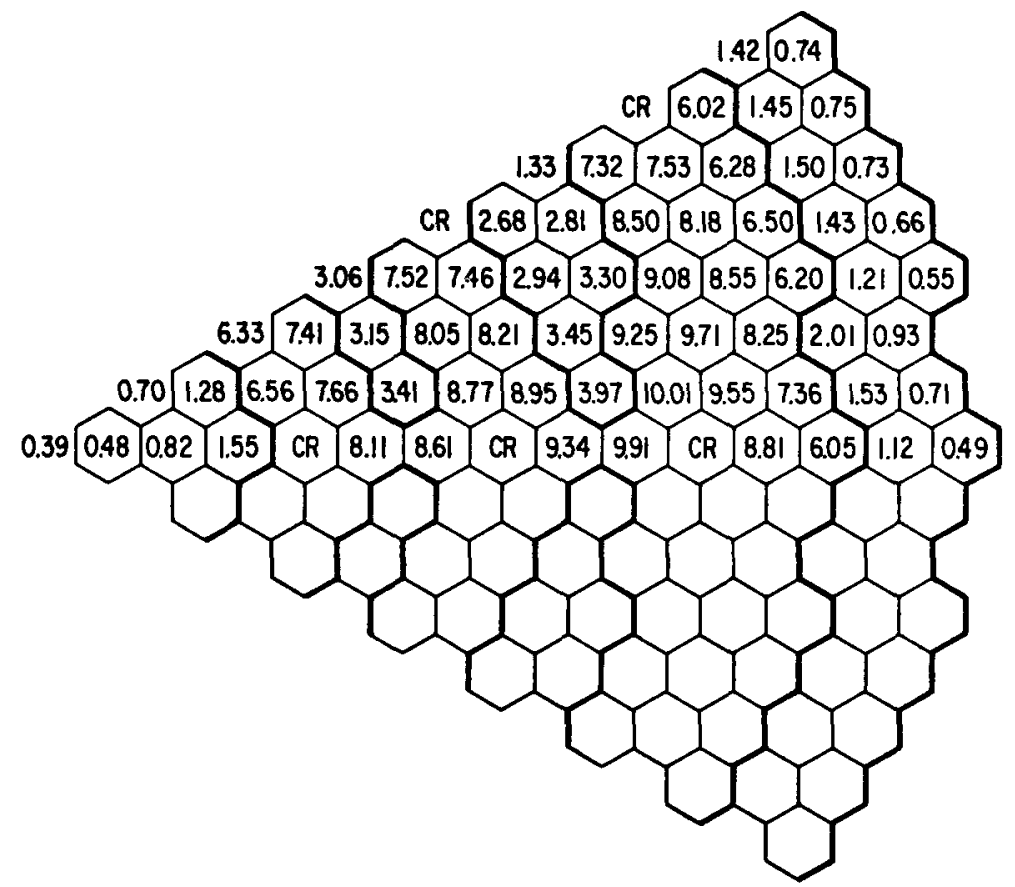

Fig. 84. Total Power Per Assembly (MWth) at EOEC, Configuration B 


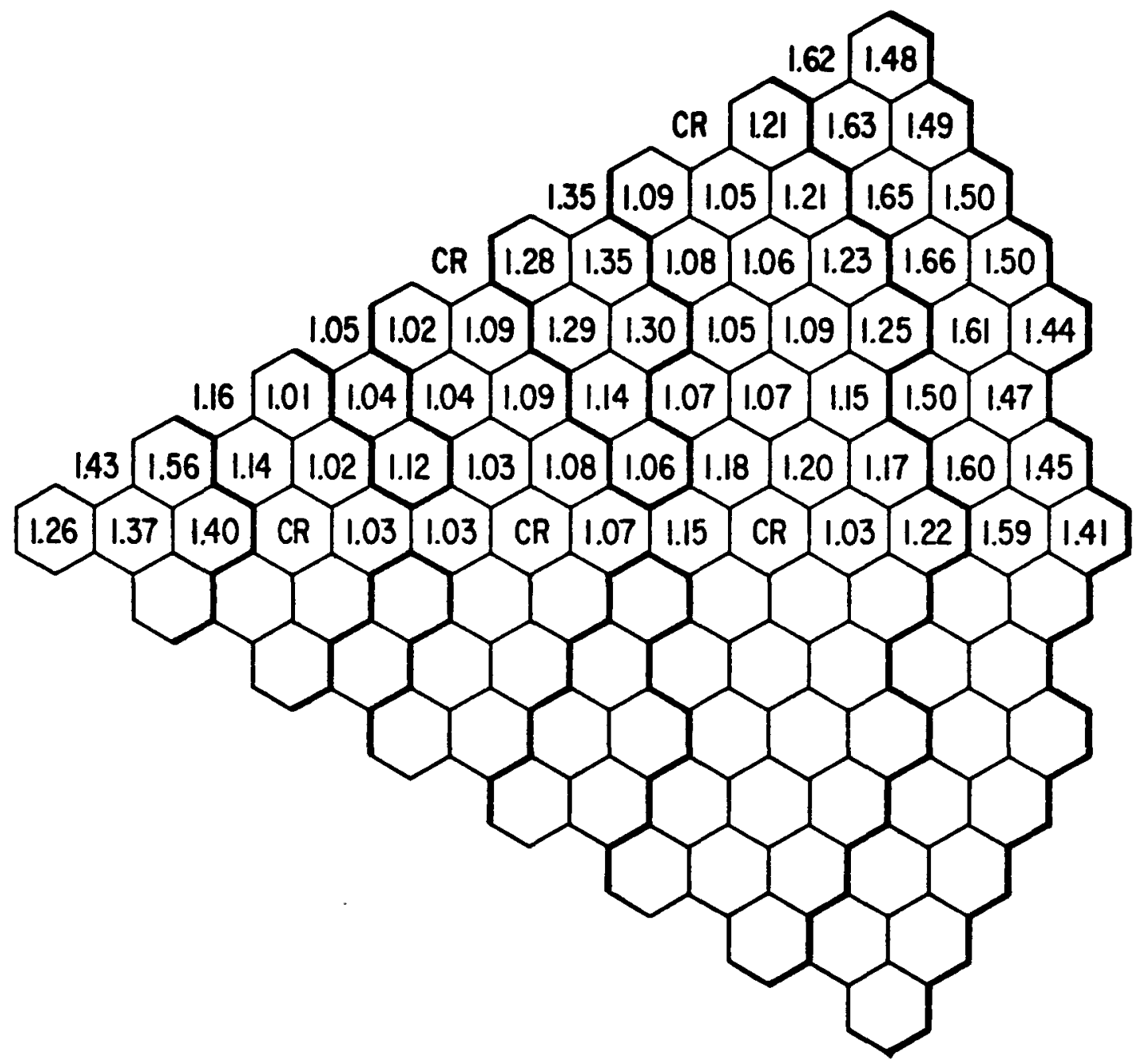

F1g. 85. Peak-to-Average Power Per Assembly at BOL, Configuration $B$ 
TABLE I. Number of Assemblies Per Region

\begin{tabular}{lcc}
\hline \multicolumn{1}{c}{ Region } & Configuration A & Configuration B \\
\hline Inner Core & 36 & 48 \\
Middle Core & 72 & 84 \\
Outer Core & 222 & 210 \\
Core & 330 & 342 \\
Internal Blanket 1 & 19 & 37 \\
Internal Blanket 2 & 24 & 30 \\
Internal Blanket 3 & 78 & 78 \\
Internal Blanket 4 & 36 & - \\
Internal Blankets & 157 & 145 \\
Control Assemblies & 24 & 30 \\
Radial Blanket & 174 & 174 \\
Shield Assemb1ies & 198 & 198 \\
\hline
\end{tabular}


TABLE II. Fissile Inventories, $\mathrm{kg}$

\begin{tabular}{|c|c|c|c|c|c|c|}
\hline & \multicolumn{3}{|c|}{ Configuration $\mathrm{A}$} & \multicolumn{3}{|c|}{ Configuration $B$} \\
\hline & BOL & BOEC & EOEC & BOL & BOEC & EOEC \\
\hline Inner Core & 415.7 & 397.7 & 363.7 & 566.7 & 537.3 & 480.7 \\
\hline Middle Core & 831.4 & 794.1 & 724.1 & 942.4 & 894.4 & 802.9 \\
\hline Outer Core & 2614.8 & 2514.0 & 2320.5 & 2281.6 & 2154.1 & 1979.9 \\
\hline Total Core & 3861.9 & 3705.8 & 3408.3 & 3790.9 & 3585.8 & 3263.6 \\
\hline Internal Blanket 1 & 0.0 & 19.5 & 55.4 & 0.0 & 64.7 & 185.3 \\
\hline Internal Blanket 2 & 0.0 & 34.3 & 95.0 & 0.0 & 46.4 & 128.1 \\
\hline Internal Blanket $3+4^{a}$ & 0.0 & 143.5 & 401.4 & 0.0 & 107.7 & 300.0 \\
\hline Total Internal Blanket & 0.0 & 197.3 & 551.8 & 0.0 & 218.8 & 520.7 \\
\hline Axial Blanket & 0.0 & 55.3 & 161.4 & 0.0 & 74.7 & 216.9 \\
\hline Radial Blanket & 0.0 & 310.0 & 453.5 & 0.0 & 334.1 & 488.5 \\
\hline Total Reactor & 3861.9 & 4268.4 & 4575.0 & 3790.9 & 4213.4 & 4489.7 \\
\hline
\end{tabular}

${ }^{a}$ Applies to configuration A only 
TABLE III. Average Fissile Enrichment, \% H.M.

\begin{tabular}{lccccccc}
\hline & \multicolumn{3}{c}{ Configuration } & & \multicolumn{3}{c}{ Configuration B } \\
\cline { 2 - 4 } & BOL & BOEC & EOEC & & BOL & BOEC & EOEC \\
\hline Inner Core & 17.7 & 17.2 & 16.3 & & 19.4 & 18.7 & 17.5 \\
Middle Core & 17.7 & 17.2 & 16.3 & & 18.4 & 17.8 & 16.7 \\
Outer Core & 18.1 & 17.6 & 16.8 & & 17.8 & 17.1 & 16.3 \\
Internal Blanket 1 & 0.0 & 0.6 & 1.8 & & 0.0 & 0.5 & 1.5 \\
Interna1 Blanket 2 & 0.0 & 0.9 & 2.5 & & 0.0 & 0.9 & 2.6 \\
Internal Blanket $3+4^{\mathrm{a}}$ & 0.0 & 0.7 & 2.2 & & 0.0 & 0.8 & 2.3 \\
Axial Blanket & 0.0 & 0.3 & 0.9 & & 0.0 & 0.4 & 1.2 \\
Radial Blanket & 0.0 & 1.1 & 1.6 & & 0.0 & 1.2 & 1.7 \\
\hline
\end{tabular}

${ }^{a}$ Applies only to Configuration A 
TABLE IV. Discharge Burnups (MWD/Kg)

\begin{tabular}{|c|c|c|c|c|}
\hline & Average & Peak & Average & Peak \\
\hline Inner Core & 62.44 & 81.34 & 73.82 & 88.34 \\
\hline Middle Core & 65.06 & 83.26 & 74.05 & 95.31 \\
\hline Outer Core & 54.63 & 83.90 & 58.64 & 100.7 \\
\hline Internal Blanket 1 & 4.88 & 12.78 & 3.44 & 9.86 \\
\hline Internal Blanket 2 & 9.66 & 19.41 & 10.60 & 19.61 \\
\hline Internal Blanket $3+4^{\mathrm{a}}$ & 7.75 & 22.10 & 7.96 & 20.96 \\
\hline Axial Blanket & 1.55 & 5.52 & 1.99 & 3.62 \\
\hline Radia1 Blanket & 5.68 & 21.21 & 5.92 & 22.19 \\
\hline
\end{tabular}

${ }^{a}$ Applies to Configuration A only 
TABLE V. Primary and Secondary Control System Assignments

\begin{tabular}{|c|c|c|c|c|c|}
\hline \multicolumn{3}{|c|}{ Configuration A } & \multicolumn{3}{|c|}{ Configuration B } \\
\hline Row & $\begin{array}{l}\text { Primary } \\
\text { System }\end{array}$ & $\begin{array}{l}\text { Secondary } \\
\text { System }\end{array}$ & Row & $\begin{array}{l}\text { Primary } \\
\text { System }\end{array}$ & $\begin{array}{c}\text { Secondary } \\
\text { System }\end{array}$ \\
\hline 4 & - & 6 & 5 & - & 6 \\
\hline 7 & 6 & - & 8 & 6 & - \\
\hline 11 & 6 & - & 9 & - & 6 \\
\hline 13 & - & 6 & 11 & 6 & - \\
\hline \multirow[t]{2}{*}{ Total } & 12 & 12 & 13 & - & 6 \\
\hline & & & Tota1 & 12 & 18 \\
\hline
\end{tabular}

TABLE VI. Control Rod Worths

\begin{tabular}{|c|c|c|c|c|}
\hline & \multicolumn{2}{|c|}{ Configuration A } & \multicolumn{2}{|c|}{ Configuration B } \\
\hline & $\begin{array}{l}\text { Primary } \\
\text { System }\end{array}$ & $\begin{array}{l}\text { Secondary } \\
\text { System }\end{array}$ & $\begin{array}{l}\text { Primary } \\
\text { System }\end{array}$ & $\begin{array}{c}\text { Secondary } \\
\text { System }\end{array}$ \\
\hline Total Worth, ${ }^{a} \% \Delta k$ & 4.28 & 3.01 & 4.95 & 3.81 \\
\hline Stuck Rod Worth, $\% \Delta \mathrm{k}$ & 0.39 & 0.27 & 0.44 & 0.21 \\
\hline Minimum Worth, \% $\frac{}{k}$ & 3.89 & 2.74 & 4.51 & 3.60 \\
\hline
\end{tabular}


TABLE VII. Control Rod Requirements

Configuration

A

B

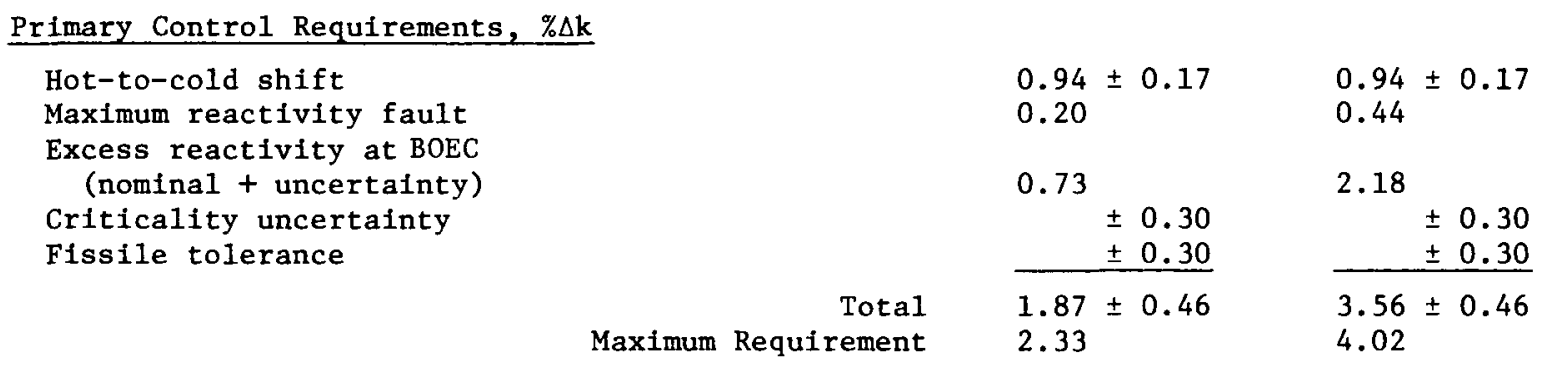

Primary Control Worths, $\% \Delta k$

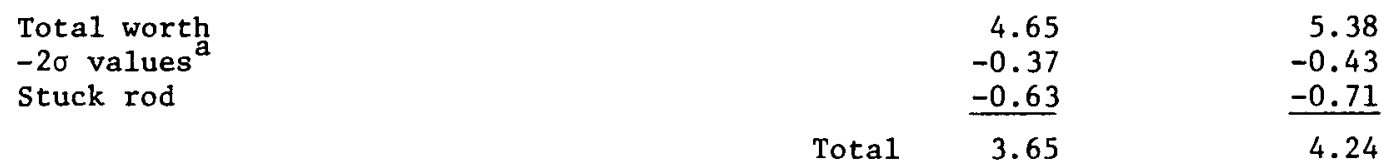

Secondary Control Requirements, $\% \Delta \mathbf{k}$

Hot-to-cold shift

Maximum reactivity fault

\begin{tabular}{|c|c|c|}
\hline & $\begin{array}{l}0.94 \pm 0.17 \\
0.20\end{array}$ & $\begin{array}{l}0.94 \pm 0.17 \\
0.44\end{array}$ \\
\hline $\begin{array}{r}\text { Total } \\
\text { Maximum Requirement }\end{array}$ & $\begin{array}{l}1.14 \pm 0.17 \\
1.31\end{array}$ & $\begin{array}{l}1.38 \pm 0.17 \\
1.55\end{array}$ \\
\hline
\end{tabular}

Secondary Contro1 Worths, $\% \Delta k$

\begin{tabular}{rrr} 
& 3.27 & 4.14 \\
& -0.26 & -0.33 \\
Total & -0.43 & -0.34 \\
\hline 2.58 & 3.47
\end{tabular}

Qunity bias, $10=4 \%$ 
TABLE VIII. Power Distribution

\begin{tabular}{|c|c|c|c|c|c|c|}
\hline & \multicolumn{3}{|c|}{ Configuration A } & \multicolumn{3}{|c|}{ Configuration B } \\
\hline & BOL & BOEC & EOEC & BOL & BOEC & EOEC \\
\hline Inner Core & 10.4 & 9.4 & 9.3 & 13.9 & 13.2 & 12.6 \\
\hline Middler Core & 21.6 & 19.8 & 19.2 & 24.2 & 23.2 & 22.2 \\
\hline Outer Core & 57.9 & 54.4 & 47.1 & 51.6 & 48.5 & 41.9 \\
\hline Total Core & 89.9 & 83.7 & 75.7 & 89.7 & 84.9 & 76.7 \\
\hline Internal Blanket 1 & 0.5 & 0.7 & 1.4 & 0.8 & 1.0 & 1.9 \\
\hline Internal Blanket 2 & 1.2 & 1.8 & 3.2 & 1.7 & 2.5 & 4.2 \\
\hline Internal Blanket $3+4^{a}$ & 4.8 & 7.4 & 12.1 & 3.3 & 4.8 & 8.5 \\
\hline Total Internal Blanket & 6.5 & 10.0 & 16.8 & 5.8 & 8.3 & 14.6 \\
\hline Axial Blanket & 1.3 & 1.6 & 2.4 & 2.0 & 2.2 & 3.3 \\
\hline Radial Blanket & 2.1 & 4.3 & 4.7 & 2.4 & 4.3 & 4.9 \\
\hline
\end{tabular}

${ }^{a}$ Applies only to configuration A 
TABLE IX. (Peak/Average) Power Densitites

\begin{tabular}{|c|c|c|c|c|c|c|}
\hline & \multicolumn{3}{|c|}{ Configuration A } & \multicolumn{3}{|c|}{ Configuration B } \\
\hline & BOL & BOEC & EOEC & BOL & BOEC & EOEC \\
\hline Inner Core ${ }^{a}$ & 1.37 & 1.36 & 1.36 & 1.42 & 1.42 & 1.46 \\
\hline Middle Core ${ }^{a}$ & 1.41 & 1.34 & 1.32 & 1.41 & 1.39 & 1.43 \\
\hline Outer Core ${ }^{a}$ & 1.52 & 1.49 & 1.58 & 1.57 & 1.53 & 1.59 \\
\hline Internal Blanket $1^{a}$ & 3.72 & 3.15 & 2.79 & 5.17 & 3.96 & 3.47 \\
\hline Internal Blanket $2^{a}$ & 2.19 & 2.21 & 2.18 & 2.48 & 2.28 & 2.25 \\
\hline Internal Blanket ${ }^{a} 3+4^{c}$ & 2.14 & 2.52 & 2.33 & 3.06 & 2.58 & 2.34 \\
\hline Axial Blanket ${ }^{a}$ & 3.66 & 3.36 & 3.35 & 3.65 & 3.21 & 3.07 \\
\hline Radial Blanket ${ }^{a}$ & 6.84 & 3.93 & 3.73 & 7.61 & 3.94 & 3.73 \\
\hline Core $e^{b}$ & 1.45 & 1.45 & 1.54 & 1.53 & 1.49 & 1.60 \\
\hline
\end{tabular}

a zone peak value/zone average value

bexcluding internal blanket regions

capplies to configuration A only 
TABLE X. Nominal Peak Nuclear Linear Heat Rating, $\mathrm{kW} / \mathrm{ft}$

\begin{tabular}{lcccc}
\hline & \multicolumn{2}{c}{ Configuration A } & & Configuration B \\
\cline { 2 - 5 } \cline { 5 - 5 } & BOL & EOL, Discharged & BOL & EOL, Discharged \\
\hline Core & 13.4 & 12.0 & 13.2 & 11.4 \\
Internal Blanket & 4.8 & 12.8 & 5.6 & 15.3 \\
Radial Blanket & 3.1 & 8.7 & 3.5 & 10.7 \\
\hline
\end{tabular}

TABLE XI. Peak Fast Fluxes

\begin{tabular}{|c|c|c|c|c|c|c|c|}
\hline & \multicolumn{2}{|c|}{ Peak Fast Flux } & \multirow{2}{*}{$\frac{10^{-15}}{\mathrm{EOEC}}$} & \multicolumn{3}{|c|}{ \% Total Flux (>0.1 MeV) } & \multirow{2}{*}{$\begin{array}{l}\text { Peak Fast } \\
\text { Fluence } \\
\left(\times 10^{-23}\right)\end{array}$} \\
\hline & BOL & BOEC & & BOL & BOEC & EOEC & \\
\hline \multicolumn{8}{|c|}{ Configuration $A$} \\
\hline Core & 3.39 & 3.32 & 3.26 & 58.1 & 58.0 & 57.6 & 1.45 \\
\hline Interna1 Blanket & 2.92 & 2.91 & 2.91 & 51.8 & 52.5 & 53.6 & 1.28 \\
\hline Radial Blanket & 1.52 & 1.60 & 1.61 & 43.7 & 46.2 & 46.9 & 0.71 \\
\hline \multicolumn{8}{|c|}{ Configuration B } \\
\hline Core & 3.96 & 3.66 & 3.57 & 60.3 & 58.7 & 58.1 & 1.59 \\
\hline Internal Blanket & 3.16 & 3.01 & 2.94 & 51.2 & 52.4 & 53.4 & 1.32 \\
\hline Radia1 Blanket & 1.63 & 1.80 & 1.98 & 42.4 & 46.4 & 47.1 & 0.83 \\
\hline
\end{tabular}


TABLE XII. Breeding Ratios

\begin{tabular}{|c|c|c|c|c|c|c|}
\hline & \multicolumn{3}{|c|}{ Configuration A } & \multicolumn{3}{|c|}{ Configuration B } \\
\hline & BOL & BOEC & EOEC & BOL & BOEC & EOEC \\
\hline Inner Core & 0.065 & 0.060 & 0.062 & 0.078 & 0.074 & 0.076 \\
\hline Middle Core & 0.135 & 0.125 & 0.128 & 0.145 & 0.139 & 0.143 \\
\hline Outer Core & 0.350 & 0.324 & 0.307 & 0.305 & 0.296 & 0.277 \\
\hline Total Core & 0.550 & 0.514 & 0.497 & 0.628 & 0.509 & 0.497 \\
\hline Internal Blanket 1 & 0.052 & 0.048 & 0.052 & 0.090 & 0.147 & 0.159 \\
\hline Internal Blanket 2 & 0.100 & 0.092 & 0.093 & 0.127 & 0.116 & 0.118 \\
\hline Internal Blanket $3+4^{a}$ & 0.414 & 0.387 & 0.378 & 0.307 & 0.269 & 0.268 \\
\hline Total Internal Blanket & 0.566 & 0.527 & 0.523 & 0.52 & 0.458 & 0.466 \\
\hline Axial Blanket & 0.144 & 0.138 & 0.139 & 0.217 & 0.174 & 0.178 \\
\hline Radia1 Blanket & 0.227 & 0.220 & 0.202 & 0.260 & 0.219 & 0.205 \\
\hline Total Reactor & 1.488 & 1.398 & 1.361 & 1.530 & 1.361 & 1.346 \\
\hline
\end{tabular}

applies only to configuration A

TABLE XIII. Breeding Performance

\begin{tabular}{|c|c|c|c|c|c|c|}
\hline Assemb1y & Residence & Time, yrs. & & & Configuration A & Configuration B \\
\hline Core & $\begin{array}{l}\text { Internal } \\
\text { Blanket }\end{array}$ & $\begin{array}{l}\text { Radial } \\
\text { Blanket }\end{array}$ & $\begin{array}{l}\text { Out-of-Pile } \\
\text { Time, yrs. }\end{array}$ & $\begin{array}{l}\text { Fuel Cycle } \\
\text { Losses \% }\end{array}$ & $\begin{array}{l}\text { Compound System } \\
\text { Doub1ing Time, yrs. }\end{array}$ & $\begin{array}{l}\text { Compound System } \\
\text { Doubling Time, yrs. }\end{array}$ \\
\hline 2 & 2 & 5 & 1 & 1 & 15.7 & 15.3 \\
\hline 2 & 1 & 5 & 1 & 1 & 15.1 & \\
\hline
\end{tabular}


TABLE XIV. Configuration A Sodium Void Reactivities ${ }^{a}$ from Perturbation Calculations

\begin{tabular}{|c|c|c|c|c|}
\hline \multirow[b]{2}{*}{ Region } & \multicolumn{2}{|c|}{$x_{\Delta \mathrm{k}}$} & \multicolumn{2}{|c|}{$s^{b}$} \\
\hline & $\overline{\mathrm{BOL}}$ & $\overline{\text { EOEC }}$ & $\overline{\mathrm{BOL}}$ & $\overline{\mathrm{EOEC}}$ \\
\hline \multicolumn{5}{|l|}{ Core } \\
\hline $\begin{array}{l}\text { Zone } 1 \\
\text { Zone } 2 \\
\text { Zone } 3 \\
\text { Total }\end{array}$ & $\begin{array}{l}0.086 \\
0.181 \\
0.282 \\
0.549\end{array}$ & $\begin{array}{l}0.135 \\
0.301 \\
0.472 \\
0.908\end{array}$ & $\begin{array}{l}0.23 \\
0.50 \\
0.77 \\
1.50\end{array}$ & $\begin{array}{l}0.37 \\
0.82 \\
1.29 \\
2.48\end{array}$ \\
\hline \multicolumn{5}{|l|}{ Internal Blanket } \\
\hline $\begin{array}{l}\text { Zone } 1 \\
\text { Zone } 2 \\
\text { Zone } 3 \\
\text { Total }\end{array}$ & $\begin{array}{l}0.006 \\
0.074 \\
0.284 \\
0.364\end{array}$ & $\begin{array}{l}0.016 \\
0.081 \\
0.307 \\
0.404\end{array}$ & $\begin{array}{l}0.02 \\
0.20 \\
0.78 \\
1.00\end{array}$ & $\begin{array}{l}0.04 \\
0.22 \\
0.84 \\
1.10\end{array}$ \\
\hline Axial Blanket & -0.078 & -0.074 & -0.21 & -0.20 \\
\hline Core + Upper Axial Blanket & 0.510 & 0.871 & 1.40 & 2.38 \\
\hline
\end{tabular}

a for voiding flowing sodium

$\beta_{\text {eff }}=0.00365$

TABLE XV. Configuration B Sodium Void Reactivities ${ }^{2}$ from Perturbation Calculations

\begin{tabular}{|c|c|c|c|c|}
\hline \multirow[b]{2}{*}{ Region } & \multicolumn{2}{|c|}{$\% \Delta \mathrm{k}$} & \multicolumn{2}{|c|}{$s^{b}$} \\
\hline & BOL & EOEC & BOL & EOEC \\
\hline \multicolumn{5}{|l|}{ Core } \\
\hline $\begin{array}{l}\text { Zone } 1 \\
\text { Zone } 2 \\
\text { Zone } 3 \\
\text { Total }\end{array}$ & $\begin{array}{l}0.071 \\
0.174 \\
0.108 \\
0.353\end{array}$ & $\begin{array}{l}0.164 \\
0.347 \\
0.348 \\
0.859\end{array}$ & $\begin{array}{l}0.19 \\
0.48 \\
0.29 \\
0.98\end{array}$ & $\begin{array}{l}0.45 \\
0.96 \\
2.38 \\
2.38\end{array}$ \\
\hline \multicolumn{5}{|l|}{ Internal Blanket } \\
\hline $\begin{array}{l}\text { Zone } 1 \\
\text { Zone } 2 \\
\text { Zone } 3 \\
\text { Tota1 }\end{array}$ & $\begin{array}{r}-0.087 \\
0.086 \\
0.162 \\
0.161\end{array}$ & $\begin{array}{l}0.006 \\
0.112 \\
0.190 \\
0.304\end{array}$ & $\begin{array}{r}-0.24 \\
0.24 \\
0.45 \\
0.45\end{array}$ & $\begin{array}{l}0.02 \\
0.31 \\
0.52 \\
0.84\end{array}$ \\
\hline Axial Blanket & -0.112 & -0.105 & -0.31 & -0.29 \\
\hline Core + Upper Axial Blanket & 0.297 & 0.806 & 0.82 & 2.23 \\
\hline
\end{tabular}

$a_{\text {for volding flowing sodium }}$

$b_{B_{\text {eff }}}=0.003614$ 
TABLE XVI. Isothermal Doppler Coefficients of Configuration A $\left(-\mathrm{T} \frac{\mathrm{dk}}{\mathrm{dT}} \times 10^{4}\right)$

\begin{tabular}{|c|c|c|c|c|}
\hline \multirow[b]{2}{*}{ Region } & \multicolumn{2}{|c|}{ Sodium - in } & \multicolumn{2}{|c|}{ Sodium - out } \\
\hline & BOL & EOEC & BOL & EOEC \\
\hline \multicolumn{5}{|l|}{ Core } \\
\hline $\begin{array}{l}\text { Zone } 1 \\
\text { Zone } 2 \\
\text { Zone } 3 \\
\text { Total }\end{array}$ & $\begin{array}{r}6.74 \\
14.42 \\
31.98 \\
53.14\end{array}$ & $\begin{array}{r}6.47 \\
13.66 \\
25.76 \\
45.89\end{array}$ & $\begin{array}{r}4.31 \\
7.19 \\
19.78 \\
31.28\end{array}$ & $\begin{array}{r}4.00 \\
8.83 \\
16.13 \\
28.96\end{array}$ \\
\hline \multicolumn{5}{|l|}{ Internal Blanket } \\
\hline $\begin{array}{l}\text { Zone } 1 \\
\text { Zone } 2 \\
\text { Zone } 3 \\
\text { Tota1 }\end{array}$ & $\begin{array}{r}2.10 \\
8.70 \\
28.61 \\
39.41\end{array}$ & $\begin{array}{r}3.71 \\
10.31 \\
34.27 \\
48.29\end{array}$ & $\begin{array}{r}1.99 \\
6.10 \\
22.68 \\
30.77\end{array}$ & $\begin{array}{r}3.17 \\
6.64 \\
25.87 \\
35.68\end{array}$ \\
\hline Radial Blanket & 4.99 & 6.34 & 4.26 & 5.41 \\
\hline Axial Blanket & 3.10 & 4.49 & 3.05 & 4.16 \\
\hline
\end{tabular}

TABLE XVII. Isothermal Doppler Coefficients of Configuration B $\left(-\mathrm{T} \frac{\mathrm{dk}}{\mathrm{dT}} \times 10^{4}\right)$

\begin{tabular}{|c|c|c|c|c|}
\hline \multirow[b]{2}{*}{ Region } & \multicolumn{2}{|c|}{ Sodium - in } & \multicolumn{2}{|c|}{ Sodium - out } \\
\hline & BOL & EOEC & BOL & EOEC \\
\hline \multicolumn{5}{|l|}{ Core } \\
\hline $\begin{array}{l}\text { Zone } 1 \\
\text { Zone } 2 \\
\text { Zone } 3 \\
\text { Total }\end{array}$ & $\begin{array}{r}6.82 \\
14.18 \\
29.76 \\
50.72\end{array}$ & $\begin{array}{r}6.56 \\
14.23 \\
25.27 \\
46.09\end{array}$ & $\begin{array}{r}4.88 \\
9.69 \\
16.91 \\
31.48\end{array}$ & $\begin{array}{r}4.36 \\
9.03 \\
14.79 \\
28.18\end{array}$ \\
\hline \multicolumn{5}{|c|}{ Internal Blanket } \\
\hline $\begin{array}{l}\text { Zone } 1 \\
\text { Zone } 2 \\
\text { Zone } 3 \\
\text { Total }\end{array}$ & $\begin{array}{r}2.04 \\
8.39 \\
16.06 \\
26.49\end{array}$ & $\begin{array}{r}3.28 \\
10.47 \\
24.15 \\
37.90\end{array}$ & $\begin{array}{r}2.17 \\
7.00 \\
13.27 \\
22.44\end{array}$ & $\begin{array}{r}3.16 \\
7.72 \\
17.82 \\
28.7\end{array}$ \\
\hline Radial Blanket & 4.88 & 7.247 & 4.09 & 6.54 \\
\hline Axial Blanket & 4.21 & 6.44 & 4.07 & 5.90 \\
\hline
\end{tabular}


TABLE XVIII. Normalized Peak Power Density $P(t) / P(0)$ for Configuration $A$ in a $60 c$ Step

Insertion into the Outer Core

\begin{tabular}{llll}
\hline & & & \\
& & & \\
& & & \\
& & & \\
& & & \\
& & & \\
\multicolumn{1}{c}{ Time, sec } & Inner Core & Middle Core & Outer Core \\
$0.3339-4$ & 1.000 & 1.000 & 1.000 \\
$0.4014-4$ & 1.067 & 1.069 & 1.092 \\
$0.5796-4$ & 1.098 & 1.103 & 1.131 \\
$0.1293-3$ & 1.186 & 1.192 & 1.226 \\
$0.6784-3$ & 1.492 & 1.499 & 1.544 \\
$0.3460-2$ & 2.369 & 2.379 & 2.448 \\
$0.1136-1$ & 2.501 & 2.511 & 2.570 \\
$0.9079-1$ & 2.486 & 2.497 & 2.553 \\
0.2908 & 2.283 & 2.294 & 2.028 \\
0.4908 & 1.970 & 1.980 & 1.838 \\
0.6908 & 1.782 & 1.791 & 1.706 \\
0.8908 & 1.648 & 1.657 & 1.606 \\
1.0000 & 1.548 & 1.556 & 1.559 \\
\hline
\end{tabular}

TABLE XIX. Normalized Peak Power Density $P(t) / P(0)$ for Configuration A in a $60 c / 500$ ms Ramp into the Outer Core

\begin{tabular}{llll}
\hline & \multicolumn{3}{c}{ Normalized Peak Power Density $P(t) / P(0)$} \\
\cline { 2 - 4 } Time, sec & Inner Core & Middle Core & Outer Core \\
\hline \multicolumn{1}{c}{0} & & & \\
$0.3339-4$ & 1.000 & 1.000 & 1.000 \\
0.1466 & 1.000 & 1.000 & 1.000 \\
0.2670 & 1.191 & 1.192 & 1.197 \\
0.3811 & 1.413 & 1.413 & 1.429 \\
0.4871 & 1.700 & 1.704 & 1.733 \\
0.5854 & 2.056 & 2.064 & 2.113 \\
0.7854 & 1.985 & 1.994 & 1.053 \\
1.0000 & 1.791 & 1.800 & 1.710 \\
& 1.650 & 1.657 & \\
\hline
\end{tabular}


TABLE XX. Normal1zed Peak Power Density $P(t) / P(0)$ for Configuration $B$ in a $60 c$ Step

Insertion into the Outer Core

\begin{tabular}{|c|c|c|c|}
\hline & Normalized & Peak Power Density & $P(t) / P(0)$ \\
\hline Time, sec & Inner Core & Middle Core & Outer Core \\
\hline 0 & 1.000 & 1.000 & 1.000 \\
\hline $0.325-4$ & 1.073 & 1.079 & 1.101 \\
\hline $0.564-4$ & 1.194 & 1. 202 & 1.235 \\
\hline $0.130-3$ & 1.515 & 1.525 & 1.564 \\
\hline $0.589-3$ & 2.326 & 2.340 & 2.388 \\
\hline $0.162-2$ & 2.485 & 2.499 & 2.549 \\
\hline $0.121-1$ & 2.490 & 2.503 & 2.553 \\
\hline 0.1170 & 2.210 & 2.222 & 2.271 \\
\hline 0.3167 & 1.911 & 1.922 & 1.969 \\
\hline 0.5167 & 1.732 & 1.743 & 1.788 \\
\hline 0.7167 & 1.608 & 1.618 & 1.664 \\
\hline 1.0000 & 1.481 & 1.489 & 1.533 \\
\hline
\end{tabular}

TABLE XXI. Normal1zed Peak Power Density $P(t) / P(0)$

for Configuration $B$ in a $60 c / 500 \mathrm{~ms}$

Ramp into the Outer Core

\begin{tabular}{llll}
\hline & \multicolumn{2}{c}{ Normalized Peak Power Density $P(t) / P(0)$} \\
\cline { 2 - 3 } Time, sec & Inner Core & Middle Core & Outer Core \\
\hline & & & \\
\hline 0 & 1.000 & 1.000 & 1.000 \\
0.1379 & 1.167 & 1.169 & 1.171 \\
0.4239 & 1.545 & 1.549 & 1.568 \\
0.5080 & 1.804 & 1.811 & 1.843 \\
0.5940 & 2.071 & 2.083 & 2.131 \\
0.7936 & 1.961 & 1.974 & 2.025 \\
1.0000 & 1.768 & 1.779 & 1.828 \\
& 1.631 & 1.642 & 1.687 \\
\hline
\end{tabular}


TABLE XXII. Inlet and Outlet Temperatures of Configuration $A$ at EOEC

\begin{tabular}{lcc}
\hline & ${ }^{\circ} \mathrm{K}$ & ${ }^{\circ} \mathrm{F}$ \\
\hline Core Inlet & 586 & 595 \\
Core Average Outlet & 760 & 908 \\
Core $\Delta \mathrm{T}$ & 174 & 313 \\
(Core + Radial Blanket) Average Outlet & 750 & 890 \\
(Core + Radial Blanket) $\Delta \mathrm{T}$ & 164 & 295 \\
Reactor Inlet & 586 & 595 \\
Reactor Outlet & 741 & 875 \\
Reactor $\Delta \mathrm{T}$ & 155 & 280 \\
\hline
\end{tabular}

TABLE XXIII. Inlet and Outlet Temperatures of Configuration A Orificed for Equal Clad Temperatures at EOEC

\begin{tabular}{lcc}
\hline Core Inlet & 586 & 595 \\
Core Average Outlet & 756 & 902 \\
Core $\Delta \mathrm{T}$ & 170 & 307 \\
(Core + Radial Blanket) Average Outlet & 750 & 890 \\
(Core + Radial Blanket) $\Delta \mathrm{T}$ & 164 & 295 \\
Reactor Inlet & 586 & 595 \\
Reactor Outlet & 741 & 875 \\
Reactor $\Delta \mathrm{T}$ & 155 & 280 \\
\hline
\end{tabular}


TABLE XXIV. Orificing Scheme of Configuration A

\begin{tabular}{ccrcccc}
\hline Zone & $\begin{array}{c}\text { Number } \\
\text { Assemblies }\end{array}$ & $\begin{array}{c}\text { Power } \\
\text { MWt }\end{array}$ & $\begin{array}{c}\text { Flow } \\
10^{6} \text { Ib/hr }\end{array}$ & $\begin{array}{c}\text { Flow/ass'y } \\
\text { Ib/hr }\end{array}$ & $\begin{array}{c}\text { Avg. } \Delta \text { T } \\
\text { deg. F }\end{array}$ & $\begin{array}{c}\text { Velocity } \\
\text { ft/sec }\end{array}$ \\
\hline 1 & 156 & 1265.4 & 45.140 & 289361 & 312.0 & 25.6 \\
2 & 126 & 911.5 & 31.869 & 252928 & 318.3 & 22.4 \\
3 & 48 & 272.0 & 10.121 & 210857 & 299.1 & 18.7 \\
4 & 36 & 122.5 & 4.511 & 125333 & 302.2 & 17.5 \\
5 & 108 & 285.1 & 11.570 & 107127 & 274.3 & 14.9 \\
6 & 90 & 146.4 & 8.289 & 92105 & 196.6 & 12.8 \\
7 & 97 & 75.3 & 4.608 & 47508 & 181.9 & 6.6 \\
8 & 222 & 5.8 & 0.340 & 1538 & 189.6 & - \\
Total & 883 & 3084.0 & 116.448 & - & 294.7 & -- \\
\hline
\end{tabular}

TABLE XXV. Orificing Scheme of Configuration A Orificed for Equal Clad Temperature at EOEC

\begin{tabular}{|c|c|c|c|c|c|c|}
\hline Zone & $\begin{array}{c}\text { Number } \\
\text { Assemb lies }\end{array}$ & $\begin{array}{l}\text { Power } \\
\text { MWt }\end{array}$ & $\begin{array}{c}\text { Flow } \\
10^{6} \mathrm{lb} / \mathrm{hr}\end{array}$ & $\begin{array}{c}\text { Flow/ass'y } \\
\text { lb/hr }\end{array}$ & $\begin{array}{l}\text { Avg. } \Delta \mathrm{T} \\
\text { deg. } F\end{array}$ & $\begin{array}{c}\text { Velocity } \\
\mathrm{ft} / \mathrm{sec}\end{array}$ \\
\hline 1 & 138 & 1123.1 & 40.854 & 296043 & 305.9 & 26.2 \\
\hline 2 & 132 & 980.8 & 34.610 & 262197 & 315.4 & 23.2 \\
\hline 3 & 60 & 345.0 & 13.435 & 223917 & 285.8 & 19.8 \\
\hline 4 & 42 & 139.9 & 5.002 & 119095 & 311.3 & 16.5 \\
\hline 5 & 180 & 400.1 & 17.696 & 98311 & 251.6 & 13.6 \\
\hline 6 & 73 & 67.3 & 3.518 & 48192 & 212.8 & 6.7 \\
\hline 7 & 36 & 22.0 & 0.945 & 26250 & 259.8 & 3.6 \\
\hline 8 & 222 & 5.8 & 0.388 & 1748 & 166.3 & - \\
\hline Total & 883 & 3084.0 & 116.448 & --- & 294.7 & --- \\
\hline
\end{tabular}


TABLE XXVI. Nomina1 Cladding Temperature Axial Profiles For Design Limiting Fuel Pin, Configuration A

\begin{tabular}{|c|c|c|c|c|c|c|c|c|}
\hline \multirow[b]{2}{*}{$\begin{array}{c}\text { Distance From } \\
\text { Bot tom of Fue } 1 \\
\text { (in.) }\end{array}$} & \multicolumn{4}{|c|}{ Beginning of Life } & \multicolumn{4}{|c|}{ End of Life } \\
\hline & \multicolumn{2}{|c|}{$\begin{array}{c}\text { Clad o.d. } \\
\text { Temperature } \\
\left({ }^{\circ} \mathrm{F}\right) \quad\left({ }^{\mathrm{K}}\right)\end{array}$} & \multicolumn{2}{|c|}{$\begin{array}{l}\text { Clad M.W. } \\
\text { Temperature } \\
\left({ }^{\circ} \mathrm{F}\right) \quad\left({ }^{\circ}\right)\end{array}$} & \multicolumn{2}{|c|}{$\begin{array}{c}\text { Clad o.d. } \\
\text { Temperature } \\
\left({ }^{\circ} \mathrm{F}\right) \quad\left({ }^{\circ} R\right)\end{array}$} & \multicolumn{2}{|c|}{$\begin{array}{l}\text { Clad M.W. } \\
\text { Temperature } \\
\left({ }^{\mathrm{O}} \mathrm{F}\right) \quad\left({ }_{\mathrm{K}}\right)\end{array}$} \\
\hline 8. & 597 & 587 & 597 & 587 & 597 & 587 & 597 & 587 \\
\hline 16. & 618 & 599 & 633 & 607 & 615 & 597 & 628 & 604 \\
\hline 24. & 693 & 640 & 718 & 654 & 680 & 633 & 703 & 646 \\
\hline 32. & 790 & 694 & 820 & 711 & 766 & 681 & 792 & 696 \\
\hline 40. & 890 & 750 & 919 & 766 & 853 & 729 & 878 & 743 \\
\hline 48. & 972 & 795 & 993 & 807 & 925 & 769 & 944 & 780 \\
\hline 56. & 1006 & 814 & 1007 & 815 & 955 & 786 & 956 & 786 \\
\hline 64. & 1006 & 814 & 1007 & 815 & 955 & 786 & 955 & 786 \\
\hline 72. & 1006 & 814 & 1006 & 814 & 954 & 785 & 954 & 785 \\
\hline
\end{tabular}


TABLE XXVII. $2 \sigma \mathrm{Cl}$ adding Temperature Axial Profiles For Design Limiting Fuel Pin, Configuration A

\begin{tabular}{|c|c|c|c|c|c|c|c|c|}
\hline \multirow[b]{2}{*}{$\begin{array}{l}\text { Distance From } \\
\text { Bottom of Fuel } \\
\text { (in.) }\end{array}$} & \multicolumn{4}{|c|}{ Beginning of Life } & \multicolumn{4}{|c|}{ End of Life } \\
\hline & \multicolumn{2}{|c|}{$\begin{array}{c}\text { Clad o.d. } \\
\text { Temperature } \\
\left({ }^{0} \mathrm{~F}\right) \quad\left({ }_{\mathrm{K}}\right)\end{array}$} & \multicolumn{2}{|c|}{$\begin{array}{c}\text { Clad M.W. } \\
\text { Temperature } \\
\left({ }^{\mathrm{O}} \mathrm{F}\right) \quad\left({ }^{0} \mathrm{~K}\right)\end{array}$} & \multicolumn{2}{|c|}{$\begin{array}{c}\text { Clad o.d. } \\
\text { Temperature } \\
\left({ }^{0} \mathrm{~F}\right) \quad\left({ }^{\mathrm{K}}\right)\end{array}$} & \multicolumn{2}{|c|}{$\begin{array}{c}\text { Clad M.W. } \\
\text { Temperature } \\
\left({ }^{\mathrm{O}} \mathrm{F}\right) \quad\left({ }^{\mathrm{O}} \mathrm{K}\right)\end{array}$} \\
\hline 8. & 598 & 588 & 599 & 588 & 597 & 587 & 598 & 588 \\
\hline 16. & 633 & 607 & 665 & 625 & 629 & 605 & 656 & 620 \\
\hline 24 . & 733 & 663 & 786 & 692 & 717 & 654 & 763 & 679 \\
\hline 32. & 858 & 732 & 919 & 766 & 826 & 714 & 879 & 744 \\
\hline 40 & 982 & 801 & 1038 & 832 & 933 & 774 & 983 & 801 \\
\hline 48. & 1078 & 854 & 1119 & 877 & 1017 & 820 & 1054 & 841 \\
\hline 56. & 1103 & 868 & 1105 & 869 & 1039 & 833 & 1041 & 834 \\
\hline 64. & 1102 & 868 & 1103 & 868 & 1039 & 833 & 1039 & 833 \\
\hline 72 . & 1101 & 867 & 1101 & 867 & 1038 & 832 & 1039 & 833 \\
\hline
\end{tabular}


TABLE XXVIII. Peak Temperatures for the Assembly With the Hottest Fuel Pin, Configuration A

\begin{tabular}{|c|c|c|}
\hline & \multicolumn{2}{|c|}{ Temperature, ${ }^{\circ} \mathrm{F}$} \\
\hline & Nominal & $2 \sigma$ \\
\hline \multicolumn{3}{|l|}{ Cladding } \\
\hline Outer Diameter & 1015 & 1122 \\
\hline Mid Wal1 & 1026 & 1145 \\
\hline Inner Diameter & 1037 & 1178 \\
\hline Coolant ${ }^{a}$ & 1003 & 1098 \\
\hline Duct $^{a}$ & 863 & 925 \\
\hline
\end{tabular}

a Local peak values within the assembly. 
TABLE XXIX. Inlet and Outlet Temperatures of Configuration $B$

\begin{tabular}{lcc}
\hline & ${ }^{\circ} \mathrm{K}$ & ${ }^{\circ} \mathrm{F}$ \\
\hline Core Inlet & 586 & 595 \\
Core Average Outlet & 759 & 907 \\
Core $\Delta \mathrm{T}$ & 173 & 312 \\
(Core + Radial Blanket) Average Outlet & 750 & 890 \\
(Core + Radial Blanket) $\Delta \mathrm{T}$ & 164 & 295 \\
Reactor Inlet & 586 & 595 \\
Reactor Outlet & 741 & 875 \\
Reactor $\Delta \mathrm{T}$ & 155 & 280 \\
\hline
\end{tabular}

TABLE XXX. Inlet and Outlet Temperatures of Configuration B Orificed for Equal Clad Temperatures at EOEC

\begin{tabular}{lll} 
Core Inlet & 586 & 595 \\
Core Average Outlet & 754 & 898 \\
Core $\Delta \mathrm{T}$ & 168 & 303 \\
(Core + Radial Blanket) Average Outlet & 750 & 890 \\
(Core + Radial Blanket) $\Delta \mathrm{T}$ & 164 & 295 \\
Reactor Inlet & 586 & 595 \\
Reactor Outlet & 741 & 875 \\
Reactor $\Delta \mathrm{T}$ & 155 & 280 \\
\hline
\end{tabular}


TABLE XXXI. Orificing Scheme of Configuration B

\begin{tabular}{|c|c|c|c|c|c|c|}
\hline Zone & $\begin{array}{c}\text { Number } \\
\text { Assemblies }\end{array}$ & $\begin{array}{l}\text { Power } \\
\text { MWt }\end{array}$ & $10^{6} \mathrm{lb} / \mathrm{hr}$ & $\begin{array}{c}\text { Flow/ass'y } \\
\text { lb/hr }\end{array}$ & $\begin{array}{l}\text { Avg. } \Delta \mathrm{T} \\
\text { deg. } F\end{array}$ & $\begin{array}{c}\text { Velocity } \\
\mathrm{ft} / \mathrm{sec}\end{array}$ \\
\hline 1 & 138 & 1243.3 & 43.458 & 314911 & 318.4 & 25.6 \\
\hline 2 & 90 & 690.7 & 24.795 & 275502 & 310.0 & 22.4 \\
\hline 3 & 114 & 791.1 & 29.032 & 254666 & 303.3 & 20.7 \\
\hline 4 & 84 & 276.4 & 11.461 & 136436 & 268.4 & 17.8 \\
\hline 5 & 36 & 90.7 & 3.603 & 100096 & 280.2 & 13.1 \\
\hline 6 & 102 & 137.2 & 7.567 & 74185 & 201.8 & 9.7 \\
\hline 7 & 97 & 65.2 & 3.302 & 34041 & 219.7 & 4.5 \\
\hline 8 & 228 & 5.4 & 0.318 & 1395 & 189.0 & -- \\
\hline Total & 889 & 3300.0 & 124.604 & ----- & 294.7 & --- \\
\hline
\end{tabular}

TABLE XXXII. Ofiflcing Scheme of Configuration B Orificed for Equal Clad Temperatures at EOEC

\begin{tabular}{crrrrrr}
\hline 1 & 132 & 1205.9 & 44.876 & 339969 & 299.1 & 27.6 \\
2 & 66 & 527.0 & 18.567 & 281311 & 315.9 & 22.9 \\
3 & 144 & 992.2 & 36.798 & 255543 & 300.1 & 20.8 \\
4 & 48 & 169.6 & 6.521 & 135848 & 289.4 & 17.8 \\
5 & 72 & 197.5 & 7.560 & 104993 & 290.7 & 13.8 \\
6 & 90 & 126.0 & 5.831 & 64784 & 240.5 & 8.5 \\
7 & 109 & 76.5 & 4.069 & 37329 & 209.2 & 4.9 \\
8 & 228 & 5.4 & 0.381 & 1671 & 157.7 & -- \\
Total & 889 & 3300.0 & 124.604 & - & 294.7 & --- \\
\hline
\end{tabular}


TABLE XXXIII. 20 Cladding Temperature Axlal Profiles for Design Limiting Fuel Pin, Configuration B

\begin{tabular}{|c|c|c|c|c|c|c|c|c|}
\hline \multirow[b]{2}{*}{$\begin{array}{c}\text { Distance From } \\
\text { Bottom of Fuel } \\
\text { (in.) }\end{array}$} & \multicolumn{4}{|c|}{ Beginning of Life } & \multicolumn{4}{|c|}{ End of Life } \\
\hline & \multicolumn{2}{|c|}{$\begin{array}{c}\text { Clad o.d. } \\
\text { Temperature } \\
\left({ }^{\mathrm{O}} \mathrm{F}\right) \quad\left({ }^{\mathrm{O}}\right)\end{array}$} & \multicolumn{2}{|c|}{$\begin{array}{l}\text { Clad M.W. } \\
\text { Temperature } \\
\left({ }^{\mathrm{O}} \mathrm{F}\right) \quad\left({ }^{\mathrm{O}} \mathrm{K}\right)\end{array}$} & \multicolumn{2}{|c|}{$\begin{array}{c}\text { Clad o.d. } \\
\text { Temperature } \\
\left({ }^{\mathrm{O}} \mathrm{F}\right) \quad\left({ }_{\mathrm{K}}\right)\end{array}$} & \multicolumn{2}{|c|}{$\begin{array}{l}\text { Clad M.W. } \\
\text { Temperature } \\
\left({ }^{\mathrm{O}} \mathrm{F}\right) \quad\left({ }^{\mathrm{O}}\right)\end{array}$} \\
\hline 8. & 597 & 587 & 598 & 588 & 597 & 587 & 597 & 587 \\
\hline 16. & 614 & 596 & 630 & 605 & 612 & 595 & 626 & 603 \\
\hline 24 & 735 & 664 & 788 & 693 & 719 & 655 & 767 & 681 \\
\hline 32. & 878 & 743 & 939 & 777 & 845 & 725 & 901 & 756 \\
\hline 40 & 1016 & 820 & 1071 & 850 & 968 & 793 & 1018 & 821 \\
\hline 48. & 1115 & 875 & 1151 & 895 & 1055 & 841 & 1088 & 860 \\
\hline 56. & 1118 & 876 & 1120 & 878 & 1059 & 844 & 1060 & 844 \\
\hline 64. & 1118 & 876 & 1118 & 876 & 1059 & 844 & 1059 & 844 \\
\hline 72. & 1117 & 876 & 1118 & 876 & 1058 & 843 & 1058 & 843 \\
\hline
\end{tabular}


TABLE XXXIV. Nominal Cladding Temperature Axial Profiles for Design Limiting Fuel Pin, Configuration B

\begin{tabular}{|c|c|c|c|c|c|c|c|c|}
\hline \multirow[b]{2}{*}{$\begin{array}{c}\text { Distance From } \\
\text { Bottem of Fue } 1 \\
\text { (in.) }\end{array}$} & \multicolumn{4}{|c|}{ Beginning of Life } & \multicolumn{4}{|c|}{ End of Life } \\
\hline & \multicolumn{2}{|c|}{$\begin{array}{l}\text { Clad o.d. } \\
\text { Temperature } \\
\left({ }^{\circ} \mathrm{F}\right) \quad\left({ }^{\circ}\right)\end{array}$} & \multicolumn{2}{|c|}{$\begin{array}{l}\text { Clad M.W. } \\
\text { Temperature } \\
\left({ }^{\circ} \mathrm{F}\right) \quad\left({ }^{\circ} \mathrm{K}\right)\end{array}$} & \multicolumn{2}{|c|}{$\begin{array}{l}\mathrm{Clad} \text { o.d. } \\
\text { Temperature } \\
\left({ }^{\mathrm{O}} \mathrm{F}\right) \quad\left({ }^{\circ} \mathrm{K}\right)\end{array}$} & \multicolumn{2}{|c|}{$\begin{array}{l}\text { Clad M.W. } \\
\text { Temperature } \\
\left({ }^{\circ} \mathrm{F}\right) \quad\left({ }^{\circ}\right)\end{array}$} \\
\hline 8. & 596 & 586 & 597 & 587 & 596 & 586 & 597 & 587 \\
\hline 16. & 606 & 592 & 614 & 596 & 598 & 588 & 599 & 588 \\
\hline 24. & 694 & 641 & 720 & 655 & 682 & 634 & 706 & 648 \\
\hline 32. & 805 & 703 & 836 & 720 & 781 & 689 & 809 & 705 \\
\hline 40. & 918 & 765 & 946 & 781 & 881 & 754 & 906 & 759 \\
\hline 48. & 1003 & 813 & 1022 & 823 & 957 & 787 & 974 & 796 \\
\hline 56. & 1019 & 821 & 1020 & 822 & 971 & 795 & 972 & 795 \\
\hline 64. & 1019 & 821 & 1020 & 822 & 971 & 795 & 971 & 795 \\
\hline 72. & 1019 & 821 & 1019 & 821 & 971 & 795 & 971 & 795 \\
\hline
\end{tabular}


TABLE XXXV. Peak Temperatures in the Assembly with the Hottest Fuel Pin, Configuration A

\begin{tabular}{|c|c|c|}
\hline & \multicolumn{2}{|c|}{ Temperature, ${ }^{\circ} \mathrm{F}$} \\
\hline & Nominal & $2 \sigma$ \\
\hline \multicolumn{3}{|l|}{ Cladding } \\
\hline Outer Diameter & 1028 & 1140 \\
\hline Mid Wall & 1041 & 1164 \\
\hline Inner Diameter & 1054 & 1188 \\
\hline Coolant ${ }^{a}$ & 1016 & 1114 \\
\hline Duct $^{a}$ & 877 & 942 \\
\hline
\end{tabular}

${ }^{a}$ Local peak values within the assembly. 
TABLE XXXVI. Fuel Pin and Assembly Data

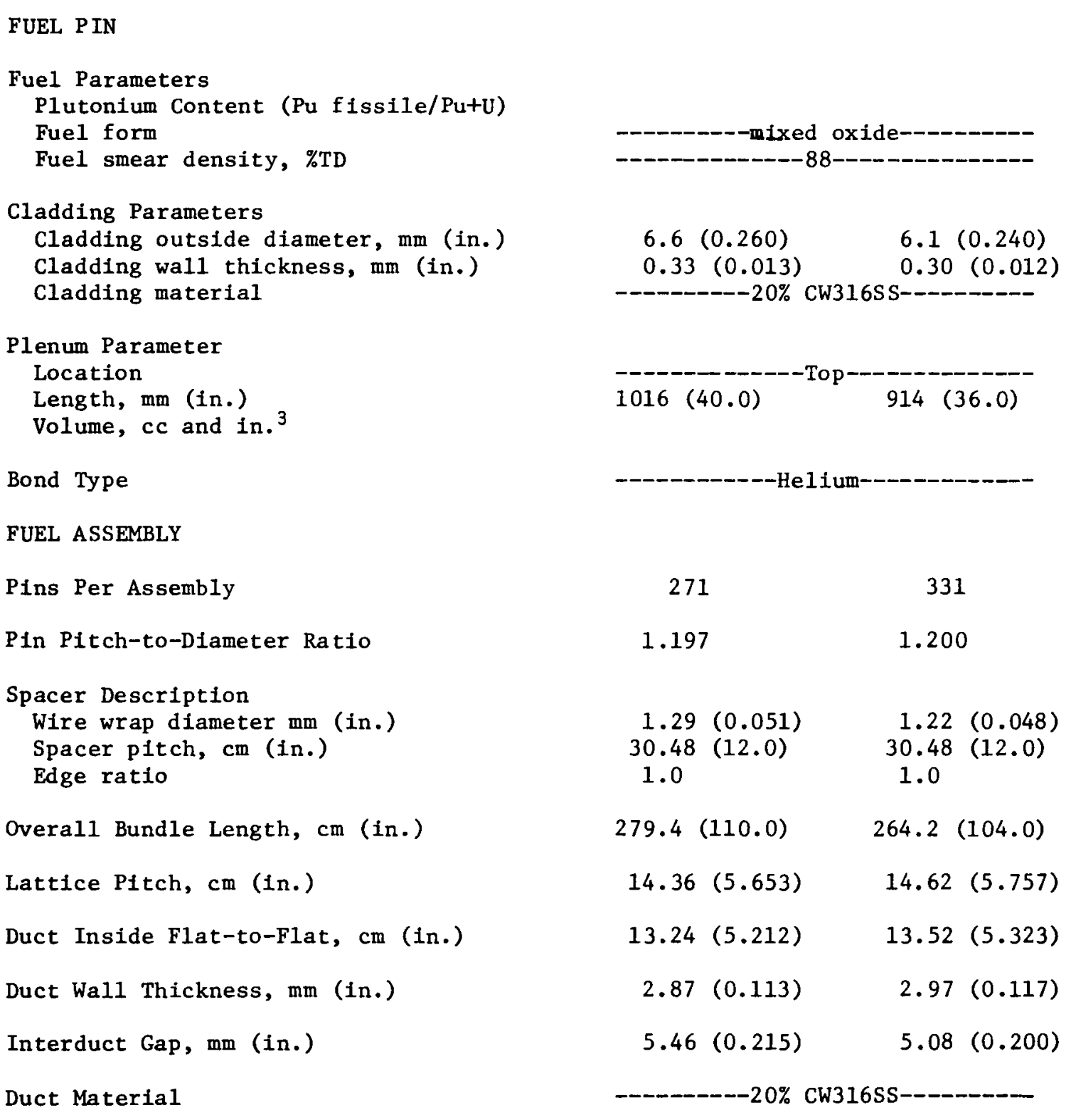


TABLE XXXVII. Blanket Pin and Assembly Data

Configuration A Configuration B

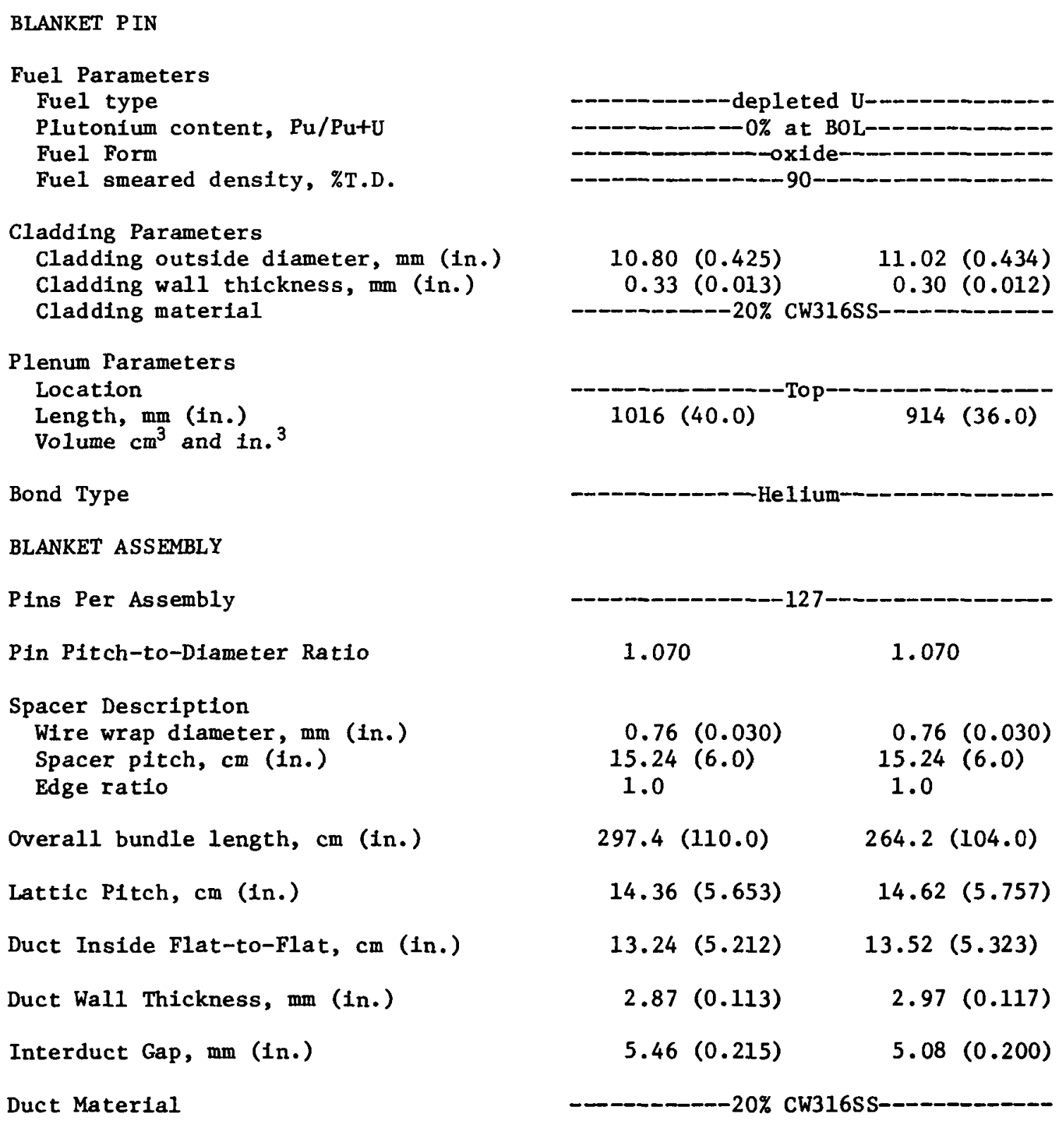


TABLE XXXVIII. Control Assembly Compositions

\begin{tabular}{ll} 
Control rod full in & \\
$\mathrm{B}_{4} \mathrm{C}$ Pellet & 0.3174 \\
Void & 0.0216 \\
Coolant & 0.3323 \\
Structure & 0.3287 \\
Control rod full out & \\
Coolant & 0.8842 \\
Structure & 0.1158 \\
\hline
\end{tabular}


TABLE XXXIX. Duct Wall Pressure Differential Profile For Design Limiting Duct

\begin{tabular}{|c|c|c|}
\hline \multirow{2}{*}{$\begin{array}{l}\text { Distance Above } \\
\text { Bottom of Active } \\
\text { Fuel (in.) }\end{array}$} & \multicolumn{2}{|c|}{$\begin{array}{c}\text { Duct Wal1 Pressure, } \\
\text { psi }\end{array}$} \\
\hline & Configuration A & Configuration $B$ \\
\hline 0 & 61.7 & 62.0 \\
\hline 2 & 60.4 & 60.6 \\
\hline 4 & 59.1 & 59.2 \\
\hline 6 & 57.8 & 27.8 \\
\hline 8 & 56.5 & 56.3 \\
\hline 10 & 55.2 & 54.9 \\
\hline 12 & 53.9 & 53.5 \\
\hline 14 & 52.6 & 52.1 \\
\hline 16 & 51.3 & 50.7 \\
\hline 18 & 50.0 & 49.3 \\
\hline 20 & 48.7 & 47.9 \\
\hline 22 & 47.4 & 46.5 \\
\hline 24 & 46.1 & 45.1 \\
\hline 26 & 44.8 & 43.7 \\
\hline 28 & 43.5 & 42.3 \\
\hline 30 & 42.2 & 40.8 \\
\hline 32 & 40.9 & 39.4 \\
\hline 34 & 39.6 & 38.0 \\
\hline 36 & 38.3 & 36.6 \\
\hline 38 & 37.0 & \\
\hline 40 & 35.7 & \\
\hline
\end{tabular}


TABLE XL. Fabrication Cost Breakdown

\begin{tabular}{lrr}
\hline & Core A & Core B \\
\hline Fixed Overhead, \$ & 19,945 & 19,945 \\
Variable Overhead, \$ & 13,235 & 13,235 \\
Assembly, \$ & 13,397 & 13,397 \\
Pin, \$ & 24,034 & 28,956 \\
Heavy Metal, \$ & 1,204 & 1,125 \\
Fissionable Material, \$ & 10,771 & 10,118 \\
Pellet, \$ & 1,211 & 1,442 \\
Steel, \$ & 11,957 & 13,129 \\
Axial Blanket, \$ & 1,729 & 1,918 \\
10\% Change, \$ & 9,748 & 10,327 \\
Total Cost, \$ & & 113,592 \\
$\quad$ \$/Assembly & 107,232 & 1,900 \\
$\quad$ \$/kg Heavy Metal & 1,675 & 343 \\
$\quad$ \$ / Pin & 396 & \\
\hline
\end{tabular}

These costs should be used only for comparing cores A and B. Actual costs are expected to be significantly lower. 
TABLE XLI. Fuel Cycle Costs of Configuration A

\section{RESIDENCE \\ TIME \\ (YRS)}

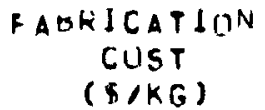

(S/KG)

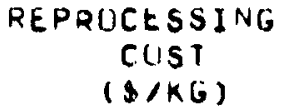

$0.59500 E 03$

$0.59500 E \quad 03$

$1) .59500$ OS

$0.59300 \mathrm{~F} 03$

0.595 CUE O3

$0.59500 E$ OS

U.595UUE 03

0.59500 OI

$0.59500 E$ U3

ZUNE 8 0.50005E 01

ZUNE $90.60006 E$ OI

\section{FARRICATIUN RFPHICESSING \\ (MILL/KMH) \\ (NILL/KNH)}

USAGE
FACT IK
(KE/KWH)

$0.16590 t-v 2$

0.0

0.0

$0.12810 t-02$

Q. 0

1). 0

$0.19581 t-U 2$

$0.86775 t-163$

0.0

REPRUCESSIP.G

$C C$

(MILL/KWH)

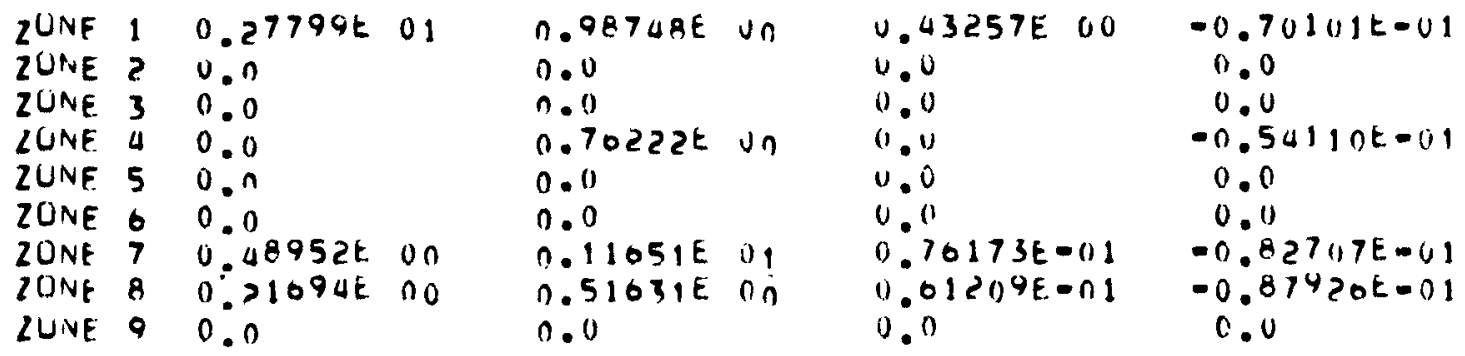

CARRY CHAKGE ON PII INVENTLIRY = REVENUE

CHARGE UN REVEHUE

LUSSES

CARRY CHAKGE ON LUSSES

ABRILATIUN
CC
(MILL/KMH)

CKEUIT FUK SALE AT PLANT ERL

TUTAL FIIEL CYCLF COST

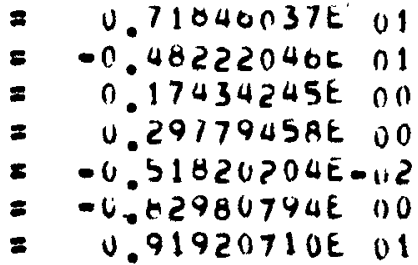


TABLE XLII. Fuel Cycle Costs of Configuration B

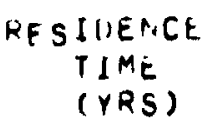

$$
\begin{gathered}
\text { FAdRICATICIN } \\
\text { CUST } \\
\text { (b/KG) }
\end{gathered}
$$

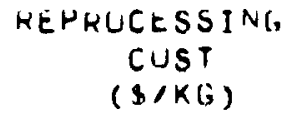

IISAGE

\begin{tabular}{|c|c|c|c|}
\hline ZUNE. & 1 & $0.20002 t$ & $n$ \\
\hline ZUNE & 2 & $0.20002 E$ & 01 \\
\hline ZONE & 3 & $0.20002 t$ & 01 \\
\hline ZUN & 4 & $002 E$ & 01 \\
\hline ZUNE. & 5 & $0.20002 E$ & 0 \\
\hline $\begin{array}{l}\text { ZUNE } \\
\text { ZUNE }\end{array}$ & $\begin{array}{l}6 \\
7\end{array}$ & $\begin{array}{l}0.20002 E \\
0.20002 E\end{array}$ & 0. \\
\hline ZUNE. & 8 & $0.50005 t$ & $n$ \\
\hline ZUNE & 9 & $0.60000 \mathrm{E}$ & \\
\hline
\end{tabular}

I $\triangle C T O R$

(NG/KWH)
ก.19000E $1 \mathrm{~T}$

ก.19000E "IS

ก.19000E 0.

$$
0.0
$$

0.0

$n .0$

0.25000 U 3

0.25000 J3

n. 25 UnOE U3
$0.59500 E \quad 13$

0.59500 ) 03

U.5950 if 03

U.5950ut Os

0.5950 JE 03

ט.s 45 CIUE U3

ט. 595 Uue 03

$0.5950 u t ~ 03$

$\because .59500 t 03$
$11.1 B \cap 7 A E=112$

n. 1

C.1

$0.1473 \leq t=02$

0.11

0.0

$0.1 \times 748 t-0 ?$

$0.09900 t-n 3$

i. 0

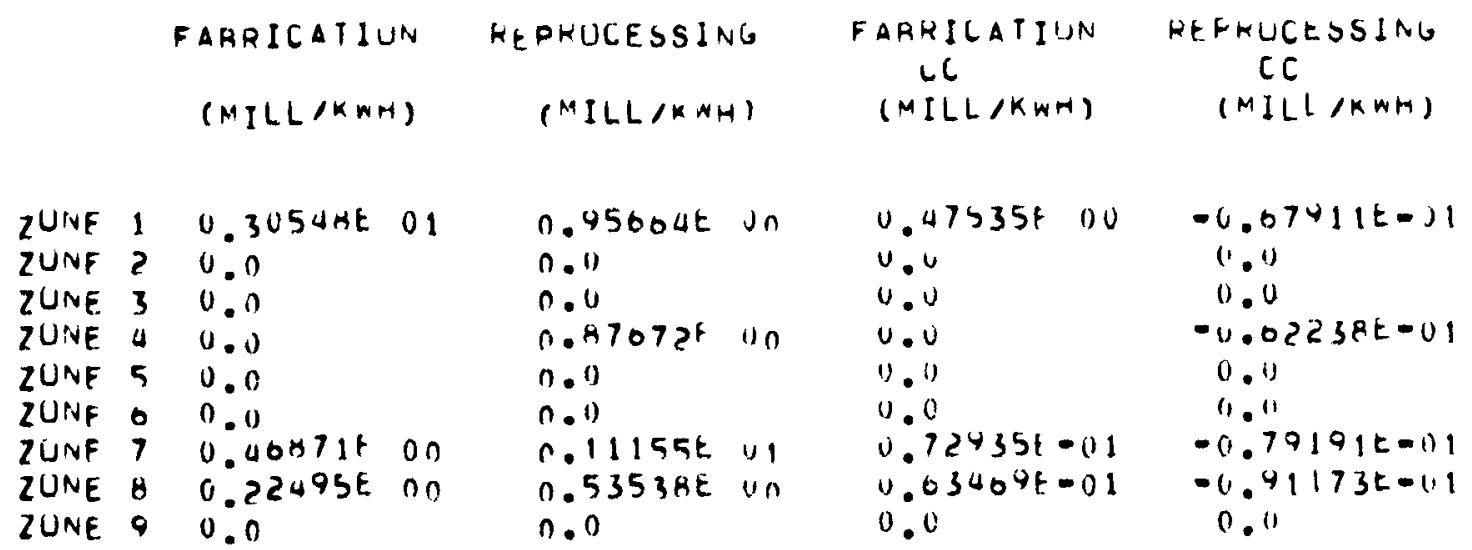

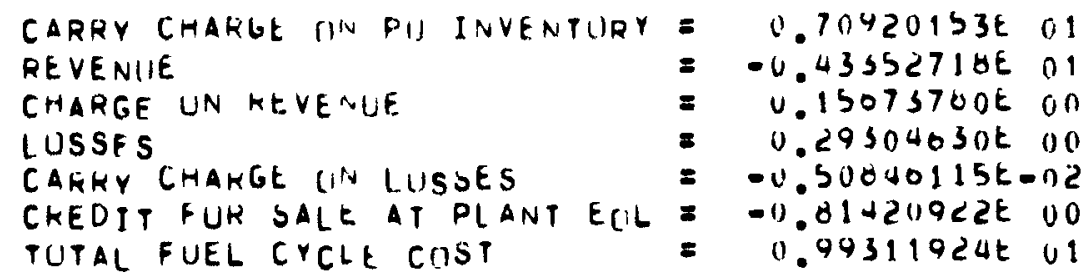

